\title{
QH 541
}

\author{
.5 \\ W3 A683 \\ 2002 \\ Copy 1
}




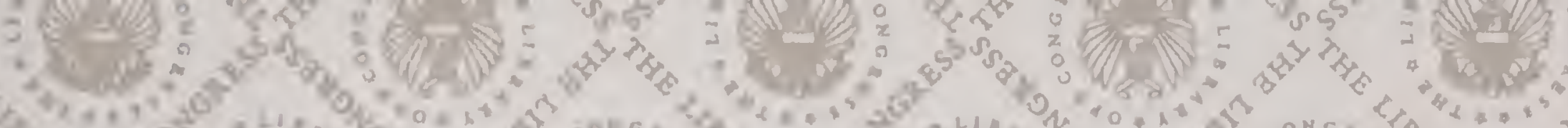

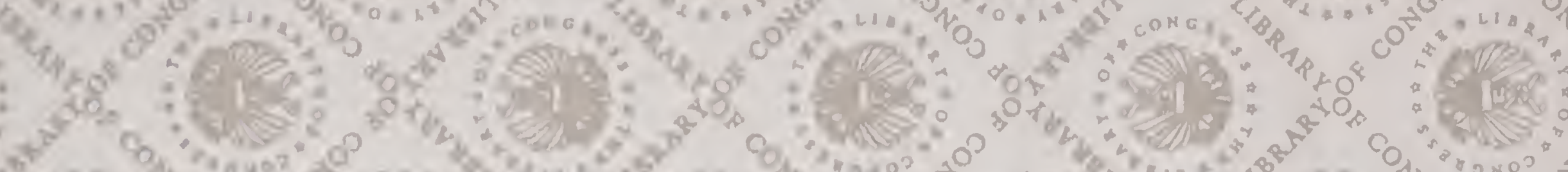

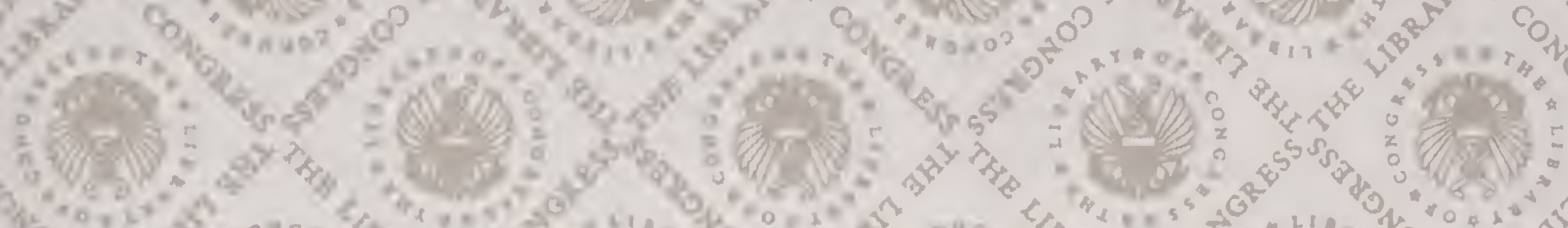
$(3)=$

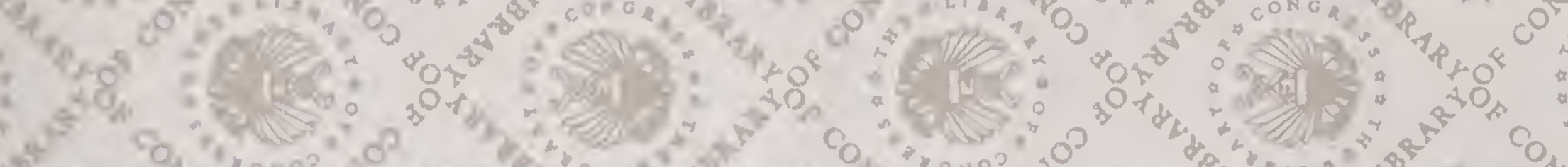

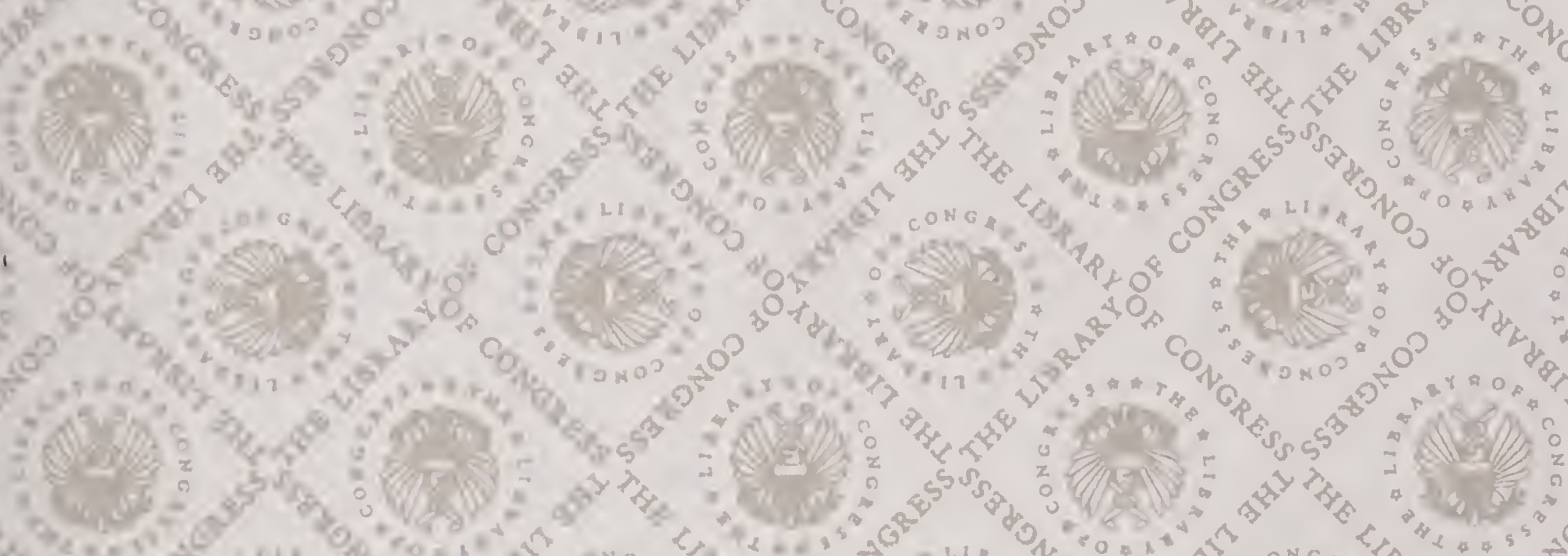

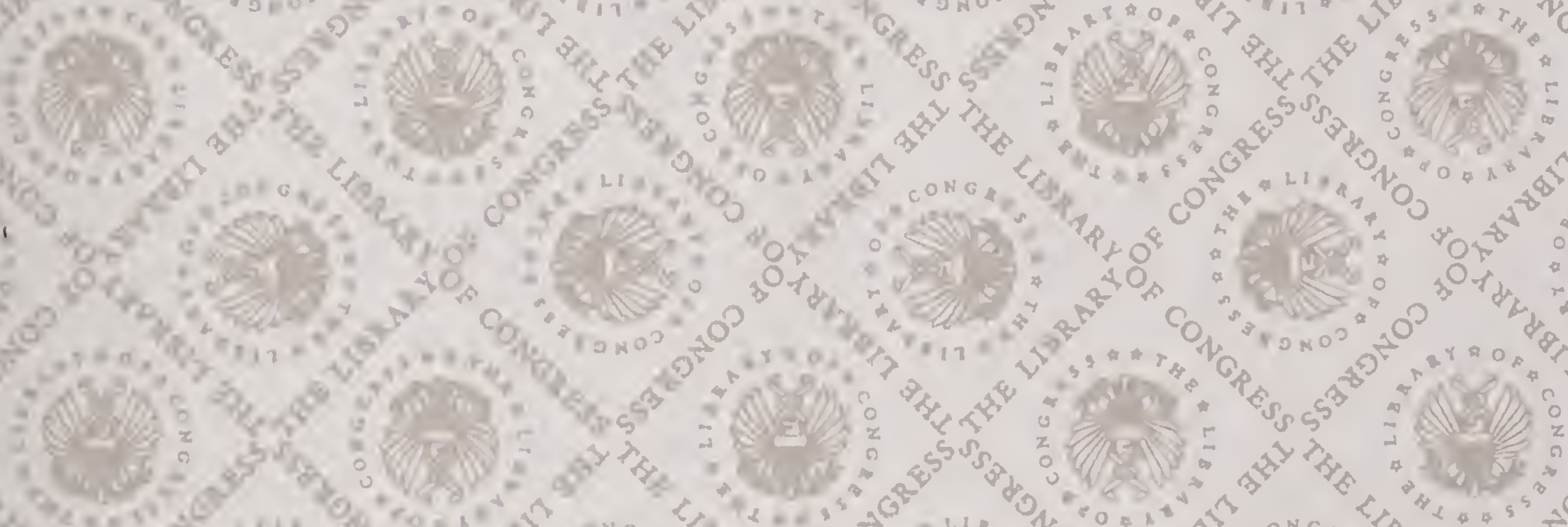
ras ing O
(a) 30
(a)
o a
(a)
8

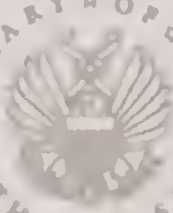

(8)

(6)
of
î. If
10

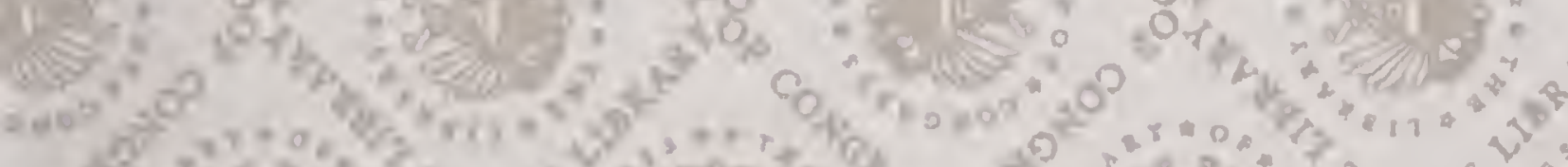

신.
30
3.
40
(ent)

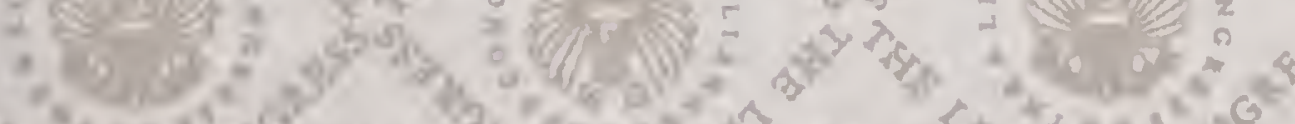

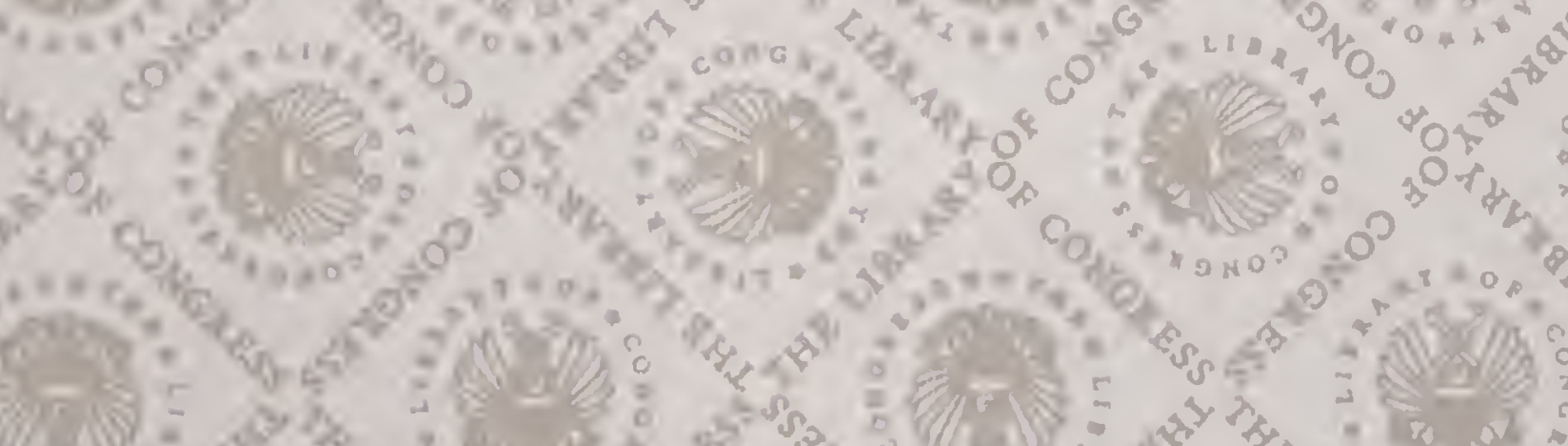

0.10

(1)

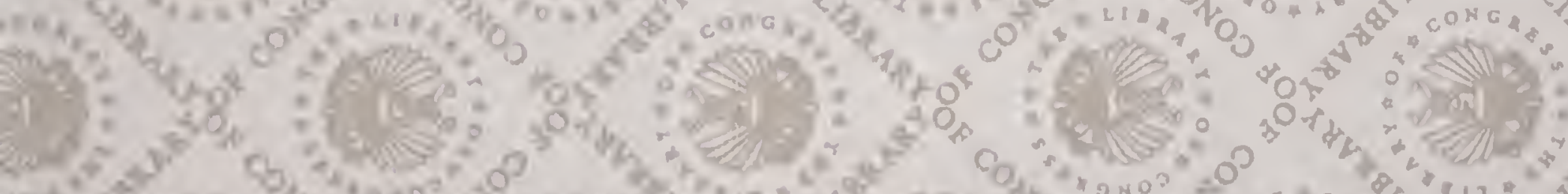

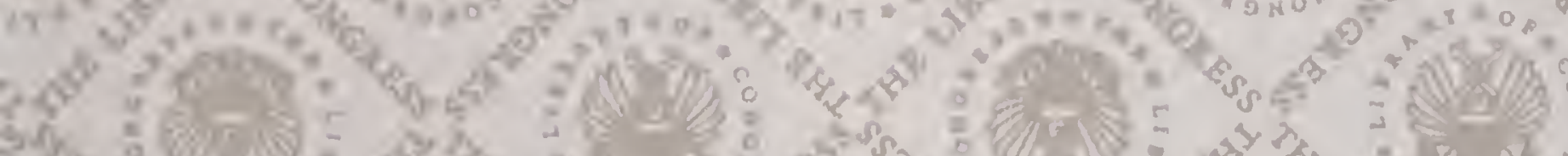




EPA $600 /$ R-02/074

September 2002

\section{Aquatic Stressors}

\section{framework and implementation plan for effects research}

U.S. Environmental Protection Agency Office of Research and Development

National Health and Environmental Effects Research Laboratory Research Triangle Park, NC 27711 


\section{Foreword}

The National Health and Environmental Effects Research Laboratory (NHEERL), as part of the Environmental Protection Agency's (EPA's) Office of Research and Development (ORD), is responsible for conducting research on the effects of anthropogenic stresses on human and ecosystem health. This research is intended to address key Agency problems in a timely and responsive manner. To meet this responsibility, NHEERL is developing research implementation plans to achieve the following objectives:

- Optimize responsiveness of research activities to Agency needs,

- Sharpen the focus of research programs where needed,

- $\quad$ Provide a forum for engagement of scientific staff on issues and approaches,

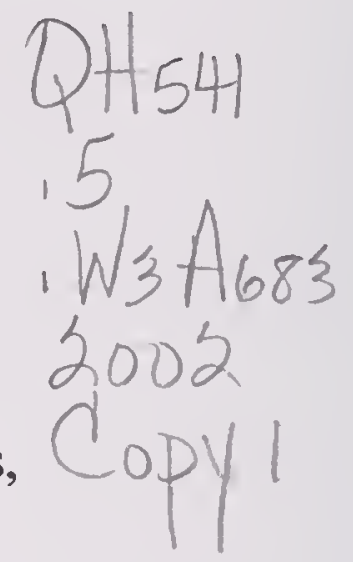

- Focus on multi-year planning explicitly linked to Agency performance goals, and

- $\quad$ Provide a mechanism for prioritizing research.

This approach builds on the ORD planning process that identifies and prioritizes research topics. Current areas for research include particulate matter, air toxics, drinking water, aquatic stressors, support to the Food Quality Protection Act, safe communities and ecosystems, the Environmental Monitoring and Assessment Program, ecological risk assessment, human health risk assessment, and endocrine disruptors.

This document identifies the scientific problems and the research that will be conducted concerning aquatic stressors. The ultimate goal of this research is to develop scientifically valid approaches for protecting the ecological integrity of aquatic ecosystems from multiple aquatic stressors, in support of EPA's goal to provide clean and safe water. The framework section was developed by a steering committee composed of representatives from NHEERL Divisions, other ORD Laboratories and Centers, EPA's Office of Water, and EPA's Regional Offices.

Implementation plans for research on habitat alteration, nutrients, suspended and bedded sediments, toxic chemicals, and diagnostics were developed by work groups in the Ecology Divisions. The document is intended to reflect research that will be conducted over the next several years. As progress is made in achieving these goals, this document will be updated to address new and remaining water quality challenges.

Lawrence W. Reiter

Director

National Health and Environmental Effects Research Laboratory 


\begin{abstract}
This document describes the framework and research implementation plans for ecological effects research on aquatic stressors within the National Health and Environmental Effects Laboratory. The context for the research identified within the framework is the common management goal of protecting aquatic systems to prevent degradation of habitat, loss of ecosystem function, and reduced biodiversity. Five main research products for meeting this goal are identified in the framework: 1) methods to predict biological effects of habitat alteration; 2) population, community, and ecosystem stressor-response models; 3) diagnostic tools to determine impairment or causes of impairment to aquatic systems; 4) classification approaches to aid in the prediction and management of problems; and 5) methods and models to support development of ecological criteria. The research implementation plans herein focus on the effects of four aquatic stressors, including habitat alteration, nutrients, suspended and bedded sediments, and toxic chemicals. This approach is consistent with recent scientific consensus, recognizing that these stressors have the greatest potential for causing adverse effects to aquatic ecosystems. In addition, the document outlines research that will develop diagnostic tools for a decision support system for resource managers. The major goals, the critical path for research, specific research projects, and a gap analysis are provided for each of the five research implementation plans along with the time table of research products that will support EPA's Goal 2 (Clean and Safe Water) research under the Government Performance and Results Act.
\end{abstract}




\section{Table of Contents}

Foreword $\ldots \ldots \ldots \ldots \ldots \ldots \ldots \ldots \ldots \ldots \ldots \ldots \ldots \ldots \ldots \ldots \ldots \ldots \ldots$ ii

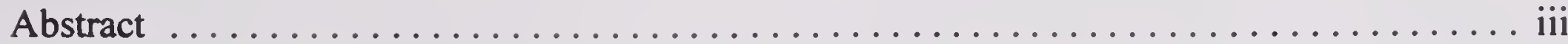

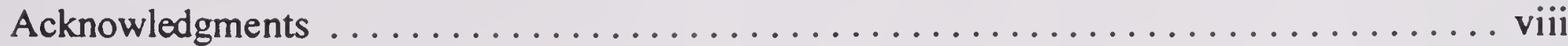

Glossary $\ldots \ldots \ldots \ldots \ldots \ldots \ldots \ldots \ldots \ldots \ldots \ldots \ldots \ldots \ldots \ldots \ldots \ldots \ldots \ldots \ldots \ldots \ldots$

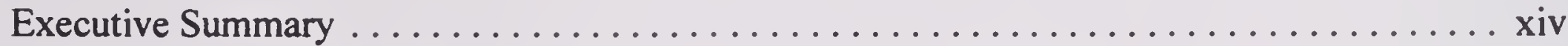

Section 1 .

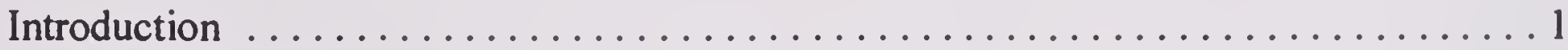

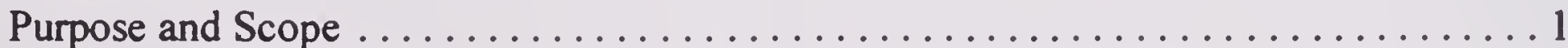

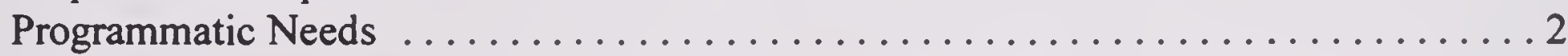

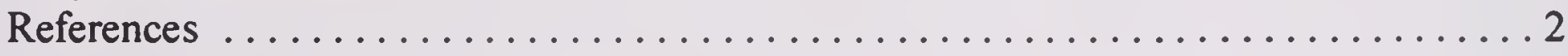

Section 2.

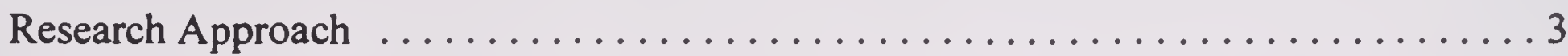

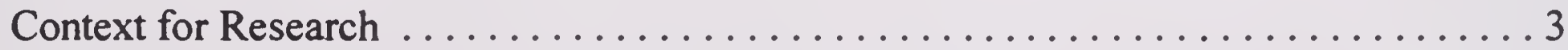

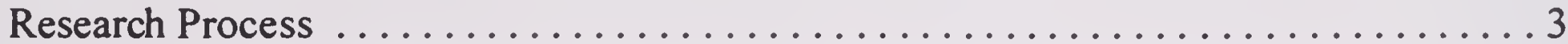

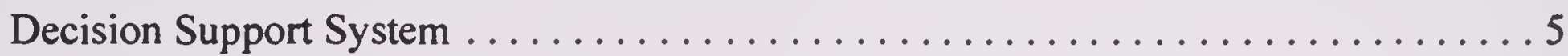

Section 3.

Research Products and Implementation Plans $\ldots \ldots \ldots \ldots \ldots \ldots \ldots \ldots$

Section 4.

Implementation Plan for Habitat Alteration Research $\ldots \ldots \ldots \ldots \ldots \ldots \ldots \ldots$

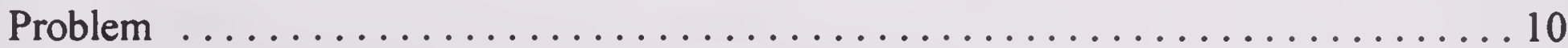

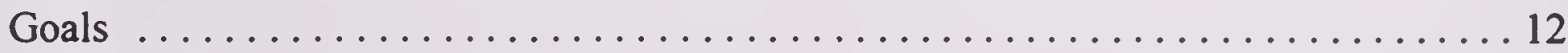

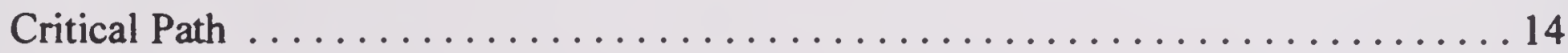

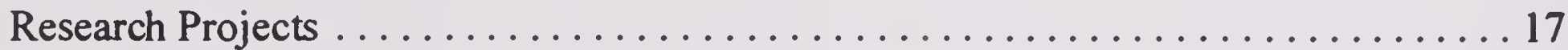

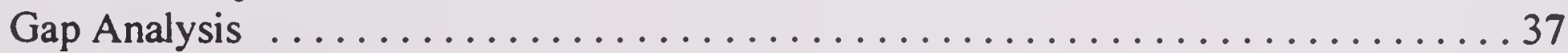

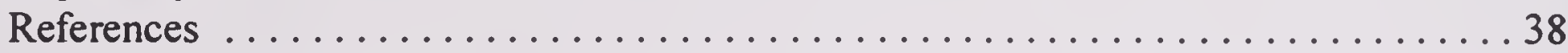

Section 5.

Implementation Plan for Nutrients Research . . . . . . . . . . . . . . . . 40

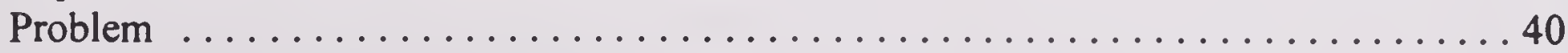

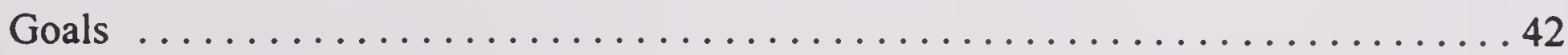

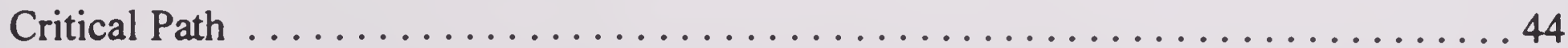

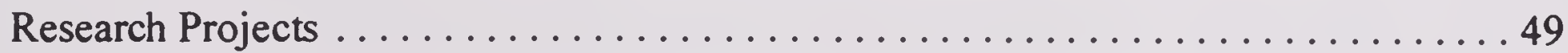

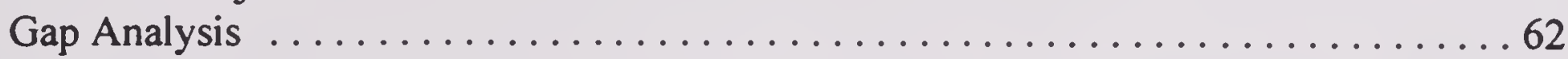

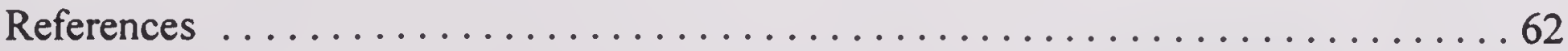




\section{Table of Contents (continued)}

Section 6.

Implementation Plan for Suspended and Bedded Sediment Research . . . . . . . . 66

Problem .............................................66 66

Goals ...........................................67 67

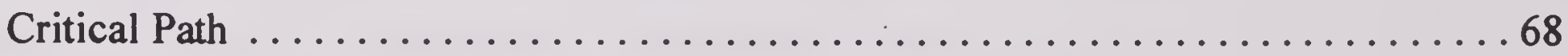

Gap Analysis ........................................... 75

References ........................................... 75

Section 7.

Implementation Plan for Toxic Chemicals Research $\ldots \ldots \ldots \ldots \ldots \ldots \ldots \ldots 77$

Problem ........................................... 77

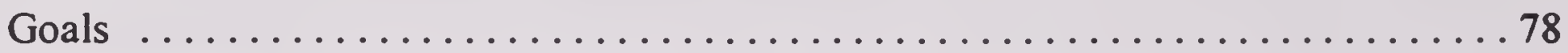

Critical Path ............................................. 79

Research Projects ...................................... 95

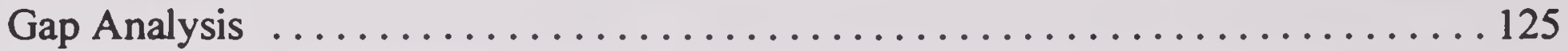

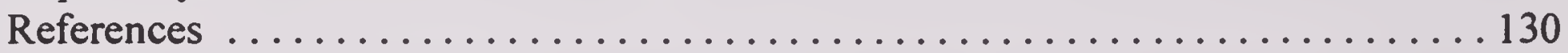

Section 8 .

Implementation Plan for Diagnostics Research $\ldots \ldots \ldots \ldots \ldots \ldots \ldots \ldots \ldots \ldots \ldots$

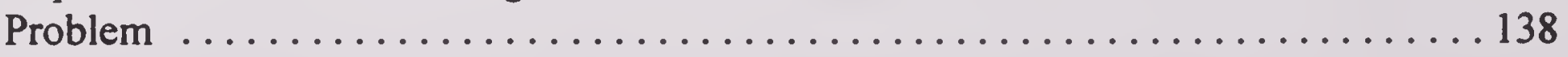

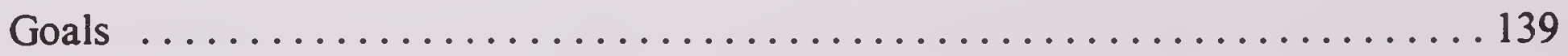

Critical Path .............................................. 141

Research Projects ......................................... 146

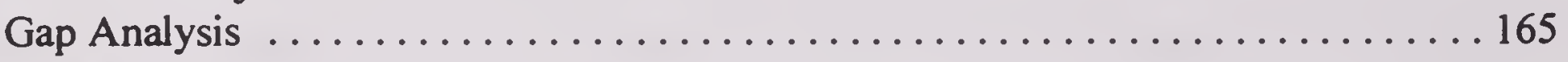

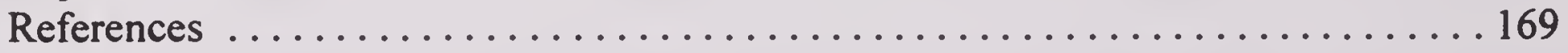

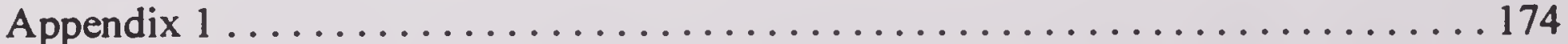

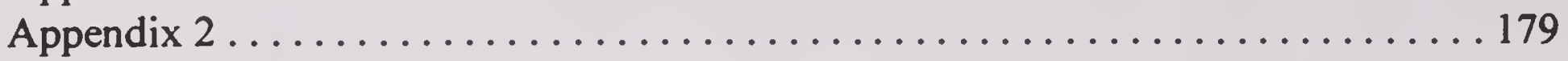




\section{Figures}

Figure 1. Research process and products for meeting the goal of effective management and protection of aquatic resources. . . . . . . . . . . . . . . . . . . . 4

Figure 2. Manager's decision support system to protect and restore aquatic resources using ORD's research products (SI box is modified from EPA 2000b)...........6 6

Figure 3. Critical path for habitat alteration research (APGs) refer to those listed and described in the Goals subsection). 15

Figure 4. Components of coastal vegetated habitat with possible pathways for direct and indirect effects of habitat alteration on fish, shellfish, and wildlife.

Figure 5. Critical path for research on the development of nutrient response relationships for coastal receiving waters.

Figure 6. Conceptual diagram of the feedbacks among data mining, model development, field monitoring, and experimental hypothesis validation.

Figure 7. Critical path for suspended and bedded sediments research. ............69 69

Figure 8. Ecological risk assessment framework (modified from EPA 1992). . . . . . . 80

Figure 9. Critical path for developing site-specific methodologies for establishing the risks of toxic chemicals to aquatic life and aquatic dependent wildlife. ........... 81

Figure 10. Simple conceptual model for risk assessments of nonbioaccumulative toxicants. . . 84

Figure 11. Conceptual model for risk assessments and criteria development involving determination of safe loadings of bioaccumulative toxicants to aquatic systems. . .91

Figure 12. Critical path (flow of APGs) for diagnostics research. . . . . . . . . 142

Figure 13. A logic for characterizing the causes of ecological injuries at specific sites. Modified from Figure 4-1 in SI document (EPA 2000c) to show potential inputs from aquatic stressors diagnostics research. .......................... 144

Figure 14. Relationship between current stages of State/Tribal assessment, TMDL and watershed restoration planning processes, and proposed combined path. .......... 145

Figure 15. Locations of national water-quality assessment study units.

Figure 16. Conceptual model of cause-and-effect relationships in coastal systems, providing a framework for a decision support system. See key to model components at base of figure. Loading terms include atmospheric component. ............. 163 


\section{Tables}

Table 1. Time line for habitat alteration research $\ldots \ldots \ldots \ldots \ldots \ldots \ldots \ldots \ldots$

Table 2. List of candidate species for study in marine and Great Lakes coastal regions . . . . 18

Table 3. Preliminary list of factors influencing response to excess nutrient inputs in coastal

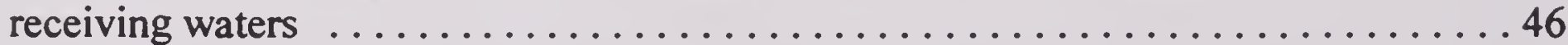

Table 4. Existing or proposed approaches to classification at regional, watershed, water-body,

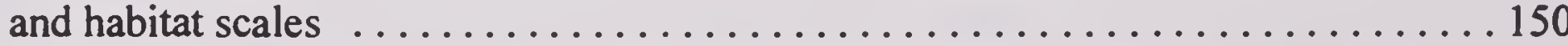

Table 5. Examples of methods incorporated in conceptual framework (Figure 16) for decision support system. .................................... 164

Table 6. Single aquatic stressors method development covered by other research areas within the Aquatic Stressors Framework . . . . . . . . . . . . . . . . . 166

Table 7. FTE resource allocation for diagnostics by year $(\mathrm{FW}=$ freshwater, $\mathrm{SW}=$ saltwater $)$ 


\section{Acknowledgments}

\section{Authors}

The principal authors of Sections 1-3 (framework for aquatic stressor research) are members of the National Health and Environmental Effects Laboratory's Aquatic Stressors Steering Committee, which is composed of representatives from the Office of Research and Development's (ORD) Laboratories and Centers, Office of Water (OW), and Regional offices. Principal authors for Sections 4-8 (Research Implementation Plans for Habitat Alteration, Nutrients, Suspended and Bedded Sediments, Toxic Chemicals and Diagnostics) are members of work groups from NHEERL's four Ecology Divisions: Atlantic Ecology Division, Narragansett, RI; Gulf Ecology Division, Gulf Breeze, FL; Mid-Continent Ecology Division, Duluth, MN; and Western Ecology Division, Corvallis, OR (see below).

\section{NHEERL Aquatic Stressors Steering Committee}

Mid-Continent Ecology Division (MED)

Bob Spehar (Chair)

Jack Kelly (Co-chair)

Atlantic Ecology Division (AED)

Jonathan Garber/Steve Schimmel

Walter Berry

Gulf Ecology Division (GED)

Bill Walker

Skeet Lores

Western Ecology Division (WED)

Walt Nelson

Spence Peterson

Neurotoxicology Division (NTD)

Bob MacPhail

Experimental Toxicology Division (ETD)

Bob Luebke

NHEERL Assistant Laboratory Director

Jennifer Orme Zavaleta/Barbara Walton

National Exposure Research Laboratory/Ecological Exposure Research Division (EERD)

Susan Cormier 


\section{Acknowledgments (continued)}

National Risk Management Research Laboratory/Subsurface Protection and Remediation Division (SPRD)

Steve Schmelling

National Center for Environmental Assessment/Exposure Analysis and Risk Characterization Group (EARCG)

Sue Norton

OW/Health and Ecological Criteria Division (HECD)

Bill Swietlik

Regions/Region 4

Joel Hansel

\section{NHEERL Aquatic Stressors Work Groups}

Habitat Alteration

Cathy Wigand, Giancarlo Cicchetti (AED)

Rich Devereux, John Macauley (GED)

John Brazner, Anett Trebitz (MED)

Bob Lackey (Chair), Jim Wigington, Jim Power (WED)

Nutrients

Jim Latimer (AED)

Skeet Lores (Chair), Rick Greene, Michael Murrell (GED)

Jo Thompson, John Morrice, Jack Kelly, Russ Kreis (MED)

Pete Eldridge, Robbins Church (WED)

Suspended and Bedded Sediments

Walter Berry (AED)

Bill Walker, Mike Lewis (GED)

Danny Tanner, Mike Sierszen (MED)

Steve Paulsen (Chair), Phil Kaufmann, Mark Johnson (WED)

Toxic Chemicals

Walter Berry, Matt Mitro, Diane Nacci (AED)

Larry Goodman, Michael Hemmer (GED)

Russ Erickson (Chair), Bob Spehar, Rick Bennett, Phil Cook (MED)

Jennifer Orme-Zavaleta (WED)

Diagnostics

Skip Nelson, Dan Campbell, Rob Burgess (AED) 


\section{Acknowledgments (continued)}

Virginia Engle, Jan Kurtz (GED)

Naomi Detenbeck (Chair), Larry Burkhard, Bill Richardson (MED)

Jennifer Orme-Zavaleta, Jana Compton (WED)

\section{Reviewers}

A preliminary draft of this document was reviewed by staff within the ORD Laboratories and Centers, OW, and the Regions. A subsequent draft was reviewed in February 2002 by the following reviewers outside of EPA:

Dr. Brian Bledsoe

Engineering Research Center

Colorado State University

Dr. Scott Dyer

The Procter and Gamble Company

Dr. Ken Rose

Coastal Fisheries Institute

Louisiana State University

Dr. Patricia Chow-Fraser

McMaster University

Dr. Scott Phillips

US Geological Survey

Water Resources Division
Dr. Keith Solomon

Center for Toxicology

University of Guelph

Dr. Jonathan Higgins

The Nature Conservancy

Dr. Paul McCormick

Everglades Program Team

Department of the Interior

Dr. Al Steinman

Annis Water Resources Institute

Lake Michigan Center

Dr. David Rudnick

South Florida Water Management District

Everglades Division 


\section{Glossary}

ACE

ACWI

AED

AhR

APG

APM

AQUIRE

AVS

BAF

BASINS

BLM

BO

BSAF

CADDIS

CENR

CFR

CTR

CWA

CWAP

DEM

DO

EC50

ECOTOX

EDNA

ELS

EMAP

EPT

EqP

ESA

ESG

FGDC

FTE

FWS

GAP

GC/MS

GED

GIS

GLEI

GPRA

HAB

HAPR

HUC

IBI
Acute-to-Chronic Estimation

Advisory Committee on Water Information

Atlantic Ecology Division

Aryl hydrocarbon Receptor

Annual Performance Goal

Annual Performance Measure

AQUatic toxicity Information REtrieval

Acid Volatile Sulfide

Bioaccumulative Accumulation Factor

Better Assessment Science Interacting Point and Nonpoint Sources

Biotic Ligand Model

Biological Opinion

Bioaccumulative Sediment Accumulation Factor

Casual Analysis and Diagnosis Decision Information System

Committee on Environment and Natural Resources

Clark Fork River

California Toxics Rule

Clean Water Act

Clean Water Action Plan

Digital Evaluation Model

Dissolved Oxygen

Effective Concentration (50\%)

Ecological Toxicity Database

Elevation Derivatives for National Applications

Early Life Stage

Environmental Monitoring and Assessment Program

Ephemeroptera, Plecoptera, Trichoptera

Equilibrium Partitioning

Endangered Species Act

Equilibrium-partioning Sediment Guideline

Federal Geographic Data Committee

Full Time Equivalent

Fish and Wildlife Service

Gap Analysis Program

Gas Chromatography/Mass Spectrometry

Gulf Ecology Division

Geographic Information System

Great Lakes Environmental Indicators

Government Performance and Results Act

Harmful Algal Bloom

Habitat Alteration Population-Response Model

Hydrologic Unit Code

Indices of Biotic Integrity 


\section{Glossary (continued)}

$\begin{array}{ll}\text { ICE } & \text { Interspecies Correlation Estimation } \\ \text { Kow }_{\text {owP }} & \text { Octonal-water Partition Coefficient } \\ \text { LaMP } & \text { Lakewide Management Plan } \\ \text { LC50 } & \text { Lethal Concentration (50\%) } \\ \text { MAHA } & \text { Mid-Atlantic Highlands Assessment } \\ \text { MED } & \text { Mid-continent Ecology Division } \\ \text { NAWQA } & \text { National Water Quality Assessment } \\ \text { NCEA } & \text { National Center for Environmental Assessment } \\ \text { NED-H } & \text { National Elevation Dataset (Hydrology) } \\ \text { NEP } & \text { National Estuarine Program } \\ \text { NERL } & \text { National Exposure Research Laboratory } \\ \text { NHEERL } & \text { National Health and Environmental Effects Research Laboratory } \\ \text { NMDS } & \text { Nonmetric Dimensional Scaling } \\ \text { NMFS } & \text { National Marine Fisheries Service } \\ \text { NOAA } & \text { National Oceanographic and Atmospheric Administration } \\ \text { NOAEL } & \text { No Observed Adverse Effect Level } \\ \text { NPDES } & \text { National Pollutant Discharge Elimination System } \\ \text { N/P } & \text { Nitrogen/Phosphorus } \\ \text { NPS } & \text { Nonpoint Source } \\ \text { NRC } & \text { National Research Council } \\ \text { NRDA } & \text { Natural Resources Damage Assessment } \\ \text { NRMRL } & \text { National Risk Management Research Laboratory } \\ \text { OEI } & \text { Office of Environmental Information } \\ \text { OPP } & \text { Office of Pesticide Programs } \\ \text { OPPTS } & \text { Office of Prevention, Pesticides, and Toxic Substances } \\ \text { ORD } & \text { Office of Research and Development } \\ \text { OST } & \text { Office of Science and Technology } \\ \text { OW } & \text { Office of Water } \\ \text { OWOW } & \text { Office of Wetlands, Oceans, and Watersheds } \\ \text { PAH } & \text { Polycyclic Aromatic Hydrocarbon } \\ \text { PBTK/TD } & \text { Physiologically-Based Toxicokinetic/Toxicodynamic } \\ \text { PBT } & \text { Persistent Bioaccumulative Toxicant } \\ \text { PCB } & \text { Polychorinated biphenyls } \\ \text { PCDD } & \text { Polychorinated dibenzo dioxins } \\ \text { PCDF } & \text { Polychorinated dibenzo furans } \\ \text { PHYTOTOX } & \text { Terrestrial Plant Toxicity Database } \\ \text { REMAP } & \text { Regional EMAP } \\ \text { RFP } & \text { Request for Proposals } \\ \text { SAV } & \text { Submerged Aquatic Vegetation } \\ \text { SI } & \text { Stressor Identification } \\ \text { SOLEC } & \text { State of the Lake Ecosystem Conference } \\ \text { SPARROW } & \text { Spatial Referenced Regressions on Watersheds } \\ \text { SPRC } & \text { Strategic Planning Research Coordination } \\ & \end{array}$




\section{Glossary (continued)}

$\begin{array}{ll}\text { STAR } & \text { Science to Achieve Results } \\ \text { STORET } & \text { STOrage and RETrieval database } \\ \text { TCDD } & 2,3,7,8-\text { Tetrachlorodibenzo-p-dioxin } \\ \text { TERRETOX } & \text { Terrestrial Wildlife Toxicity Database } \\ \text { TIE } & \text { Toxicity Identification Evaluation } \\ \text { TMDL } & \text { Total Maximum Daily Load } \\ \text { USGS } & \text { US Geological Survey } \\ \text { UV } & \text { Ultraviolet } \\ \text { WATERS } & \text { Watershed Assessment Tracking and Environmental Results System } \\ \text { WED } & \text { Western Ecology Division } \\ \text { WQC } & \text { Water Quality Criteria } \\ \text { WQS } & \text { Water Quality Standards } \\ \text { WRS } & \text { Wildlife Research Strategy }\end{array}$




\section{Executive Summary}

This document describes the framework (Sections 1-3) and implementation plans (Sections 4-8) for ecological effects research on aquatic stressors within the U.S. Environmental Protection Agency's (EPA) National Health and Environmental Effects Research Laboratory (NHEERL). The ultimate goal of this research is to develop scientifically valid approaches for protecting and restoring the ecological integrity of aquatic ecosystems from the impacts of multiple aquatic stressors. The immediate focus is to develop and improve assessment methodologies, diagnostic capabilities, and ecological criteria to guide management options for 1) protection and restoration and 2 ) remediation efforts to meet designated uses.

The context for this research is the common management goal of protecting aquatic systems to prevent degradation of habitat, loss of ecosystem function, and reduced biodiversity. To this end, environmental managers must be able to: 1) assess the condition of an aquatic resource and determine the degree of impairment, 2) diagnose the causes of impairment, 3) forecast the effects of changes in stressor levels, and 4) develop and implement remediation and maintenance strategies. Meeting the goals of effective management and protection of aquatic resources requires that multiple research elements be in place to provide the needed tools. This document provides a means to develop these tools. The research approach presents a generally linear sequence, although many research elements will be conducted simultaneously.

The research herein focuses on the effects of aquatic stressors, including habitat alteration, nutrients, suspended and bedded sediments, and toxic chemicals. This approach is consistent with recent scientific consensus, recognizing that these stressors have the greatest potential for causing adverse effects to aquatic ecosystems. In the context of this effects research, the document also provides research that will develop diagnostic tools for a decision support system for resource managers.

The importance of habitat quality and quantity for maintaining species is indisputable, but quantifying exactly how species depend on habitats is multi-faceted and complex. Research is needed to quantitatively link alterations in key habitats to provide the scientific basis to implement regulations and policies to protect fish, shellfish, and wildlife populations, and the ecosystems upon which they depend. To quantitatively assess effects over a range of foreseeable stressor conditions, stressor-response relationships need to be determined. These relationships provide fundamental information that helps to define response thresholds, or other patterns, and to improve aquatic life and aquatic dependent wildlife criteria. As stressor-response relationships are determined, research can be directed towards developing a "diagnostic tree" approach to list, analyze, and characterize the causes of impairment. EPA's Stressor Identification Workgroup has developed such an approach.

Another research need is to develop ecosystem classification approaches that allow for reasonable extrapolations of diagnostic approaches and stressor-response models. Classification is valuable for grouping ecosystems according to similar criteria and for spatially classifying ecosystems connected via stressor actions. Since little is known about scale relative to ecosystem classification, effects research also will provide guidance about the most appropriate scale for 
various ecosystem classification approaches, up to and including the watershed scale. At the same time, current criteria, methods, and approaches for stressors need to be improved where major uncertainties exist, or developed for others where information is scarce. Finally, all aquatic stressor research elements from this process need to be combined to develop management strategies to protect the ecological integrity of aquatic ecosystems. A series of EPA workshops and workgroup meetings has identified five main research products for meeting this goal:

- Methods to predict biological effects of habitat alteration;

- Population, community, and ecosystem stressor-response models;

- Diagnostic tools to determine impairment or causes of impairment to aquatic systems;

- Classification approaches to aid in the prediction and management of problems; and

- Methods and models to support development of ecological criteria.

In some cases, these products are under development, but in others, development has not yet begun. Sections 4-8 of this document provide the plans for implementing research in each of NHEERL's priority areas.

Section 4 focuses on quantifying the life support functions of specific habitat and habitat complexes to predict the biological effects of habitat alteration and/or loss on populations of fish, shellfish, and wildlife. The main goal of this research is to quantify the role of habitat in maintaining healthy aquatic and aquatic-dependent populations by 1) describing the relationships between habitat and biota at the appropriate scales to quantify effects on population endpoints due to habitat alteration and 2) synthesizing the cumulative support function of individual habitats and aquatic ecosystems, and integrating habitat alteration effects with effects from other stressors. Necessary elements of this research include providing: suites of species endpoints, assessment and measurement endpoints and strategies, habitat alteration-population response relationships, classification schemes, and models for extrapolating data across spacial scales. Research projects in this plan deal specifically with coastal vegetated habitat; shoreline, lake, and estuary scale habitat; and landscape scale habitat.

Section 5 centers on understanding the responses of receiving waters to excess nutrients. The main goal of this research is to define and quantify relationships between nutrient loading and ecological responses for different aquatic resource types to develop the basis for deriving numeric nutrient criteria. Principal components of this research include providing conceptual models for specific assessment endpoints, a state of the science evaluation to develop and improve nutrient-load responses, classification schemes, standard measurement endpoints, and nutrient load-response models. Research projects in this plan deal primarily with coastal receiving waters and the development of nutrient load-response relationships for dissolved oxygen, submerged aquatic vegetation, and food web and community composition changes.

Section 6 deals with the direct and indirect effects of suspended and bedded sediments in aquatic ecosystems. The primary goal of this research is to provide and demonstrate the approach for 
establishing sediment criteria that support aquatic life in streams/rivers, lakes/reservoirs, wetlands, and estuaries. NHEERL's effort concerning suspended and bedded sediments has been redirected since this section was first written. The majority of the work in this research area will now occur under Goal 8 (EMAP) because EMAP design techniques will be applied to develop effect thresholds for suspended and bedded sediments in aquatic systems. Some of these techniques are described generally in the Critical Path subsection of this section. However, at this time, the effort under aquatic stressors will only include a literature review of suspended and bedded sediments research. Results from this review will be combined with EMAP approaches to synthesize and evaluate the state of the science. Once the review has been completed, data gaps will be identified and additional research will be conducted, if warranted. Additional goals and research topics are proposed, but will depend on the results of this combined effort.

Section 7 focuses on developing methods to reduce uncertainty and significantly advance current methods to derive criteria for toxic chemicals. The general goal of this research is to develop scientifically-defensible methods for better characterizing the risks of toxic chemicals to aquatic and aquatic-dependent populations and communities. The key elements for improving aquatic risk assessments and criteria for toxic chemicals include providing methods to: improve criteria at the individual level based on improved characterization of risks, link individual-level data to population endpoints, support risk assessments for chemicals with limited data, and evaluate risks on populations at various spatial scales in the context of other stressors. Research projects under this plan center around conceptual models that will support the development and demonstration of frameworks for better assessing the risks of both non-bioaccumulative and bioaccumulative chemicals.

Section 8 provides an approach for diagnosing the causes of biological impairment linking watersheds with receiving water bodies to support the TMDL process and other regulatory programs. The primary goals of this research are to provide: a framework for interpreting cause and effect relationships, single-stressor diagnostic methods and models to determine the primary source of biological impairment of aquatic ecosystems, and methods and models to allocate and forecast causality among multiple stressors for use in restoration and remediation actions. The principal components of this research area align with the primary goals and will provide: the scientific foundation and information management scheme for the $303 \mathrm{~d}$ listing process, and a classification framework for surface waters, watersheds, and regions; diagnostic methods to distinguish among major classes of single and multiple aquatic stressors; and diagnostic tools for forecasting approaches. Specific research projects will be conducted to establish the conceptual framework to guide implementation of diagnostics, provide case studies to develop and test methods for both single and multiple stressors, and to establish the structure for a decision support system.

Over the next six years (2002-2008) the proposed research, integrated across areas, will provide increasingly sophisticated tools to help resources managers assess ecological conditions, diagnose impairment and causes of impairment, and forecast the effects of changes in stressor levels. As short-term to intermediate-term research on aquatic stressors is completed, this implementation plan will change, so that new or continued research will provide the tools necessary to identify, assess, and manage aquatic stressors and contaminated sediments to meet goals under the Government Performance and Results Act. 
Further development of this plan will require continuing interaction between the Office of Research and Development's (ORD) Laboratories and Centers, as well as with EPA's Program Offices and Regions, to ensure that the approaches developed are compatible with those for exposure and risk characterization. Collaboration with the Office of Water, Regions, States, and Tribes will be essential to ensure that this research directly supports regulatory mandates. In addition, it will be essential to integrate the research with future grant initiatives (including EPA's Science to Achieve Results [STAR] program) to ensure that ORD-sponsored research complements in-house programs. 



\section{Section 1. \\ Introduction}

\section{Purpose and Scope}

This document describes the framework and implementation plans for ecological effects research on aquatic stressors within the National Health and Environmental Effects Research Laboratory (NHEERL) beginning in 2002. The ultimate goal of the planned research is to develop scientifically valid approaches for protecting the ecological integrity of aquatic ecosystems from multiple aquatic stressors. The framework first defines the context and process for conducting research to reduce the risks aquatic stressors pose to aquatic resources, including aquatic life and aquatic-dependent wildlife populations and communities. Specific research plans then identify and describe NHEERL's priority research areas, linkages among the areas, and specific research projects which include the types of products that can be expected over the next several years. Although this document outlines the research that will be conducted within these research areas, it does not prioritize work across research areas.

This document also provides discussion points for use with other organizations regarding uncertainties in risk assessment techniques, potential collaborative research, and other interactions.

The scope of the document is defined by NHEERL's research areas under the Government Performance and Results Act (GPRA), Goal 2, Clean and Safe Water, sub-objective 2.2.3: "Provide the means to identify, assess, and manage aquatic stressors, including contaminated sediments." This Goal is one of 10 EPA strategic goals that cover the programmatic needs of the Agency. NHEERL's research under Goal 2 focuses on the development of stressor-response models for habitat alteration, nutrients, suspended and bedded sediments, and toxic chemicals; and on the development of diagnostic methods that are applicable up to and including the watershed scale.

This document does not include work on some aquatic stressors (e.g., invasive species, microbial pathogens, and climate change), monitoring under the Environmental Monitoring Assessment Program (EMAP), many aspects of biocriteria, or some work related to the aquatic stressors effort, which is covered under other GPRA goals (e.g., molecular and cellular mechanisms of toxic chemicals). Research on invasive species is being conducted elsewhere as EPA is an active member of the Inter-Agency Invasive Species Advisory Council, which includes the Fish and Wildlife Service (FWS), National Oceanographic Atmospheric Administration (NOAA), and other federal agencies. Monitoring under EMAP and biocriteria research occurs under GPRA Goal 8 and other research issues are covered under other NHEERL strategic goals (see http://www.epa.gov/nheerl).

Aquatic stressors research will require continuing interaction between the Office of Research and Development (ORD) Laboratories and Centers, EPA's Program Offices, and Regions, to ensure that the efforts are not duplicated and that the approaches developed are compatible with those for exposure and risk characterization. 


\section{Programmatic Needs}

EPA recognizes the need to advance risk assessment knowledge bases and to develop methods for reducing risks from aquatic stressors. The immediate focus is to develop and improve ecological criteria and diagnostic capabilities for managers, to help them meet designated uses, and to develop options for protection and remediation efforts. Three elements provide the regulatory context for NHEERL's aquatic stressors research:

- First, the Clean Water Act (CWA) provides the legislative mandate to restore and maintain the chemical, physical, and biological integrity of the Nation's waters.

- Second, to fulfill this mandate, EPA has established under GPRA Goal 2, sub-objective 2.2.3, requirements for establishing ecological criteria that protect use designations for the Nation's aquatic resources. Research directed toward this goal will be linked to Annual Performance Goals (APGs) and Measures (APMs), which NHEERL has identified for 2002-2008 (see Sections 4-8).

- Finally, the Administration's Clean Water Action Plan (CWAP) establishes key actions focused on watershed, wetland, and stream corridor protection and restoration; nutrient assessment and criteria development; and development of a contaminated sediment strategy (EPA 1998).

A response to these mandates requires the development of research approaches and products that enhance the Agency's capabilities with respect to the management of aquatic resources.

\section{References}

EPA. 1998. Clean Water Action Plan. EPA 840-R-98-001. 


\section{Section 2. \\ Research Approach}

\section{Context for Research}

The common management goal for all aquatic ecosystems is to maintain ecological integrity by protecting aquatic systems against degradation of habitat, loss of ecosystem functions and services, and reduced biodiversity. To this end, environmental managers must be able to: 1) assess the condition of an aquatic resource and determine the degree of impairment, 2) diagnose the causes of impairment, 3) forecast the effects of changes in stressor levels, and 4) develop and implement remediation and maintenance strategies. The first step in this process is to assign a designated use for a water body and then to apply the available chemical and biological criteria necessary to protect the use. If a resource does not support the designated use, the cause of the impairment must be diagnosed.

To accomplish these tasks, managers must be able to make proper assessments, know the appropriate reference conditions against which to compare their assessments, have the diagnostic tools necessary to ascertain causes, and understand specific aquatic systems well enough to forecast the effectiveness of potential remediation processes. While other ORD Laboratories and Centers will make important contributions to GPRA Goal 2, sub-objective 2.2.3, NHEERL will focus on conducting ecological effects research relative to steps 1-3 above.

The focus on aquatic stressors such as habitat alteration, nutrients, suspended and bedded sediments, and toxic chemicals is consistent with recent scientific consensus, recognizing that these undeniably widespread concerns have the potential for tremendous impact on aquatic ecosystems (e.g., National Research Council [NRC] 1993, Naiman et al. 1995, Vitousek et al. 1997, EPA 1998, NOAA 1999, EPA 2000a). Because of these stressors, an aquatic resource often fails to meet its designated use. States and Tribes commonly report these stressors as part of their Section 303(d) lists under the CWA, thus requiring the development of total maximum daily loads (TMDLs). Therefore, managers need a decision support system to discern the probable causes of impairment and to identify remediation action that will restore and protect the resource.

\section{Research Process}

Effective management and protection of aquatic resources requires multiple research elements. The research process for developing these elements and the products of the research are shown in Figure 1. This process presents a generally linear research sequence, although some research elements will be conducted simultaneously. State and Tribal management agencies can protect the ecological integrity of aquatic ecosystems only through appropriate management action, but NHEERL can help by providing methods and tools for assessing conditions, diagnosing impairments, and forecasting changes. 
Research Process

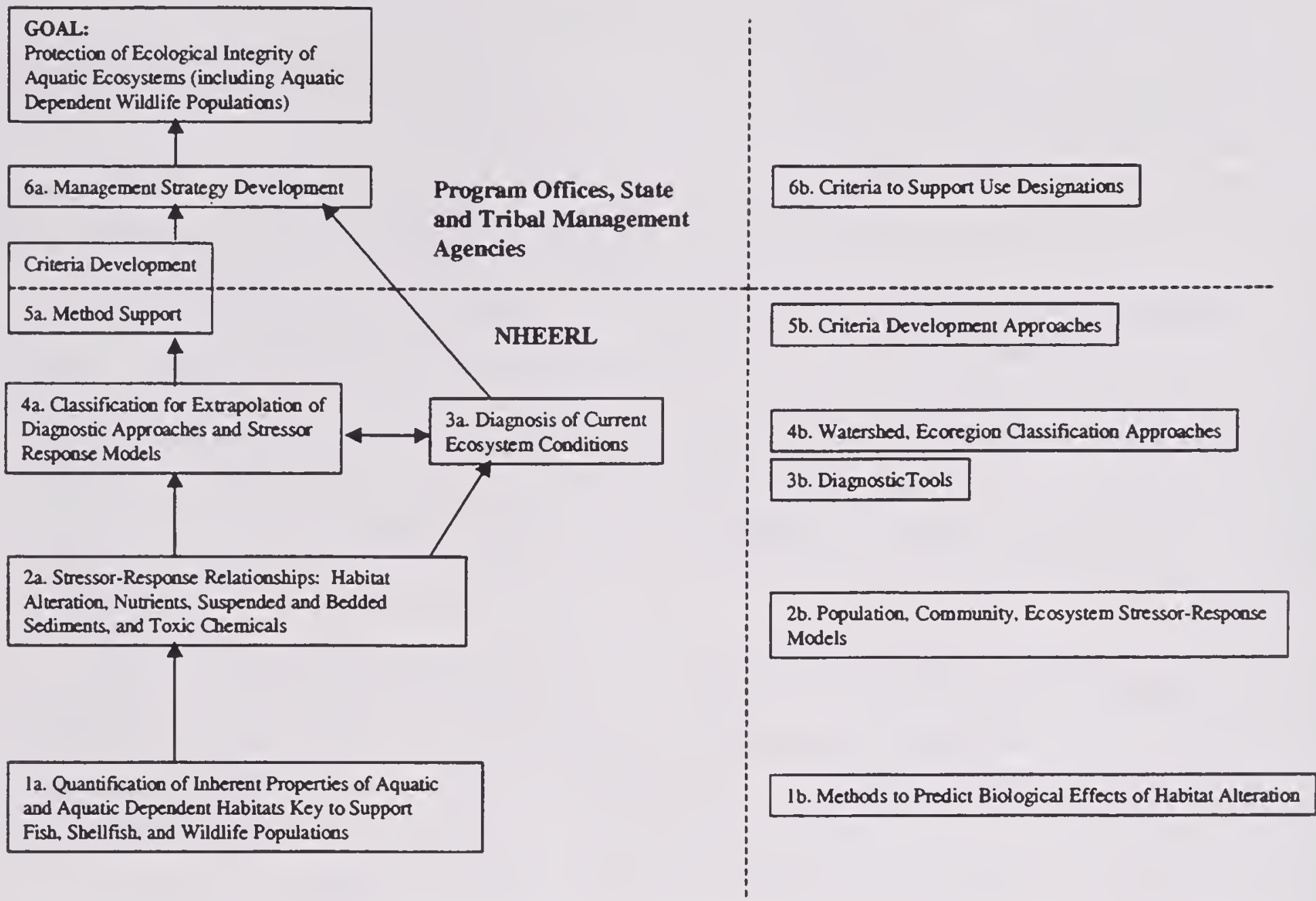

Figure 1. Research process and products for meeting the goal of effective management and protection of aquatic resources.

Protection of the ecological integrity of aquatic ecosystems must begin with a quantification of the inherent properties of aquatic and aquatic-dependent habitats which are critical to the support of important fish, shellfish, and aquatic-dependent wildlife populations (box la). Research in this area will help to assess the life support functions of habitats and habitat complexes and provide methods to predict biological effects which result from habitat alteration (box 1b). EMAP contributes, in part, to these basic needs under GPRA Goal 8. Ecological characterization and identification of the priority aquatic research elements are key to developing stressorresponse relationships within each of the aquatic stressor areas (box 2a). Stressor-response relationships are needed to quantitatively assess effects over a range of foreseeable conditions of the stressor. These relationships provide the fundamental information required to define response thresholds or other patterns and to improve criteria. Determining stressor-response relationships also should help define symptoms of a problem and identify diagnostic measures that can be broadly applied. This research will provide stressor-response models, if needed, within each of the aquatic stressor areas (box 2b). Eventually, these models must be capable of dealing with multiple stressor interactions if they are to support the development of approaches that allow characterization of the ecological condition of aquatic systems relative to a desired condition. However, initial research will focus on the stressor-response relationships of the individual stressors, in order to set the stage for the more difficult problem of dealing with multiple stressors in the longer term. 
As stressor-response relationships are determined, research will be directed towards developing diagnostic approaches (box 3a), which will provide tools (box $3 \mathrm{~b}$ ) for building a decision support system. Resource managers then can use the system to assess the condition of a water body, diagnose the causes of any demonstrated impairment, and predict the results of any corrective actions that might be needed.

Stressor-response relationships can be specific to different classes of systems. Thus, research also will focus on developing ecosystem classification approaches (boxes $4 a, b)$ that allow for reasonable extrapolations of diagnostic approaches and stressor-response models. Classifying ecosystems is valuable for two primary reasons: 1) grouping ecosystems according to similar criteria and 2) spatially classifying ecosystems that are connected via stressor actions to facilitate an effective means for managing the consequences of stressors. Since little is known about scale relative to ecosystem classification, effects research also will provide guidance about the most appropriate scale for various ecosystem classification approaches, up to and including the watershed scale.

At the same time, research identified in boxes la-4a will result in methods and approaches for deriving criteria (boxes 5a,b) for protecting aquatic ecosystems. Existing approaches, based on laboratory tests, have focused on individual aquatic life and wildlife species. However, much uncertainty is associated with extrapolating data to predict safe levels for populations and communities exposed to individual and multiple stressors (physical and/or chemical). Therefore, we need to improve current criteria, methods, or approaches for some stressors where major uncertainty exists, or develop them for others where little information is known (see Sections 48). In some cases, research will lead to relatively short-term fixes (1-2 years) to existing guidance. In others, research conducted over the longer term (3-6 years) will result in methods or models useful for deriving criteria with associated uncertainties.

All aquatic stressor research elements (boxes 1-5) thus combine to help improve the tools available to managers for meeting designated uses (boxes $6 a, b$ ). It is important to recognize that NHEERL research on aquatic stressors supports the development of protective criteria, although actual criteria and management strategies fall beyond the research responsibilities of NHEERL. A discussion on a decision support system for using the products of this research follows.

\section{Decision Support System}

A general approach that a resource manager might follow for managing water bodies is outlined in the left side of Figure 2. The assessment of the condition of an aquatic resource to support ecological use designations first requires ecological criteria and a reference condition with which to compare those criteria. As shown in the right side of Figure 2, GPRA Goals 2 and 8 research products will support the development of both chemical and biological criteria that can assist managers in determining if designated uses are met.

If designated uses are not met, managers will require a means of identifying the stressors causing the impairment. EPA's Stressor Identification (SI) workgroup has developed an example of a "diagnostic tree" approach for SI that can be used by resource managers (EPA 2000b). NHEERL research will contribute by determining stressor-response relationships and specific diagnostic 
indicators for aquatic stressors and by developing additional decision support tools as needed. In this approach, the SI process is iterative, usually beginning with retrospective analysis of available data, and includes the identification of stressors that might be causing the impairment.

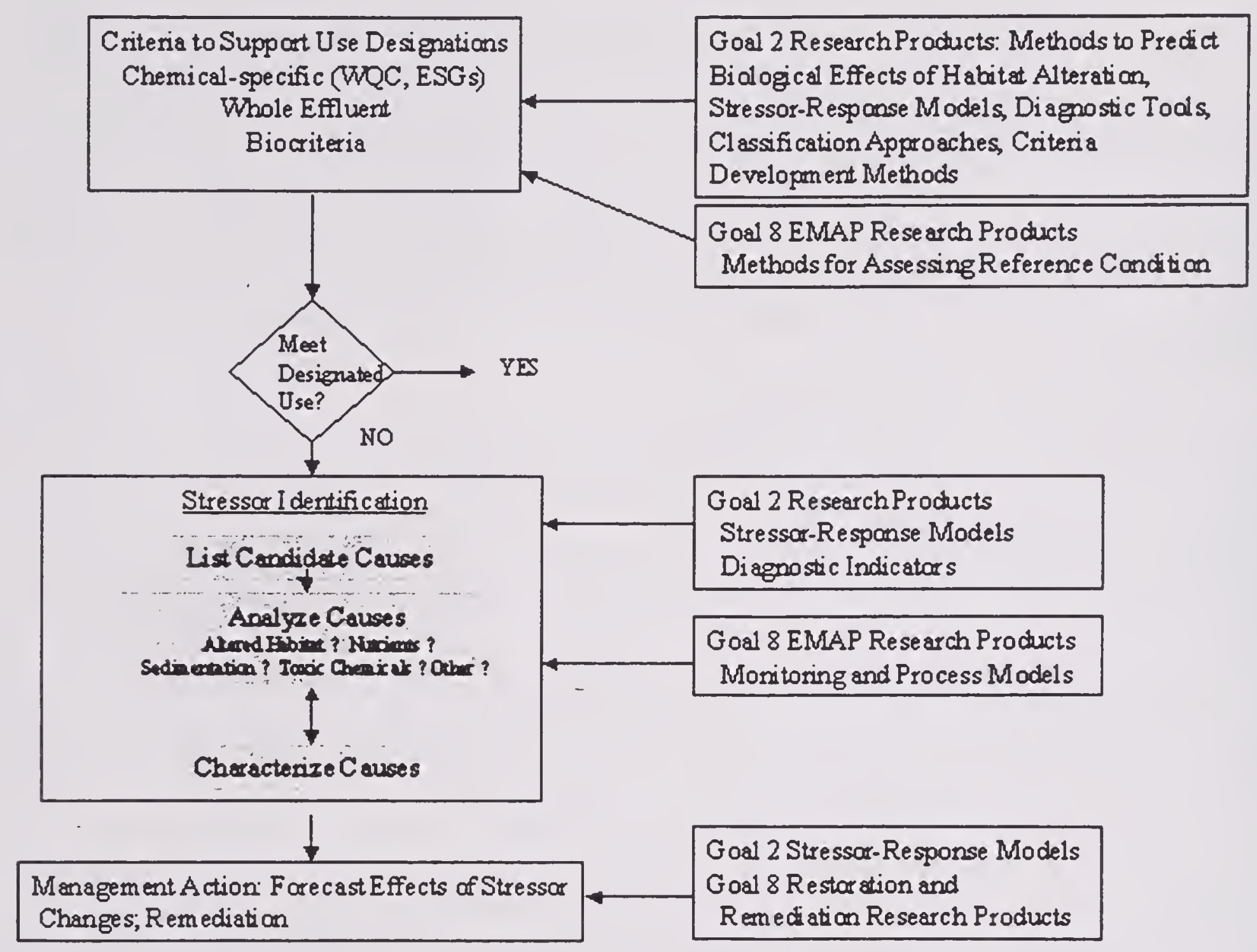

Figure 2. Manager's decision support system to protect and restore aquatic resources using ORD's research products (SI box is modified from EPA 2000b).

Stressor identification consists of three main steps, the core of the SI process: 1) listing candidate causes of impairment, 2) analyzing these candidate causes, and 3) producing a causal characterization. The support system also involves interactions with decision makers and stakeholders to assist in forecasting the effects of the stressors and in taking remediation action, if needed. Remediation requires, first, criteria for what is acceptable in a given environment, and second, the models necessary to link changes in stressors with improvements in the system. Additional information is provided in Section 8 (Diagnostics) of this document concerning the development of a framework for a decision support system. NHEERL-generated products from this research will be combined with exposure models and with restoration and remediation techniques developed by the National Exposure Research Laboratory (NERL) and National Risk Management Research Laboratory (NRMRL), respectively, to meet management needs. 


\section{References}

EPA. 1998. Water quality criteria and standards plan - priorities for the future. EPA 822-R-98003.

EPA. 2000a. OW/ORD Strategic Planning Research Coordination workshop document, version 2. January 31.

EPA. 2000b. Stressor identification guidance document. EPA-822-B-00-025. OW/ORD, Washington, DC, December.

Naiman, R.J., Magnusen, J.J., McKnight, D.M., Stanford, J.A., eds. 1995. The Freshwater Imperative: a Research Agenda. Island Press, Washington, DC.

NOAA. 1999. National estuarine eutrophication assessment: a summary of conditions, historical trends, and future outlook. Draft. National Ocean Service, Silver Spring, MD, June.

NRC. 1993. Managing wastewater in coastal urban areas. Washington, DC.

Vitousek, P.M., Aber, J.D., Howarth, R.W., Likens, G.E., Matson, P.A., Schindler, D.W., Schlesinger, W.H., Tilman, D.G. 1997. Human alteration of the global nitrogen cycle: sources and consequences. Ecol. Appl. 7:737-750. 


\section{Section 3. \\ Research Products and Implementation Plans}

Five main products from this research have been identified for meeting the goal of protecting ecological integrity of aquatic systems (Figure 1, boxes 1b-5b). These are:

- Methods to predict biological effects of habitat alteration;

- Population, community, and ecosystem stressor-response models;

- Diagnostic tools to determine impairment or causes of impairment to aquatic systems;

- Classification approaches to aid in the prediction and management of problems; and

- Methods and models to support the development of ecological criteria.

Although research to produce these products might need to be conducted independently at first, it also will have to be coordinated so that these products can be integrated into a manager's decision support system. In some cases, these products have been established, but need to be improved. In others, they will have to be developed. Therefore, research is being planned around compatible approaches, scales, critical areas, and geographic regions, when possible.

The remainder of this document (Sections 4-8) provides the plans for implementing research in each of NHEERL's priority areas. Each plan describes the problem the Agency faces, the goals, critical path for conducting the research, specific research projects to be conducted, a gap analysis, and references. The research projects within each plan contain the general objectives, scientific approach, products, benefits of the products to the client, and an estimate of the workload (in full time equivalents, FTEs) it will take to complete each project.

Currently, the work groups identified at the beginning of this document along with other staff within NHEERL's Ecology Divisions are detailing the projects outlined in the implementation plans in Sections 4-8 (Note: these detailed projects plans are not included in the present document). Each project will describe further coherent portions of the critical paths conceived to meet the goals stated in each implementation plan and will show how the projects will be completed to produce the products listed. Cross divisional projects will be conducted by scientists from more than one Ecological Division, while others will be conducted by staff of a single Division. Each project will consist of a design narrative (design, approach, and analysis) a Quality Assurance (QA) Plan, Health and Safety and Environmental Compliance Plan, and an Animal Care and Use Plan (if required) consistent with the Ecological Divisions' project plan documentation, and will undergo internal review prior to final approval. Work load (FTEs) and staff also will be provided in more detail than what is stated in the implementation plans shown in Sections 4-8.

The completion of research outlined in this document will require continued interaction within and across NHEERL's Ecological Divisions, between ORD's Laboratories and Centers, and 
within EPA's Program Offices and Regions. Collaboration with OW, Regions, States, and Tribes will be essential to ensure that this research directly supports regulatory mandates. In addition, it will be essential to integrate the research with present and future extramural initiatives (including EPA's Science to Achieve Results [STAR] program) to ensure that ORDsponsored research complements in-house programs and to fill research gaps that have been identified within each of the implementation plans. Many of these interactions are outlined in Sections 4-8; others will be delineated further in the detailed research projects that are now being developed by NHEERL staff. 


\section{Section 4. \\ Implementation Plan for Habitat Alteration Research}

\section{Problem}

Significant improvements in some aspects of the North American environment have been realized over the past several decades, but the continuing increase in human populations and associated activities has created an array of regulatory and policy challenges (e.g., land-use changes, hydrologic modification, climate change, altered biological diversity, introduction of nonnative species, concern about ecological sustainability, and cumulative effects of manmade chemicals) that defy traditional command/control approaches (EPA 1999). Many anthropogenic activities exert their influence on biota via effects on habitat, and habitat alteration is arguably the most important cause of declines in ecological resources in North America (EPA 1990).

Thriving populations of fish, shellfish, and wildlife are valued by the public, not only for commercial, recreational, and aesthetic reasons, but also as tangible and visible surrogates for the overall condition of the environment. Habitats essential to the well being of these species are rapidly being affected by a myriad of land-use activities. Habitat alterations have been identified as a major cause of endangerment for species within the United States. For example, the U.S. has the most diverse temperate freshwater fish fauna in the world, but $35-40 \%$ of its 790 fish species are imperiled because of poor land use practices, wetland alteration, introductions of exotic species, and other habitat-altering factors (Warren and Burr 1994, Stein and Flack 1997).

EPA has not traditionally focused its research, regulatory, or policy effort on habitat alteration. However, a number of factors converge to justify a new EPA emphasis on habitat issues. The CWA has a goal "to restore and maintain the physical, chemical, and biological integrity of the Nation's waters," including the "protection and propagation of fish, shellfish, and wildlife." While the chemical integrity of aquatic resources is much improved, physical and biological integrity remains a concem. Habitat alteration is a common cause for the failure of aquatic systems to meet designated uses as required by the CWA, and addressing these failures increasingly requires ameliorating the cumulative impacts of diffuse stressors including nutrient loading, sedimentation, and altered hydrologic regime. The necessary integrated approach to environmental protection is perhaps best provided by habitat-based criteria. As required by the Endangered Species Act (ESA), EPA is increasingly being asked to participate in interagency species protection and restoration efforts where habitat issues play a key role. Because one of EPA's core ecological regulatory authorities is the CWA, the species endpoints for which habitat alteration is of greatest concem are aquatic species (i.e., fish and shellfish), and water- and wetland-dependent wildlife. By focusing on aquatic ecosystems and habitats supporting species of combined ecological and societal importance, EPA can advance broad environmental protection goals while directly addressing issue-driven stakeholder concerns.

EPA's Office of Water (OW) has identified priority ecosystem types for which habitat alteration research is especially needed. These systems include freshwater and estuarine wetlands, stream corridors, and marine and Great Lakes coastal zones. Not coincidentally, these resource types are of considerable importance in sustaining ecologically and societally valuable fish, shellfish, and 
wildlife populations. More than $50 \%$ of U.S. marine fisheries exploit species that are estuarinedependent at some life stage, and many estuarine fisheries are in decline due to combined effects of over fishing, habitat alteration, and pollutants (Houde and Rutherford 1993). Virtually all Great Lakes fish depend at least indirectly on coastal wetland habitats, where habitat alteration is an important threat (Whillans 1992). Within these priority ecosystem types, OW has a particular interest in vegetated habitats. Aquatic vegetation is not only a key habitat for many wetland, estuarine, and coastal species, but also a key mediator of stressor effects on aquatic biota and a primary response variable for anthropogenic stressors such as nutrient and sediment loading. The combination of $\mathrm{OW}$ interests, pressures affecting societally and ecologically important species, and NHEERL research expertise leads to a focus on these endpoints in the this plan.

Assessing the ecological consequences of habitat alteration has been called one of the most challenging scientific problems and environmental policy issues confronting society (NRC 1997, Rapport et al. 1998, EPA 1990). The importance of habitat quality and quantity for maintaining species is indisputable, but quantifying exactly how species depend on habitats is multi-faceted and complex. Habitat provides a wide array of species life-support functions, ranging from providing shelter, substrate, and appropriate physiological conditions; to mediating natural disturbances and anthropogenic stressors; to maintaining food webs by hosting primary and secondary production. Consequently, habitat alteration can degrade diversity, food-web structure, ecosystem function, and populations of valued fish, shellfish, and wildlife species via complex effect pathways. Mobile and migratory species can use multiple habitats to meet developmental requirements or sustain local populations, and "habitat" for them may refer to a combination of quantity, quality, extent, and arrangement of different habitat types at a variety of spatial scales. Many stressors interact with aquatic systems in ways that alter the normal spatial distribution or mosaic of habitat patches, with important implications for ecosystem function and dependent fish, shellfish, and wildlife populations. More generally, successful preservation of biological diversity and ecosystem structure and function requires protection of multiple habitats within a landscape framework and not merely individual habitats in isolation. For many important aquatic habitats, there is little quantitative information on the relationship of habitat to dependent biota; in particular how changes in habitat quality influence the well being of fish, shellfish, and wildlife populations. Finally, broad biogeographic gradients affect the responses of ecosystems and biota to habitat alteration. For all these reasons, it is a significant research challenge to quantify the life support functions of specific habitats and habitat complexes in sufficient detail to predict the biological effects of both incremental and catastrophic habitat alteration.

NHEERL has initiated a nationwide research program to quantitatively link alterations in key habitats to fish, shellfish, and wildlife endpoints because habitat alteration is such an important, pervasive stressor on valued aquatic resources. The research involves all four Ecological Divisions of NHEERL and spans the coastal resources of the East, West, Gulf states, and the upper Midwest. NHEERL will enter into partnerships with other management agencies and research entities as appropriate to further these research goals. The research described in this plan will help build the scientific basis to implement regulations and policies to protect aquatic populations and the ecosystems upon which they depend. 


\section{Goals}

The overarching goal of this plan is to provide the scientific basis for assessing the role of essential habitat in maintaining healthy populations of fish, shellfish, and wildlife and the ecosystems upon which they depend.

Such a scientific understanding is essential in devising habitat protection and restoration priorities and schemes. The spatial pattern and temporal dynamics of habitats and habitat conditions within landscapes play significant roles in the long-term viability of aquatic populations, species assemblages, and ecosystem functions. Ecosystem level responses to stressors are functions of both the tolerance of individual species and habitats to those stressors, and the spatial distribution and connectivity of habitats within the landscape. Furthermore, habitat components themselves play ecosystem roles that mediate the response of species and assemblages to stressors. Finally, habitat influences populations and assemblages at hierarchical spatial scales ranging from patches (micro-scale) to entire ecosystems (macro-scale) to watersheds or regions (landscape scale). Understanding how effects of anthropogenic stressors are mediated by alteration in habitat quality, abundance, and configuration at various spatial scales is necessary in order to develop aquatic resource protection criteria and to predict the resiliency, restorability, and recovery of fish and wildlife populations and their supporting ecosystems.

More specifically, APGs and APMs for the research are:

APG 1 FY02 Provide suites of relevant fish, shellfish, and wildlife species endpoints suitable for setting regional-scale habitat protection criteria for coastal systems, along with preliminary reviews of methods, modeling approaches, and available data for relating habitat alteration to changes in those species.

APM 1 A FY02 Listings of the high-priority species of fish, shellfish, and aquaticdependent wildlife for study in each biogeographic region, and listings of the habitats that are considered to be critical to each (WED).

APG 2 FY04 Provide models for linking habitat alteration stressors and mercury to the regional problems of Northeast Loons and to landscape-watershed alterations for Pacific salmon.

APM 2A FY03 Prototype watershed-stream network modeling approach for Pacific salmon (WED).

APM 2B FY04 Habitat suitability indices to support population models for projecting relative risks of multiple stressors including toxic chemicals and habitat alteration to common loons (AED).

APG 3 FY04 (GPRA \# 8) Provide demonstration stressor-response relationships and/or models linking loss and alteration of habitat to selected fish, shellfish, and wildlife endpoints.

APM 3A FY03 Penaeid shrimp dependence on seagrass habitat (GED). 
APM 3B FY03 Finfish dependence on seagrass and oyster reef habitats (GED).

APM 3C FY04 Report characterizing the relationship between habitat in stream networks and salmon-native fish for coastal Oregon watersheds (WED).

APM 3D FY04 Report characterizing the relationship between alteration of vegetated habitats and nekton use of those habitats (AED).

APM 3E FY04 Report characterizing relationships between multiple habitat types and economically valuable fish at the scale of an estuarine shoreline (AED).

APM 3F FY04 (GPRA \# 58) Preliminary report characterizing relationships between abundance, quality, and arrangement of various habitat types and selected biotic assessment endpoints in coastal systems (WED).

APG 4 FY05 Provide indices of patch, ecosystem, and landscape-scale habitat integrity based on support for selected fish, shellfish, and wildlife assemblages.

APM 4A FY05 Develop indices of watershed integrity based on land use/land cover and relationships to fish (WED, MED).

APG 5 FY06 Provide stressor-response relationships and/or models linking loss and alteration of habitat to selected fish, shellfish, and wildlife endpoints.

APM 5A FY05 Reports characterizing the relationship between landscape-scale habitat mosaics and native fish by wetland type in the Great Lakes (MED).

APM 5B FY06 Report characterizing relationships between abundance, quality, and arrangement of various habitat types and selected biotic assessment endpoints in coastal systems (WED, AED, GED, MED).

APG 6 FY08 Provide suites of habitat alteration-biological response relationships and generalization/extrapolation schemes suitable for developing broad-scale habitat criteria for streams and coastal systems, and provide approaches for evaluating combined effects of habitat alteration and other stressors.

APM 6A FY04 Ecological consequences of marine derived nutrients and nutrient enrichment for aquatic biota and stream habitat quality, with an emphasis on salmon and native fish (WED).

APM 6B FY07 Regional models of landscape influence of salmon/native fish in the Pacific Northwest and native fish in Great Lake coastal wetlands (WED, MED).

APM 6C FY08 Synthesized quantitative species-habitat relationships suitable for developing regional habitat-based biocriteria for shorelines, lakes, and estuaries (AED, GED, MED, WED). 
APM 6D FY08 Interactions between stream nutrients and habitat alteration on water quality and aquatic life (WED).

\section{Critical Path}

Determining the role of essential habitat in maintaining fish, shellfish, and wildlife populations involves two distinct research components:

1. Describing the relationship between habitat and biota at appropriate spatial scales and with sufficient detail and resolution to quantify the effects of both incremental and catastrophic habitat alteration; and

2. Synthesizing the cumulative support function of individual habitats and ecosystems and integrating habitat alteration effects with effects of other stressors, so that resource protection and restoration priorities can be evaluated at spatial scales up to and including regions or large receiving bodies.

Within these two research components, research efforts can be further categorized by spatial scale, ranging from habitats within ecosystems to entire ecosystems to landscapes and regional habitat mosaics. A critical path diagram illustrating this two-component research strategy and the spatial focus of research efforts is given in Figure 3. Table 1 gives a overall time-line for the overall plan.

\section{Component 1}

NHEERL proposes to focus research describing relationships between habitat and biota on coastal marshes, estuaries, and nearshore environments. Two primary spatial scales will be considered: the scale of habitat elements, especially vegetated habitat, within marsh and estuarine systems; and the scale of entire coastal wetland and estuarine ecosystems (i.e., micro and macro-habitat scale). Synthesizing the cumulative population support functions of coastal habitats and ecosystems on a regional basis is a long-term goal, but the initial emphasis will be on quantifying habitat-biota relationships at the ecosystem and within ecosystem scale.

Necessary elements of this habitat research include:

1. Identifying suites of endpoints that provide a nationally comprehensive and comparable basis for linking alteration of key coastal habitats to species and assemblages of economic or societal 
Habitat alteration - biota response relationships suitable for setting habitat criteria and protection/restoration priorities

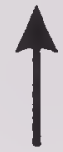

Extrapolation across ecosystems requires classification \& regionalization schemes and datasets [APG5, 6]

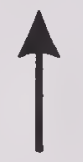

Habitat integrity indices based on habitat biota response relationships [APG4]

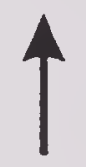

Field work, data analysis, and modelling to develop habitat - biota response relationships $\&$ mechanisms [APG3]

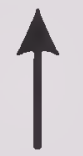

Review available data \& models for linking habitat to biotic endpoints [APG1]

Identify species, ecosystems, and habitats of concern [APG1]
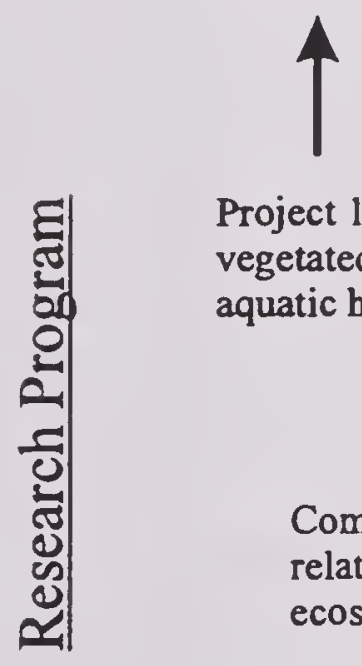

\section{Project 1}

vegetated

aquatic habitat
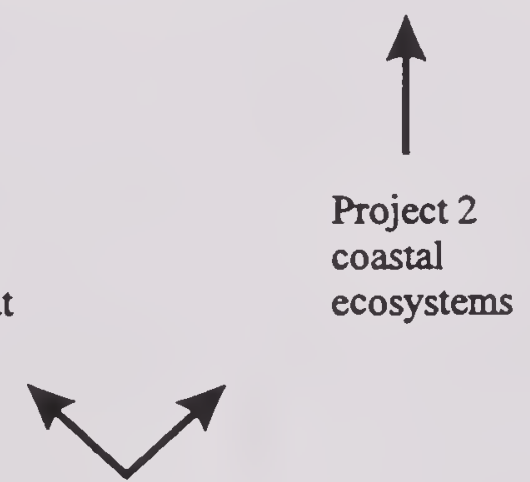

Component 1: habitat biota relationships (habitat and ecosystem scale)
Methods for integrating habitat alteration and other stressors in a regional or landscape level effects context

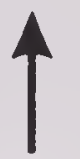

Evaluation of the relative \& cumulative effects of stressors including habitat loss on spatially structured populations [APG5, 6]

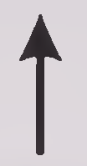

Landscape scale habitat integrity indices [APG4]

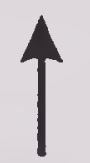

Landscape scale habitat - biota response relationships \& mechanisms [APG3]

$$
4
$$

Models and approaches for assessing importance of spatial structure and connectivity [APG2]

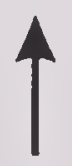

Project 3

salmonids /

native fishes

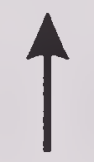

Project 4 piscivorous birds

\begin{abstract}
Component 2: scaling up to the landscape (reach, network, watershed, region)
\end{abstract}

Figure 3. Critical path for habitat alteration research (APGs) refer to those listed and described in the Goals subsection. 


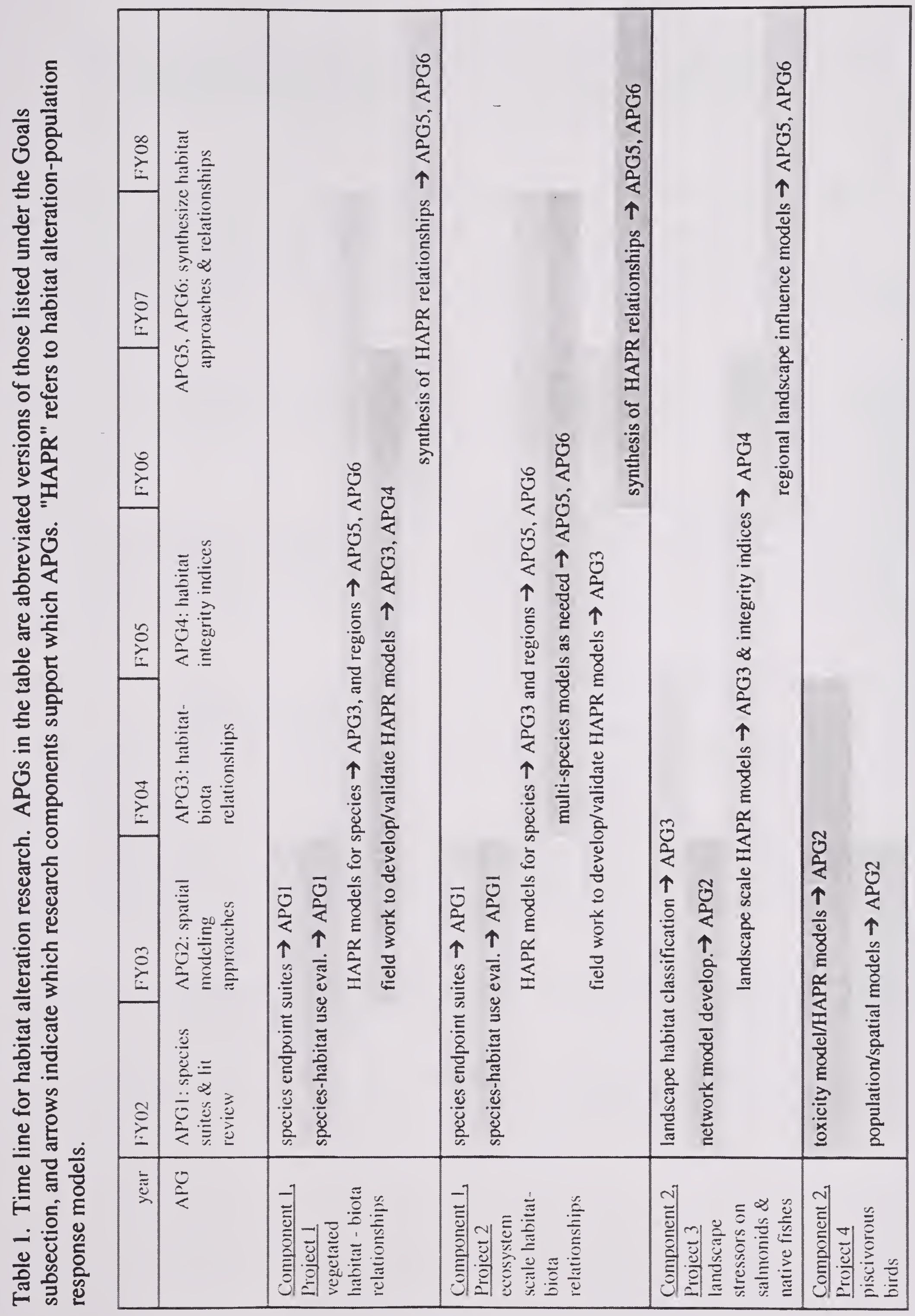


relevance, and identifying data and models available to make these linkages.

2. Devising assessment and measurement endpoints and strategies for the fish, shellfish, and wildlife populations and habitat elements of concern so that measurements are comparable or complementary and informative across regions, ecosystems, and habitats.

3. Developing habitat alteration-population response relationships for the species and habitats of concern capable of quantifying effects of both incremental and catastrophic habitat alteration. The relationships must deal with both individual habitat components and interactions among them. Habitat-biota relationships may require intermediate steps to properly describe the linkage pathways (e.g., to capture the productivity subsidy to fishes from coastal wetland vegetation).

4. Devising regionalization and classification schemes reflecting the range and distribution of coastal habitats and ecosystems to identify biogeographic expectations and capture ecosystem constraints and forcing factors.

5. Identifying data sets and approaches for extrapolation, both to specific unstudied systems, and to make inferences for the population of systems from the suite sampled.

\section{Component 2}

NHEERL plans to pursue the influence of human activities on habitat at landscape, regional, and watershed scales via two conceptually linked studies. One project will examine watershed and landscape scale habitat issues affecting recovery of Pacific Northwest salmon, and fishes reliant upon Great Lakes coastal wetlands. A second project will examine the interaction of a suite of anthropogenic stressors including habitat alteration affecting piscivorous birds (e.g., common loons) distributed across heterogeneous lake districts. Unlike the wetland/nearshore research described above, Component 2 research projects emphasize modeling and Geographic Information Systems (GIS), and explicitly consider the interaction among habitat alteration and other stressors. Common components of these research projects include:

1. Identifying data sets, approaches, and measurements for characterizing the factors, including habitat alteration and other stressors that affect selected species or assemblages at large or hierarchical spatial scales.

2. Developing and comparing approaches, indices, and models for extrapolating from individual or local habitat-biota relationships to effects on regionally-distributed populations or metapopulations.

3. Assessing the importance of spatial structure and connectivity of habitats via modeling efforts at varying spatial scales and resolutions.

\section{Research Projects}

This plan is divided into four parallel but closely linked projects. Project 1 (Coastal Vegetated Habitat Research) addresses societally important endpoints of concern that are affected by 
alteration of critical habitats, especially vegetated aquatic habitats, within coastal ecosystems. Project 2 (Shoreline, Lake, and Estuary Scale Habitat Research) also deals with societally important endpoints, but focuses on those coastal ecosystems where the interactions of multiple habitats predominantly determine the condition of fish, shellfish, and wildlife populations. Project 3 (Salmon and Native Fish Habitat Research) and project 4 (Multiple Stressor Risks to Common Loon and Other Piscivorous Bird Populations [cross-listed in Section 7, Toxic Chemicals, Project B3]) concentrate on providing the scientific basis to protect critically important endpoints such as wild salmon and migratory wildlife whose populations are at risk due to, among various factors, large scale changes in their habitats. As described in the Critical Path, work at the vegetated habitat and multiple habitat scale primarily addresses the need for developing habitat-biota-response relationships. Work at the watershed/regional/landscape scale is divided into two projects that are conceptually related but deal with different ecosystems and biological endpoints. Research will directly address the consequences of habitat alteration for societally important fish, shellfish, and wildlife species. Table 2 lists those species that, on the basis of initial assessment, appear as the best candidates for study under projects 1 and 2 . During development of specific research plans by NHEERL Ecological Divisions, a more detailed

Table 2. List of candidate species for study in marine and Great Lakes coastal regions.

\begin{tabular}{|l|l|}
\hline $\begin{array}{l}\text { Northeast Atlantic Coast } \\
\text { (Atlantic Ecology Division) }\end{array}$ & $\begin{array}{l}\text { Gulf Coast } \\
\text { (Gulf Ecology Division) }\end{array}$ \\
\hline $\begin{array}{l}\text { Winter flounder } \\
\text { Striped bass, bluefish, and weakfish } \\
\text { Tautog } \\
\text { Bay scallops and lobster } \\
\text { Waterfowl and shorebirds }\end{array}$ & $\begin{array}{l}\text { Penaeid shrimp } \\
\text { Blue crab } \\
\text { Red drum and other sciaenids } \\
\text { Oysters } \\
\text { Waterfowl and shorebirds }\end{array}$ \\
\hline $\begin{array}{l}\text { Great Lakes } \\
\text { (Mid-Continent Ecology Division) }\end{array}$ & $\begin{array}{l}\text { Northwest Pacific Coast } \\
\text { (Western Ecology Division) }\end{array}$ \\
\hline $\begin{array}{l}\text { Northern pike } \\
\text { Walleye } \\
\text { Yellow perch } \\
\text { Largemouth and smallmouth bass } \\
\text { Waterfowl and shorebirds }\end{array}$ & $\begin{array}{l}\text { Salmon and trout } \\
\text { Dungeness crab } \\
\text { Pacific herring } \\
\text { Threatened and endangered native fishes } \\
\text { Waterfowl and shorebirds }\end{array}$ \\
\hline
\end{tabular}

analysis of the current state of knowledge concerning the species-habitat relationships for those on this list will be done. Development of research efforts on particular organisms under this plan will be closely coordinated with other efforts, both within EPA and in other organizations. For example, NHEERL also has developed a Wildlife Research Strategy (WRS) (EPA 2000), and the related research initiated here will be integrated with any NHEERL research on semi-aquatic wildlife.

A systematic approach will be used to evaluate candidates and select species using a consistent societal value-based scheme. A data table will be constructed for each region listing the species 
and their associated societal values or characteristics, such as economic value, charismatic value, stock status, and extent of coastal/estuarine dependency. Species will then be prioritized.

Development of a final list from the top-priority populations will be used to select species from a range of life histories and ecological niches to best represent biological diversity and ecosystem function. The final list also will include information that will consider the scientific feasibility of studying populations, because species with certain life histories may be very difficult or impractical to study given the available research tools. For some species, research often will focus on the juvenile stages because juveniles are typically more dependent on specific habitats and are not subject to direct fishing pressure, but adults will sometimes be the endpoint that best integrates over the suite of habitat elements being considered. Secondary species endpoints for each of the above areas are the key forage fishes and invertebrates upon which larger societally valuable species depend, and these will be considered as well.

\section{Project Tüle 1: Coastal Vegetated Habitat Research}

Project Coordination and Resources (11.15 FTEs: AED-5.05, GED-2.0, MED-1.0, WED-3.1)

Objectives

- To quantify the role of aquatic vegetated habitat in providing structure and life support functions (e.g., food and shelter) to selected and societally important fish, shellfish, and wildlife populations.

- To identify those attributes of habitat within vegetated aquatic systems that are key to sustaining societally important species, and to further determine the functional relationships between those attributes and the utilization of that habitat by primary and secondary (e.g., forage organisms) assessment endpoints.

- To integrate the results of habitat-specific research results with other NHEERL habitat research that focuses on larger scale questions that range from localized among-habitat differences to the landscape and regional scale.

- To provide to other research teams within NHEERL the functional relationships between aquatic vegetation attributes found to be important to endpoints, and that are also impacted by stressors.

- To transmit the results of this research to resource managers in a format appropriate for its application in policy and regulatory decisions.

\section{Scientific Approach}

The definition of "habitat" invariably combines two concepts: a geographic location; and the flora and fauna that are regarded as dependent upon, or otherwise functionally associated, in some way, with that location. Aquatic habitats can range in character from bare sand, sediment, or rock substrates to areas of submerged or emergent vegetation. This portion of the plan focuses on aquatic vegetation - the areas of freshwater or estuarine wetlands, marshes, and sea grass beds 
that, by virtue of their attachment to the substrate, are also associated with location. Areas of aquatic vegetation represent the smallest, discrete scale that research described in this plan will concentrate upon and will be studied at the greatest level of detail. Project 2 (Shoreline-, Lakeand Estuary-Scale Research) extends to larger scales, but at lesser detail, and will consider how vegetated habitat interacts with other habitat types to determine biotic structure at the ecosystem scale.

The emphasis on aquatic vegetation in this project is appropriate for several reasons. First, aquatic vegetation is one of the most widespread and important types of aquatic habitat, in part because of the exceptional productivity of the plants. Recreationally and commercially important fish, shellfish, and wildlife, as well as rare and endangered species that are especially valued by human society, frequently exploit this productivity, either using the vegetation as a direct food resource, or indirectly, by feeding on smaller forage organisms that rely directly on the vegetation. Aquatic vegetation also strongly influences local physical and chemical habitat conditions of significance to fish and shellfish, including substrate type and stability, wave and current energy, and water quality. The structural complexity of aquatic vegetation provides shelter and nursery areas for its inhabitants. Overall, research will focus on evaluating the importance of habitat attributes of vegetated aquatic systems to the assessment endpoints of interest to society (see Figure 4). Aquatic vegetation is itself a key endpoint of research plans being formulated under the other aquatic stressors implementation plans, including Nutrients (Section 5) and Diagnostics (Section 8), and research outlined in this plan will be closely integrated with those efforts.

\section{Identification and Prioritization of Assessment Endpoints}

The assessment endpoints are organisms believed to be dependent on aquatic vegetation and identified as of societal value, and hence of regulatory and policy importance. Societal relevance will be the dominant criterion for assessment endpoint selection, but societal relevance needs to be intersected with ecological relevance and EPA research capabilities and regulatory mandates. Endpoints most likely will be chosen from the above listing of candidate species. However, other, intermediate endpoints such as forage fish species may also be required because the link between societally relevant species and aquatic vegetation may be mediated through secondary production, water quality, or other functional aspects of aquatic vegetation. During the development of specific research plans, the researchers participating in this effort will evaluate critically the suitability and appropriateness of proposed assessment endpoints with regard to regional EPA concerns, the laboratory capabilities, and the research activities of other agencies. Additionally, a concerted effort will be made to coordinate this research with that of other offices within ORD such as NERL and Federal and State resource management agencies, 


FISHISHELUFISHMILDLFE
- abundance
- species composition
- guild structure -\% exotics
- population structure

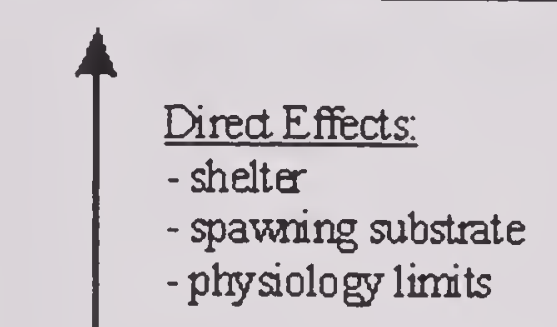

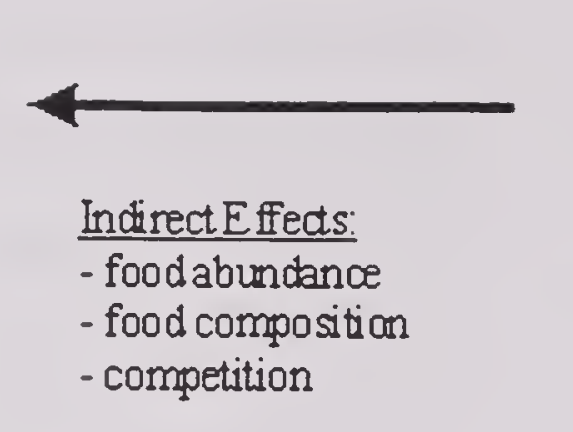

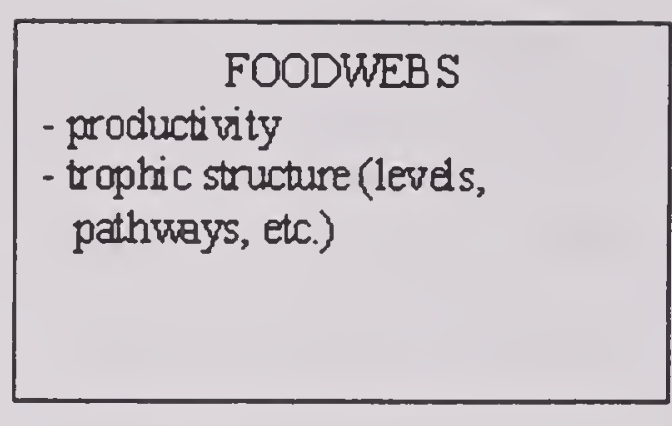

Dired Effects:

- habitat for prey organisms

- primary produdion

- disturbance regime

\begin{tabular}{|llll|}
\hline \multicolumn{4}{c|}{ HABITAT COMPONENTS VILNERABLE TO ALTERATION } \\
Sediments & Water quality & Plants & Morphology \\
-grain size & -DO & -growth form & -area \\
-\% organic & -pH & -areal extent & -bathymary \\
& -turbidity & -biomass & -chamnel vs. badkrater \\
& -temperature & -species & \\
\hline
\end{tabular}

Figure 4. Components of coastal vegetated habitat with possible pathways for direct and indirect effects of habitat alteration on fish, shellfish, and wildlife.

so as to preclude duplication of effort, allow the differing objectives of the agencies to be represented (e.g., utilization vs. conservation), and foster synergy. As an example, both the South Atlantic Fishery Management Council and the Atlantic States Marine Fishery Commission have explicitly identified submerged aquatic vegetation (SAV) as areas of concern with respect to fishery resources, and EPA research efforts will be coordinated with those entities. Research on endangered species, such as Pacific salmonids, will necessitate close collaboration and coordination with other agencies, because authorization for and logistics of discrete, stand-alone efforts may be difficult or impossible. Additionally, a number of existing EPA or other Federal and State databases and software (e.g., those available at http://www.epa.gov/OW/soft.html) may be useful during the implementation of this research.

\section{Assessment of Key Habitat Elements for Biota of Vegetated Aquatic Systems}

Assessing effects of incremental habitat alteration on species requires quantitative understanding of a given organism's reliance upon vegetated aquatic habitat. For clarity, this step is listed separately from the step of identifying candidate organisms, but at least a partial assessment of vegetation dependency will be done concurrently with species identification and prioritization. This step will integrate data from ongoing or published research, but EPA field efforts for some species, ecosystems, and habitat types will be required. It is necessary to critically evaluate the nature and level of the organism's dependence on vegetated habitat, both with respect to life history stages and the importance of vegetated habitat relative to alternative habitats. For 
example, there may be a perception that a given organism is dependent on aquatic vegetation when in fact it is more of a case of co-occurrence between the organism and the vegetation that share similar physical requirements, rather than a dependence of the organisms on conditions provided by the vegetation. An example would be migratory fishes, such as Pacific salmonids. The level to which these fishes utilize estuarine habitat in their migratory cycle is not well known, and the utilization of estuarine seagrass beds is thought to vary greatly among salmonid species and stocks. If such vegetation were not present, would salmon simply reduce their residence time in the estuary and continue their seaward migration sooner than they would otherwise? It must also be assessed whether the organism is associated with the vegetated habitat throughout its life, or only occupies the habitat during specific life history phases or seasons. It should be noted that many species have life history stages that are notoriously difficult to observe or sample, and it may be difficult to establish whether and how much these organisms are truly dependent on aquatic vegetation.

\section{Characterization of the Species (Assessment Endpoint)-Habitat Relationships}

In order to quantify species-habitat relationships, it is necessary to define the structural and functional attributes of aquatic vegetation that are to be documented and their alignment with the hypothesized assessment endpoint requirements. Standardization is necessary to ensure that data are collected in an agreed upon and consistent manner among the research efforts. There must also be agreement and coordination among broader research groups: aquatic vegetation is considered in this document from the perspective of its function as a habitat, but other research will be evaluating the effect of nutrient loading and other anthropogenic stressors on aquatic vegetation, and so the data collected for habitat and nutrient work (e.g., see Section 5) should support one another. Examples of vegetation attributes include species composition, areal extent, fragmentation or patchiness of the habitat, zonation, productivity, density, growth rates, condition (or other evaluations of the vegetation's "health"), degree of protection from predators the vegetation might afford, substrate characteristics, water quality, seasonal alterations to the habitat, and whether it directly provides food for an assessment endpoint or food for a secondary endpoint such as forage organisms. Standardization of data is highly desirable, but it must not neglect regional differences in vegetated habitat. For example, many marine vegetated habitats are spatially extensive and largely monotypic, and efforts to characterize habitats may focus largely on vegetation condition and extent. In contrast, vegetated habitat of Great Lakes coastal wetlands is diverse and variable over relatively small spatial scales, so that research efforts here will focus on distribution and interspersion of habitat types with the ultimate goal of deriving habitat evaluation procedures capable of synthesizing habitat components across entire wetlands.

\section{Quantifying the Consequences of Alteration of Vegetated Aquatic Habitats}

After identifying important species that depend in some way on aquatic vegetation, and having defined the suite of vegetation attributes relevant to those organisms, the research will then quantify the relationships between the two. Quantifying species-vegetated habitat relationships in sufficient detail to permit evaluation of both catastrophic and incremental habitat alteration requires developing mechanistic or empirical relationships spanning a range of habitat extent and characteristics. Insofar as possible, research also should identify key portions of the response relationships including response thresholds, maximum biological potential, and levels above 
which factors other than habitat limit populations. Because ecological constraints and co-factors independent of vegetated habitat will also determine local biological potential, there is likely to be a family of curves for different ecological conditions; for example, for different salinities, wave energy regimes, or wetland types. Assigning habitats or systems to the appropriate response curve will require development and evaluation of classification systems and methods for determining ecological potential. This work will be done with the objective of contributing to the larger-scale habitat considerations (described below). Therefore, achieving broad spatial coverages for species-habitat relationships will require stratifying response curves by ecoregion or latitude, devising methods for extrapolation outside the range of measured habitat types and co-factors, and schemes for regionalizing population endpoints when specific populations of interest have insufficiently broad distributions. The balance among empirical and mechanistic investigations will depend on the strength of the linkage among the particular species endpoint and the habitat, and on the spatial extent for which relationships are desired. For example, situations where the primary concem is a particular species with identifiable demographic bottlenecks that depend directly on specific, measurable habitat elements may lend themselves to mechanistic species-habitat relationships. For other situations, where the dependence on vegetated habitat is more diffuse and specific population bottlenecks cannot be identified or where a suite of endpoints is applied over large regions, empirical relationships may be more easily obtained and appropriate.

\section{Products}

APM 1A FY02 Listings of the high-priority species of fish, shellfish, and aquatic-dependent wild life for study in each biogeographic region, and listings of the habitats that are considered to be critical to each (WED).

APM 3A FY03 Penaeid shrimp dependence on seagrass habitat (GED).

APM 3B FY03 Finfish dependence on seagrass and oyster reef habitats (GED).

APM 3D FY04 Report characterizing the relationship between alteration of vegetated habitats and nekton use of those habitats (AED).

APM 3F (GPRA \# 58) FY04 Preliminary report characterizing relationships between abundance, quality, and arrangement of various habitat types and selected biotic assessment endpoints in coastal systems (WED).

APM 5B FY06 Report characterizing relationships between abundance, quality, and arrangement of various habitat types and selected biotic assessment endpoints in coastal systems (WED, AED, GED, MED).

APM 6C FY08 Synthesized quantitative species-habitat relationships suitable for developing regional habitat-based biocriteria for shorelines, lakes, and estuaries (AED, GED, MED, WED). 


\section{Benefits of Products}

The Office of Water will be supplied with information on the effects of alteration of aquatic vegetated habitat on key endpoints (fish, shellfish, and wildlife populations) to support development of policies protective of these societally important endpoints.

\section{Project Title 2: Shoreline, Lake, and Estuary Scale Habitat Research}

Project Coordination and Resources (5.75 FTEs: AED-2.0, GED-0.75, MED-2.0, WED-1.0)

\section{Objectives}

- Identify the high-priority populations of fish, shellfish, and wildlife in each region; identify the habitats that are critical to these populations; and characterize the contributions of each habitat to life-support for these populations. Much of this objective will be accomplished through synthesizing the available literature.

- Develop and validate habitat alteration-population response relationships (classified, quantitative models) for the identified species and habitats in each region at the scale of the shoreline, lake, or estuary.

- Where feasible, develop and validate comprehensive multi-species models to predict quantitative changes in fish, shellfish, and wildlife resource value that would result from habitat alteration to a habitat-mapped shoreline, lake, or estuary.

\section{Scientific Approach (Overview)}

This subcomponent of NHEERL habitat research will focus on economically valuable and charismatic coastal species that use multiple habitats. Population responses will be evaluated at the scale of an aquatic shoreline (including shallow and intertidal habitats through deeper water habitats) or at the scale of an entire lake, cove, estuary, or subestuary. This approach is needed because many fisheries and wildlife species depend on several habitats in their life histories and migratory patterns. Houde and Rutherford (1993) list 21 estuarine-dependent species that make up more than $50 \%$ of all U.S. commercial fisheries landings, exclusive of Alaska pollock. All 21 of these species depend on multiple habitats at one or more stages of their life histories. EPA needs to plan research that will examine availability and alteration of multiple habitats within lakes and estuaries.

The primary goal of this work is to produce habitat alteration-population response models for high-priority populations of fish, shellfish, and wildlife. These habitat alteration-population response models will be designed to fit into spatially explicit risk assessment population models. A subsequent goal is to produce larger, comprehensive, multi-species models that can integrate single-species models to predict the total consequences of habitat alteration to a suite of economically valuable and charismatic species. Where vegetated habitats are involved, this work will be conducted with strong ties to project 1 . These research plans differ in that this project examines all the major vegetated and unvegetated habitats at larger scales, but delivers a cruder 
level of detail for the individual habitats compared to work proposed in project 2. Where overlap occurs, both groups of habitat researchers will work together to convey data and findings, and to avoid duplication of effort. This collaboration will occur at every step of the scientific approach described here. Other collaborations within EPA and with different Federal agencies also will be necessary to accomplish these research goals. These collaborations need to be actively pursued and nurtured from the onset of this research.

\section{Scientific Approach (Research Steps)}

\section{Identify suites of species and habitats that are most critical in each region, and characterize} each habitat's contributions towards the survival of these species.

Species for study in each region will be prioritized and selected as described above in the introduction to the section on Research Projects. For each selected species, key habitats will be identified. These habitats might be defined on the basis of "bioengineering" species (such as SAV, or burrowing shrimp), or on the basis of depth and substrate. It will be necessary to determine how important each "critical" habitat is relative to the other habitats these populations utilize. To this end, an understanding of how each habitat functions to support these populations will greatly help the development of habitat alteration-population response models. For estuarine and marine fishes and shellfish, the National Marine Fisheries Service (NMFS) Essential Fish Habitat work has already gone through this process, and summaries of the literature are readily available. Other compiled resources such as the FishBase Dataset, the FWS Species and Community Profiles, and the NOAA/NMFS Technical Memoranda will also be very useful. In many cases, substantial aspects of this research step can probably be accomplished by synthesizing the available literature.

\section{Quantify population responses to habitat alteration at the shoreline, lake, or estuary scale for} the identified high-priority species.

Simple validated models will be developed to quantitatively predict changes in societally valuable populations due to areal loss (either partial or total) of a given habitat within the spatial mosaic of habitats that constitute an aquatic shoreline or an entire lake or estuarine system. This is the central focus of this research component. Development of single-species models to show changes to high-priority populations that result from areal habitat loss will be a worthwhile stand-alone goal for NHEERL. Once these single-species models have been developed, research can proceed to research step 3 (below), the development of multi-species models.

The single-species models may be based on quantitative empirical measures of population density, production, or export in each habitat; or on quantitative estimates of fecundity and survival. As appropriate (when species life history dictates, or when broad regional coverage is needed), models also may be based on relative measures of population response. In each region, EPA researchers will need to determine which approach is best suited to accomplishing the goals of this research, with an eye towards ultimate application to risk assessment models.

As a first step in model development, researchers will consider the available literature, assemble existing models and data, and determine appropriate research approaches for each habitat and 
population. Wherever possible, existing models and data will be used to develop these habitat alteration-population response models. When this is not possible, researchers will plan the research needed to develop the models.

This work will be done from the aquatic shoreline scale (including intertidal and shallow habitats through deep water habitats) to the whole-lake/whole-estuary scale, as appropriate for the populations in question. The majority of lake research will probably take place in the U.S. Great Lakes, but smaller lakes are not excluded from consideration. In addition to developing these habitat alteration-population response models, targeted community-level and process-level work may be required to achieve the desired results. For example, it may be necessary to quantify key functions of certain habitats, or to examine how species in habitats of interest are linked to adjacent habitats. In each situation, proposed research will be designed to support habitat alteration-population response models.

An important point is that these models need not consider the full life history of each population. The goal of this work is to provide the scientific basis for resolving environmental protection policy and regulatory questions, not for policies to enhance fishable biomass, and so models may focus on specific stages of valuable species (e.g., juveniles). These "population models" may then actually model a sub-population, a single life history stage, or a specific "bottleneck" in a population. Otherwise, full-life-history models would need to consider harvest and over fishing, which is only going to be of incidental policy interest to EPA regulatory staff. The models we propose are designed to provide the necessary scientific basis to protect habitats by relating habitat characteristics to population or sub-population endpoints for fish, shellfish, and wildlife.

Spatial habitat mapping also will be a component of this work. The consequences of habitat loss need to be considered in the context of how much of each key habitat is available in the area of interest. Habitat mapping a shoreline, lake, estuary, or subestuary will be a vital tool in application of models. For this reason, spatial habitat mapping also should be a part of the quantitative research involved in creating these models.

In some cases when developing these models, it will be possible to link the status of a certain population to alteration of a single (often vegetated) habitat. This is most realistic for species that are very tightly tied at key life stages to single habitats that act as population "bottlenecks". This may apply to penaeid shrimp and vegetated marsh and seagrass habitats in the Gulf of Mexico, to bay scallops and seagrass habitat in the Mid-Atlantic and Northeast, and to other species and habitats. In these situations, project 1 will be a more appropriate means of determining population response. Project 1 evaluates in better detail at the single-habitat scale. Project 2 is intended to be fairly crude at the scale of the individual habitat, looking primarily at the effects of areal habitat loss on populations within a larger setting; the shoreline, lake, or estuary. Altematively, project 2 analyses may look at how habitat mosaics and landscape patterns affect the identified populations. In order to best meet the goals of the Aquatic Stressors Framework, projects 1 and 2 will need to work closely together. Approaches, data, and results will be shared between the two groups to produce the best product and to eliminate duplication of effort. In most cases, results of the more detailed habitat alteration work conducted under project 1 will be directly incorporated into the larger scale habitat alteration-population response models described here. 
For some populations, a single-habitat approach as in project 1 above may not be the most appropriate model. In particular, many economically valuable fishes are mobile, migrating from habitat to habitat. The scale which affects these populations most is that of an entire aquatic shoreline or even an entire lake or estuary, all of which are composed of many interconnected habitats. The shoreline approach, which considers the entire nearshore mosaic of habitats from intertidal through shallow subtidal and into deeper habitats, may be the smallest scale that can be applied meaningfully to mobile, economically valuable finfishes. Many of these species recruit into nearshore habitats (marshes, seagrass beds, and mud and sand shallows) for their juvenile development, then move into deeper habitats as they grow. Shallow waters, whether vegetated or not, provide juveniles with a significant refuge from predation by larger aquatic predators (Ruiz et al. 1993). Shallow waters are also very susceptible to habitat destruction. The general life history pattern of "shallow-to-deeper" is true for many finfishes and mobile shellfish. Research at the scale of a shoreline, estuary, or lake is appropriate for species with these life history patterns. Thus the two projects will work together to deliver habitat alteration-population response models for high priority species.

Researchers also will need to consider temporal variability in constructing these models. Given the short time frame for results $(\sim 8$ years) relative to the time frame for cyclical fluctuations of some aquatic populations, researchers will need to consult historical long-term data sets for the species of primary concern. Fortunately, the focus on commercially and recreationally important aquatic species increases the likelihood that long term abundance data will be available.

In order to achieve larger goals, continuing collaboration and coordination among Divisions will strive towards the goal of establishing comparable and quantitative methodologies. These efforts will also link closely to different Aquatic Stressors research implementation plans that are delivering habitat alteration as stressor-response endpoints. Examples are the Nutrients plan (Section 5) and collaboration with other EPA laboratories, and other Federal and State agencies also will be required to develop the best possible products. Another important aspect of model development will involve determination of the data quality required to produce models with adequate predictive power. Models will be designed to provide valid information EPA needs to meet its regulatory requirements.

\section{Develop comprehensive multi-species models to quantify population responses to habitat alteration at the shoreline, lake, or estuary scale.}

A series of validated habitat alteration-population response relationships for the individual high priority species at the shoreline-, lake-, or estuary-scale (as described above) is the first-order goal of these efforts. Development of these single-species models would be a valuable and sufficient contribution of this project. However, where feasible, this work will be taken a step further. A subsequent goal of this work is, for each region, to develop comprehensive multispecies models that can quantify the effects of habitat alteration on the entire suite of economically valuable and charismatic populations within a shoreline, lake, or estuary. These comprehensive multi-species models will be constructed initially by combining the species models described above, taking care to ensure that the sum of these models represents the complete set of major species. 
As a whole-system example, consider seagrass habitat. When seagrass habitat is lost, it is not replaced with a lifeless void, but more typically with macroalgal or unvegetated habitats.

Seagrass loss may cause populations of some valuable species to decrease, but populations of other valuable species in the estuary may simply move over, or may even increase. The total impacts of loss of a single habitat to aquatic populations within a lake or estuary must be assessed first, with consideration of those habitats that will replace the lost habitat; and second, with consideration of the entire suite of economically valuable fish, shellfish, and wildlife that will be affected. If only a small number of the important species are considered, "comprehensive" habitat alteration models will be driven by the initial selection of species, and may not reflect the true effects of habitat alteration. EPA ultimately wants to evaluate the societal impacts of habitat alteration. Though ambitious, it is therefore a priority (where possible) to develop truly comprehensive multi-species models that can examine habitat alteration and accurately predict a large majority of the impacts to economically valuable and charismatic species.

These synthesis-oriented comprehensive models might also consider emergent properties that develop from combinations and arrangements of habitats within a shoreline, lake, or estuary. For example, a diversity of habitats arranged as a patchwork may or may not support more fish, shellfish, and wildlife than would uninterrupted expanses of the same habitats, or certain combinations of habitats, such as marsh and adjacent SAV, may be of particular value to fish, shellfish, and wildlife. These models might further consider how certain sentinel species are linked to the health of the ecosystems upon which they depend. Development of comprehensive multi-species models will require a synthesis phase (and iteration) to assemble the individual habitat alteration-population response relationships. The result will be validated comprehensive models, based on quantitative data, that can predict the total consequences of areal habitat loss to the great majority of economically valuable and charismatic populations. These comprehensive models also should be designed to place a quantitative fish/shellfish/wildlife resource value on shorelines, lakes, and estuaries, based on spatial habitat mapping. This resource value should reflect aquatic populations, and need not be tied to monetary standards. Multi-species models should predict quantitative changes in aquatic resource value that would result from habitat alteration to any mapped shoreline, lake, or estuary. This will allow better assessment and management of aquatic habitats and resources.

Both the individual models and the comprehensive multi-species models should be designed around application to a risk-assessment framework. This will allow insertion of the habitat models into larger spatially explicit risk assessment models that can consider multiple stressors including habitat alteration, toxic chemicals, and others.

\section{Develop classification schemes within each identified habitat or system type where other} important factors (salinity, geomorphology, and tidal energy) will affect the ability of habitats or systems to support priority populations.

A classification scheme is necessary to allow appropriate application of the single-species and multi-species habitat alteration-population response models described above. For example, juvenile summer flounder settle in shallow sandy or muddy mesohaline and polyhaline estuarine habitats in the Mid-Atlantic, but do not utilize oligohaline areas (Rogers and Van Den Avyle 
1983). As support for summer flounder populations, Mid-Atlantic shallows should be classified by salinity. Other examples of classification may include lagoonal systems versus riverine systems versus embayments, and microtidal systems versus macrotidal systems. Regionalization will, of necessity, be part of this exercise as well. In some cases, these questions of habitat classification will be answerable through the literature; in other cases new research efforts may be required.

\section{Products}

APM 1A FY02 Listings of the high-priority species of fish, shellfish, and aquatic-dependent wildlife for study in each biogeographic region, and listings of the habitats that are considered to be critical to each (WED).

APM 3F (GPRA \# 58) FY04 Preliminary report characterizing relationships between abundance, quality, and arrangement of various habitat types and selected biotic assessment endpoints in coastal systems (WED).

APM 5B FY06 Report characterizing relationships between abundance, quality, and arrangement of various habitat types and selected biotic assessment endpoints in coastal systems (WED, AED, GED, MED).

APM 6C FY08 Synthesized quantitative species-habitat relationships suitable for developing regional habitat-based biocriteria for shorelines, lakes, and estuaries (AED, GED, MED, WED).

\section{Benefits of Products}

This work is designed to provide EPA Program Offices and Regions with simple validated models that can quantify the effects of alteration or loss (either partial or total) of any major lake or estuarine habitat on populations of economically valuable or charismatic fish, shellfish, and wildlife. This work will also be of value to other Federal, State, and local managers striving to protect living aquatic resources from degradation due to habitat alteration.

This work will also link to the load-response efforts proposed in the Nutrients research implementation plan (Section 5), in that habitat alteration can occur through destruction and fragmentation, nutrient loadings, or other stressors. The products in the Nutrient plan (Section 5) regarding load-response models include loss of SAV habitat, loss of benthic habitat due to hypoxia and anoxia, and increases in macroalgal habitat; but do not focus on fish, shellfish, and wildlife. The aquatic shoreline, whole-estuary, and whole-lake scale habitat alterationpopulation response work proposed here can tie the nutrient habitat endpoints to population endpoints for economically valuable or charismatic species.

Since these habitat alteration-population response models will be designed to fit within a riskassessment framework by quantitatively linking habitat alteration to population response, this work can also integrate into larger, multi-scalar, spatially explicit, multiple stressor risk assessment models. 


\title{
Project Title 3. Salmon and Native Fish Habitat Research
}

\author{
Project Coordination and Resources (9.4 FTEs: MED-1.3, WED-8.1).
}

\section{Introduction}

The research described in this project deals with the influence of human activities on aquatic and aquatic-dependent biota at landscape, watershed, and regional scales. Specifically, it will examine watershed and landscape scale habitat issues affecting salmon and native fishes in the Pacific Northwest, and fishes reliant upon Great Lake coastal wetlands.

\section{Objectives}

- To evaluate and to quantify the influence of human activities at the landscape and watershed scales on native fish habitat and fish populations, including wild Pacific salmon and economically and ecologically important Great Lakes fishes.

- To evaluate how habitat spatial structure and connectivity of habitat in stream networks, wetlands, lakes, and estuaries influence native fishes, including wild Pacific salmon and wetland-dependent fish populations and overall biodiversity.

\section{Scientific Approach}

Although many aspects of aquatic habital-fish population relationships have been studied, many knowledge gaps exist. Relatively little attention has been focused on the relationships between landscape structure and fish assemblages, and landscape structure and aquatic habitat.

Population declines of salmon and other native fish accentuate the need for the quantification of these landscape relationships. In the report, From the Edge: Science to Support Restoration of Pacific Salmon, the Committee on Environment and Natural Resources (CENR) identified science needs for Pacific salmon and related species (CENR 2000). CENR indicated that habitat for salmonids and all native aquatic species, and hence their populations, are strongly influenced by watershed conditions at a landscape scale. Modeling and decision support tools are required to incorporate land use change relative to habitat on the extensive spatial scale, and must incorporate temporal changes (habitats are dynamic).

The research will be conducted in two regions, the Great Lakes and the Pacific Northwest. In the Great Lakes, research will focus on coastal wetland fish assemblages. There are approximately 200 species of fish in the Great Lakes. It is estimated that about $90 \%$ of those species are directly dependent on coastal wetlands for some aspect of their life history. Among those species that are heavily dependent on coastal wetlands are yellow perch, northern pike, largemouth bass, walleye, and a number of forage fishes (Jude and Pampas 1992, Brazner 1997). All of these populations also have relatively important commercial and/or sport fisheries throughout the Great Lakes and all appear to be in decline. Habitat alteration is thought to be the most important contributor to these declines, but over-fishing, pollutants, and exotics are also considered important threats (Whillans 1992). In the Pacific Northwest, research will focus on wild Pacific salmon and native fish. Many of the anadromous salmonids populations in the Pacific Northwest are in serious 
decline, and numerous populations are now listed under ESA. Landscape change, water pollution, introduced predators, fishing, hydro power development, disadvantageous ocean conditions, and other factors have led to the extinction or decline of many stocks (Bauer and Ralph 1999, CENR 2000). Research will be developed to allow for comparisons of factors influencing native fish assemblages in the two regions.

\section{Upland and Riparian Effects on In-stream and Coastal Wetland Condition}

In the Pacific Northwest, these efforts will be based on an integrated modeling/field study approach. An existing model developed by NMFS (1992) simulates coho salmon population dynamics based on in-stream habitat condition. For this model, in-stream habitat condition was determined through simple stream reach classification that does not reflect watershed land use/land cover conditions. If, however, we are to be able to examine how upland management affects fish dynamics, then it is necessary to understand how in-stream habitat condition is influenced by the surrounding uplands and riparian areas. Shading by riparian trees, woody debris supply, non-point source introduction of sediments and nutrients, and landslides are all examples of important upland processes that can affect in-stream habitat condition and which could be influenced by upland management actions. Such information also allows us to predict habitat condition, based on upland characteristics, at locations which have not been sampled. Besides affecting habitat condition, upland factors can also influence fish mobility. For example, warm water temperatures or landslides could reduce or completely prevent fish movement between stream reaches. Another important upland/riparian issue associated with the restoration of Pacific salmon is the possible need for nutrient additions (i.e., raw or processed salmon carcasses, and commercially produced organic or inorganic fertilizers) to headwaters (e.g., watersheds, lakes, or streams) to compensate for the loss of marine derived nutrients previously supplied by healthy salmon populations. Determining the ecological effects of surrounding upland areas on in-stream condition is therefore a critical component of our research.

Technical approaches to examining upland effects on in-stream condition could include field studies, empirical modeling, and process modeling. Empirical modeling approaches would develop correlations between upland independent variables and in-stream response variables. Upland variables could be derived from GIS DATANET, and could be used to represent the watershed as a whole or the riparian zone in particular. Data for explanatory and response variables could be obtained through field sampling, other research projects (e.g., Environmental Monitoring and Assessment Program, EMAP) or agencies, or through the literature. Process models would relate upland factors to in-stream condition based on specific processes. Examples include a model that predicts in-stream suspended sediment concentration based on soil characteristics, slope, upstream load, or a physical model that calculates water temperature based on shading by trees. Other modeling approaches are also available. We envision linking such models with a salmon population model to be able to examine the influence of land use changes on salmon and fish populations.

In the Great Lakes, initial efforts to understand landscape influences on coastal wetland habitat condition and native fishes will be based on field studies designed to help build quantitative empirical models that can eventually be used to construct more process-oriented models. The current knowledge base related to watershed fragmentation effects in Great Lakes coastal 
wetlands is quite limited. Although watershed fragmentation has been shown to be related to the structure and function of biotic assemblages in streams from Western Lake Superior (Detenbeck et al. 2000), fragmentation effects on habitat condition and biota associated with Great Lakes coastal wetlands have not been well documented. We suspect that this sort of fragmentationinduced habitat alteration also will cause changes in higher tropic levels in Great Lakes coastal wetlands.

Some of our endpoints for testing this idea may be yellow perch and northern pike population abundances, and overall fish biodiversity at river-influenced coastal wetlands having differences in fragmentation levels in their watersheds. GIS characterization, statistical analysis, and model development sequences will parallel those planned for stream watersheds in the Pacific Northwest. We plan to refine our definition of fragmentation to incorporate a variety of land-use types by using a "land-use equivalency" approach which will allow us to place our wetland sites along a vulnerability gradient, and provide a better opportunity to link watershed land-use to habitat and fish response curves for Great Lakes coastal wetlands. Collaborations with researchers from other institutions will allow us to increase the number of sites where fish data will be available and expand the vulnerability gradient to include much of the Great Lakes that would not otherwise have been possible.

Because we think the response to watershed fragmentation by wetland fishes will vary with wetland type, we will need to test whether a wetland classification system effectively groups coastal wetlands into similar response classes. Although there is a presumption that coastal wetland hydro geomorphology influences biota, there is little direct supporting evidence. It is well known, however, that aquatic community structure of higher tropic levels is influenced by vegetation structure in coastal wetlands, and vegetation structure appears to be related to hydrogeomorphology. So, it seems likely that our fish response variables (population and assemblage level) also will be related to differences in wetland hydrogeomorphology. After assessing whether this is the case at different coastal wetland types (e.g., open estuary, barred estuary, barrier beach lagoons, open coastal), we will be better able to extrapolate the significance of our fragmentation results on a region-wide basis by knowing the distribution of wetland types across the landscape and the fragmentation levels in their watersheds.

\section{Effects of Network Structure and Connectivity on Fish Movement}

Because fish are mobile, they are not limited to nor exclusively influenced by the habitat quality of a single stream reach. Rather, they move between reaches and may require different habitat conditions during different life stages. The spatial distribution of habitat condition and the ability of fish to move between reaches are therefore important considerations. For example, salmonids returning from the ocean attempt to reach the same stream reach in which they were spawned. Any obstruction in the stream network, which forces them to expend more energy to return, could affect spawning success. If a barrier completely prevented them from returning to a particular home reach, then the ability of strays to decolonize new habitat would depend on the spatial distribution of habitat near the home reach and the occurrence of other obstructions to movement. Thus any effort aimed at examining watershed management effects on fish populations needs to consider the effect of the watershed on the spatial structure of the network (e.g., the distribution of habitat condition) and on the level of connectivity among stream reaches. 
This work will primarily be conducted in the Pacific Northwest, but the hydrogeomorphic classification being tested in Great Lakes coastal wetlands is based on hydrologic connectivity of wetlands to adjacent lake habitats and their watersheds, so many of the same habitat connectivity issues are relevant to the Great Lakes studies and will be implicitly incorporated into their design.

In the Pacific Northwest, the approach to examining the effects of network structure and connectivity will be to build a spatially explicit network data structure that includes habitat quality and connectivity attributes and which can be linked to specific biological response models. Such a network structure could be used in a number of ways. For example, it might be desirable to conduct simulations of several specific drainage networks, and to compare results between basins with high habitat quality and low habitat quality. Alternatively, it might be desirable to examine the effect of certain watershed characteristics (e.g., slope, catchment area, stream density) on fish dynamics by systematically varying those characteristics using synthetic landscapes.

\section{Biological Response of Fish to Habitat and Stream.Network}

EPA has responsibilities under the CWA to restore and maintain the biological integrity of the nation's waters. Therefore, it is desirable to understand how activities aimed at managing salmon would affect other fish species, in particular, native fish. To address these needs, field research and modeling efforts will be developed to examine how management actions would affect dynamics of various fish groups. This may include modeling at different levels of organization. First, species-level models would examine the biological response of particular species to watershed and network structure. Models would be run separately for salmon and possibly a few other species representative of different life history strategies. This will allow us to examine how salmon and fish with different habitat needs respond to a common set of management actions. Second, the biological response modeling could also include exploratory assemblage-level modeling. In this case the dynamic behavior being tracked is overall species richness, rather than abundance of a particular species. This allows us to examine communitylevel response to management actions.

Products

APM 2A FY03 Prototype watershed-stream network modeling approach for Pacific salmon (WED).

APM 3C FY04 Report characterizing the relationship between habitat in stream networks and salmon-native fish for coastal Oregon watersheds (WED).

APM 6A FY04 Ecological consequences of marine derived nutrients and nutrient enrichment for aquatic biota and stream habitat quality, with an emphasis on salmon and native fish (WED).

APM 4A FY05 Develop indices of watershed integrity based on land use/land cover and relationships to fish (WED, MED). 
APM 5A FY05 Reports characterizing the relationship between landscape-scale habitat mosaics and native fish by wetland type in the Great Lakes (MED).

APM 6B FY07 Regional models of landscape influence of salmon/native fish in the Pacific Northwest and native fish in Great Lake coastal wetlands (WED, MED).

APM 6D FY08 Interactions between stream nutrients and habitat alteration on water quality and aquatic life (WED).

Benefits of Products

Research will allow explicit evaluation of human activities at landscape and watershed scales on salmon and native fish. This will be of direct benefit to OW, EPA Regions, and an interagency effort on salmon restoration.

\section{Project Title 4. Multiple Stressor Risks to Common Loon and Other Piscivorous Bird Populations (cross-listed in Section 7, Toxic Chemicals, Project B3)}

Project Coordination and Resources (1.5 FTEs)

AED-1.5, and 6.9 additional FTEs devoted to mercury-loon research described in Section 7,Toxic Chemicals, project B3.

Introduction

This project examines the interactive effects of multiple stressors, including landscape-level habitat alteration and mercury, on common loons and other piscivorous bird populations ('loon project'). This project was developed as a case study implementing NHEERL's WRS (EPA 2000), and demonstrating an integrated approach to large scale, population-landscape-stressor assessments. There are significant habitat components to this project, including evaluating the spatial configuration of loon habitat and mercury impacts in the landscape mosaic and the issue of scaling up from local to regional impact assessments. Because habitat and toxic chemicals issues are integrally linked within the demonstration project, the project is relevant to issues within this section, as well those relative to toxic chemicals (Section 7). Therefore, a brief description of those elements of the loon project related to the assessment of risks of habitat alterations at multiple geographic scales, appears here as project 4 . To avoid redundancy, a complete description of the project appears in Section 7, project B3.

Two key research areas, defined within the WRS and described below, reflect the need to consider landscape context and scale in order to achieve the scientific and management goals of the risk assessment.

1. Research to Advance Techniques for Assessing the Relative Risk of Chemical and Nonchemical Stressors on Wildlife Populations. 
Landscape characterization studies, combined with experimental approaches, are required to better quantify the relative impacts of chemical stressors, habitat alterations, and the introduction of exotic species on wildlife populations. Associated with this effort is the need to develop and integrate predictive models so that the outcome of different management scenarios, based on chemical loading, habitat alterations, exotic species control, and other management options, can be quantified.

\section{Research to Define Appropriate Geographical Regions/Spatial Scales for Wildlife Risk} Assessments.

A significant effort is needed to define scientifically credible spatial scales for wildlife risk assessments. Habitat requirements for wildlife species associated with aquatic and terrestrial ecosystems must be established and referenced to regulatory jurisdictions to ensure coordinated implementation of risk-based decisions. A consensus on current or potential habitat ranges are needed to identify wildlife species of concern and to evaluate approaches in risk assessments that consider spatial population structure (EPA 2000).

Within the WRS, three major research objectives have been defined to address these needs. The third objective defines the focus for the habitat alteration component of the loon project, i.e., the development of approaches for evaluating relative risks from chemical and non-chemical stressors on spatially structured wildlife populations across large areas or regions ("geospatial modeling"). Research described in the loon project will address issues associated with the spatial and temporal heterogeneity of populations and stressors in real landscapes. This landscape context provides a basis for understanding and quantifying how spatio-temporally varying stressors influence the distribution of wildlife populations. Thus, the approaches, models, and methods developed within this project are designed both to assess risks from multiple stressors and evaluate the relative effectiveness of altemative management strategies.

\section{Objectives}

Specific to the goals for habitat alteration research, the relevant research objective can be described as the development of approaches for evaluating the relative risks from chemical and non-chemical stressors on spatially-structured wildlife populations across large areas or regions. Consistent with this objective and to address the WRS objectives described above, research activities within the loon demonstration project focus on the development of geospatial modeling methods to assess the relative impact of heterogeneously distributed stressors, including dietary methylmercury, habitat degradation, acidification, and human disturbance on populations of the common loon, which is resident to the northeastern portion of the U.S. and Canada. For this purpose, research activities will include the develop of methods to identify spatial relationships among stressors (i.e., correlations in distributions), potential interactions among stressors, and the relative risks among potential stressors to populations of loons at varying spatial scales.

\section{Scientific Approach}

Consistent with the approach described generally for habitat alteration research, there are two distinct research components for habitat research within the loon project. The first of these 
addresses the need to describe the relationship between habitat and biota ("habitat/suitability models") at appropriate spatial scales and with sufficient detail and resolution to quantify the effects of both incremental and catastrophic habitat alteration. The second step involves integrating habitat alteration effects with those of other stressors ("integration within a spatial context"), so that resource protection and restoration priorities can be evaluated at spatial scales up to and including regions or large receiving bodies.

For this project, the focal species was selected partly to take advantage of existing data that may permit the development of linkages between habitat and biological fitness. Specifically, finescaled spatially-referenced information on presence and condition of individual loons across large geographic areas is available through long-term loon monitoring programs that exist in the upper Midwest and the Northeast. In addition to information from these programs, available monitoring databases and/or aerial photographs, provide information to characterize habitat quality. For loons, key habitat characteristics may include the presence of suitable nesting and brood rearing sites, measures of human disturbance, density or extent of human dwellings and other activities around lakes, turbidity, and availability of suitable forage fish supplies. This unique set of spatially-referenced data will permit the development of habitat suitability approaches and models, relating environment factors and biological condition.

Within the loon project, integration within a spatial context has been approached through the development and application of spatially-explicit population models that incorporate stressorresponse relationships that will be applied within the spatially-diverse landscape. Specifically, within this project, spatial models will be used to evaluate how loon life history, spatial heterogeneity, and interactions among stressors in the landscape drive the relationship among breeding success on individual lakes and population trends across broad regions. These models will be used to: 1) define what constitutes a population (within the context of the assessment question) and how sub-populations interact in a heterogeneous landscape, 2) determine the appropriate spatial scale for assessment questions, and 3) determine the relative risks presented by different stressors. This model development would be a primary objective of this demonstration project.

\section{Products}

As defined within this plan, these specific products will be developed:

APM 2B FY04 Habitat suitability indices to support population models for projecting relative risks of multiple stressors including toxic chemicals and habitat alteration to common loons (AED).

Also see Section 7 Toxic Chemicals, Project B3 for associated products.

\section{Benefits of Research}

This research will allow explicit evaluation of multiple stressors on piscivorous wildlife and lead to the development of risk-based criteria. This will be of direct benefit to Program Offices, Regions, and interagency efforts to protect important wildlife species. More broadly, this 
research will permit an evolution towards a landscape assessment approach for examining critical environmental problems over larger spatial scales and the assessment of the cumulative risk resulting from multiple stressors. This approach allows for a more comprehensive perspective for evaluating the condition of communities, watersheds and ecoregions. A landscape assessment approach also provides the ability to evaluate the status and trends of a variety of ecological resources at multiple scales so that relationships of stressors and effects can be developed to establish conditions which are influencing the impacts on wildlife populations.

\section{Gap Analysis}

A. The following research is within the scope of this plan but outside NHEERL's current manpower, expertise, or sampling capability:

- Assessment data required to extrapolate habitat-biota relationships studied by ORD to the population of all systems for which nutrient, sediment, and biocriteria are required will necessitate collaboration with other Federal and State agencies, non-governmental organizations, and academic institutions.

- Near shore fish sampling in Great Lakes (e.g., abundance of commercially and recreationally valuable species) to support multiple habitat research will require collaboration with entities capable of open-water fish sampling.

- Development of habitat alteration-population response models for the southern Atlantic coast (e.g., Carolinian biogeographic province), the southern Pacific coast (e.g., San Diego biogeographic province), and Puerto Rico and the U.S. Virgin Islands, especially for populations of commercially valuable fish and shellfish.

Survey of songbird, hawk, and waterfowl utilization of reference coastal wetlands of high ecological integrity, and of disturbed wetlands of varying anthropogenic alteration are currently outside NHEERL expertise and/or manpower. Wetlands of interest for the surveys are all coastal vegetated habitats such as fresh- and salt-water marshes, SAV, and emergent aquatic vegetation.

- Development of quantitative methods to evaluate the restoration success of the structure and function of habitats that support populations of commercially valuable fish, shellfish, and wildlife.

B. The following research is outside the scope of this plan (which focuses primarily on fish, shellfish, and wildlife population endpoints of concern to society), but relates to other ecological endpoints that may be also relevant to society:

Understanding of the effects of habitat alteration on fish and other biotic assemblages (e.g., zoobenthos, macroinvertebrates) from both a structural (including biodiversity) and functional perspective even where these responses cannot be immediately linked to fish, shellfish, and wildlife populations of interest. 
- Understanding of the effects of habitat alteration (both within watersheds and their coastal ecosystems) on the exchange of materials (e.g., dissolved nutrients, particulate organic matter, organisms) with adjacent waters where these responses cannot be immediately linked to fish, shellfish, and wildlife populations of interest.

- Role of areas of critical habitats along the coast in providing flood and erosion control, and an understanding of the effects of habitat alteration (both within watersheds and their coastal ecosystems) on the retention of sediments by coastal ecosystems.

- Importance of areas of critical habitats in watersheds adjacent to coastal waters in providing nutrient filtration (e.g., riparian zones, inland wetlands, forests, salt marshes).

- Effect of nonindigenous organisms on the structure and function of wetlands and other critical habitats.

- Mechanistic understanding of nutrient effects on vegetation and tropic structure of critical habitats.

\section{References}

Bauer, S.B., Ralph, S.C. 1999. Aquatic habitat indicators and their application to water quality objectives within the Clean Water Act. EPA 910-R-99-014. EPA, Region 10.

Brazner, J.C. 1997. Regional, habitat, and human development influences on coastal wetland and beach fish assemblages in Green Bay, Lake Michigan. J. Great Lakes Res. 23:36-51.

CENR. 2000. From the edge: science to support restoration of Pacific salmon. National Science and Technology Council.

Detenbeck, N.E., Arthur, J.W., Bertelsen, S.L., Brazner, J.C., Snarski, V.M., Taylor, D.L., Thompson, J.A. 2000. Western Lake Superior comparative watershed study.

Environ. Toxicol. Chem. 19:1174-1181.

EPA. 1990. Reducing risk: setting priorities and strategies for environmental protection. SAB-EC-90-021.26 pp.

EPA. 1999. EPA's framework for community-based environmental protection. EPA 237-K-99001. Washington, DC. $40 \mathrm{pp}$.

EPA. 2000. Wildlife Research strategy. EPA. NHEERL/ORD. September.

Houde, E.D., Rutherford, E.S. 1993. Recent trends in estuarine fisheries: predictions of fish production and yield. Estuaries 16:161-176.

Jude, D.J., Pampas, J. 1992. Fish utilization of Great Lakes coastal wetlands. J. Great Lakes Res. 18:651-672. 
NMFS. 1992. Quantifying resource loss through habitat degradation: proceedings of the first NMFS Northeast environmental workshop, March 13-14 1991. NMFS-F/NER-3. Northeast Regional Operations Office, Gloucester, MA. 137 pp.

NRC. 1997. Building a Foundation for Sound Environmental Decisions. National Academy Press, Washington, DC. 87 pp.

Rapport, D.J., Costanze, R., Epstein, P.R., Gaudet, C.L., Levins, R. 1998. Ecosystem Health. Blackwell Science, Malden, MA. 372 pp.

Rogers, S.G., Van Den Avyle, M.J. 1983. Species profiles: life histories and environmental requirements for coastal fishes and invertebrates (South Atlantic) -- summer flounder. FWS/OBS-82/11.15. U.S. Fish and Wildlife Service, U.S. Army Corps of Engineers, TR EL-82-4. 14 pp.

Ruiz, G.M., Hines, A.H., Posey, M.H. 1993. Shallow water as a refuge habitat for fish and crustaceans in non-vegetated estuaries: an example from Chesapeake Bay. Mar. Ecol. Prog. Ser. 99:1-16.

Stein, B.A., Flack, S.R. 1997. 1997 species report card: the state of U.S. plants and animals. The Nature Conservancy, Arlington, VA.

Warren, M.L., Burr, B.M. 1994. Status of freshwater fishes of the United States: overview of an imperiled fauna. Fisheries 19:6-17.

Whillans, T.H. 1992. Assessing threats to fishery values of Great Lakes wetlands. In Kusler, J., Smardon, R., eds., Wetlands of the Great Lakes: Protection, Restoration, Policies and Status of the Science, Proceedings of the International Wetland Symposium, May 16-19, 1990, Niagara Falls, NY, pp. 156-165. 


\section{Section 5. \\ Implementation Plan for Nutrients Research}

\section{Problem}

There is growing evidence that human activities have dramatically changed the amounts, distribution, and movement of major nutrient elements (nitrogen- $\mathrm{N}$ and phosphorus- $\mathrm{P}$ ) in the landscape and have increased nutrient loading to receiving waters. Some of these changes affect use of the nation's aquatic resources, and pose risks to human health and the environment (NRC 2000). EPA is in the process of developing guidelines that States and Tribes must use to set nutrient criteria for our nation's waters. For waters failing to meet WQS, States and Tribes will be required to develop TMDLs to eliminate the causes of non-attainment. Our current level of understanding of aquatic ecosystem function is inadequate to allow us to extrapolate knowledge of nutrient loading relationships for systems for which we have intensive data to accurately predict adverse effects on specific systems with more limited data. NHEERL research will provide the scientific information on load-response relationships that are required to develop numeric nutrient criteria protective of aquatic life.

This research implementation plan is ambitious. A complete understanding of the effects of nutrients on aquatic ecosystems will require additional research. The projects listed in this plan outline the objectives needed to establish the scientific basis for WQC and TMDLs associated with nutrients in coastal systems (coastal wetlands, embayments, estuaries, and near coastal waters). The decision to focus on coastal waters is based on the complexities of these systems and $\mathrm{OW}$ 's prioritization of research needs by waterbody type. The most important response categories for study are given below:

Increase in algal production (or carbon supply as defined by Nixon 1995) and/or changes in algal community composition, which can result in harmful algal blooms (HABs), are principal causative agents for the three following effects:

1. Low dissolved oxygen (DO) or hypoxia leading to fish kills or loss of shellfish and degradation of benthic habitats;

2. Loss of natural $S A V$ habitat, important to fish and other biota and due to changes in water clarity, epiphytic growth, or smothering by invasive algae;

3. Shifts in basic food webs leading to loss of commercially important fisheries and overall aquatic biodiversity.

The following pathways define our current understanding of how nutrients affect each of these endpoints: 


\section{Low DO}

Increased nutrient loading to an estuary/receiving water stimulates primary production (largely, though not exclusively, phytoplanktonic) and produces excess carbon biomass that sinks to the bottom waters/benthos resulting in respiratory oxygen demand that may exceed oxygen supply. For this endpoint, our objective is to define relationships between nutrient load and factors affecting DO concentration in sensitive portions of receiving water bodies. As part of this effort, NHEERL is developing DO requirements to protect indigenous species in various coastal regions (North and South Atlantic, Gulf of Mexico, and Pacific). Criteria have been developed for the Atlantic coastline between Cape Cod and Cape Hatteras (EPA 2000). Ultimately, this research will provide relationships between nutrient inputs and DO concentrations, which will protect indigenous species in various coastal regions.

\section{SAV LosS}

Increased nutrient loading can result in an accumulation of phytoplankton, epiphytic, and macroalgal biomass/carbon that shades SAV or alters sediment geochemistry and results in loss of areal coverage. For this endpoint, our objectives are to develop, for the nation's coastal receiving waters, sufficient understanding of the relationship between SAV loss and nutrient loading to provide a sound scientific basis for establishment of nutrient criteria that would protect these important habitats from degradation or loss and aid in restoration efforts. This work will directly support or interact with the Habitat Alteration (Section 4) and Diagnostics (Section 8) research implementation plans.

\section{Shifts in Food Webs}

Changing nutrient loadings (includes increased loading, changes in loading ratios, and changes in the mode/timing of delivery) alter species composition of primary producers. Effects of this shift are transmitted through the food web, altering the consumer-food web dynamics (carbon or energy flow pathway) in receiving waters. The result is a change in primary producers that does not support existing food webs (and hence alters the biological integrity of ecosystems) and does not support commercially important fish and shellfish production. The objective of food web research is to identify nutrient loading thresholds that cause shifts in primary producers and other key components of the food web. In addition, we will assess the use of food web structure and processes to improve our ability to classify systems and to predict differences in response to nutrients that affect hypoxia and SAV.

This research will require developing classification schemes for each of these endpoints so that aquatic systems can be grouped according to their expected responses to nutrient loading, to aid in the process of setting nutrient criteria and TMDLs. NRC (2000) recommends that classification frameworks be developed that can be generalized to a broader range of features and processes than the current classification schemes, which are focused on individual features (i.e., flushing or light). NHEERL's classification efforts will focus on coastal receiving waters (including estuaries, near-coastal waters and the Great Lakes). Our classification efforts will focus on understanding and linking the influence of physical, chemical, and biological factors to the response to nutrients across the Nation's coastal receiving waters. 
NHEERL nutrient research efforts will provide nutrient-response relationships for diagnostic efforts (Section 8) and, once additional critical habitats subject to effects of nutrients are identified by habitat alteration research (Section 4), we will develop plans for nutrient loadresponse research in those critical habitats. To maximize our efforts, we also must link our efforts with other Laboratories in EPA (e.g., NERL), other Federal agencies (e.g., U.S. Geological Survey [USGS]), NOAA, and academic institutions collecting data on coastal systems. We have initiated efforts to provide common data and files across NHEERL's Divisions and will continue to seek collaborations to strengthen our efforts.

\section{Goals}

The primary goal of this research is to provide the scientific basis and load-response relationships that are required to develop numeric nutrient criteria protective of aquatic life. The focus of this research is on coastal receiving waters and does not apply directly to the understanding of loadresponse relationships for other water bodies (e.g., streams, rivers, lakes, and wetlands). Therefore, NHEERL research will initially define and quantify relationships between nutrient loading and ecological responses for coastal aquatic resources. The APGs and associated APMs for this research are listed below. Note: some APGs and APMs (including those under GPRA) were established before this document was written. They are listed here along with APGs and APMs that were developed under the aquatic stressors process.

APG 1 FY02 (GPRA \# 030) Provide a strategic approach for developing TMDL-driven thresholds for protecting ecosystems from nutrients and sedimentation.

APM 1A FY02 (GPRA \# 163) Generalized seagrass/rhizosphere model capable of predicting effects of reduced light, sedimentation, nutrient depletion, and toxic effects of sulfides (WED).

APM 1B FY02 (GPRA \# 164) Effects on estuarine submerged aquatic vegetation from changes in light quantity and quality due to increased levels of suspended solids (GED).

APM 1C FY02 (GPRA \# 165) Minimum dissolved oxygen requirements of aquatic animals in the Gulf of Mexico estuaries as a measure of the effect of nutrient enrichment (GED).

APM 1D FY 02 (GPRA \# 166) Effects of nutrient loadings and altered nutrient ratios on HABs (GED).

APG 2 FY03 Provide the science to support consistent dissolved oxygen criteria for prevention of hypoxia impacts in all coastal regions of the US.

APM 2A FY03 Minimum DO requirements for a suite of the important marine organisms (fish and crustaceans) from the Atlantic, Pacific, and Gulf of Mexico coastal waters of the U.S. (AED). 
APG 3 FY03 (GPRA \# 15) Complete the framework for including dissolved oxygen and other receiving water thresholds into watershed management for nutrients.

APM 3A (GPRA \# 201) Comparison of effects of zooplankton grazing on estuarine phytoplankton community under differing natural levels of grazing (GED).

APG 4 FY04 Provide first generation protocol to classify eutrophication models for nutrient load allocation in coastal systems.

APM 4A FY03 Propose classification scheme for predicting sensitivity of coastal receiving waters to effects of nutrients on DO (MED, AED, GED).

APG 5 FY07 Provide the scientific foundation for establishing site-specific nutrient threshold criteria to protect estuarine SAV.

APM 5A FY02 Report on structural and functional characteristics of SAV rhizospheric communities (GED).

APM 5B FY03 Correlation of water quality with SAV change (GED).

APM 5C FY04 Report on environmental requirements of three main species of seagrasses (WED).

APM 5D FY04 Development of stress-response model for Zostera marina in Pacific Northwest and validation of stress-response model for Thalassia testudinum (WED).

APM 5E FY04 Development of empirical load-response models for Zostera marina in NE U.S. (AED).

APM 5F FY05 Development of load-response models for estuaries of Pacific Northwest and Gulf Coast, and validation of stress-response model for Zostera marina in NE U.S. (WED, GED, AED).

APM 5G FY05 Propose classification scheme for predicting sensitivity of coastal receiving waters to the effects of nutrients on SAV (WED, GED, AED).

APM 5H FY06 Report on the empirical and numeric models for SAV (WED, GED, AED).

APM 5I FY07 Report on a classification scheme for grouping coastal receiving waters based on sensitivity to nutrients (WED, GED, AED).

APG 6 FY07 Provide scientific foundation for development and application of quantitative measures of food web attributes that are sensitive to ecological changes associated with nutrient enrichment. 
APM 6A FY04 Sensitivity of food web responses to nutrient loading in coastal systems (GED).

APM 6B FY05 Propose classification scheme for predicting sensitivity of coastal receiving waters to effects of nutrients on food web structure (GED).

APM 6C FY06 Report on empirical and numeric models for food webs (WED).

APM 6D FY 06 Report on parameterization of food web models (GED).

APM 6E FY06 Report on classification scheme for grouping coastal or lake receiving waters based on sensitivity to food web alterations (WED, GED, AED, MED).

\section{Critical Path}

The components of the critical path seen in Figure 5 consist of five main steps that are the same or each of the response endpoints (DO, SAV, Food Webs):

Step 1. Mine and Assess Existing Information.

Evaluate available data and models from the peer-reviewed literature and determine if the data and models are useful to aid the development and improvement of nutrient load-response models. This will be a continuous process since new data and models are continuously being developed by other Federal and academic institutions.

\section{Step 2. Develop Conceptual Models.}

Conceptual models, describing how the three assessment endpoints respond to excess nutrients, will be defined in order to catalog the controlling mechanisms and processes.

\section{Step 3. Develop Classification Scheme.}

Included within this step is the development of a classification scheme and the assembly of data needed to apply a classification scheme across the Atlantic, Gulf, Pacific, and Great Lakes receiving waters. A tabulation of some of the factors that likely will be used in classifying receiving waters or in scaling or standardizing loading or response variables can be found in Table 3. 


\section{Database of existing information}

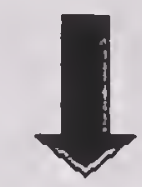

\section{Conceptual models for nutrient load-endpoint responses}

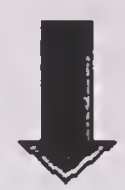

Classification scheme for receiving water bodies/endpoints

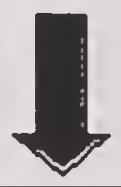

Standard or comparable methods for assessment endpoints

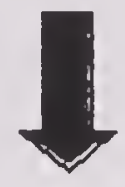

Nutrient load - water body response models

Figure 5. Critical path for research on the development of nutrient response relationships for coastal receiving waters.

\section{Step 4. Develop Standard Methods and Procedures.}

This task will involve the determination of a set of standard measurement endpoints for the assessment endpoints. Comparability of measurements and data across Regions/Ecological Divisions, where possible, will maximize utility of data collection, research, and modeling efforts. A periodic review of these endpoints and procedures across the Ecological Divisions will ensure consistency and comparability and maintain focus on our core objectives.

\section{Step 5. Develop Nutrient Loading-Ecological Response Models.}

\section{Nutrient Inputs/Loading}

In order to develop nutrient loading-response relationships for each of the three endpoints, it is necessary to estimate nutrient loadings. There are at least three ways that we may estimate loadings: 1) estimate using watershed models augmented with point source, atmospheric, and oceanic inputs [i.e., USGS Spatial Referenced Regressions on Watersheds (SPARROW) model, Smith et al., 1997]; 2) use field-based water column concentration estimates during the biologically inactive portion of the annual cycle and then back calculate to loadings; and 3) use 
field-based input studies (e.g. Cohn et al., 1989). SPARROW model based loading estimates are available from USGS for the larger watersheds throughout the nation and we will test those estimates in our response models and against field measurements when possible. However, for smaller systems, SPARROW estimates may not be available and different watershed models or alternative methods may be required. Where possible, NHEERL will also seek loading data from NERL to test other loading models and loading-relationships for coastal water bodies;

Table 3. Preliminary list of factors influencing response to excess nutrient inputs in coastal receiving waters.

\begin{tabular}{|c|c|c|}
\hline Biological Factors & Physical Factors & Chemical Factors \\
\hline $\begin{array}{l}\text { SAV } \\
\text { Food web efficiency } \\
\text { Phytoplankton community } \\
\text { Primary productivity base } \\
\text { (e.g., phytoplankton base vs. } \\
\text { sea grass based) } \\
\text { Grazing type (e.g., benthic } \\
\text { filter feeders, zooplankton) } \\
\text { and grazing intensity }\end{array}$ & $\begin{array}{l}\text { Flushing } \\
\text { Light/Suspended } \\
\text { solids/Water color } \\
\text { Stratification } \\
\text { Depth } \\
\text { Temperature } \\
\text { Volume } \\
\text { Area } \\
\text { Tidal Height } \\
\text { Geomorphology (e.g., } \\
\text { drowned river valley) } \\
\text { Physical energy (wind, etc.) } \\
\text { Hypsography (area-depth } \\
\text { relationship) }\end{array}$ & $\begin{array}{l}\text { N:P:Si:Fe Ratios } \\
\text { Salinity } \\
\text { Allochthonous C } \\
\text { Denitrification potential } \\
\text { Nutrient form } \\
\text { (organic/inorganic) }\end{array}$ \\
\hline
\end{tabular}

however, if this is not possible, we may need to estimate loading in smaller systems by direct measurement (flow versus concentration).

In addition, since water quality management is frequently based on returning to some historical loading or reference condition, to be most useful to OW, the load-response relationships should be based on historical loading to the maximum extent possible.

\section{Response Models}

Nutrient loading-response models are the ultimate products of the new research initiative. They will be produced using two parallel, yet integrated, efforts. Numerical models will be used to provide refinement of empirically derived loading-response models and to aid in understanding mechanisms. If our classification schemes are appropriate, they will identify groups of receiving water that have significantly less variability in nutrient load-endpoint response relationships than is present among all receiving waters. Improvement in these relationships will provide the test for our classification schemes (Step 3) and will provide the scientific basis for grouping receiving waters to simplify the nutrient criteria/TMDL process. 
The classification schemes and modeling efforts will be endpoint-specific. For each endpoint in each of the regions and across all coastal systems, we will begin with a data mining effort and identify and collect data on key parameters and existing models and classification schemes that will provide the parts necessary to build a sound scientific basis for nutrient criteria for each of the three endpoints (DO, SAV loss, and food webs). With empirical data and knowledge of the key parameters that influence the nutrient-response curves, we can identify correlations and develop models to test hypotheses experimentally in the laboratory and in the field. This will be an iterative process to some extent until we have adequately characterized the endpoint/nutrientresponse and controlling factor relationships needed to establish numerical nutrient criteria across the nation's coastal receiving waters. Once this is accomplished we can move on to watershed scales and/or other water body types.

Complexity in ecosystem models is always dealt with by simplification; all models are abstractions of real systems. The simplifications range from complete linearization of the system with regression models to more complex relational models that incorporate a few critical measurements of the biological, chemical, and physical domain that makes up an estuary. Food web models make up the more complex non-linear models that include most of the mechanistic relations and feedbacks within the estuarine biogeochemical system. Relative to the coupled atmospheric-watershed-estuarine models developed for Chesapeake Bay and Long Island Sound, the food web models are easy to develop and have much fewer data requirements.

\section{Regression Models}

Regression models may be used to develop relationships among variables within a single system or among multiple systems. Such models use nutrient load to predict other parameters such as phytoplankton biomass accumulation, primary production, sedimentation, and community metabolism, SAV loss, and DO-related response. This research will consist of cross-estuary analysis that focuses on common responses within classes of estuaries. Regression analysis that compares data among multiple systems has been used successfully for Maryland estuarine systems (Boynton et al. 1996); and a diverse collection of estuarine, continental-shelf, and openocean systems (Nixon et al. 1996). In the case of 37 side-embayments of Buzzards Bay, Massachusetts, such regression analysis has been applied to development of WQC and TMDLs for nitrogen (Costa et al. 1999). Such regressions are expected to have general application to systems similar to those for which they have been developed. These regressions will quantify estuary response to nutrient loading, and thus be directly useful in risk assessment and setting of nutrient criteria. In addition, regression models can be used as an adjunct to some of the proposed mesocosm and field work. For example, data from mesocosms to determine the effect of nutrient loading and benthic oxygen consumption on denitrification and nitrous-oxide production can provide insight into why some estuaries with nutrient sources having a high nitrogen/phosphorus (N/P) ratio remain nitrogen limited. Simple regression models also can be used in conservative mixing curves to determine sources and sinks of nutrients over the length of an estuary. Nitrogen, $\mathrm{P}$, silicate, or other contaminants, when plotted against salinity, provide estimates of deposition, utilization, and supply of these materials over the length of an estuary.

Vollenweider (1975) pioneered the development of regression models that allow extrapolation of data among systems using a scaling of biological processes to hydraulic residence time. This 
method has been modified (Dettmann 2002) to model the fate and concentrations of total nitrogen in estuaries. Preliminary work in extending model applicability also has shown that total $\mathrm{N}$ concentrations predicted by the model appear to correlate well with peak annual phytoplankton concentrations and peak macroalgal abundance in estuaries. The overall goal of this work has been to explain the response of estuaries to nitrogen loading using as few parameters as possible. The model appears to reasonably describe annual net $\mathrm{N}$, the dependence of annual denitrification on water residence time, and the annual average concentrations of total $\mathrm{N}$ in estuaries where it has been tested. The results emphasize the importance of water residence time in determining export, denitrification, and concentrations, and give quantitative expressions for these dependencies. At present, the model provides annualized results averaged over the entire estuary, although recent results indicate that it may also have application to seasonal response as well. The final extended model is expected to have direct applications to the evaluation of estuary sensitivity to nutrient loading, which will be useful in setting nutrient criteria. The model may also serve as part of the foundation of a classification system for estuarine sensitivity to nutrient loading.

\section{Food Web Models}

Models of food webs link the food web components to the overall ecosystem through an explicit quantification of exchanges. This makes it possible to evaluate how changes in the model components directly effect ecosystem processes. For example, the cycling of carbon and nutrients directly result from food web interactions in which many species play a role. Within many ecosystems, species that contribute little biomass still may have a large influence on nutrient cycling and energy flow, and thus affect the functioning of other species. Examples of this include bacterial grazers, which can stimulate microbial activity through nutrient recycling, and algal grazers which stimulate the productivity of submerged macrophytes by providing better light conditions through the grazing of periphytic algae. Extinction or changes in abundance of such species can have a disproportionately large influence on ecosystem function. Hence, food web approaches can be used for analyzing the effects of nutrient stressors on key target species, on the biological diversity in communities, and on the functioning of ecosystems. In this way, food webs are the wiring on the circuit board of the ecosystem, spanning different levels of ecological organization. Food web models allow managers to identify the critical food web flows within the estuarine ecosystem, for which small changes in an ecosystem component will cascade through the system and result in large changes in eutrophication, extinction of important habitats, or changes in the tropic structure of the overall ecosystem (Vézina and Pace 1994).

Food web models now being developed and evaluated in ORD are used to calculate metrics that define the state of an ecosystem (Ulanowicz 1986, Hagy 2002). These metrics are similar to diversity and commonness, but are much more sensitive to ecosystem condition than the older metrics. These new metrics can be calculated directly from the food web models now being developed at ORD. In the following two examples, we describe how these indices can be used to develop useful relationships between nutrient loading and trophodynamics:

1. Indices of ecosystem trophic efficiency can be used to quantify how carbon and nutrients supplied to the estuary are passed thought the food web to the higher tropic levels. If more nutrients and carbon are moved into higher tropic levels, then the nutrient capacity of the estuary 
may be increased. Laguna Madre during the 1990 s provides an example of an ecosystem with small nutrient loading that developed symptoms of eutrophication. An inedible phytoplankton species Aureoumbra lagunensis developed into a brown-tide bloom because most consumers could not ingest it. Those that could were being controlled by predators. Because of the mechanism by which this bloom developed, it could not be predicted easily by regression. However, susceptibility to such blooms could be predicted by food web models.

2. Food web models can be used to calculate the dependency of charismatic and recreational species on other components of the food web, and how such dependency would be altered by changes in nutrient loading. This knowledge would arm managers with a early warning system to detect alterations in an ecosystem that eventually could lead to reductions or decreased production of important species.

Each of these modeling strategies has different data requirements and makes predictions at different temporal and spatial scales. We will integrate the three approaches by working cooperatively to maximize the benefits of the approaches and minimize the limitations. The final outcome of this research implementation plan will be a set of empirical or numerical models for classes of coastal waters. These models will be able to accurately describe how increases in nutrient loading causes changes in hypoxia/anoxia in coastal receiving waters, losses of SAV, and changes in algal community composition leading to shifts in basic food webs. The models will provide the scientific basis for the development of nutrient criteria for coastal receiving waters. We should be able to extrapolate results between similar classes of receiving waters once a classification scheme incorporating key factors affecting nutrient response for coastal receiving waters is developed and tested.

NHEERL Ecology Divisions are strategically located in four major coastal systems with AED along the Atlantic Coast, GED on the Gulf Of Mexico, WED along the Pacific Coast, and MED on the Great Lakes. Each of these Divisions will focus intensive studies on a local system and collect pertinent related information from other systems in their general region. All four Divisions will work to develop a common approach for key parameters and measurements that are needed across all regions (i.e., what, when, where, and how for nutrient loading, DO, Chlorophyll a) and maintain that approach through annual reviews. Other measurements (e.g., community metrics or depth of oxygen penetration into sediment) may be developed within or compared across multiple regions as individual Divisional research plans are developed further.

\section{Research Projects}

\section{Project Tüle 1. Development of nutrient load-DO Response Relationships for Coastal Receiving Waters}

Project Coordination and Resources (9.0 FTEs: AED-4.0, GED-3.0, MED-1.0, WED-1.0) 


\section{Objectives}

To define nutrient load-DO response relationships for coastal receiving waters that will be used by the States and authorized Tribes to aid in the development of nutrient-related WQC and TMDLs.

\section{Scientific Approach}

Low DO in coastal receiving waters is a symptom of eutrophication. Therefore, controlling the effects of low DO is not accomplished by directly regulating DO but by regulating nutrients and oxygen demanding wastes.

The ultimate product of this research effort is to provide the scientific basis to develop dissolved oxygen based nutrient criteria. The critical path to this product is:

Step 1: Mine and assess existing information on DO response to excess nutrients for coastal receiving waters and minimum oxygen requirements of commercially and ecologically important organisms.

Step 2: Develop conceptual model of how different systems manifest low DO in response to excess nutrients.

Step 3: Propose a classification scheme for coastal receiving waters that groups these waters according to their sensitivity to DO depletion in response to excess nutrients.

Step 4: Develop a common approach across Divisions. Select methods, parameters, and measurement endpoints for low DO response to excess nutrients so that data and models are interchangeable across Divisions and regions.

Step 5: Test the proposed classification scheme to provide the scientific basis for development of nutrient criteria (or TMDLs) based on nutrient load-DO response relationships for different classes of receiving waters.

Excessive nutrient loading to an estuary/receiving water stimulates primary production (i.e., phytoplanktonic, macroalgal). This production, together with allochthonous (labile) organic carbon, sinks to the bottom waters/benthos resulting in respiratory oxygen demand (mostly through microbial decomposition) that exceeds oxygen supply. This leads to hypoxia or anoxia in the bottom waters, which in turn lead to fish avoidance, fish kills, and mortality of sessile organisms such as worms and shellfish. Low oxygen also changes the oxidative properties of the sediments such that organic matter accumulates rather than being oxidized. Low oxygen can decouple nitrification and denitrification processes in the sediments resulting in increased supply of nutrients to overlying waters. In addition, the death or debilitation of shellfish and other sensitive sessile organisms can cause changes in the structure and function of benthic habitats. For example, after hypoxic conditions dissipate, predators return to feed on vulnerable benthic organisms before they can rebound from the stressed conditions; this changes the energy balance of the system. 
Hypoxic/anoxic conditions typically manifest themselves on diel or seasonal time scales during critical times of the annual cycle. For southem/semi tropical regions, the critical period is typically from May to October; for northern/temperate regions the period is from June to September. Seasonal hypoxia generally develops as a consequence of water column stratification, whereas diel cycles generally occur in non-stratified or partially stratified systems. Seasonal hypoxia is persistent throughout the critical period whereas diel hypoxia may be cyclic (regular frequency and duration; e.g., diel, tidal) or episodic (irregular frequency and duration).

\section{DO Criteria}

Part of the process of setting nutrient criteria based on DO involves determination of the minimum DO requirements of aquatic organisms. NHEERL is in the process of providing the scientific basis for setting minimum DO criteria for ecologically and commercially important organisms in coastal receiving waters through laboratory exposures. Survival data from laboratory exposures, using controlled DO concentrations, will provide risk assessment managers with the basic information needed to set minimum DO protection limits for the Nation's waters.

\section{General Classification Variables}

The classification scheme for the DO endpoint will be a common effort across all Divisions. Our plan is to link and improve existing models of flushing, light limitation, primary production controls, and oxygen supply dynamics to sort coastal receiving waters into groups of similar overall relative sensitivity. The number of groups will depend on the range and variability of estimates. Chapter 6 of Clean Coastal Waters (NRC 2000) lists 12 factors that influence the susceptibility of coastal receiving waters to nutrient over-enrichment. We will start with this list and focus on those factors that will be most useful in a classification scheme to determine the relationship between nutrient loading and DO as an effect of nutrient over-enrichment. The relative magnitude of atmospheric oxygen entrainment to the bottom waters and respiratory depletion determines whether a portion of the water column experiences episodes of low DO. The most important factors that affect entrainment include: density, salinity, and/or temperature stratification. In turn, these factors are influenced by climate/weather (temperature, wind), geomorphology (tides), and circulation patterns (tides and freshwater input) of the receiving waters.

Once the classification scheme with the key parameters influencing the response of DO to nutrients has been developed, we will test the classification using field data and comparable data from literature or other institutions and agencies where available. Both empirical and numerical simulation models will be used to improve our understanding of how these parameters interact and control the DO response to increased nutrient supply across a wide range of coastal receiving waters.

\section{Measurement Endpoints}

As mentioned above, "low DO" is one of the assessment endpoints that is to be related to excess nutrients in receiving waters. There are many methods and approaches to determine DO in coastal receiving waters. Providing sound basis for a national nutrient criteria based on DO will 
require development of a common approach to be applied and tested across a wide range of coastal receiving water systems. Each NHEERL Ecology Division will need to contribute to this process, and to the extent possible identify other sources of similar data from receiving waters in their region that could be used to improve our understanding of the relationship between nutrient loading-DO and the key factors that control that relationship.

Products

APM 1C FY02 (GPRA \# 165) Minimum dissolved oxygen requirements of aquatic animals in the Gulf of Mexico estuaries as a measure of the effect of nutrient enrichment (GED).

APM 2A FY03 Minimum DO requirements for a suite of the important marine organisms (fish and crustaceans) from the Atlantic, Pacific, and Gulf of Mexico coastal waters of the U.S. (AED).

APM 4A FY03 Propose classification scheme for predicting sensitivity of coastal receiving waters to effects of nutrients on DO (MED, AED, GED).

Benefits of Products

The benefits of the products to OW will be a reduction in the uncertainty associated with setting DO based nutrient criteria and TMDLs for our nation's receiving waters. Minimum DO requirements of important species will provide a sound basis for setting protective limits for DO in coastal receiving waters. Development of an improved classification scheme will aid in setting nutrient criteria in receiving waters where large historical databases are not available. An improved understanding of the factors affecting nutrient DO-response relationships will provide water quality managers with better tools to manage nutrient input to our nation's waters.

\section{Project Title 2. Development of SAV Loss-Nutrient Load Relationships and Factors which Control SAV Response to Nutrients}

Project Coordination and Resources (9.0 FTEs: AED-1.0, GED-4.0, MED-2.0, WED-2.0)

Objectives

The objective of this research plan is to develop, for the nations's coastal receiving waters, sufficient understanding of the relationship between SAV loss and nutrient loading (N and $P$ ) to provide a sound scientific basis for establishment of nutrient criteria that would protect these important habitats from degradation or loss and aid in restoration efforts. To do this, a set of models will be used to examine how nutrients interact with the physical and biological components to affect the health of SAV populations. This work will directly support or interact with the habitat alteration research (Section 4) providing basic information on production and function of these habitats and diagnostic research (Section 8 ) by providing nutrient-SAVresponse relationships. 


\section{Scientific Approach}

Research on SAV survival and production has generally focused on a few "key" parameters (e.g., light, nutrients), and much is known about the basic light requirements of SAV. Nutrients primarily affect SAV through their effects on water quality and the associated effects on light availability caused by increasing algal biomass (pelagic and epiphytic). Light availability is generally considered to be the major factor related to SAV survival (e.g., Kenworthy and Haunert 1991, Tomasko and Lapointe 1991, Fourqurean and Zieman 1991, Dennison et al. 1993, Stevenson et al. 1993, Dunton 1994) and depth of distribution (Dennison 1987, Dawes and Tomasko 1988, Duarte 1991). However, recent work is beginning to suggest that a more holistic approach may help delineate additional factors and improve our understanding of the relationship between nutrients and SAV loss (Koch 2001, Kaldy et al. 2002). In addition to understanding the requirements of SAV, we must also understand the interactions of nutrients and the physical, chemical, and biological factors that control accumulation of phytoplankton biomass in our receiving waters. This is similar to research needed to understand the relationship between nutrients and hypoxia (project 1); however, there are some differences in the factors associated with accumulation of biomass versus the increase in production associated with hypoxia.

The approach will be consistent with the general critical path stated above. Essentially, the main components for this research are:

1. Data gathering, literature review, and compilation of scientific literature (including existing information on SAV models for coastal systems) will focus on SAV-nutrient relationships. Where existing nutrient-SAV community data are available, this will include the compilation and statistical analysis of data. Over the last 30 years, a large body of literature has been published with regard to seagrass and other SAV. These publications should provide strong guidelines for directing EPA research. As part of this step, we plan to develop a report on the basic requirements (e.g., light, salinity, sediment characteristics) of three rooted aquatic seagrasses (Thalassia, Halodule, and Zostera) which together represent a large fraction of the SAV found in estuarine/marine systems along the coast of the U.S. Our research on SAV loss-nutrient load relationships will not be limited to these three seagrasses and will include freshwater and brackish rooted SAV as well.

2. Develop conceptual models of how SAV communities and nutrients interact with various environmental parameters to result in decreased survival or production in this important habitat. These models may be regionally specific because of the inherent differences; however, we will seek to make them as broadly applicable as possible. Our current conceptual model of how nutrients are involved in SAV loss suggests that increased nutrients leading to increased algal biomass accumulation is the basis for this pathway. The most likely factors affecting algal biomass accumulation are flushing rates, grazing rates, turbidity, climatic conditions, and water depth. We realize that excess nutrients also can cause nitrate toxicity, and increase sediment sulfide concentrations and/or toxicity.

3. Propose a classification scheme for coastal receiving waters that groups these waters according to their sensitivity to SAV loss in response to excess nutrients. Evaluate and modify existing models in order to develop nutrient-SAV loss responses. Classification parameters will 
certainly include dominant SAV species as well as many of the parameters listed in Clean Coastal Waters (NRC 2000). Development of a classification scheme for the SAV endpoint will be a common effort across all Divisions. Our plan is to use knowledge of species-specific requirements and link existing models or develop models that include the effects of light, nutrients, and sediment geochemistry on seagrass physiology. We also will link these with models of water column chlorophyll a-light absorption/attenuation and nutrient-phytoplankton biomass relationships to provide a basis for setting nutrient criteria for coastal receiving waters where protection or restoration of SAV is needed.

4. Develop a common approach across Divisions. Select methods, parameters and measurement endpoints for SAV response to excess nutrients so that data and models are interchangeable across Divisions and regions. Each Division will provide measures of the key parameters (the final list of these parameters will be developed and standardized); however, Division-specific research plans may focus on specific parameters or measurements as part of individual research projects (e.g., epi-periphyton community metrics, sediment sulfide production/toxicity). This phase of the plan development will include interaction with seagrass and SAV specialists in other governmental and academic institutions where possible.

5. The final step of this SAV critical path is a verification that tests the model's prediction and our classification scheme against the actual endpoint response. Once tested and verified, the proposed classification scheme and models will provide the scientific basis for development of nutrient criteria or TMDLs based on nutrient load-SAV response for different classes of receiving waters.

\section{Modeling Plan}

Our modeling approach for the seagrass endpoint is embodied in a three-tiered scheme that couples model development, field monitoring, and direct experiments to test specific hypotheses (Figure 6). We plan to use both holistic and mechanistic approaches that integrate the scientific literature and conceptualize how seagrasses are affected by stressors by using numerical and empirical models that quantify the production and distribution of seagrass. Characterization of a suite of parameters (e.g., light, sediment biogeochemistry, nutrients, and exposure during part of the tidal cycle) and their inclusion in models and classification schemes will allow EPA to determine which stressors are most important controlling factors in a particular region. Stressors which will impact SAV vary between regions as a result of variations in climate, industry, agriculture, and other land use practices. Consequently, it is critical to include a wide variety of parameters that influence all SAV (seagrass and freshwater aquatics), regardless of region. The appropriate scientific approach will likewise be an approach combining model development, field monitoring, and direct experimentation to test specific hypotheses generated by the models.

Built into this SAV modeling plan is a set decision point used to determine if the conceptual model, the numerical or empirical model, or the field test of the model has been successful. This 


\section{SAV}

\section{Model Development}

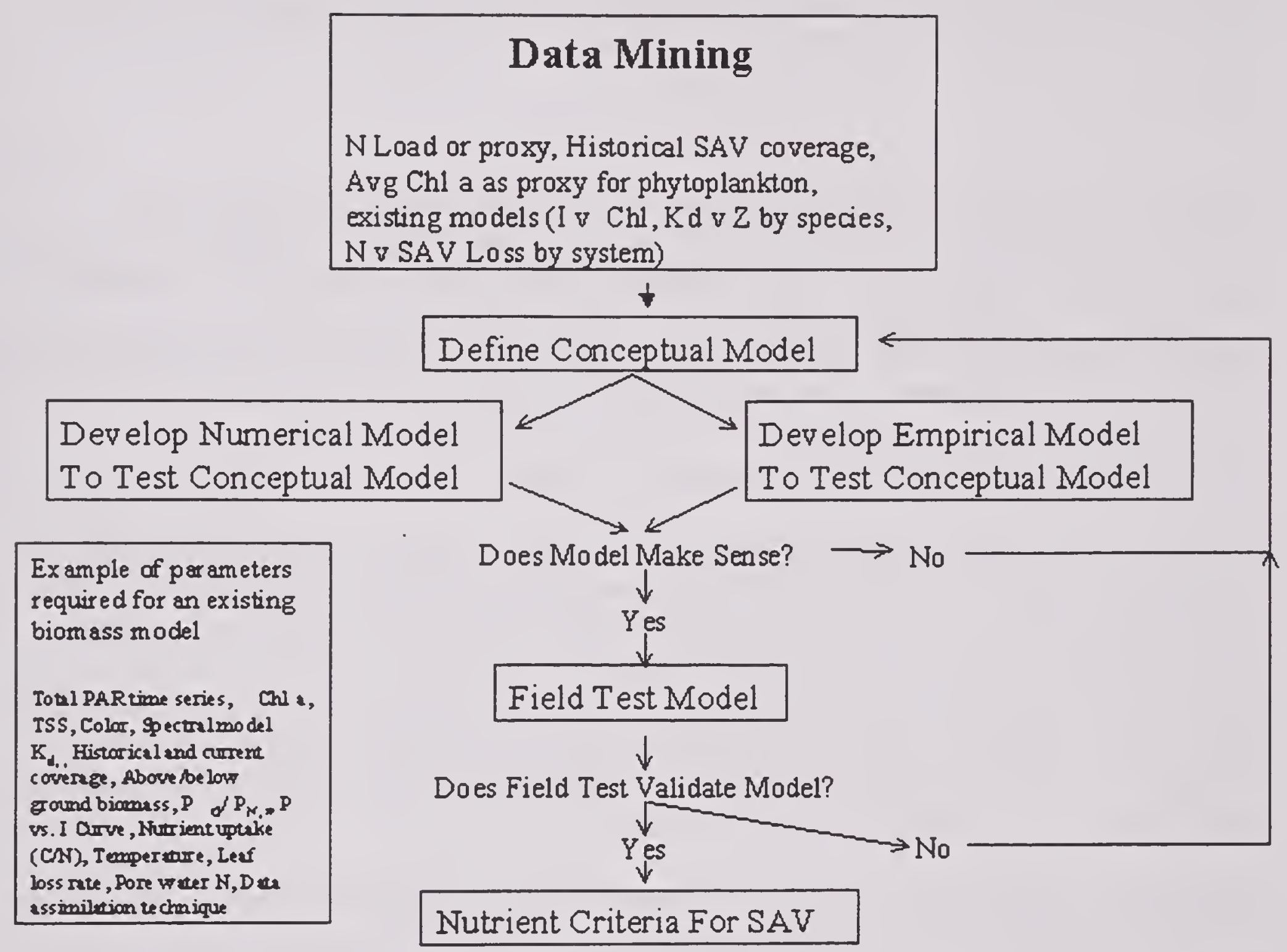

Figure 6. Conceptual diagram of the feedbacks among data mining, model development, field monitoring, and experimental hypothesis validation.

iterative process assures that at each stage in the critical research path, error in data and models are sufficiently small that the completed analysis will be accurate enough to make meaningful prediction of the SAV response to nutrients.

\section{Model Development}

Seagrass models are generally a composite of numerical and empirical relationships that provide a quantitative prediction of seagrass growth or loss. Each of these components has to be tested individually and in concert with other relationships that make up the model. Although all SAV models will have components in common, each regional model will be individualized to incorporate locally important species, the biogeochemistry of the water-column and sediments, 
and the local physical regime (Table 3). Successful model development will require long-term continuous data sets using instruments to measure important plant parameters (e.g., spectral irradiance, temperature, and salinity). It is critical that monitoring be conducted at appropriate temporal and spatial intervals that are relevant to the organism(s) and system(s) in question. Development and implementation of any long-term monitoring plan for use in modeling activities should be a cooperative effort involving the appropriate personnel (e.g., modelers, biologists, and field technicians).

\section{Field Monitoring}

The purpose of the field monitoring portion of this plan is to collect data on the range of responses and variability that are present in coastal systems and to provide input data to generate or refine models. Aquatic environments in general, and particularly estuaries, are stochastic systems that often exhibit large variations along many temporal and spatial scales. Long-term data sets are required to determine if variability expressed in a system is a consequence of natural variability (e.g., storm events) or anthropogenic impacts.

\section{Direct Experimentation (Field and/or Mesocosm Studies)}

One of the most important features of a model is the ability to develop testable hypotheses that will provide confidence in the model. In most cases, field experiments would be the preferred experimental environment; however, it is often difficult if not impossible to control all of the variables in the field (e.g., water column nutrient concentrations). The ability to replicate treatments also permits statistical data analysis. Consequently, mesocosm experiments bring together the best features of field and laboratory experiments offering environmental parameter control and a natural environment, while facilitating quantitative data collection (for review see Lalli 1990).

Development of the proposed models would provide testable hypotheses about the influence of any number of factors, such as the toxicity thresholds of SAV to various water column and sediment constituents (e.g., nitrate, ammonium, or sulfide concentrations). Another example would be determination of dessication stress, or sediment and water column anoxia on photosynthesis, or the interactions controlling the relationships between nutrients and phytoplankton versus epiphytes versus macroalgae versus seagrass. Physical factors such as the impact of wave exposure could also be investigated using replicated mesocosm experiments.

\section{Current Activities}

AED is developing empirical relationships between nitrogen loading and the areal extent of SAV normalized to historical SAV habitat extent. MED is investigating the relationship between nutrient loading and several quantitative attributes of wetland SAV including: \% cover, diversity, relative abundance, and maximum depth of macrophyte growth. GED is in the fourth year of developing a database of changes on water quality, light availability, and changes in the deepwater margin of SAV beds. WED is developing models of seagrass growth and production based on field data including seagrass biomass and production, underwater light, and sediment biogeochemistry. Other activities that support this SAV plan include GIS mapping of seagrass 
distribution over multiple annual cycles and the development of spatially explicit models to examine seagrass bed dynamics (e.g., expansion). Skills and knowledge represented by these research projects will be integrated across Divisions and will provide the basis for comparison and testing of approaches outlined above across the nation's SAV communities. Again, to be most useful to OW, SAV coverage and the loading response relationships should be based on historical information to the maximum extent possible since water quality management is frequently based on returning to some historical reference condition (realizing that such data is often not available).

Products

APM 1 A FY02 (GPRA \# 163) Generalized seagrass/rhizosphere model capable of predicting effects of reduced light, sedimentation, nutrient depletion, and toxic effects of sulfides (WED).

APM 1B FY02 (GPRA \# 164) Effects on estuarine submerged aquatic vegetation from changes in light quantity and quality due to increased levels of suspended solids (GED).

APM 5A FY02 Report on structural and functional characteristics of SAV rhizospheric communities (GED).

APM 5B FY03 Correlation of water quality with SAV change (GED).

APM 5C FY04 Report on environmental requirements of three main species of seagrasses (WED).

APM 5D FY04 Development of stress-response model for Zostera marina in Pacific Northwest and validation of stress-response model for Thalassia testudinum (WED).

APM 5E FY04 Development of empirical load-response models for Zostera marina in NE U.S. (AED).

APM 5F FY05 Development of load-response models for estuaries of Pacific Northwest and Gulf Coast, and validation of stress-response model for Zostera marina in NE U.S. (WED, GED, AED).

APM 5G FY05 Propose classification scheme for predicting sensitivity of coastal receiving waters to the effects of nutrients on SAV (WED, GED, AED).

APM 5H FY06 Report on the empirical and numeric models for SAV (WED, GED, AED).

APM 5I FY07 Report on a classification scheme for grouping coastal receiving waters based on sensitivity to nutrients.(WED, GED, AED). 
The benefits of the products will be a reduction in the uncertainty associated with setting SAV based nutrient criteria and TMDLs for our nation's receiving waters. A compendium of requirements of important SAV species will provide a convenient reference and a sound basis for setting protective limits in coastal receiving waters. Development of a classification scheme will aid in setting nutrient criteria in receiving waters where large historical databases are not available. An improved understanding of the factors affecting nutrient-SAV loss relationships will provide water quality managers with better tools to manage nutrient input to our nations waters while protecting these important habitats.

\section{Project Title 3. Food Web and Community Composition Changes in Response to Nutrient Loading in Freshwater and Marine Coastal Systems (Estuaries and Coastal Wetlands)}

Project Coordination and Resources (14 FTEs: AED-3.0, GED-5.0, MED-3.0, WED-3.0)

Objectives

The primary objective of food web research is to identify nutrient loading thresholds that cause shifts in primary producers and other key components of the food web. A secondary objective is to assess the use of food web structure and processes to improve our ability to classify systems and to predict changes in response to nutrients that affect hypoxia and SAV. Research will require identification of measurement endpoints that are sensitive to nutrient loading and reliably forecast adverse effects to assessment endpoints.

\section{Scientific Approach}

As with the DO and SAV assessment endpoints for nutrient research, we are concerned that increased concentrations or changes in ratios or timing of nutrient inputs can adversely affect populations of ecologically and commercially important organisms. For food webs, nutrient loading-response relationships are not as well understood as for DO and SAV; however, food webs may reveal subtle, low threshold responses to nutrient loading that are more sensitive than DO or SAV endpoints (Livingston 2000). Changes in patterns of energy flow alter habitats and support systems required by important organisms. Variations in nutrient ratios, concentrations, or timing of inputs can alter the competitive advantages of primary producers causing the demise of species on which important consumers depend. Research investigating the relationships between nutrient loading and food webs will focus on identifying thresholds of nutrient loading where pathways of energy flow from primary producers to consumers are altered and populations of commercially and ecologically organisms are adversely affected. NHEERL research will focus on the effects of nutrients on primary producers and subsequent interactions with pelagic and benthic communities. Process-oriented research, such as analysis of food web structure via stable isotopes will provide basic data for development of nutrient load-response relationships, and will provide insight into biological factors controlling primary production and energy flow in coastal systems. This research will focus on three critical food web shifts: 1) changes from benthic to pelagic basis of production (i.e., SAV or periphyton to phytoplankton), 2) shifts in 
pelagic algal communities from desirable (edible, nutritious) to undesirable (non-edible, nuisance, HAB species), and 3) shifts in emergent or marsh grass systems.

Major challenges of this research are to identify practical measurement endpoints (response variables) and relate those responses to assessment endpoints (e.g., high performance liquid chromatograhy [HPLC] accessory pigments may be useful as measure of changes in the phytoplankton community leading to or associated with decreased fisheries production). We will investigate development of indices of tropic status associated with high nutrient conditions, such as ratios of algal biomass to zooplankton and/or fish, benthic and pelagic community metrics that reflect algal composition (e.g., percent blue-greens, and relative abundance of centric and pennate diatoms, algal size distributions). Developing load-response relationships, which reflect changes in food web structure, will be challenging due to the complex feedback mechanisms which accompany degraded habitats in coastal systems (Jude and Pampas 1992, Chow-Frazer 1998). Increasing phytoplankton biomass may uncouple primary production from grazing. This then leads to algal blooms, possibly toxic or noxious algae (HABs) and successions in pelagic and benthic communities. The causal mechanisms for HABs remain poorly understood; some have always occurred and are entirely natural. However, other blooms are tied to nutrient enrichment, thus leading to more frequent and longer lasting blooms as nutrient loading increases (NRC 2000). Even more uncertainty exists regarding relationships between nutrient loading and basic changes in food webs supporting productive marine and freshwater ecosystems. In addition to nutrients, the activity of top consumers can exert strong controls on zooplankton and/or phytoplankton affecting phytoplankton size, abundance, and production. Biogeochemical processes resulting from blooms (i.e., enhanced sedimentation and redox changes) can cause changes in species diversity, size spectrum of organisms, and average tropic level of the community. The secondary effects of these water-column and sediment changes may be persistent changes in pelagic and benthic species assemblages and alterations in the nutrient recycling potential of aquatic habitats. Our approach is to determine nutrient load-response thresholds for endpoints reflecting shifts in the food web structure or species composition.

The Scientific approach will be consistent with the general critical path (Figure 5). Essentially, the main components for this research are:

1. Data gathering and literature review of food web information for coastal food web systems will be done collaboratively across Divisions, where existing nutrient-food web/community data are available, statistical analysis will be conducted.

2. Conceptual models that include both bottom up effects models and bottom up-top down community models will be developed. The bottom up model (nutrients to primary production, Menge 2000) shows influences on aquatic communities, including the formation of some HABs and ultimately changes in important fish and shellfish populations. The community level model includes interactions among populations that form the food web and identify critical interactions that may lead to changes in species diversity, commercial harvest, eutrophication, and designated use.

3. A classification scheme for coastal receiving waters that groups these waters according to their sensitivity to food web changes in response to excess nutrients will be provided. Existing 
food web models will be evaluated and modified in order to develop nutrient-food web responses incorporating classification schemes.

4. We will develop common approaches across Divisions for parameters related to food web shifts (e.g., HPLC pigment analysis, stable isotope measurements, community metrics). We will select common methods, parameters, and measurement endpoints for food web response to excess nutrients when available, so that data and models are interchangeable across Divisions and regions, which will provide the basis for comparison and testing of our models, methods, and classification schemes.

5. Testing of the proposed classification scheme and models will provide the scientific basis for development of nutrient criteria and/or TMDLs based on nutrient load-food web response for different classes of receiving waters.

Initial research projects adopted by all four Ecology Divisions, to collect data for identifying potential assessment endpoints or testing classification schemes and models, will help in the development of a better understanding of the processes leading to shifts in food webs and help identify factors and parameters in common with the process. Comparison of results and application of successful techniques across Divisions will speed identification of practical assessment endpoints and development of models and understanding of food web-nutrient relationships. We plan to use stable isotope measurements in systems with various types of dominant primary producers at the base of the food web (i.e., pelagic phytoplankton, saltmarsh, benthic algae, and SAV). Indices that we plan to predict include ascendancy and/or flow diversity. This indice predicts the relative stability of food webs. System with low flow diversity tend to have large temporal variations in structure, usually at the lower tropic levels, but sometimes at the mid and high tropic levels. In the long-term, these systems eventually come to a new stable state that may be more eutrophic than the original food web. Hence, we can predict what systems are at risk (unstable) even though no model can reliably predict species succession. Nutrients as a stressor can reduce food web flow diversity and the ensuing systems instability may result in $\mathrm{HABs}$, macroalgae, and other harmful species. With sufficient data in the various system types, we can use optimization techniques to correlate changes in flow diversity (stability) with nutrient load.

WED-Food web models will be developed that track nutrient and carbon flow through aquatic systems using a combination of stable isotope and population level data. This is a community level model designed specifically to identify critical food web interactions that lead to changes in species diversity, commercial harvest, eutrophication, and other factors that could effect the designated use of a habitat. This stable isotope based model will be used to compare energy flow in the different types of coastal systems where each of the Divisions are located. Application of this model across all four Divisions will provide insight into carbon and nutrient processing across a wide variety of systems.

GED-Will provide stable isotope measurements to test the WED food web model and will focus on factors controlling shifts in the phytoplankton community structure and size in Escambia Bay, $\mathrm{FL}$, which is dominated by pico-cyanobacteria blooms in summer. Size of phytoplankton is an important factor that determines the structuring of both the pelagic and benthic food webs. 
Picoplankton is associated with a microbial food web while nanoplankton is associated with zooplankton consumers and commercially and charismatically important higher tropic levels. This research will provide insight into the chemical and biological factors controlling pelagic phytoplankton community.

AED-Will also measure stable isotope shifts and will provide a test of the WED food web model including average food chain length. AED will investigate the effects of nutrients on saltmarsh species changes and generate methods to relate nutrient loading to chl-a levels using remote sensing, (i.e., airframe and satellite spectral analyses), including the ability to distinguish between different types of phytoplankton blooms (diatoms vs. dinoflagellates).

MED-Will initially focus on two of the Great Lakes, Lake Superior, and Lake Michigan. In addition to using stable isotopes to investigate food web structure in Great Lakes coastal wetlands, nutrient effects oriented research will be employed to investigate several assumptions:

- Algal-zooplankton size distribution in response to nutrient loading,

- Algal community responses to N/P ratios in freshwater coastal wetlands, and

Modeling efforts focusing on establishing relationships of nutrient loadings and ambient concentrations with chlorophyll, DO, N/P ratios, phytoplankton species composition, food chain productivity, and water column transparency.

In addition, where possible, we will partner and collaborate with other coastal nutrient efforts (i.e., State of the Lake Ecosystem Conference [SOLEC], GLEI, Atlantic Coast Environmental Indicators Consortium, Great Lakes Coastal Initiative, States, and Tribes).

Products

APM 1D FY 02 (GPRA \# 166) Effects of nutrient loadings and altered nutrient ratios on HABs (GED).

APM 3 (GPRA \# 201) Comparison of effects of zooplankton grazing on estuarine phytoplankton community under differing natural levels of grazing (GED).

APM 6A FY04 Sensitivity of food web responses to nutrient loading in coastal systems (GED).

APM 6B FY05 Propose classification scheme for predicting sensitivity of coastal receiving waters to effects of nutrients on food web structure (GED).

APM 6C FY06 Report on empirical and numeric models for food webs (WED).

APM 6D FY 06 Report on parameterization of food web models (GED).

APM 6E FY06 Report on classification scheme for grouping coastal or lake receiving waters based on sensitivity to food web alterations (WED, GED, AED, MED). 
These products will include:

FY03 State of the Science report on nutrient food web relationships in Coastal Systems (AED, GED, MED, WED).

FY04 Interim report on sensitivity of food web response to nutrient loading in coastal systems (AED, GED, MED, WED).

FY05 Recommendation on use of food web related endpoints to predict effects of nutrients on important fish and shellfish populations (AED, GED, MED, WED).

\section{Benefits of Products}

This research will provide the basis for setting ecologically relevant nutrient criteria for $305 b$ reporting and TMDL development that supports the protection of aquatic life as mandated under CWA. By providing standardized methodology, it will provide guidance to the States and EPA Regions for developing appropriate monitoring protocols. In addition, a better understanding of nutrient-food web response relationships will significantly improve our ability to predict ecosystem response to other nutrient endpoints (DO and SAV loss).

\section{Gap Analysis}

In order to focus on what can be accomplished with the available resources, we have chosen the four coastal regions described above. There are other major coastal regions we are not covering such as Mid and South Atlantic systems or Southern Pacific coastal waters. In addition, this research is focused on coastal receiving waters. It does not directly focus on understanding nutrient response relationships in streams, rivers, lakes, inland wetlands, or headwater seeps, for which additional research is needed. Longer range plans do include an integrated watershed approach as resources become available. We are not developing DO criteria for any freshwater species of fish or SAV light requirements for freshwater SAV.

Currently we do not have sufficient understanding of how the biological components of an ecosystem interact to process nutrients to be able to predict how differences in these components affect the capacity of an ecosystem to assimilate nutrients. To do this more effectively, we need to improve our skills in the area of ecosystems ecology and ecosystem modeling. In addition, the presence of a database manager to establish a central database or linkages between Divisional databases would significantly improve the transfer and sharing of data to be used and tested in a variety of approaches (models and classification schemes). It is hoped that NERL will provide nutrient loadings for receiving water bodies that will be considered by NHEERL; however, if this is not possible then NHEERL will need to determine or estimate loadings.

\section{References}

Boynton, W.R., Hagy, J.D., Murray, L., Stokes, C., Kemp, W.M. 1996. A comparative analysis of eutrophication patterns in a temperate coastal lagoon. Estuaries 19B:408-421. 
Boynton, W.R., Kemp, W.M. 2000. The influence of river flow and nutrient loads on selected ecosystem processes. In Hobbie, J., ed., Estuarine Science: a Synthetic Approach to Research and Practice. Island Press, Washington, DC, pp. 269-298.

Chow-Frazer, P., 1998. A conceptual model to aid restoration of Cootes Paradise Marsh, a degraded coastal wetland of Lake Ontario, Canada. Wetland Ecol. Manag. 6:43-57.

Cohn, T.A. Delong, L.L. Gilroy, E.J. Hirsch, R.M. Wells, D.K. 1989. Estimating constituent loads. Water Resources Research 25:937-942.

Costa, J.E., Howes, B.L., Janik, D., Aubrey, D., Gunn, E., Giblin, A.E. 1999. Managing anthropogenic nitrogen inputs to coastal embayments: technical basis and evaluation of a management strategy adopted for Buzzards Bay, Buzzards Bay Project.

Dawes, C.J., Tomasko, D.A. 1988. Depth distribution of Thalassia testudinum in two meadows on the west coast of Florida; a difference in effect of light availability. Mar. Ecol. 9:123-130.

Dennison, W.C. 1987. Effects of light on seagrass photosynthesis, growth and depth distribution. Aquat. Bot. 27:15-26.

Dennison, W.C., Orth, R.J., Moore, K.A., Stevenson, J.C., Carter, V., Kollar, S., Bergstrom, P.W., Batiuk, R.A. 1993. Assessing water quality with submersed aquatic vegetation. BioScience 43:86-94.

Dettmann, E.H. 2002. Effect of water residence time on annual export and denitrification of nitrogen in estuaries: a model analysis. Estuaries (in press).

Duarte, C.M. 1991. Seagrass depth limits. Aquat. Bot. 40:363-377.

Dunton, K.H. 1994. Seasonal growth and biomass of the tropical seagrass Halodule wrightii in a hypersaline subtropical lagoon. Mar. Biol. 120:479-489.

Eldridge, P.M. Jackson, G.A. 1993. Benthic tropic dynamics in California coastal basin and continental slope communities inferred using inverse analysis. Mar. Ecol. Prog. Ser. 99:115-135.

EPA. 2000. Ambient water quality criteria for dissolved oxygen (saltwater): Cape Cod to Cape Hatteras. EPA-822-R-00-012. Office of Water, Washington, DC.

Fourqurean, J.W., Zieman, J.C. 1991. Photosynthesis, respiration and whole plant carbon budget of the seagrass Thalassia testudinum. Mar. Ecol. Prog. Ser. 69:161-170.

Hagy, J.D. 2002. Eutrophication, hypoxia and trophic transfer efficiency in Chesapeake Bay. Ph.D Dissertation, University of Maryland, College Park, MD.

Jude, D.J., Pampas, J. 1992. Fish utilization of Great Lakes coastal wetlands. J. Great Lakes Res. $18: 651-672$. 
Kaldy, J.E., Dunton, K.H., Kowalski, J.L., Lee, K.S. 2002. Evaluation of environmental factors controlling the success of seagrass revegetation onto dredged material deposits: a case study in Lower Laguna Madre, Texas. Restor. Ecol. (in revision).

Kenworthy, W.J., Haunert, D.E. 1991. The light requirements of seagrasses: proceedings of a workshop to examine the capability of water quality criteria, standards and monitoring programs to protect seagrasses. NMFS-SEFC-287. NOAA technical memorandum.

Koch, E.W. 2001. Beyond light: physical, geological and geochemical parameters as possible submersed aquatic vegetation habitat requirements. Estuaries (in press).

Lalli, C.M., ed. 1990. Enclosed Experimental Marine Ecosystems: a Review and Recommendations. Springer-Verlag, New York.

Livingston, R J. 2000. Eutrophication Processes in Coastal Systems: Origins and Succession of Plankton Blooms and Effects on Secondary Production in Gulf Coastal Estuaries. CRC Press, Boca Raton, FL. 327 pp.

Menge, B.A. 2000. Top-down and bottom-up community regulation in marine rocky intertidal habitats. J. Exp. Mar. Biol. Ecol. 250:257-289.

Nixon, S.W. 1995. Coastal marine eutrophication: a definition, social causes, and future concerns Ophelia 41:199-219.

Nixon, S.W., Ammerman, J.W. , Atkinson, L.P., Berounsky, V.M., Billen, G., Boicourt, W.C., Boynton, W.R., Church, T.M., Ditoro, D.M. , Garber, J.H., Giblin, A.E., Jahnke, R.A., Owens, N.J.P. , Pilson, M.E.Q., Seitzinger, S.P. 1996. The fate of nitrogen and phosphorus at the landsea margin of the North Atlantic Ocean. Biogeochemistry 35: 141-180.

NRC. 2000. Clean Coastal Waters: Understanding and Reducing the Effects of Nutrient Pollution. National Academy Press, Washington, DC.

Smith, R.A. Schwartz, G.E. Alexander, R.B. 1997. Regional interpretation of water quality monitoring data. Water Resources Research 33:2781-2798.

Stevenson, J.C., Staver, L.W., Staver, K.W. 1993. Water quality associated with survival of submersed aquatic vegetation along an estuarine gradient. Estuaries 16:346-361.

Tomasko, D.A., Lapointe, B.E. 1991. Productivity and biomass of Thalassia testudinum as related to water column nutrient availability and epiphyte levels: field observations and experimental studies. Mar. Ecol. Prog. Ser. 75:9-17.

Ulanowicz, R.E. 1986. Growth and Development: Ecosystem Phenomenology. Springer-Verlag, New York. 203 pp. 
Vézina, A.F., Pace, M.L. 1994. An inverse model analysis of planktonic food webs in experimental lakes. Can. J. Fish. Sci. 51:2034-2044.

Vollenweider, R.A. 1975. Input-output models with special reference to the phosphorus loading concept in limnology. Schweiz. Z. Hydrol. 37:53-84. 


\section{Section 6. \\ Implementation Plan for Suspended and Bedded Sediment Research}

NHEERL's effort concerning suspended and bedded sediments has been redirected since this section was first written. The majority of the work in this research area will now occur under Goal 8 (EMAP) because EMAP design techniques will be applied to develop effect thresholds for suspended and bedded sediments in aquatic systems. Some of these techniques are described generally in the Critical Path subsection of this implementation plan. However, at this time, the effort under aquatic stressors will only include a literature review of suspended and bedded sediments research. Results from this review will be combined with EMAP approaches to synthesize and evaluate the state of the science. Once the review has been completed, data gaps will be identified and additional research will be conducted, if warranted.

\section{Problem}

The Office of Water has identified suspended and bedded sediments as one of OW's highest and most immediate priorities. The priorities within aquatic systems for developing these criteria were identified as: rivers and streams; followed by lakes, reservoirs, ponds, and estuaries. For purposes of this document, suspended sediments are those sediments that exert their negative impact via their suspension in the water column, such as the effect of shading induced by them on submerged macrophytes. Bedded sediments are those sediments that have their negative impact when they are actually settled out and on the bottom of the water body of interest such as fine sediments which smother spawning beds. Research in this section does not deal with contaminated sediments (those containing toxic chemicals, see Section 7).

In streams and rivers, fine inorganic sediments, especially silts and clays, affect both the habitat for macroinvertebrates and fish spawning, as well as fish rearing and feeding behavior. Larger sands and gravels can scour diatoms and cause saltation of invertebrates, whereas suspended sediment affects the light available for photosynthesizing plants and visual capacity of animals (Waters 1995). A major problem with suspended sediment in coastal wetlands, estuaries, and near-shore zones is the decreased light penetration which often causes aquatic macrophytes to be replaced with algal communities, with resulting changes in both the invertebrate and fish communities (Chow-Fraser 1998). Increased sedimentation also may functionally shift the fish community from generalist feeding and spawning guilds to more bottom-oriented, silt tolerant fishes (Berkman and Rabeni 1987, Muncy et al. 1979).

Thus suspended and bedded sediments are expected to have two major avenues of effect in aquatic systems: 1) direct effects on biota and 2) direct effects on physical habitat, which result in indirect effects on biota. Some examples of direct effects on biota include suppression of submersed macrophytes through reduced light attenuation, changes in benthic algal communities, and shifts to turbidity-tolerant fish communities. Effects of suspended and bedded sediments on habitat structure include changes in refugia for biota (e.g., changes in macrophyte communities), increased fines (and embeddedness) and scouring in streams, aggradation and destabilization of stream channels, and filling in of wetlands and other receiving waters (Wilcock 1998, Lisle 1982, Dietrich et al. 1989). Increased turbidity and concomitant changes in light regime could also be 
considered to be aspects of altered habitat. Indirect effects on biota will occur as the fish, invertebrates, algae, amphibians, and birds that rely upon aquatic habitat for reproduction, feeding, and cover are adversely affected by habitat loss or degradation (Platts et al. 1983, Hawkins et al. 1983, Rinne 1988).

Sea grasses and other SAV are considered "keystone" species in temperate and tropical coastal areas. These flora have a variety of beneficial attributes including providing food and shelter for many biotic species. There has been a worldwide decline in sea grasses including dramatic regional losses in the Gulf of Mexico. The reasons for the decline are unknown but reduction in light attenuation (quantity and spectral quality) is thought to be a major factor. The presence of suspended sediments is one factor that can impact water clarity, however, its significance to this effect and observed sea grass declines is relatively unknown.

Ultimately, resolution of any problems associated with increases in suspended and bedded sediments will need to address the sources of the sediment. These influxes of sediments, in general, are associated with increased sediment delivery via soil erosion often caused by changes in landuse and landcover, and changes in flow regimes that effect in-channel sediment transport and loading. Recognition of the proximal and distal "causes" of suspended and bedded sediment problems will affect the classification scheme used and the development of the "expectation" for natural sediment loads.

\section{Goals}

The primary goal for NHEERL's Suspended and Bedded Sediment program is to provide and demonstrate the approach for establishing sediment criteria that support aquatic life use in streams/rivers, lakes/reservoirs, wetlands, and estuaries. A necessary first step for achieving this goal is to assess the current knowledge and to report on the state of the science of this research area. A specific APG and APM for this assessment follows. Additional goals are proposed, but will depend on results from both EMAP research and the literature review.

APG 1 FY02 Synthesize state of the science and remaining uncertainties for developing criteria for suspended and bedded sediments.

APM 1A FY02 Report on the state of the science and progress for developing suspended and bedded sediment criteria (AED, MED).

Provide summary of biological response profiles for suspended and bedded sediments in marine and freshwater systems.

Develop models that predict and scale biological responses to suspended solids and sediment using assessment endpoints that support management decisions.

Develop classification schemes to optimize efficiency in developing suspended and bedded sediment criteria. 
Provide the scientific basis for suspended and bedded sediment criteria for marine and freshwater systems.

\section{Critical Path}

A general diagram for NHEERL's research program on suspended and bedded sediments is shown in Figure 7. An explanation of the figure is given below, including the logical sequence of information needed to develop the technical basis for deriving a criterion for suspended and bedded sediments.

The major NHEERL responsibilities in Figure 7, under Goal 2, are to: review the literature and existing State criteria and develop a general conceptual model of sediment effects, including verbal descriptions of suspended and bedded sediment criteria that are explicit enough to shape subsequent quantitative modeling (box 0 ). Based on regional-scale data (box la,b), develop ecoregionally-specific models of the effects of suspended and bedded sediments on aquatic assemblages in various types of aquatic ecosystems (box 2); then explore and confirm mechanisms of sediment effects on assemblages and ecosystems through experimental research incorporating controlled conditions and restricted taxa at smaller scales (box lc). Using these stressor-response relationships and models as a technical basis, develop an approach for establishing sediment criteria (box 3), which OW, EPA Regions, and States may use to establish criteria for suspended and bedded sediment (box 5). Using data from regional-scale surveys (e.g., EMAP, Regional EMAP [REMAP], National Water Quality Assessment [NAWQA)]) and more focused watershed studies, examine the stressor-response relationships between natural and anthropogenic controls and the levels and transport of sediment (box 8). Based on this research and models of the effects of sediments on aquatic biota (box 2), identify critical thresholds of anthropogenic disturbance that lead to biologically-relevant sediment responses (box 4). These ecoregionally-specific thresholds will be useful guidance to the TMDL process carried on by States (box 6). Finally, review and revise the stressor-response models and recommended sediment criteria based on feedback from monitoring data and further research (box 7).

The first step in this process is a review of the literature on the biological effects of suspended and bedded sediments. The Office of Water has already begun this process. NHEERL can contribute to this effort and expand it to evaluate the literature for useable stressor/response relationships. Once the available literature has been reviewed, it will be necessary to develop a conceptual model or framework of the effects of suspended and bedded sediments in aquatic environments (box 0). This will guide the development of the remainder of our research activities.

Classification of the expected response of aquatic systems to suspended solids and bedded sediments is a critical early phase of research. The first step in developing a classification scheme for sediments and suspended solids is the division of the national landscape into different eco-regions that are sufficiently fine-scaled to accurately represent the vegetation, climate, geology, and soils (box 1a). These factors will influence both the quantity and type of sediment and suspended solids that will be carried from the landscape into the receiving water body. The 


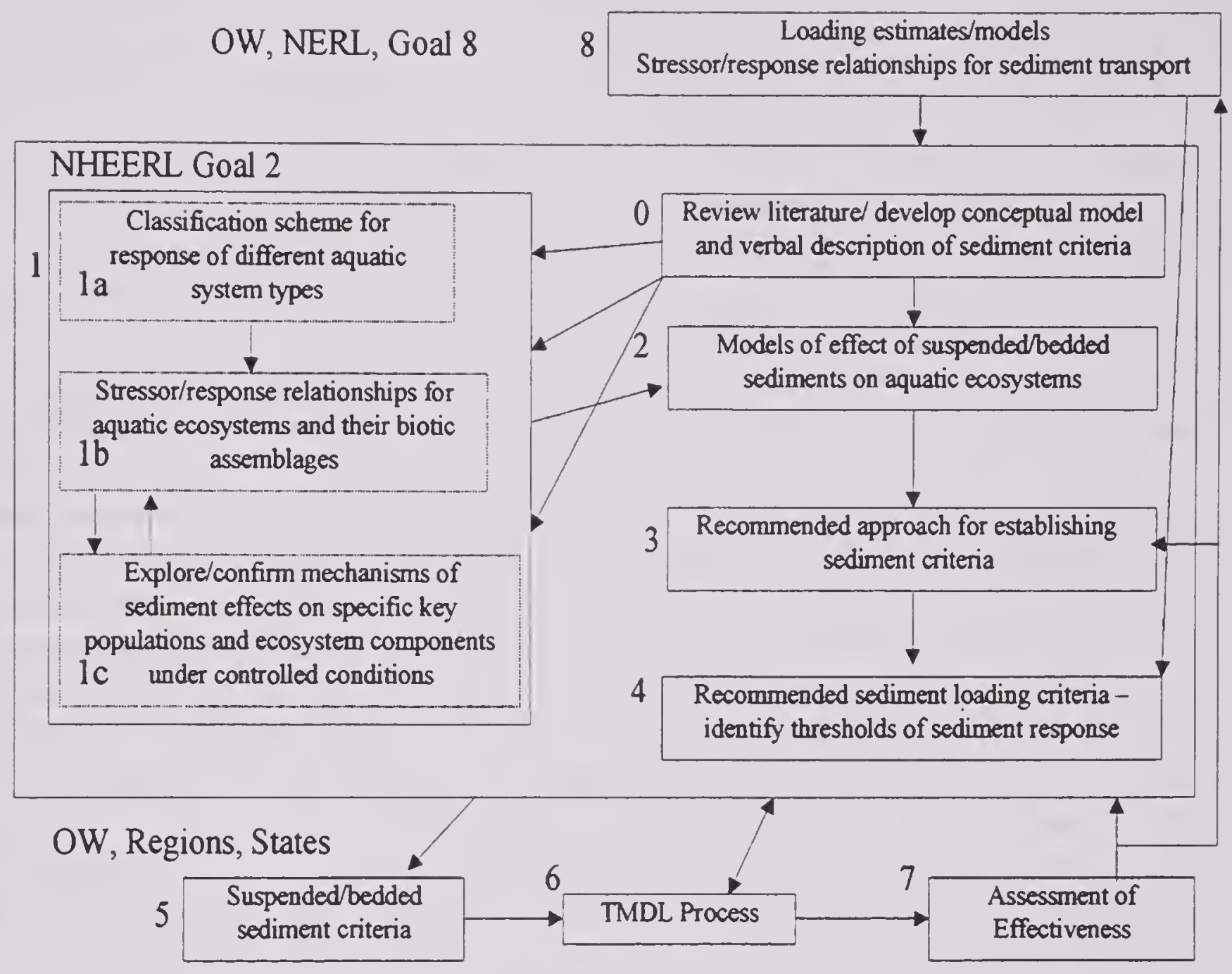

Figure 7. Critical path for suspended and bedded sediments research.

kinds of soils within these landscape delineations are particularly important. Secondly, fragmentation, storage, and hydrogeomorphic characteristics of streams and rivers need to be examined and classified at the watershed level as these factors influence the degree of flashiness of streams and rivers to precipitation, snowfall run-off, and groundwater inputs (Leopold et al. 1964, Morisawa 1968, Mackin 1948). Ultimately these affect the timing of loadings, and quantity and type of sediment, not only to streams and rivers but to the receiving bodies into which they empty. The third step is classification by ecosystem type such as streams, rivers, coastal wetlands, estuaries, or near-shore zones.

A discussion of the approaches anticipated for establishing stressor-response relationships for streams and rivers serves as a useful guide to the type of research anticipated in box $1 \mathrm{~b}$. For bedded sediments in streams and rivers, it is likely that the expected levels of bedded fine sediment in relatively undisturbed streams are ecoregionally specific, depending upon natural climatic factors, topography, lithology, soil, and potential natural vegetation. It is also likely that the intensity of the response of sediment to anthropogenic disturbance will also be dependent 
upon similar factors. The optimum regional classification to underlie modeling of sediment expectations and response to anthropogenic disturbance will be based on work described in box 1a. Using a combination of empirical data from relatively undisturbed watersheds and models describing the physics of sediment supply and transport, we will estimate expected levels of bedded sediment fines and embeddedness in stream and river reaches of specific size, slope, and location. We will then examine the association between watershed/riparian land use and the deviation of sediment concentrations from expected values, using survey data and data from more detailed watershed studies. This effort should include interaction with NERL and NRMRL to link landuse and landscape processes that may be responsible for delivering sediments. We will need to take into account the likelihood that, because of natural disturbances (fire, landslides, in-channel scouring due to instream hydrologic modifications), a certain portion of the stream or river resource may have fine sediments substantially above or below the mean expected value for the region. Therefore, the degree of impairment associated with deviations of sediment from expected values is likely to be expressed in terms of statistical probabilities.

Once the degree of sedimentation is estimated for sample sites, we will examine associations between biotic assemblages (algae, macroinvertebrates, fish, rooted aquatic plants), and/or key aquatic species or guilds and deviations of sediment from expected values. In most cases, our data sets will include sites affected by multiple stressors besides sediment that could potentially act upon these aquatic biota. In such cases, a regional plot of sediment concentration versus some biotic assemblage characteristic (e.g., \% EPT [Emphemeroptera, Plecoptera, Trichoptera]), will appear as a wedge-shaped pattern of points, where progressively higher fine sediment concentrations are sufficient to limit \% EPT numbers, but low concentrations do not guarantee abundant EPT because of other habitat or chemical limitations (Terrell et al. 1996). These patterns are consistent with a hypothesis that sediment is limiting biota. After demonstration of a plausible causal mechanism (from detailed experimental studies) and elimination of other plausible explanations for these observations, we will use these kinds of associational data in a weight-of-evidence approach to support modeling the effects of bedded sediments on aquatic biota.

For suspended sediments in streams and rivers, we will focus initially on chronic levels of suspended sediments, rather than those resulting from episodic events such as those accompanying storms. Expected natural levels of background suspended solids will be set on the basis of data from flowing waters in basins relatively undisturbed by human land uses and (in rivers) historic water clarity data to the extent possible. Regional reference areas could serve this purpose. Where no relatively undisturbed waters exist, as for large rivers, we will use historic data or reconstructions of fish and/or macroinvertebrate assemblage composition to infer (from published tolerance information) pre-disturbance suspended sediment characteristics. In an approach similar to that for bedded sediments, we will examine associations between biotic and/or key aquatic species or guilds and deviations of sediment from expected values in appropriate regional settings. As for bedded sediments, we will seek patterns that are consistent with biotic limitation by suspended sediment in a weight-of-evidence approach to support modeling the effects of bedded sediments on aquatic biota, supporting this information with controlled experimentation or literature reference to establish the suspended sediment levels that cause substantial impairment of assemblages, sensitive guilds, or key species. 
A conditional probability approach also will be explored to determine possible effects of suspended sediments on the biotic condition of streams. Data from the ORD/EMAP MidAtlantic Highlands Assessment (MAHA) streams program (EMAP indicators and design), reported in the MAHA streams report (EPA 2000), will be used in this application. The approach uses survey data (sites selected with a probability design) and determines the likelihood of impaired biological conditions for varying threshold levels of exposure or stressor variable(s) (in this case, some form of suspended sediment concentration, possibly normalized for an expectation level). The use of survey data permits an unbiased extrapolation of results to the statistical population that the probability sample was drawn from. For example, the results would be applicable to all of the wadeable streams in a state if the sample was drawn from all wadeable streams in the state.

This approach is different from typical association approaches that relate exposure or stressor conditions with impaired biological conditions, for example, water quality levels associated with impaired fish communities (fish IBI values less than 3). The approach here "stratifies" the resource for exceedance of a specified exposure or stressor value and then determines the fraction of that strata with impaired biological conditions. Since the sites were selected with a probability design, the fraction of the resource that is impaired is the probability of observing impaired biological conditions in the resource for exceedance of the threshold value. This stratification is then done for all values of the exposure or stressor variable. The result is a relationship for probability of impaired biological conditions for exceedance of the exposure or stressor values. This result is not a cumulative distribution function of the biological conditions since it relates the conditions to a threshold level of another variable, and it is more than a simple scatter diagram of biological condition with the exposure or stressor variable (the resource is incrementally integrated or summed for second variable).

Issues associated with suspended and bedded sediments may be approached in a slightly different manner in estuaries. One of the primary research needs is to determine whether sea grass decline is correlated with the presence of increased suspended sediments. A combination of laboratory and field work derived under natural (box lb) and controlled conditions (box 1c) is needed to derive protective water clarity criteria or to set management goals to maintain existing sea grass coverage and community composition. This would be accomplished by the collection of descriptive data (mapping and field data) at a variety of sampling sites. This research would include monitoring basic characteristics of sea grass communities in reference areas and areas which historically receive high levels of suspended solids using fixed transects or experimental plots. Response parameters would include, but not be limited to, photosynthetic activity, standing crop, root/shoot ratios, epiphytic coverage, blade characteristics, sea grass cover, and density. Extensive water and sediment quality monitoring would be combined with this effort.

There are a variety of experimental designs available to determine, under controlled conditions, the effects of suspended and bedded sediments on sea grass and other important submerged aquatic vegetation. The determination of sensitive species, sensitive response parameters, and modifying environmental factors are the objectives of these studies. The experimental designs include exposing different species in laboratory tests to different levels and types of suspended solids alone and in combination with other factors (such as salinity and nutrients) to determine effects on light reduction and accompanying effects on biomass, pigment content, and other 
structural characteristics. Following these tests and the derivation of the necessary information, mesocosms would be used in the laboratory and field (enclosures) to determine effects on populations and communities of seagrasses. The results of the single species, population, and community exposures will need field validation, which box $1 \mathrm{~b}$ addresses in part. Following these experiments, mesocosms could be used to determine effects on populations, and communities of seagrasses and associated biota, particularly relating the role of seagrass beds as habitat to fish and shellfish populations and communities.

The technical information on stressor/response relationships can be used to generate thresholds for sediment effects (box 4). These thresholds can be used in the development of criteria (box 4) for suspended and bedded sediments. These thresholds can serve as input to both the development of criteria (box 5) and the TMDL process (box 6). These criteria will be "integrated" criteria, similar to those discussed in the Toxic Chemical Section (Section 7). They will consider the effects of suspended and bedded sediments in a more holistic manner than the standard criteria do, taking into account effects on both benthic and water column organisms, and direct as well as indirect effects on aquatic life use. These criteria also will have to take magnitude, duration, and frequency of changes in suspended and bedded sediments into account.

The availability of sediment criteria and thresholds for sediment effects will allow for a TMDL process that is "effects based". The current TMDL methodologies focus much more on exposure and reduction of exposure, than on effects. Acceptable levels of suspended and bedded sediment can not presently be based on effects, because the models and stressor-response relationships to be derived in boxes 1 and 2 are not currently available. All that the NHEERL effort can provide, at this time, is information on effects on certain organisms and classes of organisms. Resource managers will have to use that information to make management decisions. At the same time, we will have to make sure that the data are provided in such a way that is useful in the context of designated uses. The data will have to be presented in as general a form as possible, as opposed to just presenting a list of data on individual species for specific magnitudes and durations of elevated suspended and bedded sediment concentrations. Priority will be given to those species which are tied to designated uses.

Once TMDLs are produced, their effectiveness will be assessed (box 7) and this will allow further refinement of the models developed in boxes 0,1 , and 2 .

The final piece of the TMDL process is the exposure component. Loading estimates and models are currently being developed by NERL, OW, and NHEERL (under Goal 8) (box 8). These loading estimates and models will allow estimation of the changes in suspended and bedded sediments inputs which might be needed to reach the targets set on the basis of the effects of suspended and bedded sediments effects (boxes 4 and 5). These loading estimates and models also provide input to the conceptual model, setting the bounds of bedded sediment and suspended solids inputs to aquatic systems. 


\section{Research Projects}

\section{Project Title 1. State of Science Review}

Project Coordination and Resources (0.4 FTEs: AED-0.3, MED-0.1)

\section{Objectives}

To efficiently plan and manage NHEERL research efforts, a necessary first step is to assess the current knowledge. The objective of this effort is to fulfill the first Goal under this research implementation plan, which is to report on the state of the science and progress in developing suspended and bedded sediment criteria.

\section{Scientific Approach}

NHEERL personnel will summarize and synthesize current knowledge on quantitative stressorresponse relationships among sedimentation, biota, and habitat, and the efforts to date in developing sediment criteria. The overall review will be conducted in concert with other ORD Laboratories, as well as OW, USGS, and the Army Corps of Engineers. Subject areas to be reviewed will include:

1. A review of relationships between potential classification variables and suspended and bedded sediments. Classification variables will include ecoregional factors (e.g., vegetation, climate, geology, and soils); landscape characteristics such as forest fragmentation, water storage and hydrogeomorphology; and ecosystem type (streams, rivers, reservoirs, coastal wetlands, estuaries and near-shore zones).

2. A review of the known ecological effects of suspended and bedded sediments. Effects categories include effects on different biotic assemblages such as microbes, primary producers, invertebrates, and fish; issues of scale (e.g., effects at population, community, and ecosystem levels of biological organization); and effects on habitat quality and quantity. Direct effects on biota will be contrasted with effects on physical habitat which may result in indirect effects on biota. Mechanistic, experimental approaches toward detecting and analyzing effects will be compared to large-scale empirical, correlational analyses.

3. The effects of elevated suspended solids (turbidity) and excessive bedded sediments (i.e., increased sedimentation). It is expected that the ecological effects of suspended solids differ from those of sedimented solids. The review will encompass both stressor types. Potential impacts due to lack of enough suspended and bedded sediment, which can contribute to habitat loss, also will be investigated.

4. Routes and mechanisms of the delivery of sediments to aquatic ecosystems. A critical step toward effects prediction and ecosystem protection is to understand the relationships among characteristics and processes at the landscape scale and the quantity and quality of sediment delivered to aquatic systems, whether that be terrestrial runoff with increased sediment loads or hydrologic modifications that result in increases in-inchannel erosion. 
5. Approaches toward modeling the effects of suspended solids and sediments on aquatic ecosystems.

6. Progress to date in developing state, National, and intemational suspended and bedded sediment criteria.

Products

APG 1 FY02 Synthesize state of the science and remaining uncertainties for developing criteria for suspended and bedded sediments.

APM 1A FY02 Report on the state of the science and progress for developing suspended and bedded sediment criteria (AED, MED).

Benefits of Products

An up-to-date summary of the state of the science review of suspended and bedded sediments information will be provided with recommendations of needed research to develop and validate suspended and bedded sediment criteria for $\mathrm{OW}$.

\section{Proposed Research Projects}

Based on results from EMAP research and the literature review, the following general projects are proposed assuming resources are available:

\section{Stressor-Response Relationships}

Associations between biotic assemblages and/or key aquatic species or guilds and deviations of sediment from expected values should be examined. In most cases, our data sets will include sites affected by multiple stressors besides sediment that could potentially act upon these aquatic biota. After demonstration of a plausible causal mechanism (from detailed experimental studies) and elimination of other plausible explanations for these observations, we will use these kinds of associational data in a weight-of-evidence approach to support modeling the effects of suspended and bedded sediments on aquatic biota.

\section{Thresholds for Sediment Effects}

The technical information on stressor/response relationships can be used to generate thresholds for sediment effects. These thresholds can be used in the development of criteria for suspended and bedded sediments, and thresholds can serve as input to both the development of criteria and to the TMDL process. They will consider the effects of suspended and bedded sediments in a more holistic manner than the standard criteria do, taking into account effects on both benthic and water column organisms, and direct as well as indirect effects on aquatic life use. 


\section{Classification}

The purpose of the classification research is to develop an effective scheme for defining those waters for which similar ambient levels of suspended or bedded sediments are expected. We anticipated the final solution will incorporate information about water body type, geographic setting, and specific, local hydrologic settings. This proposed classification scheme that results should be review with or compared to the classification in use (at that time) for establishing reference conditions for biological criteria.

\section{Gap Analysis}

Research into the problems associated with suspended and bedded sediments also is being carried out by other groups. The Army Corps of Engineers is working on the effects of resuspension associated with dredging projects, for example (Wilber and Clarke 2001). Goal 8 research (Kaufmann et al. 1999, Kaufmann and Robison 1998, EPA 2000), research supported by the Office of Wetlands, Oceans, and Watersheds (OWOW) (TMDL framework for clean sediments), and NERL are currently contributing to the development of loading estimates and models (Figure 7, box 8). However, the work has barely begun on the effects of sediments to aquatic systems, at the low levels that may exert long-term, chronic effects. The first step outlined in the critical path is the review of the state of science. The intent of this gap section is to describe what work would remain to reach the goals once NHEERL completed the work outlined. The dilemma is that NHEERL will not be in a position to outline the details of what we will do until we complete the state of science review. At that point and in concert with Division management decisions on FTE dedicated to this project, the gaps that will remain can be identified.

\section{References}

Berkman, H.E., Rabeni, C. F. 1987. Effect of siltation on stream fish communities. Environ. Biol. Fish. 18:285-294.

Chow-Fraser, P. 1998. A conceptual ecological model to aid restoration of Cootes Paradise Marsh, a degraded coastal wetland of Lake Ontario, Canada. Wetland Ecol. Manag. 6:43-57.

Dietrich, W.E., Kirchner, J.W., Ikeda, H., Iseya, F. 1989. Sediment supply and the development of the coarse surface layer in gravel bed rivers. Nature 340:215-217.

EPA. 2000. Mid-Atlantic highlands streams assessment. EPA/903/R-00/015. U.S. Environmental Protection Agency. Region 3. Philadelphia, PA. 364 pp.

Hawkins, C.P., Murphy, M.L., Anderson, N.J. 1983. Density of fish and salamanders in relation to riparian canopy and physical habitat in streams of the northwestern United States. Can. J. Fish. Aquat. Sci. 40:1173-1186.

Kaufmann, P.R., Robison, E.G. 1998. Physical habitat assessment. In Klemm, D.J., Lazorchak, J.M., eds., Environmental Monitoring and Assessment Program 1994 Pilot Field Operations 
Manual for Streams. EPA/620/R-94/004. EPA, Environ. Monit. Syst. Lab., Office of Research and Development, Cincinnati, OH, pp. 6-1 to 6-38.

Kaufmann, P.R., Levine, P., Robison, E.G., Seeliger, C., Peck, D. 1999. Quantifying physical habitat in wadeable streams. EPA 620/R-99/003. EPA, Environmental Monitoring and Assessment Program, Corvallis, OR.

Leopold, L.B., Wolman, M.G., Miller, J.P. 1964. Fluvial Processes in Geomorphology. W.H. Freeman and Company, San Francisco, CA, 522 pp.

Lisle, T.E. 1982. Effects of aggradation and degradation on riffle-pool morphology in natural gravel channels, northwestern California. Water. Resour. Res. 18:1643-1651.

Mackin, J.H. 1948. Concept of the graded river. Geol. Soc. Am. Bull. 59:463-512.

Morisawa, M. 1968. Streams, Their Dynamics and Morphology. McGraw-Hill, New York. 175 pp.

Muncy, R.J., Atchison, G.J., Bulkley, R.V., Menzel, B.W., Perry, L.G., Summerfelt, R.C. 1979. Effects of suspended solids and sediment on reproduction and early life of warm water fishes: a review. EPA 600/3-79-042. EPA, Washington, DC.

Platts, W.S., Megahan, W.F., Minshall, G.W. 1983. Methods for evaluating stream, riparian and biotic conditions. Gen. Tech. Rep. INT-138, U.S. Forest Service, Intermountain Forest and Range Experiment Station, Ogden, UT. 70 pp.

Rinne, J. 1988. Effects of livestock grazing exclosure on aquatic macroinvertebrates in a montane stream, New Mexico. Great Basin Nat. 48:146-153.

Simons, D.B., Senturk, F. 1977. Sediment transport technology. Water Resources Publications, Fort Collins, CO. $807 \mathrm{pp}$.

Terrell, J.W., Cade, B.S., Carpenter, J., Thompson, J.M.. 1996. Modeling stream fish habitat limitations from wedge-shaped patterns of variation in standing stock. Trans. Am. Fish. Soc. 125:104-117.

Waters, T.F. 1995. Sediment in streams: sources, biological effects, and controls. American Fisheries Society, Bethesda, MD.

Wilber, D.H., D.G. Clarke. 2001. Biological effects of suspended sediments: a review of the suspended sediment impacts on fish and shellfish with relation to dredging activities in estuaries. N. Am. J. Fish. Manage. 21:855-875.

Wilcock, P.R. 1988. Two-fraction model of initial sediment motion in gravel-bed rivers. Science 280:410-412. 


\section{Section 7. \\ Implementation Plan for Toxic Chemicals Research}

\section{Problem}

Effective management of toxic chemicals in aquatic ecosystems requires a capability to quantitatively predict the ecological effects that can be expected from different levels of chemical contamination of water, sediments, and food chains. Procedures for deriving aquatic life WQC have existed for many years (EPA 1973, 1980, 1991, 1994, 1995a; Stephan et al. 1985) and have been useful for managing toxic chemical inputs to aquatic systems. However, these procedures are based on simplifying assumptions and a relatively narrow framework that limit their use in fully assessing the risk of a wide range of toxic chemicals to both aquatic life and aquaticdependent wildlife. Sediment guidelines developed more recently (EPA 2000a,b,c,d) have many of the same limitations as WQC. To address some of these concerns, NHEERL has prepared a draft wildlife research strategy for assessing risks of multiple stressors to populations of amphibians, birds, and mammals (EPA 2000e).

Criteria derivation and application require extrapolations of toxicological effects observed in the laboratory to field conditions, which can result in significant uncertainties. Differences in water characteristics, chemical partitioning, routes of exposure, organism habits, and exposure timeseries can greatly affect the relationship between exposure concentrations and a chemical's toxicity, and thus affect the applicability of criteria to natural ecosystems. This is particularly true for PBTs, for which effects often depend on tissue residues accumulated in tissues over long times as a result of multiple exposure routes. Moreover, criteria often do not address the combined effects of multiple chemicals and other stressors, and can lack information for potentially sensitive life stages of test species.

Other uncertainties in criteria arise from the use of organismal-level toxicity to set concentrations protective of aquatic populations and communities. The relationship of toxic effects on individual organisms to population responses is not well established. Important taxa and endpoints can be missing from the sets of tests used to develop criteria and sediment guidelines. Indirect effects of chemicals on organisms (effect on food sources, competition, predation, and shelter) generally are not considered.

Criteria are also limited in that they address only specific water concentrations, rather than complete dose-response relationships, thus limiting how well risks can be characterized. Seasonal issues and the significance of the spatial extent of exposures are incompletely addressed. Current criteria procedures also do not include uncertainty analyses or address how well risk can be assessed in the presence of limited data.

Because of these limitations, efforts are needed to develop methods to better characterize risks to aquatic life and aquatic-dependent wildlife populations and communities, and to apply these risks to criteria development. Assessment endpoints should be better defined and an analytical framework developed for linking available data to a more complete and accurate description of risks for these endpoints. This assessment framework should describe a range of responses, be 
tiered to allow some decisions to be made with limited data, and should include analysis of the uncertainties in estimated risks.

\section{Goals}

The general goal of this work is to develop scientifically-defensible methods for better describing the risks of toxic chemicals to aquatic and aquatic-dependent populations and communities, in support of improving criteria procedures needed to satisfy GPRA Goal 2, Objective 2. The work to be discussed here represents only part of the ecological toxicology efforts within NHEERL and is focused on prospective assessments of chemicals for which WQC exist or are desired. As such, the proposed research will not address issues which are not closely related to such assessments and/or are a subject of research under other goals. This includes such areas as chemicals and endpoints of emerging or potential concern, biological indicators (including DNA or protein-based probes) for retrospective assessments and diagnostics, and basic investigations of the cellular/subcellular and physiological mechanisms of toxicological responses.

Further details on research needs and NHEERL research efforts to address those needs are described in the following subsections. Specific goals of these efforts are summarized in the following APGs and APMs Note: some APGs and APMs (including those under GPRA) were established before this document was written. They are listed here along with APGs and APMs that were developed under the aquatic stressors process.

APG 1 FY02 (GPRA \# 31) Provide a method for setting risk-based aquatic life criteria for toxic chemicals which minimizes uncertainties of translating national and site-specific water quality criteria.
APM 1A FY02 (GRPA \# 167) Report on integrated water and sediment quality criteria methods for assessing site-specific risks of persistent bioaccumulative toxicants to aquatic species (MED).

APG 2 FY03 Demonstrate methods to set risk-based water quality criteria for toxic substances.

APM 2A FY03 Describe a framework for WQC for nonbioaccumulative chemicals that more fully describes risk to aquatic organisms (MED).

APG 3 FY05 (GPRA \# 111) Provide methods for developing WQC based on characterization of population-level risks of toxic chemicals to aquatic life and aquatic-dependent wildlife.

APM 3A FY04 (GPRA \# 59) Population models that project the relative risks of multiple stressors (toxic chemicals, habitat alterations) to piscivorous birds (AED, MED).

APG 4 FY06 Provide methods for extrapolating chemical toxicity data across exposure conditions and across endpoints, life stages, and species, which can support assessment of risks to aquatic life and aquatic-dependent wildlife for chemicals with limited data. 
APM 4A FY02 Interspecies correlation estimations (ICEs) for acute toxicity to aquatic organisms (GED).

APM 4B FY02 Time-concentration-effect models for use in predicting chronic toxicity from acute toxicity data (GED).

APM 4C FY03 Acute-to-chronic estimation (ACE) user guide and software (GED).

APM 4D FY06 Report evaluating importance of dietary route of exposures to aquatic risk assessments for metals (MED).

APG 5 FY08 Provide approaches for evaluating the relative and cumulative risks from toxic chemicals, with respect to risks from nonchemical stressors, on populations of aquatic life and aquatic-dependent wildlife at various spatial scales.

APM 5A FY05 Report regarding assessment of risks to aquatic organisms from combined exposure to polycyclic aromatic hydrocarbon (PAHs) mixtures and ultraviolet (UV) radiation in natural systems (MED).

APM 5B FY06 Approaches for addressing spatial scale issues in assessing risks of multiple stressors to wildlife populations in spatially-diverse landscapes (AED, MED).

\section{Critical Path}

Defining critical research paths needed to improve aquatic risk assessments and criteria development for toxic chemicals should start with consideration of the problem formulation that should be part of any good risk assessment (Figure 8). There needs to be clear definition of the assessment problem, including the ecological effects (assessment endpoints) and exposure scenarios of concern, and better conceptual models which define the logical structure of the assessments. These conceptual models should identify critical toxicological endpoints to be used in the assessment (i.e., measurement endpoints) and how these are to be related to the assessment endpoints, based on knowledge of the dynamics of the ecosystem(s) of concem. There also should be specification of how assessments might be tiered initially, basing evaluations on limited data to determine whether risks might be significant, and adding data as needed to make more definitive assessments.

With better definition of the conceptual model, the needs of the other phases of a risk assessment can be better identified. Methods are needed so that the exposure profiles (Figure 8) can describe, in sufficient detail, the distribution of the toxicant(s) relative to the biological receptors. This would include evaluation of the temporal and spatial variability of exposure and the chemical's speciation and partitioning to the extent needed to determine the distribution of toxicological responses. Response profiles (Figure 8) need to provide good organism-level response models and linkages between organism response and population/community responses. When limited toxicological data are available, methods for extrapolating among species and endpoints also will be needed. Methods must support risk characterizations which describe a 


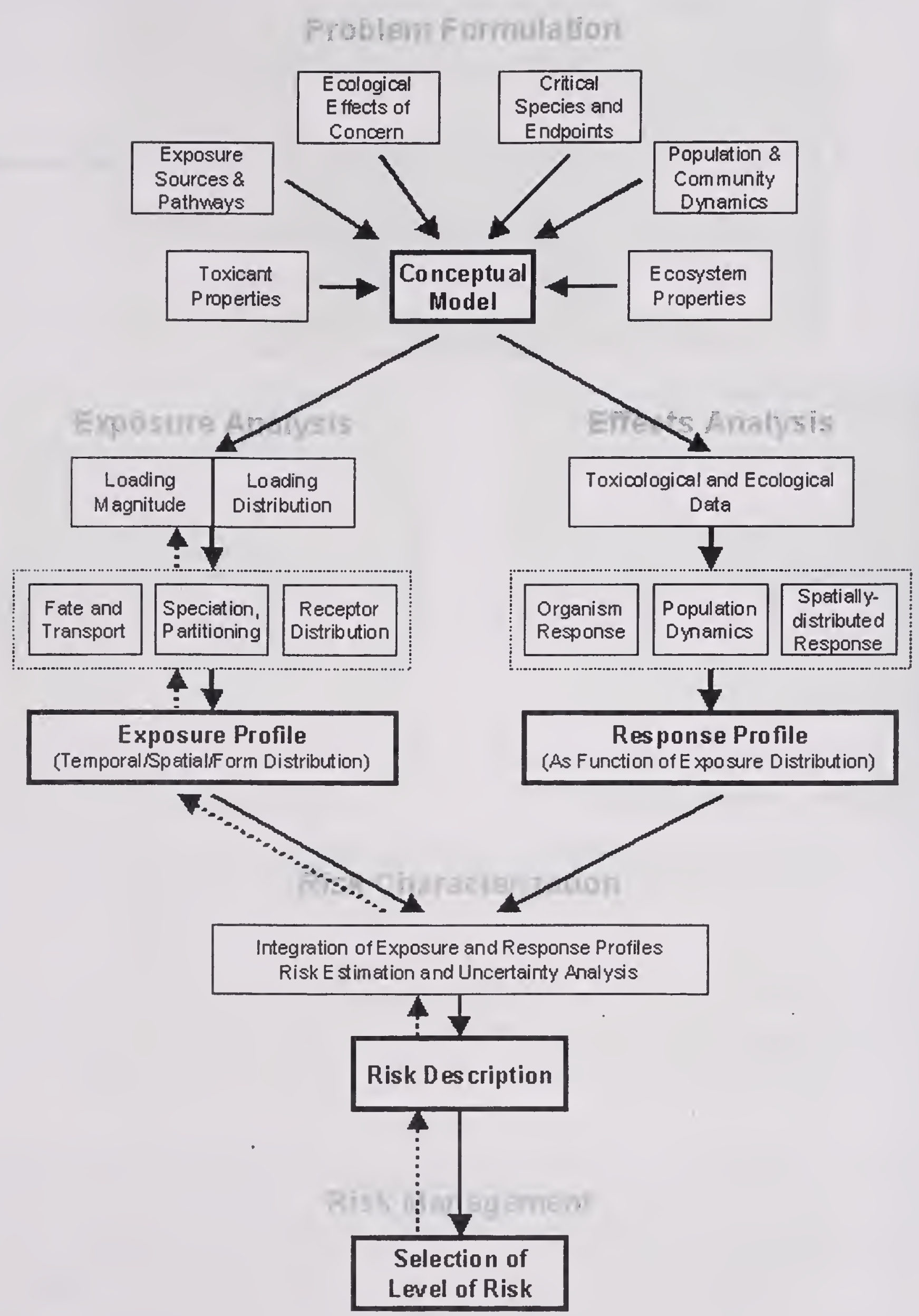

Figure 8. Ecological risk assessment framework (modified from EPA 1992). 
range of effects, including their uncertainties, and sufficiently account for important site characteristics. The resultant risk descriptions should allow risk managers to assess the implications of different exposure scenarios and, once acceptable risks are specified, to backcalculate acceptable loadings (dotted line on Figure 8).

Critical research paths also should recognize the need to implement progressive improvements in the assessment methodology. Figure 9 shows four steps in such improvement, which largely parallel the APGs described in the preceding Goals subsection. The first step will demonstrate how criteria can reflect more comprehensive risk characterizations, based on more complete descriptions of organism-level dose-response relationships and how they vary with exposure conditions. The second step will involve the development and application of methods to address population-level risks. The third step will involve the development of extrapolation methods so that the risks can be assessed for chemicals or situations for which limited data is available. The fourth step will include further enhancement of these techniques and emphasize their incorporation into multistressor assessments at various spatial scales.

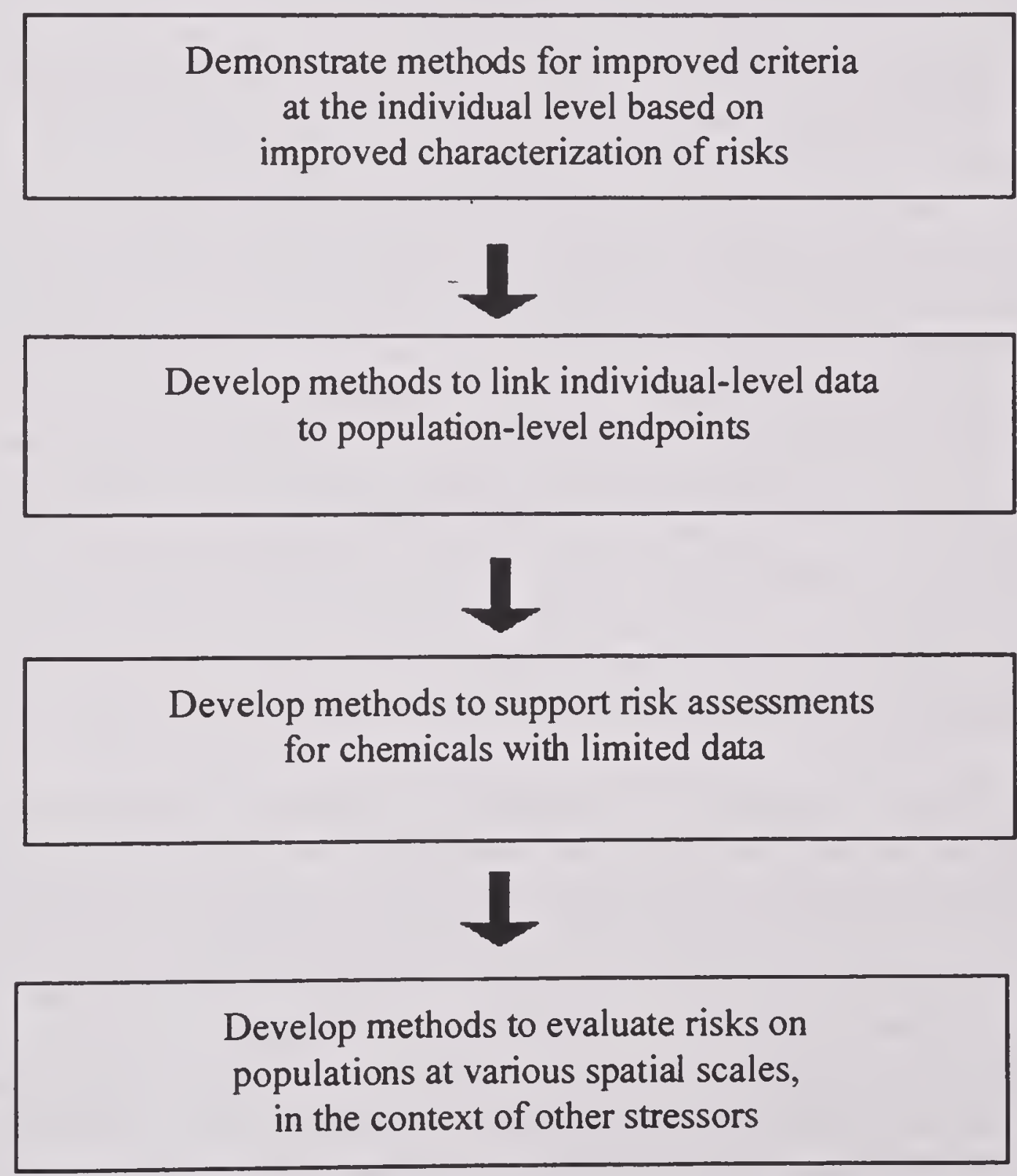

Figure 9. Critical path for developing site-specific methodologies for establishing the risks of toxic chemicals to aquatic life and aquatic dependent wildlife. 
The rest of this section will further discuss the improvements needed in aquatic risk assessment methods and identify the research and development efforts needed to realize these improvements. This will be done in the context of conceptual models which identify the essential components of assessments and emphasize the link of this research to the risk assessment framework. The nature of the assessments and the needed research can vary depending on the chemical and system of concern. One issue of particular importance is the degree to which chemicals bioaccumulate. Risk assessments for highly bioaccumulative toxicants will differ in some key features from assessment for chemicals which have low bioaccumulation. For bioaccumulative toxicants, dietary exposure will be especially important, residue-based dose-response models will be more important, and bioaccumulation models will be needed for dose determinations. Toxicokinetics for these chemicals are generally slow, so acute toxicity and short-term temporal variation in exposures will often, but not always, be of less importance than for nonbioaccumulative toxicants. Biomagnification makes risk relatively more important for organisms high in the food chain, and some risk assessments of bioaccumulative chemicals could concentrate on populations of such organisms, rather than on the broad aquatic community. Because of these differences, the assessment needs will be discussed separately below for nonbioaccumulative and bioaccumulative toxicants.

It is true that assessments of these two groups of chemicals will share many common features and principles, and thus these separate discussions will involve some redundancies. For example, toxic response for almost all chemicals and endpoints is ultimately related to the amount of chemical which accumulates at an internal site of action, so a residue-based framework is of value to nonbioaccumulative chemicals as well as bioaccumulative chemicals. Also, the consequences to populations and communities of toxic effects on individual organisms will entail the use of similar tools for both groups of chemicals. Furthermore, whether a chemical is "bioaccumulative" is a matter of degree, not a discrete category. Nonetheless, the relative importance of various issues will vary between assessments of chemicals with low versus high bioaccumulation. Separate discussions are useful in highlighting how assessments will vary, and in identifying needed work. However, the results of the work proposed below will often transcend the chemical group and efforts will be made to apply any results as broadly as is appropriate.

\section{Nonbioaccumulative Toxicants}

Nonbioaccumulative toxicants include a wide range of organic and inorganic chemicals that are of concern in many aquatic risk assessments. Notable examples include heavy cationic metals (such as copper, zinc, lead, cadmium, and silver), which are significant contaminants in mining areas and various effluents; and ammonia, which is at high concentrations in sewage effluents, in some fertilizer runoff, and in areas with high inputs of nitrogen-containing organic compounds. These chemicals have been documented to have substantial impacts on certain aquatic systems and are responsible for many instances of noncompliance with WQC. Treatment and remediation costs associated with meeting criteria for these chemicals can be high. However, as discussed above, current assessment and criteria methodology entail various uncertainties regarding the actual risks of these chemicals and thus whether the regulatory controls are necessary and sufficient. 
Cationic metals and ammonia will be used as examples, where helpful, in the discussion here and as candidates for chemical-specific research discussed later. They represent major concems in current aquatic risk assessments and have a rich toxicity literature that will support development of dose-response models, and evaluation of the quality of assessments made with limited data. However, while the discussion here will in part highlight these chemicals, the issues discussed are true for many nonbioaccumulative toxicants. General methods developed for any particular chemical should be directly, or by example, applicable to other nonbioaccumulative toxicants. Conceptual Model

As discussed above, research needs for development of risk assessment methods need to relate to the conceptual model for the assessment(s). Figure 10 presents a simple conceptual model that identifies important elements that need to be considered in conducting and developing methods for aquatic risk assessments and criteria development. The horizontal series of boxes on the bottom of the figure represent major stages in linking chemical stressors to ecological responses. Loadings of toxic chemicals to an aquatic system are distributed throughout the system, resulting in exposures to biological receptors. These exposures may adversely affect the survival, growth, and reproduction of individual organisms. Such individual-level effects may be expressed at the population level as changes in population size, growth rate, and structure. Changes at the population level may in turn elicit changes in the community. The "stacked-boxes" used to represent these stages are intended to indicate that assessments often will involve multiple chemicals and/or biological species.

The arrows linking the lower series of boxes represent mechanistic relations among these stages, and involve the application of various models identified by the series of ovals in the center of the figure. The arrows are bi-directional to indicate the fundamental similarities between two modes of environmental protection: 1) criteria development and application that determine chemical loadings consistent with protecting desired system values (left-to-right) and 2) assessments that characterize risks expected from chemical exposures (right-to-left).

The boxes on the top of Figure 10 identify data needs for the models used in the assessment. All of the models will generally require various information on various physical, chemical, and biological characteristics of the system. The exposure and toxicity models also will require information on the nature of the chemical and its toxicity to various biological receptors.

This conceptual model helps to identify and evaluate research needed to improve aquatic risk assessments and criteria development. Primary attention should be given to the four basic models in Figure 10. How are current assessments limited by the inability of exposure models to completely and accurately predict and describe the relationship between chemical loadings and exposure concentrations? How well do current methods actually describe risks to individuallevel endpoints under exposure conditions expected in natural systems? What is the significance of organismal-level effects to populations and communities? Another research focus would be the adequacy of data needed for these models. Can required chemical properties be estimated well? Does available toxicity data address the endpoints needed in the assessment? 


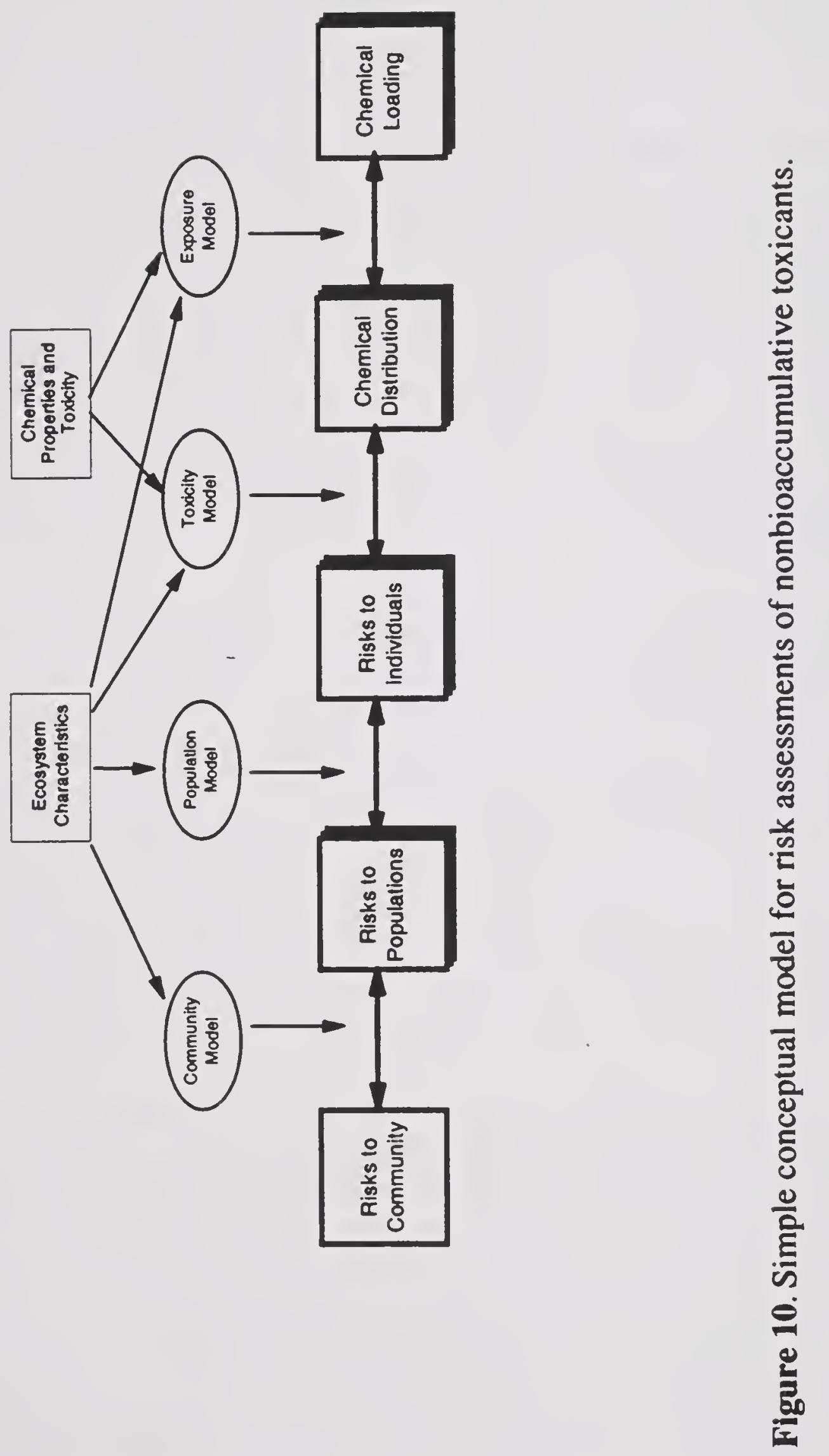


How well can toxicity data be extrapolated among species and endpoints? Finally, research efforts should address the need to describe and test a complete methodology for conducting assessments and developing criteria.

\section{Research Needs}

Per the conceptual model presented in Figure 10, fundamental tools of assessments are the models linking the state variables. Brief descriptions of each model and its research needs are as follows:

\section{Exposure Model}

The exposure model should produce a description of the spatial/temporal distribution and the speciation of the chemical that satisfies the input needs of the effects models. It must also describe other physical and chemical properties that can affect toxicological response. Because NHEERL research primarily addresses effects assessment, only a brief overview of exposure research needs will be given here. These do, however, represent significant knowledge gaps that need to be addressed if improved risk-based criteria are to be implemented.

The exposure model must assess physical transport, degradation, speciation, and partitioning of the chemical. Current implementations of WQC and WQS often use simple models that will not support more comprehensive characterizations of risks. For physical transport, the primary need is to adapt and apply better methods and models that are available. In particular, better risk characterizations need dynamic, two- and three-dimensional models, which can more fully describe the spectrum of exposures experienced by biological receptors.

Degradation is not an issue for elemental toxicants such as metals, but is of utmost important for ammonia. Decomposition of nitrogen-containing organic matter produces ammonia, while nitrification in oxygenated water reduces ammonia concentrations. Nitrification is reduced at colder temperatures, resulting in higher and more widespread ammonia concentrations during winter months. More comprehensive characterization of risk will require more complete modeling of the spatial and seasonal distribution of ammonia. Of particular concern is the ammonia concentrations in or near the sediment that results from the interaction of organic matter decomposition, nitrification, and mixing processes.

Speciation is well characterized for ammonia, but current models for metal speciation have considerable uncertainty, especially regarding complexation by organic matter. There is a need both to improve current predictive models and also to develop analytical techniques that can reliably and efficiently measure metal speciation in laboratory tests and natural systems. Whether by model or measurement, these methods must describe speciation sufficiently for the interpretation and application of the effects of various chemical parameters on metals toxicity.

Partitioning between sediment and overlying water is of utmost importance to assessing the risk of both ammonia and metals. Exposure analyses for the application of WQC need to incorporate the role of sediment as a source or sink of chemical, processes that entail considerable uncertainty. Currently there are no published EPA guidelines for ammonia in sediment, but 
Equilibrium-partitioning Sediment Guidelines (ESGs) for metals (EPA 2000a) use acid volatile sulfide (AVS) and interstitial water to predict biological effects. These methods have been demonstrated to be very useful in predicting biological effects in laboratory experiments and in a limited number of field experiments, but few of them have examined the importance of temporal and spatial variability in exposures within and near sediments, which limits the usefulness of these equilibrium approaches. Research is needed to characterize how AVS and metals concentrations at the sediment/water interface vary seasonally and due to hydrological events to support better characterization of effects.

\section{Toxicity Model.}

The toxicity model in a risk assessment must integrate exposure information, toxicological data, interspecies extrapolations, dose-response models, and effects of exposure conditions into characterizations of risks for various organism-level endpoints, species, and life stages. Depending on the requirements of the assessment, including the tier level, various research and development needs exist.

A significant shortcoming in current criteria and many assessments for nonbioaccumulative toxicants is consideration of toxicity information for only a single level of effect at a set exposure duration (e.g., 96-hr LC50). Critical to better risk characterization are models that more comprehensively describe toxic response, including both the magnitude of response and the effect of exposure time series. Some capabilities for this have long existed. Models that describe the relationship of effects to concentration or time are standard tools in toxicity, but traditionally have not combined the effects of both. Furthermore, these models generally assume that concentrations are constant. Mancini (1983) described a model that would describe the effects of fluctuating concentrations based on standard toxicity tests, but did not incorporate variable levels of effects into the model. Subsequent work has tested the utility of this approach with mixed results and broadened the model to describe variable levels of effects as a function of both concentration and time. Although this model does involve significant uncertainties, it is well suited to form the core element in risk assessments and criteria development. It can use toxicity information from standard tests and describe the level of effects, with uncertainties, expected from any exposure series. This model can thus be combined with expected spatial and temporal exposure distributions to produce individual-level risk curves for populations of biological receptors. This would provide the individual-level risk characterization in Figure 10 needed for any further risk characterization at the population or community level. Other modeling approaches, such as proportional hazard and accelerated failure models, also might provide a basis for better describing toxicological risks and their dependence on exposure time-series. Based on current information, the critical immediate need is to further develop these techniques, establish their validity and uncertainty, and describe their application to WQC, which would be a major part of the first step in Figure 9. This would establish a core framework for improving criteria, but also would identify knowledge gaps that should be addressed by further research.

Chemical toxicity to aquatic organisms can be influenced markedly by various physicochemical exposure factors. For example, ammonia toxicity can vary by orders of magnitude due to the combined effects of $\mathrm{pH}$ and temperature and by significant amounts due to $\mathrm{DO}$ and certain major ions. EPA aquatic life criteria for ammonia (EPA 1999) are a function of $\mathrm{pH}$ and temperature, 
but do not fully account for these effects and do not account at all for other factors. An especially important uncertainty (which is also relevant to other chemicals) is the effect of winter conditions on chronic ammonia toxicity to life-stages of sensitive organisms present during the winter. Aquatic life WQC for metals currently are expressed as dissolved metals, with a correction for hardness in fresh water, reflecting empirical observations of reduced toxicity due to adsorption by suspended solids and increased hardness. Research has shown, however, that several factors other than hardness also are important in determining the toxicity of metals in water, and has identified mechanistic bases for their effects. Development of a model that incorporates many of these factors, referred to as the biotic ligand model (BLM) is currently being supported in part by OW. Applications of current versions of this model to criteria entail substantial uncertainties, especially for chronic toxicity and for certain taxonomic groups. Significant research in support of this model is underway under the support of $\mathrm{OW}$ and various industry groups. Such efforts will contribute to the third step in Figure 9.

As discussed above regarding exposure research issues, organisms dwelling in or on sediments can receive chemical exposures with large temporal and spatial variation, due to hydrologic events disturbing the sediments or seasonal changes affecting partitioning or processing of chemicals. Decomposition of nitrogen-bearing organic matter in the sediment can cause substantial gradients between sediment and overlying water. For metals, sediment can be relatively more contaminated than overlying water due to past inputs, diagenesis of deposited particles, or seasonal fluctuations in loads to systems, leading also to substantial gradients from sediment to overlying water that are subject to marked variation. Sediment pore water metal concentrations in anoxic layers are greatly affected by AVS, which varies with season and depth and can be oxidized when sediment is resuspended. Even in laboratory tests, sediments and overlying water are likely at some disequilibrium that varies with time and between tests. Regulations based on assumptions of equilibrium therefore can involve considerable uncertainty. The toxicological implications of non-equilibrium conditions (such as resuspension and seasonality) need to be investigated as part of the extrapolation methods represented in the third step in Figure 9.

Laboratory tests used for aquatic risk assessments of nonbioaccumulative toxicants typically include exposures only via chemical dissolved in water, the organisms either not being fed or fed food that is not contaminated commensurate with the water concentrations. This is not an issue with ammonia, as ammonia per se would not be a significant contaminant in food, although catabolism of food is a source of ammonia that organisms must eliminate. However, the significance of the dietary route of exposure is an important issue for metals assessments. Aquatic animals certainly can accumulate substantial amounts of metals from their diets, and diets contaminated with high concentrations of metals can cause adverse effects. However, the importance of this route of exposure when there is also commensurate amounts of metal dissolved in the water is uncertain. Some studies have presented evidence that dietary uptake results in increased uptake and/or risk compared to water exposure alone, while other studies have suggested the opposite. The uncertainty regarding the significance of dietary uptake to metal risk is a fundamental barrier to good risk assessments for these chemicals and could have substantial implications to regulatory programs. 
A common uncertainty in any aquatic risk assessment is the sensitivity of species and endpoints not directly tested. In some cases, there is considerable toxicity data, but certain important data are missing, for example, having acute mortality data, but not chronic reproduction data, for a critical or sensitive species. Additionally, there are many cases where desired assessments have available only a limited number of laboratory toxicity data, if any. Therefore, there is a need for models that address extrapolations across endpoints and/or species, and the uncertainties of these extrapolations. This relates to the toxicity data needs box in Figure 10 and is a major part of the third step in Figure 9. A research effort is needed to improve and test extrapolation methods, and to apply these methods to simulated risk assessments with limited data, providing better methodology for conducting interspecies extrapolations for nonbioaccumulative toxicants in general.

A final area of major concern is the joint effects of multiple chemical stressors and the effects of chemicals in the presence of non-chemical stressors. Much laboratory-based research has been done on these issues, but has seen little application to EPA criteria, except recently for sediment toxicity assessments. A principal need is to determine how this past work should be incorporated into assessments, and to better identify what additional work will be worthwhile.

\section{Population Model}

Toxicity tests can provide information on a diverse set of endpoints, but comparing the relative risk of these endpoints and their significance at the population and community level is difficult. An important step in better defining the significance of these toxicological effects is to incorporate them into population model that will translate these effects into some common "currency" of population dynamics. A critical research need therefore is to develop, test, and apply population models for a variety of species relevant to assessments of nonbioaccumulative toxicants. This is represented in the second step in Figure 9. These models will be used not only to describe the significance of observed and predicted organism-level toxicity, but also to evaluate the usefulness of toxicity tests and to determine needed changes in the types of tests conducted.

Stage-structured population models can be used to link individual-level effects to the population level, such that a set of vital rates defines the dynamics of a population. Such models require estimates of vitai rates for all life stages, which may or may not show effects from a given level of toxic chemical exposure. A set of vital rates also can define the life history strategy of a species. Life history strategies vary along a continuum from species with early reproduction, high fecundity, and short life expectancy (r-selection model) to species with delayed reproduction, low fecundity, and long life expectancy (K-selection model). Population-level responses may differ between species because of differences in life history strategies, even though individuals of different species may show a similar response to a toxic contaminant. Variation in life history strategies, and therefore variation in population-level responses to toxic contaminants, also may occur geographically in the same species.

Population models should be constructed for fish, shellfish, and wildlife species exhibiting different life history strategies (i.e., species exhibiting different sets of vital rates). Population models generic to groups of species whose life history strategies are similar also can be 
developed for use at the screening level or tier of risk assessments, to be followed by models specific to individual species in higher-tiered assessments.

An important issue regarding population models is the type of individual-level effects they need as inputs to provide useful assessments of population-level effects. The toxicity tests and data typically available are often limited with regard to the endpoints and life-stages tested, often leaving significant gaps in the information needed to assess impacts of toxicity on population dynamics. Population model development needs to identify the critical inputs and be coordinated with toxicity model research to provide the methodology to make this information available. In particular, efforts to improve extrapolation of toxicity data should take such needs into consideration.

\section{Community Model}

Unless assessments are simply intended to provide protection to the most sensitive taxonomic groups, some synthesis is needed to relate expected effects on populations or individuals to consequences to the aquatic community. As mentioned above, current WQC are premised on the judgment that occasional low level toxicity to sensitive species constitutes acceptably low risk to those species and to the aquatic communities to which they belong. This might be a sound judgment, but the lack of quantification makes it impossible to conclude whether higher exposures might also pose minimal risk, or what acceptably low risk means.

There is thus a need to better quantify the association between toxic effects and effects on aquatic communities. This could entail a few lines of efforts. Better meta-analysis is needed of the variety of community assessments in experimental or natural ecosystems, linking these to a metric that better describes available toxicity data. More efforts are needed to study responses to toxic chemicals in complex aquatic ecosystems. Aquatic community models could be developed that integrate effects at the individual or populations-level. As part of these efforts, there is also a need to identify individual-and population-level endpoints important for supporting better community-level assessments, and to coordinate with toxicological research to provide this necessary information.

\section{Bioaccumulative Toxicants}

Toxicity risks associated with PBTs are expected to be advantageously assessed with residuebased dose response models. This important concept may be used to describe the minimum degree to which chemicals must be persistent and bioaccumulative in order to fall into this class. The degree of persistence determines what concentrations in water and sediments are available for incorporation of the chemical into benthic and pelagic food chains which lead to exposure of vulnerable organisms. The potential for a chemical to bioaccumulate in an organism is commonly referenced to concentrations of the chemical which persist in water and sediments. Thus, bioaccumulation factors (BAFs) and biota sediment accumulation factors (BSAFs), in accordance with mechanistic food chain models which integrate all routes of exposure, are extremely important components of the risk assessment methodology for PBTs. For organic chemicals, hydrophobicity, as measured by the octanol-water partition coefficient $\left(\mathrm{K}_{\mathrm{ow}}\right)$, is the primary determinant of bioaccumulation potential with metabolism in the food chain as an 
important factor for decreased bioaccumulation potential. Bioaccumulation for other PBTs, such as organometallic compounds like methyl mercury or organic chemicals with mechanisms for bioaccumulation different than hydrophobicity, must be assessed on the basis of the mechanism for their bioaccumulation.

The first residue-based WQC for PBTs (PCBs, DDT and metabolites, mercury, and 2,3,7,8tetrachlorodibenzo-p-dioxin [TCDD]), were developed for the Great Lakes under the Great Lakes Water Quality Guidance (EPA 1995a). Criteria were developed for risks to human health and wildlife, but not aquatic life. A similar procedure with BAFs was used to promulgate the National methodology for deriving human health criteria (EPA 2000f).

\section{Conceptual Model}

The Great Lakes Water Quality Guidance (EPA 1995a) for PBTs is consistent with a conceptual model for risk based criteria development for determination of safe loadings to aquatic systems or remedial actions in cases where unsafe loadings have created contaminated sediment problems. This conceptual model (Figure 11) illustrates a number of factors that are relevant to development of risk assessment methods and water quality criteria for PBTs in aquatic ecosystems. The double arrows represent models and relationships for transforming and linking the data and conditions represented by the boxes in the conceptual model. Concepts therein which provide an initial basis for development of projects for aquatic PBT research are:

1. Wildlife, aquatic life, and human health risk assessment methodologies for PBTs follow parallel tracks with common elements such as toxicity models, bioaccumulation factors, and chemical fate and transport models.

2. Residue-based WQC for PBTs should incorporate all of the elements of the risk assessment paradigm (problem formulation, effects/hazards analysis, exposure analysis, risk characterization, and risk management). Setting water and sediment quality standards, in accordance with the PBT conceptual model (Figure 11), requires a left to right logic for acquiring data and assembling models.

3. Retrospective risk assessments (e.g., what are/were the ecological risks associated with the mass of chemical $\mathrm{X}$ in lake $\mathrm{Y}$ ?) most often occur in response to a chemical stressor diagnosis and utilize the models and data in a right to left direction.

4. While prospective and retrospective risk assessments tend to flow from left to right and from right to left, respectively (Figure 11), in reality, site specific assessments are expected to involve iterations with reverse flows in data collection and modeling. For example, in a prospective risk assessment differences in exposure for species in a particular ecosystem may alter assumptions of the species at risk and require extrapolation of toxicity data (return to effects analysis) to complete a risk characterization. 

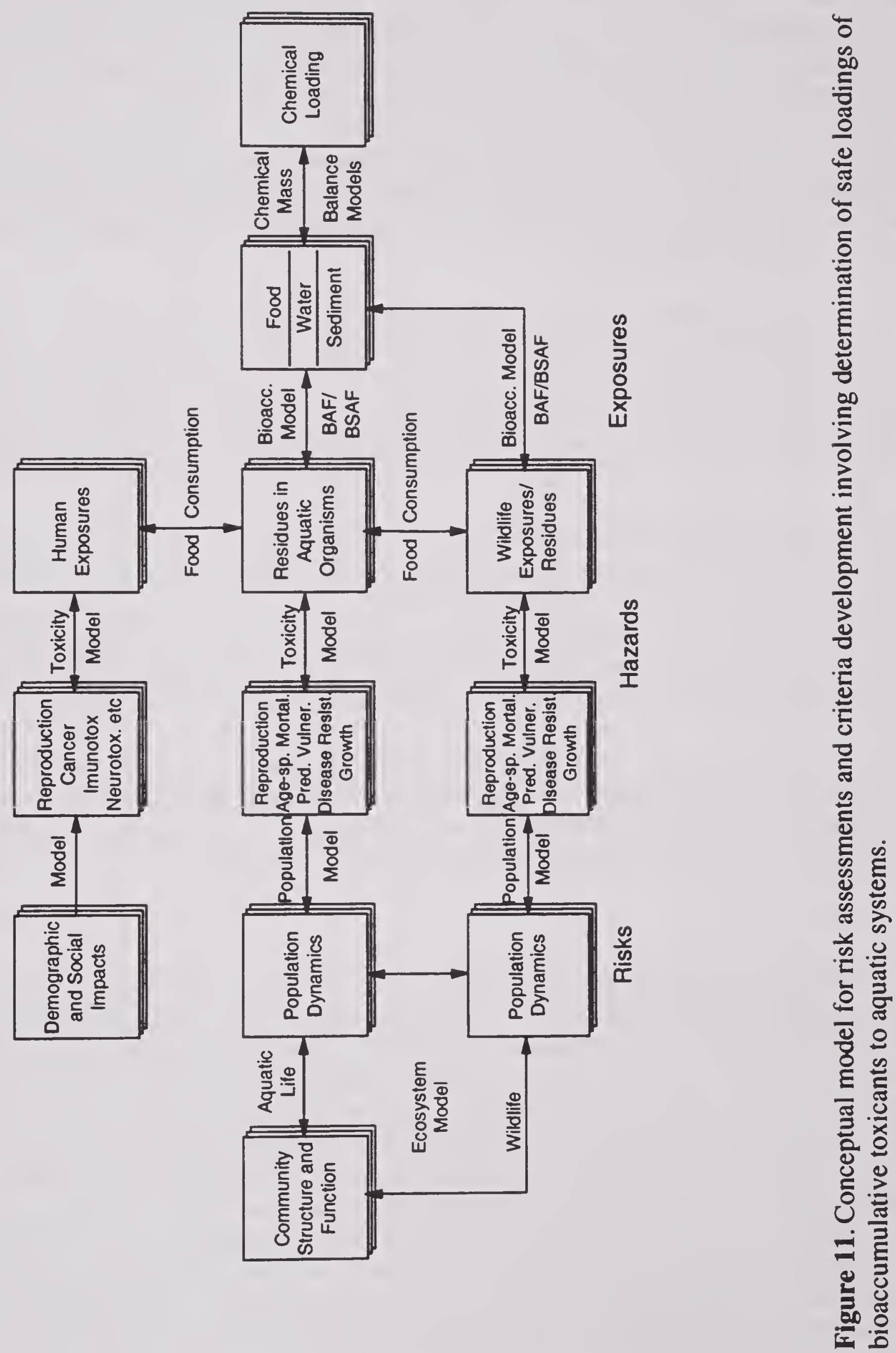
5. To date, PBT risk assessment methods for wildlife and humans have been based on assessment of dietary exposures involving concentrations in aquatic food organisms, principally fish and shellfish. Although this results in common BAFs/BSAFs for aquatic life and wildlife, BAFs/BSAFs specific for wildlife species are measurable and could be modeled to reduce uncertainties associated with the present dietary exposure methodology.

6. Determination of sensitive species, critical end points for population sustainability, and residue-based toxicology data are largely generic considerations which can be assembled on a national basis. However, bioaccumulation, exposure conditions, and chemical mass balance are more site-specific considerations.

7. The conceptual model applies to deterministic or probabilistic analyses.

8. Toxicity risks are linked to changes in chemical loadings or remedial actions and vice versa, so that tiered assessments are possible with choice, in the problem formulation, of steady state as either a specific assessment condition or as a reference condition for time-dependent risk assessment.

9. Spatially explicit risk assessments require spatially explicit exposure and bioaccumulation analysis with feedback (right to left) to population model responses through the residue based toxicology model (Figure 11). Spatially explicit risk analysis for PBTs can be conceptualized, in accordance with Figure 11, as multiple fish or wildlife tracks based on different exposure levels, a common toxicity model, and the potential for different population level responses (assuming discrete populations, or meta-populations exposed within the assessment region).

10. The third dimension in the conceptual model (stacked boxes) may be viewed as the multistressor component, particularly for chemical mixtures. Each chemical has to satisfy the risk assessment requirements in a parallel manner with a joint toxicity model (such as toxicity equivalence) linking each chemical's contribution to the net exposure.

\section{Research Needs}

For this discussion, the five different paths in Figure 11 (box-arrow-box components) that involve the generation and use of data to accomplish components of risk assessments will be examined for research needs. Separate but parallel chains of the five paths emerge for aquatic and wildlife species from the conceptual model for PBTs. The five components are: 1) the relationships between chemical loadings to the ecosystem and exposures via food, water, and sediment; 2) the relationships between concentrations in food, water, and sediment to concentrations in tissues of organisms at risk; 3 ) the relationships between concentrations in organisms and incidence of effects; 4 ) the relationships between incidence of effects and population changes; and 5) the relationships between specific population changes and community structure and function. The chemical loading, fate and transport, and exposure path (mass balance model) is not a direct NHEERL research concern but must be considered as a reference point for integration of effects research with exposure research. 


\section{Bioaccumulation Model}

Much progress has been made in the last decade toward providing a reliable bioaccumulation prediction capability for aquatic organisms through complementary use of empirical BAFs and more mechanistic food chain models. Site-specific variations in bioavailability have been largely reduced through lipid and organic carbon normalization and tropic level determination. Besides the chemical's hydrophobicity and potential for metabolism in the food chain, we now recognize the distribution between water and sediments and the relative benthic versus pelagic food web composition as critical determinants of bioaccumulation. The following important gaps need to be filled:

1. Rates of metabolism are needed for many PBTs in order to allow accurate predictions of bioaccumulation with food chain models. These rates are best determined from field data in order to fit the risk assessment needs.

2. The metabolism rate gap extends to bioaccumulation of PBTs like the PAHs in embryo-larval stages of fish with potential vulnerability to photo-induced toxicity.

3. Very few bioaccumulation data sets are of sufficient quality to validate the uses of BAFs and BSAFs, especially when extrapolated across species and/or ecosystems.

4. Existing BAFs, BSAFs, and food chain models are based on whole adult organisms and thus may not be sufficient when dose to early life stages (ELSs) and/or specific tissues must be evaluated. Early life stage dosimetry-based bioaccumulation factors and PB-TK models are needed to fill this gap.

5. Comprehensive and compatible BAFs, BSAFs, and food chain models are needed to meet the requirements of joint action toxicity models such as for TCDD toxicity equivalence or photoinduced PAH toxicity.

\section{Toxicity Model}

As would be expected, existing toxicity data vary greatly in amount and applicability for different PBTs. The risk assessment paradigm (Figure 8) and the conceptual model for PBTs (Figure 11) provide contexts for determining toxicological research needs for PBTs. Chemical residue-based dosimetry is an essential requirement. Ideally, residue dose-response models should relate to the most sensitive end points, species, and life stages which may result in population declines. Often, however, the toxicity data available are obtained prior to establishment of specific risk assessment requirements. This increases the need for development of tools for extrapolation of effects across species and end points. It also increases the need to plan future toxicology research so that the data fit into an ecological risk assessment profile for the particular class of PBT. Such a profile might be based on the mechanism of toxicity, ecological and exposure vulnerability of species, and expectations for differences in species sensitivity. A trivial example would be the low benefit to be expected from investigation of a specific receptor mediated toxicity in a class of aquatic organisms which is known to not possess the receptor. Most PBTs fall in groups based 
on a common mechanism of toxicity and thus joint toxicity models are an important facet of this path. The following important gaps need to be filled:

1. Residue-based toxicity data bases need to be advanced and evaluated for applicability to aquatic ecological risk assessment requirements for PBTs.

2. Is absence of overt mortality, even for early life stages, an adequate effects end point for preventing population declines caused by PBTs? If not, how do we determine what is adequate?

3. Commonly measured biochemical effect indicators, such as P450 enzyme induction, have uncertain relationships to organismal, much less population-level, risks.

4. Complex, multi-stressor models, such as required for photo-induced PAH toxicity to fish during embryo-larval stage of development, need to be developed and applied to determine the magnitude of ecological risks which are presently highly uncertain.

5. Virtually unexplored are the toxicokinetic and toxicodynamic determinants for interspecies and inter-effect extrapolations of potency ratios required for PBT mixture toxicity risk assessment using a toxic units model approach, such as the additive TCDD toxicity equivalence model.

\section{Population Model}

Population models are used to translate organismal responses to toxicity into population changes which may reflect risk to the population. Thus, life stage specific mortality or chronic effects which reduce survival may lead to a reduced population or extinction. While population models, such as the Leslie matrix age-class or individually based models, have been developed, relatively few applications in retrospective risk assessments for aquatic organisms exposed to PBTs have been reported. Examples of prospective use of population models for protection of aquatic life from PBT toxicity are fewer. This is unfortunate because WQC and other forms of risk assessment for protection of aquatic life from PBT toxicity should have a problem formulation based on the levels of population protection required. Clearly, the population model path is important for relating toxicity-induced mortality of individual organisms to population level changes in an ecosystem. However, a potentially equally important use is for the systematic definition of species characteristics, life stages, and toxicity effects that are most likely to determine risks to populations associated with PBTs having a particular mechanism of action. The following important gaps need to be filled:

1. Population models need to be developed and applied through case studies to explicitly demonstrate risk assessment requirements for prediction of adverse population impacts, as a result of PBT toxicity caused reductions in survival of aquatic organisms.

2. Complex mixtures of PBTs are the norm, so interspecies differences in potency, as well as in bioaccumulation, for individual chemicals in the mixture must be factored into population level risk predictions. 
3. Because PBTs tend to distribute widely, if not uniformly, in aquatic habitats, uncertainty exists for the extent to which spatially explicit population models are requisite for problem formulations.

4. A national WQC methodology for different classes of PBTs needs definition, through use of a generic population model, of the species characteristics, life stages, and toxicity effects that are most likely to determine risks to populations, regardless of site conditions. This information will provide the basis for determining site-specific model and data requirements for application of the criteria.

\section{Research Projects}

The research and development needs presented in the critical path constitute a very large effort encompassing integrated assessment methodology, generic assessment components applicable to many chemicals, and data or model needs for specific chemicals. Formulating a Goal 2 toxic chemicals research program for NHEERL requires consideration of what can be done with available resources to produce the most beneficial improvements in assessment methodology over the next several years, while also considering what research will be done in other goals and by other parties. The research presented here was selected to provide both general methods development and reduction of specific uncertainties.

\section{Overview of Projects-Nonbioaccumulative Toxicants}

At the most general level, there is a need to describe the overall framework and methods that should be used to improve aquatic risk characterizations and criteria development/application. This includes a short-term need, as represented by the initial step in Figure 9, to describe general approaches for improving assessments for nonbioaccumulative toxicants and the use of currentlyavailable methods and knowledge, thus providing a starting point for criteria development and further research. There also is a longer-term need to periodically update the recommended framework and methodologies as research in various areas produces useful results. Project N1 (Improved Risk Characterization Methods for Developing Aquatic Life Criteria for Nonbioaccumulative Toxicants) will address these needs and serve as a focal point for developing research projects, and applying and integrating their results. Initial products from this project will address APG 2, but efforts will continue under this project to synthesize results from other research, describe their application to assessments, and address, in whole or part, other APGs. This continuing work will be in large part in collaboration with $\mathrm{OW}$ efforts to revise their guidelines for WQC derivation. The nature and time line of additional products will be defined as these collaborative efforts develop during FY03.

As discussed in the Critical Path subsection, more meaningful aquatic risk assessments require improved approaches and knowledge in various areas. Prominent among these are models that address the significance of toxicological responses at the population-level (APG 3). Projects that we will pursue in this area will only involve bioaccumulative toxicants (see below), but the results of such work will have relevance to nonbioaccumulative toxicants and will be part of continuing efforts in project N1. Proposed research projects involving nonbioaccumulative toxicants involve the general topic area identified in APG 4 (extrapolation of toxicity among 
exposure conditions and biological endpoints). This encompasses many important issues, and three specific areas were selected which address major uncertainties or gaps for criteria, which are feasible with available resources, and which are not being resolved to our knowledge in other research programs.

Methods which can extrapolate toxicity data across different endpoints, species, and life-stages can benefit criteria development and application in two major ways. First, the importance of endpoints or organisms missing from toxicological data sets used for criteria development can be estimated (e.g., endangered species). Second, criteria for some chemicals could be developed from more limited data sets than generally required. Project N2 (Methods for Extrapolating Chemical Toxicity Data Across Endpoints, Life Stages, and Species Which Can Support Assessment of Risks to Aquatic Life for Chemicals with Limited Data) will address certain methods for conducting such extrapolations.

The toxicities of some contaminants are particularly sensitive to exposure conditions, sometimes varying by orders of magnitude. Even with a better risk assessment framework and other tools, good risk assessments of such contaminants are not possible without resolution of the effects of various exposure parameters on toxicity. A particularly noteworthy uncertainty is the bioavailability of metals. The Office of Water is currently supporting development of BLM, which addresses the effects of various chemical constituents on metal toxicity and is based in part on previous work in this area by NHEERL. Because of these efforts and various industry-funded research projects, further work on water-borne metal bioavailability is not being proposed here. Rather, work is proposed in areas that represent critical knowledge gaps that are receiving less attention.

Toxicological responses of organisms in or on sediment are affected by temporal and spatial variations in chemical concentrations and speciation in the sediment/water boundary zone. This is true in laboratory test systems and even more so under field conditions, making the interpretation and application of toxicity data highly uncertain. This area of concern will be addressed in project N3 (Assessing the Significance of Non-equilibrium Conditions on Aquatic Guidelines to Better Predict Field Effects). (Note: Because of resource reductions after the initial preparation of this plan, this project will not be pursued at this time.)

Aquatic life criteria for metals have generally assumed that exposure is predominantly via water, with dietary exposure being negligible; however, some work has indicated that this assumption is not true and that risk might be substantially underestimated. Project N4 (Risks of Heavy Metals to Aquatic Organisms from Dietary Exposures) will address this area of uncertainty for metals risk assessment and should also provide results and insights that can help address this issue for other nonbioaccumulative toxicants.

\section{Overview of Projects-Bioaccumulative Toxicants}

The residue-based toxicity approach for PBTs embodied in the conceptual model for ecological risk assessments and criteria development (Figure 11) is the foundation for advancing methods that will effectively link PBT loadings to aquatic ecosystems, or watersheds to risks for adverse population changes in aquatic life and wildlife associated with aquatic food webs. Therefore, 
there is a need to establish a residue-based toxicity framework with associated models. This framework is intended to improve aquatic ecological risk assessments and criteria development/application. In so doing, it can also be used to design, conduct, and report results for a long term PBT aquatic risk research program. The framework, like the framework for nonbioaccumulative toxicants, should be updated periodically and revised as new research improves and expands the methods, models, and data available for effectively applying the conceptual model. These periodic improvements need to be reported to OW and other interested Program Offices in a context that emphasizes integration into the framework and practical applications of the resulting risk assessment methodology. Project B1 (Framework for Development and Application of Population Risk-Based Criteria for Fish and Wildlife Exposed to Persistent Bioaccumulative Toxicants) serves this need. The initial products under project B1 will address APG 1. Subsequent improvements to the framework and validation efforts will concentrate on population level impacts and thus address APG 3. As for project N1, work in this project will in large part be in conjunction with $\mathrm{OW}$ efforts to update WQC guidelines. The nature and time line of additional products will be defined as these collaborative efforts develop during FY03.

As discussed in the Research Needs subsection for bioaccumulative toxicants, BAFs and models are essential for application of the residue-based toxicity approach. Although basic models and approaches are available for predicting bioaccumulation throughout aquatic food webs, improved capabilities are needed. Prime examples are the need to incorporate the effects of chemical metabolism into predictions of whole organism chemical elimination rates, the need to predict site-specific bioaccumulation with minimum data sets, and the need to extend bioaccumulation models to allow tissue residue predictions for vertebrates during the embryo and subsequent early stages of development. Project B2 (Incorporate Chemical Metabolism Rates and Site-specific Bioavailability into Bioaccumulation Models Structured for Practical Assessments of Risks to Fish and Wildlife Exposed to PBTs) is intended to advance the state of knowledge and risk assessment capabilities for all five of the major gaps identified under the Bioaccumulation Model Path. In so doing, project B2 will ultimately share with project B4 a goal of development of a model for fish ELS bioaccumulation of chemicals with significant metabolism potential such as PAHs. Although influencing APG 3 and APG 5, project B2 will primarily address APG 4. Note: Because of resource reductions after the initial preparation of this plan, this project will not be pursued at this time.)

Projects B3 and B4, although focused on specific PBTs, will provide products needed to fill important gaps associated with both the toxicity model and the population model paths of the conceptual model. Exposure to methyl mercury arguably creates the most widespread and intractable PBT risk problem for piscivorous birds. Project B3 (Multiple Stressor Risks to Common Loon and Other Piscivorous Bird Populations) will provide population models that are capable of evaluating relative risks of multiple stressors, including habitat alterations, in response to APG 3. Project B3 will also advance methods for interspecies extrapolation of dose-response relationships through development of PBTK/TD models in support of APG 4, and extend the population model to assessment of risks to wildlife from multiple stressors across spatially diverse landscapes in support of APG 5. Project B4 (Risks to Fish Populations from PAHs in Natural Systems) inherently addresses complex chemical mixture modeling issues with complexity added in association with the need to model photo-activation of PAHs in tissues of organisms, including early life stages of fish. Since data will probably always be limited for 
assessing photo-induced PAH toxicity and thus extrapolations are required to assess risks, project B4 will contribute to APG 4. Project B4 also will provide the key aquatic life related contribution to APG 5. The determination of the extent to which populations of aquatic organisms, including fish during early life stages, are reduced due to photo-induced toxicity across the broad range of PAH contamination in aquatic ecosystems will require achievement and application of a highly advanced PBT risk assessment capability. This PBT risk problem will provide a uniquely challenging test of PBT risk assessment methodologies because, although concentrations of complex mixtures of PAHs in organisms may be sufficiently described as a steady-state condition, the timing of UV exposure required for photo-activation is highly variable in time and space as well as being subject to habitat conditions and organismal/species behavior.

\section{Project Title N1. Improved Risk Characterization Methods for Developing Aquatic Life Criteria for Nonbioaccumulative Toxicants}

Project Coordination and Resources (4.0 FTEs: AED-1.5, GED-0.5, MED-2.0)

\section{Objectives}

Current WQC incorporate only limited information regarding the magnitude and timedependency of the responses of aquatic organisms to toxic chemicals. They address only one point (the fifth percentile) in the distribution of toxic effects concentrations among tested species. No uncertainty estimates are made and the importance of untested species and endpoints is not assessed. Assessments are not made at all in the absence of certain minimum datasets. The spatial variation of exposure, especially between sediment and water column, is not addressed. Except for recent efforts regarding sediment assessments, the effects of multiple stressors are generally not considered nor are the consequences of toxic effects on populations as a result of exposure of individuals. These limitations result in a weakly defined definition of risk associated with criteria conditions and an inability to quantify how risk would change with exposures above or below criteria concentrations.

Methods do exist for more completely addressing many of these issues, albeit with some uncertainty, and thus providing a more meaningful statement of risk. However, this will require adoption of more comprehensive risk assessment framework for criteria. A major short term objective of this project will be to describe a methodological framework for such risk characterization that could be used to improve criteria derivation. Current and possible methodologies for the components of this framework will be described, identifying where improvements to criteria are possible with current knowledge and where research efforts are needed. This effort will provide APM (2A) under APG 2.

The longer term objective of this project will be to further test, refine, and describe this framework and its component methodologies, based on results of research conducted in other projects in this program and elsewhere. In particular, we will address application of methods for population-level assessments and for extrapolation of toxicological information among endpoints and exposure conditions (APG 3 and APG 4). Products will consist of reports which synthesize new information and update descriptions of risk assessment methods relevant to aquatic life criteria. Much of this work will be pursued in collaboration with OW efforts to update WQC 
guidelines, and the specific nature and time line of products will be developed as part of this collaboration.

\section{Scientific Approach}

This project will use existing and developing information to evaluate and demonstrate procedures for more fully characterizing risks of nonbioaccumulative toxicants to aquatic organisms, and incorporating these risks into aquatic life criteria. These efforts will address a variety of issues, identified and discussed as follows. For all these issues, initial efforts will describe general approaches, discuss the capabilities and limitations of current methods, and identify needed research efforts.

- Improved descriptions of risk must start with methods which better describe individuallevel concentration-response relationships than endpoints that address only a single level of effect under narrow exposure conditions (e.g., 96-hr LC50). A chemical will be selected (likely candidates: ammonia, copper) for which raw toxicity test data are available for a large number of tests and diverse aquatic species. Existing methods for describing the effects of exposure time series on toxicological response (Mancini 1983, Breck 1988, Erickson et al. 1989, Hickie et al. 1995, Meyer et al. Newman 1995) will be evaluated, refined, and tested using these data sets. Models and estimation procedures for describing fixed-duration concentration-response curves also will be evaluated. These methods will be used to develop procedures for describing risks, and their uncertainties, for individual-level endpoints as a function of exposure parameters in a manner useful for criteria development and application.

- Efforts also will address better description of species-sensitivity distributions to allow criteria to address more than just a single level (i.e., the fifth percentile genus) in the range of available toxicity data. Methods for describing the distribution of toxic sensitivities among taxa (Kooijman 1987, Wagner and Lokke 1991, Aldenberg and Slob 1993, Baker et al 1994, Solomon et al. 1996, Hall et al. 1998, Newman et al. 2000) will be reviewed and used to develop an aggregate, continuous measure of risk from the assemblage of available toxicity data, which can be applied to various exposure conditions and provide a more quantitative basis for specifying aquatic life criteria. Uncertainties in this analysis will be described to the extent possible and the effects of using limited data on the estimated risks and their uncertainties will be evaluated.

The use of population models in the recently developed saltwater DO criteria will be reviewed and the broader applicability of population models to criteria will be addressed in initial efforts. Subsequent work will, as appropriate, review advances in methods from other research in this plan (projects B1 and B3) and elsewhere, and update recommendations regarding assessment methods for aquatic life criteria.

- Correlations of responses among taxa and endpoints will be discussed with regard to how criteria can address data gaps and limited data. Current work on interspecies extrapolation in project $\mathrm{N} 2$ will be summarized in initial products, and results of continued work in this project will be included in later efforts. 
The importance of spatial variation in exposure for assessing risk to aquatic communities will be evaluated and discussed. This will include the general issue of the spatial extent of the area that WQC criteria are intended to protect. It will also include consideration of the effects of spatial and temporal variability at the sediment/water interface (drawing on results from project $\mathrm{N} 3$ ) and the implications of this to the integration of sediment and water column criteria.

- The effects of physicochemical exposure conditions and of multiple routes of exposure will be addressed. Initial efforts will include general reviews of the importance of such factors and current abilities to address these effects. Later efforts will address developments from ongoing research regarding these effects, including results from project N4 on effects of dietary metals.

- Exposure to multiple chemicals will be addressed. Existing literature which describes the effects of chemical mixtures will be reviewed, procedures appropriate for WQC development will be developed, and the significance of joint toxic action to common contamination scenarios will be examined.

\section{Products}

FY03 Journal articles evaluating methods for describing the relationship of toxic responses to time and concentration and their application to improved expressions of risk for WQC (part of APM 2A).

\section{Benefits of Products}

This work will provide OW with a prototype framework for criteria based on a more accurate and informative characterization of organismal-level risk, and will provide a more quantitative basis for deriving and evaluating criteria. This framework will address several of the limitations of current criteria and support incorporation of tools addressing other limitations, such as population-level effects and extrapolations among species and toxicity endpoints. Products will provide a technical basis for making changes to procedures for developing criteria.

Project Title N2. Methods for Extrapolating Chemical Toxicity Data Across Endpoints, Life Stages, and Species Which Can Support Assessment of Risks to Aquatic Life for Chemicals with Limited Data

Project Coordination and Resources (1.5 FTEs: GED-1.5)

Objectives

Ambient WQC have enabled the states to develop scientifically defensible standards and thereby reduce the amount of specific chemicals discharged into our nation's surface waters. However, environmental managers must frequently perform risk analyses and make decisions regarding compounds for which WQC and the data necessary to derive them (EPA 1980) do not exist. Guidance is needed on comparative sensitivity relationships and on limits of extrapolation, and 
uncertainty for use by managers who must on many occasions, make decisions based on the limited data that may be available. This is of particular concern for the protection of certain endangered species which cannot be tested or other species that are not feasible to test.

Most species sensitivity comparisons have been made on individual chemicals, and modes of action have been used for certain extrapolations for individual species. However, there is little understanding of the relationships and uncertainty between chemical classes and the sensitivity of taxonomic groups of species to these chemical classes. A particular mode of action (chemical class) may pose greater or lesser jeopardy to certain families/populations of organisms than others, al lowing one to better assess what will occur ecologically (diversity). This concept will be evaluated in extrapolating chemical toxicity data across species and taxonomic groupings. The present research specifically covers five major modes of action (see second item below), but will add others from existing data bases, further supporting chemical modes of action/structureactivity research being addressed by NHEERL/WED.

Effects on native fish and invertebrate populations are important indicators of changes in surface waters due to human-related impacts such as the damming of rivers, lowering of aquifers, addition of pollutants, and introduction of non-native species. The planned research to determine the utility of using surrogate species in hazard evaluations to estimate the potential for toxic chemicals to affect other aquatic species has the following objectives:

1. Assess the rainbow trout, fathead minnow, and sheepshead minnow as appropriate surrogate test species for endangered fishes and other species.

2. Determine differences in acute sensitivity to chemicals with differing modes of action (carbaryl, copper, 4-nonylphenol, pentachlorophenol, and permethrin) between surrogate test species and selected endangered organisms.

3. Develop interspecies correlations between surrogate test species and endangered fishes and other aquatic species using 48-h EC50/96-h LC50 data for the above five chemicals.

4. Develop user manual and software for interspecies correlations of acute toxicity data for aquatic species using data bases from Mayer and Ellersieck (1986), Mayer (1987), OPP, and AQUatic toxicity Information REetrieval (AQUIRE).

5. Perform acute toxicity tests to fill data gaps identified in item 4 where performance of specific tests would significantly enhance the number of data sets available for use in developing interspecies correlations (e.g., additional modes of action in item 2).

6. Enhance utility of ACE (acute-to-chronic endpoint) model to predict chronic toxicity to endangered and other species on a population basis.

This research will further develop project N1 by addressing the importance of untested species and endpoints and providing methodology for assessing limited data sets and filling data gaps. In addition, models for estimating chronic toxicity from acute toxicity data will concentrate on population-level assessments. 


\section{Scientific Approach}

Existing toxicity data bases, comparative toxicity literature, and methods for extrapolation among endpoints, life stages, and species of aquatic organisms will be reviewed to identify areas where improvements can be made in extrapolation based on existing data.

Specific data gaps, particularly those addressing modes of action/structure-activity, will be identified and tests conducted where performance of laboratory toxicity tests would significantly enhance the ability to extrapolate among endpoints, life stages, and species. This research can best be accomplished by collaboration among the Ecology Divisions, because some of the data gaps will involve freshwater testing and others will involve testing of saltwater species. Collaboration with other governmental agencies such as the FWS, NOAA, and U.S. Geological Survey (USGS) is also desirable.

Methods for acute tests will be based on standard methods such as Weber (1993) and ASTM (1988). Dissolved oxygen, $\mathrm{pH}$, salinity, and temperature will be measured in all treatments on day 0 through day 4 . Most of the effort with endangered species has been completed and any additional testing of such species will be conducted by USGS/BRD, Columbia Environmental Research Center, Columbia, MO through an interagency agreement jointly funded by $\mathrm{ORD}, \mathrm{OW}$, and Office of Prevention, Pesticides, and Toxic Substances (OPPTS).

Statistical analyses will be performed on survival data with probit analysis or the SpearmanKarber program to generate as a minimum, 24-, 48-, 72- and 96-h EC/LC50s. Three-way analysis of variance is performed using SAS to determine statistical differences between species LC50s, among chemicals, and at each time interval.

Interspecies correlations will be conducted using Model II least squares methodology for two independent variables (Mayer and Ellersieck 1986) on a combined data base from Gulf Breeze, FL, Columbia, MO (USGS), Office of Pesticide Programs (OPP), and AQUIRE. Slopes and intercepts are derived from the equation $\log y=a+b(\log x)$, where $x$ equals 48-h EC50/96-h LC50 values for the surrogate test species and y equals 48-h EC50/96-h LC50 values for the endangered or other species. Chemical groupings by mode of action will also be compared to taxonomic groupings of species to ascertain any differences in vulnerability. A user manual and software, based on a Windows platform, will be developed to use the data base as a reference catalog and for user interaction to derive calculated values based on their input data.

For acute-to-chronic predictive models, both classical and non-classical time-to-event approaches (Crane et al. 2001, Jones 1964) will be used. The appropriate computer language(s) to combine all three acute-to-chronic models, linear regression, multifactor probit analysis, and accelerated life testing (Mayer et al. 1994, Lee et al. 1995, Sun et al. 1995), including life table subroutine, will be determined. The accelerated life testing model will be the population-based estimation procedure using an underlying life-time distribution/survival probability distribution (e.g., exponential, Weibull, extreme value, log-normal, gamma, or log-gamma models). This approach will define extra response above natural mortality due to chemical exposure. We will develop appropriate computer commands using compatible language that will allow for: 1) data input/transfer from pre-established data bases, 2) selective and continuous processing of data 
through all or selected combinations of the three models, and 3) printouts of graphics. The final phase is establishment of a user-friendly Windows version of the ACE software. This will be a joint effort with the University of Missouri, Columbia, MO, through a cooperative agreement funded by ORD/NHEERL, OW, and OPPTS.

For selected classes of chemicals, the utility of estimating WQC values based on limited data will be examined by applying extrapolation techniques to subsets of data for existing WQC. This exercise will provide insights into the accuracy and margin of error that might be expected by such extrapolations.

\section{Products}

FY01 Report on sensitivity of threatened and endangered fishes to contaminants with comparisons to that of standard surrogate species.

APM 4A FY02 ICEs for acute toxicity to aquatic organisms (GED).

APM 4B FY02 Time-concentration-effect models for use in predicting chronic toxicity from acute toxicity data (GED).

APM 4C FY03 Acute to chronic estimation (ACE) user guide and software (GED).

FY06 Refinement of ICEs for acute toxicity to aquatic organisms based on new data.

Benefits of Products

Research products developed under this plan will provide managers with extrapolation methods and guidance to use when making decisions based on limited data sets. Specifically, 1) interspecies correlations will allow the user to estimate the acute toxicity for a species having no data from a common test species having acute data and 2) ACE allows prediction of chronic toxicity using only acute toxicity data. Estimates for both acute and chronic endpoint predictions include measures of accuracy and uncertainty.

Note: Because of resource reductions after the initial development of this plan, the following project will not be pursued at this time.)

\section{Project Title N3. Assessing the Significance of Non-Equilibrium Conditions on Sediment Guidelines to Better Predict Field Effects}

Project Coordination and Resources (3.0 FTEs: AED-3.0)

\section{Objectives}

The majority of U.S. EPA's sediment guidelines are based on the assumption that equilibrium conditions exist (EPA 2000a,b,c,d). This assumption may be one of the largest weaknesses in these guidelines. In the laboratory, where many guidelines are developed, this assumption is 
probably correct. However, in the field, where these guidelines are applied for regulatory applications, equilibrium conditions may not always be present. Examples of non-equilibrium conditions include seasonal changes in the benthic environment resulting in changes in AVS levels (Leonard et al. 1993), storm events and dredging operations under which sediments become suspended into the water column (Karickhoff and Morris 1985a,b, Calvo et al. 1991, Simpson et al. 1998, Latimer et al. 1999, Bonnet et al. 2000), and the presence of unusual binding phases in the water column and benthos (e.g., soot carbon) (Gustafsson and Gschwend, 1997). The occurrence of conditions resulting in non-equilibrium may alter how well guidelines function and cause under-protective situations as well as introducing unacceptable uncertainty. Non-equilibrium, along with the importance of dietary uptake, is one of the greatest remaining sources of uncertainty in the development of criteria for non-bioaccumulative compounds.

The over-all objective of this project is to perform research allowing the Agency to better understand the importance of non-equilibrium conditions and have greater confidence in the use of aquatic guidelines under field conditions. The research will focus on three predominant areas which may result in non-equilibrium: seasonality, sediment suspension, and unusual binding phases. Seasonality affects nearly every environmental setting and therefore its impacts on the effectiveness of aquatic guidelines must be understood. Sediment suspension occurs under a variety of environmental situations ranging from storms to dredging, and signifies a potential source of toxic chemicals to most coastal systems. Unusual binding phases are a recently recognized source of variability to the application of aquatic guidelines but nonetheless may represent a significant source of error to existing regulatory values. Another critical component of this research will be to complete an evaluation of how well current guidelines predict adverse effects in field sediments. This information will be very useful in designing studies to assess the effects of non-equilibrium conditions on guidelines development and application. Although this work focuses on non-equilibrium in the sediment, the issues explored also have consequences for the water column, via the sediment-water interface, and for other sources of heterogeneity in the sediment as well.

Scientific Approach

\section{Seasonality}

Seasonality is especially important in relation to metals in sediment. Currently there are no published EPA guidelines for metals in sediment, but ESGs for metals are under development. These guidelines use AVS and interstitial water to predict biological effects. These methods have been demonstrated to be very useful in predicting biological effects in laboratory experiments and in a limited number of field experiments. The current draft guidelines do not explicitly consider the effects of seasonality on AVS and metal bioavailability. However, it is known that AVS varies with season and depth as a function of seasonality (Leonard et al. 1993); therefore, it is possible that metal bioavailability will correspondingly vary. If metal bioavailability varies significantly over an annual cycle, decisions based on the comparison of sediment guidelines with measured chemistry taken at one time of year may not be appropriate for other times of the year. Research in this section will seek to quantify the magnitude of fluctuation of metal bioavailability as a function of season. 


\section{Sediment Suspension}

As noted above, sediment suspension is a natural and anthropogenic process that results in the release of contaminants into the water column. Research has demonstrated this geochemical phenomena (e.g., Latimer et al. 1999, Cantwell et al. in prep.) but little study has investigated the biological effects of sediment suspension and contaminant release on benthic organisms. This section of the project will perform studies to assess the magnitude of contaminant release and effects under realistic environmental scenarios.

Initially, resuspension and benthic flux experiments will be performed under controlled (laboratory) conditions in order to determine the significance of specific variables in the remobilization of contaminants from sediments. In this phase, toxicity tests will be performed to measure adverse effects. Resuspension of contaminated field sediments will be performed at a number of energy levels and time scales which are representative of estuarine conditions, with continuous monitoring of chemical changes to the sediment and overlying water. Additional experiments will take place resuspending sediments and monitoring longer term (1-6 month) fluxes and chemical changes to the sediment. Once a better understanding of the variables influencing stressor availability is gained, field-based experiments will be conducted.

\section{Unusual Binding Phases}

Currently, ESGs for metals and organic chemicals are based on the concentrations of the binding phases AVS and organic carbon, respectively, in the benthos. In recent years, it has been speculated and observed that other binding phases may also influence the bioavailability of metals and organic chemicals. For example, organic carbon has been speculated to affect metal bioavailability beyond the influence of AVS (DiToro et al. 2002). Further, while the bioavailability of organic chemicals like pesticides and PCBs are well predicted using organic carbon (EPA 2000b, Burgess et al. 2000), the behavior of PAHs vary widely (Gustafsson and Gschwend 1997). Unusual binding phases like soot carbon have been proposed to explain these discrepancies (Gustafsson and Gschwend 1997).

To address the significance of unusual binding phases, research will be conducted to assess the relative importance of these phases as compared to AVS and organic carbon as currently applied by Agency guidelines. The draft ESGs for both metals and PAHs contain adjustments for unusual binding phases but these adjustments are crude and based on limited scientific information (EPA 2000a,d). Consequently, research will be performed to expand and/or improve the current adjustments factors to ultimately reduce the variability in regulatory guidelines these unusual binding phases introduce when used in the field.

\section{Field Validation of Aquatic Guidelines}

It is prudent to field validate the existing aquatic guidelines as this provides a way to determine their effectiveness. One efficient way to do this is to use the guidelines along with our increased understanding of the effects of contaminants in dynamic and variable sediments to predict the toxicity of sediments collected in large data bases for which concurrent chemistry and toxicity data are available, such as the EMAP and NOAA Status and Trends data bases. Numerous 
attempts have been to match toxicity data to various sediment guidelines, but there are no published reports of a study which used all of the available guidelines to predict and explain toxicity in the samples.

In this project, the sediment guidelines (i.e., which are based on the equilibrium partitioning [EqP] model) will be applied using a toxic unit model to determine whether concentrations of chemicals measured commonly in sediment monitoring programs (cationic metals, PAHs, PCBs and other non-PAH narcotic chemicals, and pesticides) appear sufficient to explain observed toxicity (EPA 2000a,b,c,d). Where they are not, it may be inferred either that unmeasured chemicals (e.g., ammonia) or measured chemicals not included in the toxic unit model are contributing to toxicity, or that the EqP model does not provide protective guidelines. Part of this effort will be to improve the EqP model to correct these potential errors.

Products

As a result of this project, a data set will be generated describing the effects of those factors resulting in non-equilibrium conditions including seasonality, suspended sediments, and unusual binding phases. This research recognizes the equilibrium assumption of existing guidelines as a potential weakness which may compromise their utility if not better understood. Further, we will perform an assessment of how effective current guidelines are for predicting field effects.

FY02 Report to OW on the effectiveness of ESGs in the prediction of amphipod mortality in sediments.

FY02 Peer-reviewed journal article on the usefulness of EqP in the prediction of amphipod mortality in sediments.

FY05 Report to OW on the importance of seasonality and resuspension in predicting the biological effects of contaminants in sediments.

FY06 Report to OW on the importance of unusual binding phases in predicting the biological effects of contaminants in sediments .

Benefits of Products

Currently, the usefulness of the Agency's sediment guidelines, which are based on EqP is potentially limited in regard to field application by our poor understanding of the effects of seasonality, resuspension, and unusual binding phases. For example, AVS has been used to develop ESGs for metals, but its application is limited. Better understanding of the biological effects of contaminants under non-equilibrium conditions would greatly increase the applicability of the guidelines in the field.

The Office of Water has chosen EqP as the method for developing ESGs, but before these guidelines can be accepted in the scientific and regulatory community, they must receive further validation in the field. This research is one step in that validation. 


\section{Project Title N4. Risks of Heavy Metals to Aquatic Organisms from Multiple Exposure Routes}

Project Coordination and Resources (4.0 FTEs: MED-4.0)

\section{Objectives}

A fundamental uncertainty with the use of typical laboratory toxicity tests in assessing risks of nonbioaccumulative toxicants to aquatic organisms is the failure to account for other routes of chemical exposure which may occur in natural systems. Of particular concern is exposure to chemicals via food or by incidental ingestion of contaminated non-food solids. For many nonbioaccumulative toxicants this failure is arguably of little consequence, but for some chemicals risk might be significantly underestimated using only water exposures. Conventional wisdom in aquatic toxicology was that water is the primary exposure route for metals (e.g., copper, cadmium, nickel, lead, zinc) to fish and other aquatic organisms (with the exception of metals such as mercury which form significant amounts of bioaccumulative organometallic species). Although exposure to metals via the diet was known to produce some level of bioaccumulation, it was not considered to significantly increase risk relative to water-only exposures, unless the diet was highly contaminated relative to that in equilibrium with water. Thus, environmental criteria and other toxicity assessments for metals have focused on waterborne toxicity, but there has been considerable concern whether this is adequate.

Beginning in the early-1990's a series of dietary toxicity studies were conducted (Woodward et al. 1994, 1995; Farag et al. 1994) that involved feeding young rainbow trout diets prepared from invertebrates collected from metal-contaminated rivers, primarily the Clark Fork River (CFR) in Montana. The Clark Fork watershed is highly contaminated with several metals, with copper being generally considered to be the metal of greatest concern. Results of these studies showed that fish fed a diet of pellets prepared from metal-enriched invertebrates showed reduced growth relative to fish fed similar diets prepared from invertebrates from reference areas, or less contaminated portions of the CFR. A more recent study from the same laboratory (Farag et al. 1999) reports comparable findings for invertebrates from the Coeur d'Alene watershed in Idaho, where the primary metals of concern are lead and zinc. The authors of these studies conclude that the metals in these diets are the cause of the toxicity to rainbow trout. However, these conclusions conflict with previous studies which have not shown such toxicity from dietary metals. Additionally, Mount et al. (1994) conducted a laboratory study which fed a live diet of brine shrimp (Artemia) that were cultured at high metal concentrations to produce nauplii that were high in metal content. These studies did not indicate that dietary metals caused the degree of effects noted in studies with the field-collected invertebrate diet. The discrepancies among these studies is attributed by some to differences in the form of the metal in the diet.

For invertebrates, similar uncertainties and conflicting results exist regarding the importance of the dietary route of exposure. A variety of studies have demonstrated uptake of metals via ingestion in various molluscs and crustaceans, but the importance of this uptake relative to uptake via water and its significance to toxic response generally has not been well determined. In particular, there are questions about differences in the efficacy of metals taken up via different routes, about the water exposure a particular dietary exposure should be compared to, and about 
how separate water and dietary exposures relate to combined exposures. However, Hook and Fisher (2001) have demonstrated reproduction of freshwater cladocerans and marine copepods to be reduced at much lower silver concentrations when exposure was via food equilibrated to various water concentrations, as opposed to directly to water at those same concentrations. Other unpublished work by Hook and Fisher (2000) has indicated the same is true for mercury, zinc, and cadmium. However, in similar experiments, Kim et al. (2000) have reported that reproduction of cladocerans was more severely affected by waterborne cadmium than by dietary cadmium.

The repercussions of this issue in regulatory programs are large and persistent. The significance of dietary exposure has not only been a major point of contention in the Superfund assessment of the CFR, but has infiltrated debates on a number of regulatory issues. These include the adequacy of ambient WQC for metals, to advisability of assessing waterborne metals on the basis of dissolved (rather than total recoverable) metal, and the adequacy of EPA's proposed ESGs (formerly Sediment Quality Criteria) for metals. None of these programs currently considers dietary exposure to metals as part of assessing risk. Yet, at present, the technical debate is mired in conflicting and insufficient data with no clear resolution of the biological significance of the dietary pathway, much less a way of quantifying the risk for incorporation into environmental regulation. This project will address this fundamental uncertainty in the toxicity model for metals and will contribute to APG 4.

The general objective of this project will be to assess the importance of considering routes of exposure other than water in aquatic risk assessments and criteria development for cationic metals. Initial efforts will address the importance of dietary exposure relative to water and will include 1) review and synthesis of past and ongoing work of other investigators to better define the state of knowledge regarding the importance of dietary exposure, and 2) targeted experiments which confirm critical work and address uncertainties.

\section{Scientific Approach}

\section{Dietary Metals Effects on Fish.}

This will include a series of experiments in which juvenile fish (rainbow trout, fathead minnows, channel catfish) will be fed diets of live, intact invertebrates that have been enriched with metal in a variety of ways, including through waterborne exposure of the prey to metals and through rearing prey in metal-contaminated sediment, both field-collected and artificially spiked. The oligochaete, Lumbriculus variegatus, has a number of attractive features as a prey species, including ease of mass culture and tolerance of sediment contamination, and we anticipate using it as a primary prey model. However, we will also conduct limited experiments with other invertebrates, such as the midge, since some researchers have speculated that the metal interaction with chitin may be involved in the observed effects. By using sediments collected from field locations such as the CFR and the Keweenaw Waterway (Michigan), these experiments can also address responses to real-world mixtures of metals in addition to laboratory-prepared mixtures. Exposures in initial experiments will be solely through the diet, minimizing exposure via water by maintaining high flows of uncontaminated water through exposure tanks and by not allowing excess prey to remain in the tanks. Concentrations both in 
the diet and the pore water of the sediments used to contaminate the diet will be documented, allowing comparison of water concentrations that directly cause toxic effects with the water concentrations needed to result in toxic concentrations in diet. If these experiments demonstrate significant toxic effects from diet that might substantially increase risk from water alone, additional experiments will be conducted with metal exposure both via water and diet to further evaluate the relative importance of these two routes.

\section{Dietary Metals Effects on Zooplankton.}

This will include experiments in which zooplankton (freshwater cladocerans and saltwater copepods) are chronically exposed to metals dissolved in water and incorporated into food, both separately and combined. Methods will build on those of Hook and Fisher (2001) and Kim et al. (2000) and will address the reasons for the discrepancies between these studies and the relative importance of these different routes of exposure under conditions expected in natural systems. Experiments will be designed to supplement and complement related research in progress elsewhere.

\section{Products}

FY03 Journal article regarding importance of dietary exposure to chronic metal toxicity to juvenile fish.

FY04 Journal article regarding importance of dietary exposure to chronic metal toxicity to cladocerans.

APM 4D FY06 Report evaluating importance of dietary route of exposures to aquatic risk assessments for metals (MED).

\section{Benefits of Products}

The existing controversy over dietary exposure to metals is influencing regulatory decisionmaking in several Regions and programs. In addition to the Superfund process and Natural Resources Damage Assessment (NRDA) litigation on the CFR, similar issues have been raised regarding the assessment of mining impacts on the Coeur d'Alene River in Idaho. With respect to State WQS, ORD staff have been contacted by State representatives concerned that shifting standards from total to dissolved will increase metal loadings and thereby increase risk from metal toxicity via other pathways such as dietary and sediment exposure. In the consultation of Region 9 and OW by the Department of Interior on the California Toxics Rule (CTR), the issue of dietary exposure to metals figured prominently in the draft Biological Opinion (BO), with DOI citing uncertainty regarding dietary uptake as reason for using total, rather than dissolved, metals as a measure of compliance. Enhancing understanding of combined waterborne and dietary exposures to metal mixtures will improve the ability of environmental managers in the EPA and elsewhere to make informed decisions on the assessment of ecological risk from metals in aquatic systems. 


\title{
Project Title B1. Framework for Development and Application of Population Risk-Based Criteria for Fish and Wildlife Exposed to Persistent Bioaccumulative Toxicants
}

\author{
Project Coordination and Resources (3.0 FTEs: AED-1.5, MED-1.5)
}

\section{Objectives}

The primary goal of this project is to describe and demonstrate a framework for assessing ecological risks and developing risk-based WQC criteria for fish and wildlife populations exposed to PBTs, as required by APG1. Currently, national WQC or contaminated sediment screening levels are not available for protection of fish and wildlife exposed to PBTs. However, ecological risk assessment methodologies, with PBT doses based on residues in tissues of organisms, have been under development and extensively discussed for at least a decade (Cook et al. 1992). Recently, scientific experts have favorably reviewed the state of the models and methods for risks to fish and wildlife populations associated with early life stage toxicity from bioaccumulated PBTs. For example, the residue-based, additive toxicity equivalence approach for dioxin-like chemicals that act through an aryl hydrocarbon receptor (AhR) mediated mechanism of action was examined in great detail in 1998 and found to be ready for application in ecological risk assessments (EPA 2001). The fundamental purpose of this project is to insure that appropriate chemical residue-based toxicity data and models are effectively used, in conjunction with bioaccumulation and population dynamics models, to determine site-specific water quality conditions required to sustain populations of aquatic organisms and aquaticdependent wildlife. A general risk assessment framework and associated methods will be developed for all PBTs based on the principles contained in EPA's Guidelines for Ecological Risk Assessment (EPA 1998). Also, the PBT framework and associated methods will allow probabilistic and spatially explicit representations of population level risks to the extent possible and beneficial.

\section{Scientific Approach}

This project will function as a framework for a continuing development and application of riskbased water quality criteria for PBTs. The framework will be based on the conceptual model for bioaccumulative toxicants (Figure 11). Three major groups of PBTs that must be addressed are halogenated organics, of which the chlorinated organics are preponderant (Carey et al. 1998); PAHs which are ubiquitous contaminants of aquatic ecosystems with potential for increased aquatic life exposures in the future associated with increasing rates of fossil fuel production and combustion (Neff 1979); and organometallic compounds such as methyl mercury which are a particular concern for wildlife connected to aquatic food webs (EPA 1997).

Initially, the conceptual model for risk assessments and criteria development involving determination of safe loadings of PBTs to aquatic systems (Figure 11) will be applied to existing data and models for chlorinated aromatic chemicals that act through an AhR mediated toxicity mechanism in vertebrates. This class of chemicals includes polychlorinated biphenyls (PCBs), polychlorinated dibenzo dioxins (PCDDs), and polychlorinated dibenzo furans (PCDFs) for which residue-based ELS toxicity data and a mixture toxicity model are available. Thus, ecological risk assessment tools and approaches will be described and demonstrated for risk 
based criteria development and application, including use in TMDLs designed to protect populations of sensitive fish and wildlife species. The association of the historical lake trout population decline in Lake Ontario with exposure of embryos to AhR agonists such as 2,3,7,8TCDD (Cook et al. 1997) will be used as a device to examine the applicability of population models when used in tandem with residue based toxicity data. The extent to which extrapolation of lake trout risks to other species involves more than species sensitivity to TCDD and degree of exposure/bioaccumulation will be examined in the context of toxicokinetic, toxicodynamic, biochemical, and life history factors.

Data gaps and modeling limitations will be identified and further described as research needs for development of a general risk assessment capability for all PBTs. This analysis will include an initial conceptual evaluation of the degree to which similarities and differences in PBT properties and mechanisms of action will define a balance between generic and chemical specific PBT risk assessment approaches and models. For example, do the properties of persistence and bioaccumulation, in combination with principles of population dynamics, indicate that effects on ELS development and survival are invariably risk determining for PBTs in general? If so, what are the basic PBT toxicity and exposure data and modeling requirements for ecological risk assessments? Population matrix modeling will be a primary tool for evaluating vulnerability differences between species based on differences in life stage sensitivities, exposure profiles, and reproductive strategies.

Other aquatic stressors research projects involving PBTs are expected to contribute periodically new or improved risk assessment capabilities which can then be integrated into the PBT framework under this project. Although the continuing development of the framework will include incorporation of all relevant new data and models, many new capabilities are expected to become available as the result of completions of APMs. Examples of expected risk assessment capability advances, listed in association with the APGs and projects, are:

Methods for developing WQC based on characterization of population-level risks of toxic chemicals to aquatic life and aquatic-dependent wildlife (APG 3):

- Rates of metabolism and improved food chain bioaccumulation models for metabolizable PBTs (project B2).

- Models for assessing relative risks of multiple stressors to avian populations with large geographic ranges (project B3).

- Improved understanding of fish early life stage dosimetry including appearance and extent of metabolism during development (project B2).

Models for extrapolating chemical toxicity data across exposure conditions, endpoints, life stages, and species (APG 4):

- Methods for inter-site extrapolation of BAFs based on site-specific food chains and bioavailability conditions (project B2). 
- $\quad$ PB-TK model/s for inter-species extrapolation of avian exposure and tissue dosimetry data consistent with PB-TD models (project B3).

- Models for bioaccumulation and metabolism of PAHs by fish during ELSs (project B4).

Approaches for evaluating, at different spatial scales, the cumulative risks from toxic chemicals on populations of aquatic life and aquatic-dependent wildlife relative to risks from nonchemical stressors (APG 5):

- Methods for assessing spatial and temporal distributions of risks (project B3).

- Population models that predict the relative risks of multiple stressors, including toxics and habitat alteration, to piscivorous birds (project B3).

- Methods for assessing PAH risks to feral fish populations with emphasis on vulnerability of fish during early life stages to photo-induced PAH toxicity (project B4).

While integrating new capabilities into the PBT framework, this project will include expansion and generalization of the models and methods across chemicals, phyla, and effects to the extent possible and scientifically defensible in order to provide site-specific applicability with minimum data sets. Scopes of products from this project are therefore subject to the degree of success in research from the other PBT projects. Much of this work will be pursued in collaboration with OW efforts to update WQC guidelines, and the specific nature and time line of products will be developed as part of this collaboration.

\section{Products}

FY02 Journal article describing a conceptual model for relating risk-based critical residue values in fish and wildlife to chemical concentrations in sediment and water (with context of sitespecific risk-based WQC and assessments of ecological risks associated with contaminated sediments) (Part of APM 1A [GPRA \# 167]).

APM 1A (GPRA \# 167) FY02 Report on integrated water and sediment quality criteria methods for assessing site-specific risks of persistent bioaccumulative toxicants to aquatic species (MED).

\section{Benefits of Products}

This framework will provide guidance for development and application of WQC for protection of fish and wildlife populations on the basis of PBT residue-based toxicity data. The framework will allow presently available chemical mass balance models to link site-specific chemical loading, fate, and transport information to toxicity risks, including population level impacts. This, and the demonstration of capability for risk assessment of complex mixtures of PBTs having a common mechanism of toxicity, should allow EPA, the States, and Tribes to more effectively determine where and to what extent loadings of PBTs to aquatic ecosystems pose unacceptable ecological risks. 
(Note: Because of resource reductions after the initial development of this plan, the following project will not be pursued at this time.)

\section{Project Title B2. Incorporate Chemical Metabolism Rates and Site-specific Bioavailability into Bioaccumulation Models Structured for Practical Assessments of Risks to Fish and Wildlife Exposed to PBTs}

Project Coordination and Resources (4.0 FTEs: MED-4.0)

Objectives

Ecological risk-based criteria for PBTs require a strong capability to relate chemical residue based dose-toxicity response data to environmental exposure conditions, and thus to chemical loading limitations for protection of vulnerable populations of fish and wildlife. The present capability is limited by the amount and quality of data available; significant data gaps (e.g., rates of metabolism, bioaccumulation in ELSs); inconsistencies in approaches used for predicting bioaccumulation; and uncertainties associated with extrapolation of bioaccumulation data across species, life stages, and exposure conditions. This research begins with an objective to develop the first data base designed to provide a comprehensive set of BAFs and BSAFs for organisms in a complex food web, coupled with bioavailability and metabolism information, so that methods for extrapolation of measured BAFs and BSAFs to different ecosystems may be developed and validated. The ultimate objective is to extend these models to allow directly application to ELSs of fish and wildlife. ELSs are often most sensitive to PBTs, have greatest impact on population maintenance, and therefore are risk determining. Specific objectives, associated with development and application of the high quality bioaccumulation data base, are:

- $\quad$ Provide a comprehensive conceptual model for relating risk-based critical residue values in fish and wildlife to chemical concentrations in sediment and water.

- Develop a high quality bioaccumulation data base for a four trophic level, mixed benthic/pelagic food web in southern Lake Michigan.

- Provide a master set of BAFs, BSAFs, and associated bioavailability data with an evaluation of procedures for extrapolation to diverse ecosystems and chemical loading conditions.

- Develop guidelines for sampling and analysis of biota, lipid, sediment, water, and organic carbon to maximize inter-ecosystem extrapolations and comparisons of bioaccumulation data.

- Determine whole organism based rates of metabolism from the high quality bioaccumulation data base for PCBs, PCDDs, PCDFs, PAHs, and other PBTs (as data are available). 
Refine BAFs and models to incorporate metabolism in the food chain and to reduce uncertainties associated with species, life stages, and effects end points associated with ecological risks for PBTs.

- $\quad$ Provide a bioaccumulation model for complex mixture of PAHs in fish ELSs suitable for assessment of risks to feral fish populations to photo-activated toxicity under project B4.

\section{Scientific Approach}

Bioaccumulation factors, BSAFs, and food chain models incorporate both generic (non-site specific) and site specific elements of bioaccumulation science. A conceptual model for integrating high quality bioaccumulation monitoring data with mechanistically based food chain bioaccumulation models (e.g., Gobas 1993) will be used for advancing and organizing methods for linking chemical residue-based effects data to chemical concentrations in water and sediments; and then for risk based WQC development, sediment remediation evaluations, and aquatic ecological risk assessments in general. These methods are expected to be an evolutionary advancement of bioaccumulation methods presently incorporated into EPA's Great Lakes water quality guidance (EPA 1995b), the methodology for deriving ambient WQC for the protection of human health (EPA 2000f), and the framework for application of toxicity equivalence methodology for polychlorinated dioxins, furans and biphenyls in ecological risk assessment (EPA 2002). The research results will be organized to maximize the accuracy for applying general bioaccumulation data and models to site-specific assessments with no or minimum data collection on site is required.

\section{Field Data Requirements.}

In general, models and tools for extrapolation and/or prediction can be developed only when adequate experimental data are available. One of the major objectives of this research plan is to develop field data of the appropriate quality and breadth for improving bioaccumulation models and tools. Breadth of field data includes the completeness of the measurements on all components of the food web and its surroundings, and the range of properties associated with the chemicals of interest. Furthermore, these field measurements must be intrinsically connected so that data from each component are reflective of the conditions sensed or felt by the other components. Depending on the ecosystem of interest, measurements over time might be required. In this research effort, field data will be developed for all analytes using capillary column gas chromatograph/mass spectrometry (GC/MS) techniques with stable isotopes and MS resolution of 10,000 . The use of analytical techniques with these characteristics will reduce uncertainties and biases associated with field data, and when used for all environmental components, will provide data of comparable quality among all components of the food web and its surroundings.

Initially, a high quality bioaccumulation data set for a four trophic level, mixed benthic/pelagic food web from southern Lake Michigan will be developed for PCBs, PAHs, PCDDs, PCDFs, and some chlorinated pesticides. This list of analytes might be expanded after the initial analyses for other PBTs which have useful properties for development of bioaccumulation models and tools (e.g., chemicals with large molecular weights, $>600 \mathrm{amu}$, or useful metabolism rates in fish). 
This effort will include samples for components of the food web and its surroundings (i.e., phytoand zoo-plankton, benthic invertebrates, forage fishes, and piscivorous fishes), sediments, and water column. In addition, ancillary data such as lipid contents and organic carbon contents will be measured. For the purposes of evaluating extrapolation procedures, existing data sets will be used and when necessary, high quality measurements will be performed in this investigation.

\section{Determination of Metabolism Rates.}

Mechanistic models for predicting chemical residues in aquatic food webs historically have included a rate constant for the metabolic loss of chemical in organisms (Gobas 1993, Thomann et al. 1992). Although biotransformation of most all compounds occurs in fishes, common modeling practices to date set the metabolic loss rate to zero because many PBTs are thought to have rates of metabolism so slow that they can be considered non-metabolizable (although metabolism rates have not been measured for nearly all the PBTs). In the absence of measured metabolism rates, the default modeling assumption of "no metabolism" is used in modeling exercises. This practice of tacitly assuming that metabolism is not important for PBTs has largely come about because nearly all the modeling exercises have been performed for PCBs, a class of chemicals that bioaccumulate to a degree that suggests extremely low rates of metabolism. Consistent with this assumption, the validation efforts to date have shown that the food web models have excellent predictive ability for PCBs.

This research effort will evaluate the use of field data to infer and deduce information about metabolic rates for PBTs. The approach for determining rates of metabolism involves the use of mechanistic food web models together with high quality field data. With these models and the high quality field data, the models can be solved for the rate of metabolism for the chemical of interest. In essence, the difference between the model prediction using no metabolism and the actual field data is accounted for by the metabolic rate loss parameter if the model parameters are set to accurately predict bioaccumulation for non-metabolized congeners. This research effort will define for the approach the data quality requirements, and the range of metabolic rates and bioaccumulation potential for which the methodology will work.

\section{Bioaccumulation Models for Fish ELSs.}

If metabolism rates can be effectively determined from field data as proposed, the final step in bioaccumulation model development for risk assessments involving metabolizable PBTs will be the development of empirical and mechanistic bioaccumulation models for fish during ELSs. This is a four step process: 1) develop models for bioaccumulation of PBTs (with varying rates of metabolism) by female fish, 2) develop maternal transfer models (empirical to PB-TK) to predict bioaccumulation by embryos, 3 ) develop post-spawning bioaccumulation models (empirical to mechanistic) to predict uptake and elimination of PBTs (with varying rates of metabolism) by fish at different stages of development, and 4) determine inter-species differences in ELS bioaccumulation and strategies for inter-species extrapolation of ELS dosimetry data. Step 1 is part of the general bioaccumulation model development and step 2 has a foundation in field data (e.g., Guiney et al. 1996) and PB-TK models developed (e.g., Nichols et al. 1997). Step 3 is an essential element of research on risks of PAHs to fish ELSs under project B4. Thus, over time projects B2 and B4 will have an increasing degree of shared research 
objectives. Step 4 requires further consideration of fish ELS dosimetry in the context of the mechanism of toxicity associated with the PBT risk being assessed. For example, photoactivated toxicity of PAHs in larval fish will involve accumulation of the PAHs in specific tissues for which UV light activation is possible.

\section{Inter-Ecosystem Extrapolations.}

The research approach for improving inter-ecosystem extrapolations and comparisons of bioaccumulation data will involve the development of appropriate data sets for a variety of ecosystem classifications and chemical loading scenarios. With this information, bioaccumulation models and tools can be tested and evaluated. The emphasis, initially, will be on testing the effectiveness of simpler extrapolation techniques. Extrapolations and comparisons of data across ecosystems will involve consideration of differences in the sediment-water chemical concentration ratios, departure from steady-state distribution of chemical, food web depth (number of trophic levels), and food web composition (benthic-pelagic). The results of these comparisons will be used to determine the need for more specific and data intensive modeling approaches to reduce uncertainty to a level sufficient for accuracy consistent with capability to perform probabilistic risk assessments.

\section{Products}

FY02 Journal article describing the conceptual model for relating risk-based critical residue values in fish and wildlife to chemical concentrations in sediment and water (with context of risk-based WQC criteria and contaminated sediment based risk assessments).

FY02 Technical support document and site-specific methods for determination of BAFs associated with the methodology for deriving ambient WQC for the protection of human health (MED co-authorship with OW and NCEA).

FY02 Journal article on BSAFs for PCBs, PCDDs, PCDFs, and PAHs associated with the Lake Michigan food web and applicability to other ecosystems.

FY02 Journal article on validation of the BAF methods used for the methodology for deriving ambient WQC for the protection of human health.

FY03 Journal article on BAFs for PCBs, PCDDs, PCDFs, and PAHs associated with the Lake Michigan food web and applicability to other ecosystems.

FY03 Journal article on proof of concept for measurement of rates of metabolism of PCBs, PCDDs, and PCDFs from high quality food web data.

FY04 Journal article on measurement of rates of metabolism of PAHs from high quality food web data with toxicokinetic model interpretation.

FY04 Report on application of site-specific BAFs and models in conjunction with risk assessments requiring extrapolations across species, life stages, and effects endpoints. 
FY05 Journal article or internal report on bioaccumulation of PAHs by fish during early life stages of development.

FY06 Journal article on model/s (including PB-TK) for prediction of bioaccumulation by fish during early life stages of development.

Benefits of Products

The overall benefit is anticipated improvements in bioaccumulation measurements, models, and site-specific applicability, coupled with conceptual clarification of how to incorporate multimedia exposure relationships (water, sediment, food chain) into application of chemical residuebased toxicity data for development of WQC/WQS, TMDLs, or management of contaminated sediments. A specific benefit will be much improved capability, including guidance for sample collection and analysis requirements, for extrapolating measured BAFs and BSAFs between ecosystems. The capability to provide species and chemical specific rates of metabolism for food chain model predictions of bioaccumulation will be a significant improvement since many PBTs have reduced bioaccumulation in parts of the food web due to metabolism. Practical and beneficial combinations of empirical and mechanistic modeling methods will be defined to increase both ease and accuracy of bioaccumulation predictions for site-specific criteria and risk assessment applications. Also expected is demonstration of the integration of the basic bioaccumulation models with toxicokinetic models as required for PBT criteria and risk assessments involving particular modes of action and critical effect end points.

\section{Project Title B3. Multiple Stressor Risks to Common Loon and Other Piscivorous Bird Populations (cross-listed in Section 4, Habitat Alteration, Project 4)}

Project Coordination and Resources (6.9 FTEs: AED-5.4, MED-1.5)

\section{Objectives}

This project has been developed as a demonstration and evaluation of the utility of the research approaches described in NHEERL's WRS (EPA 2000e). The wildlife strategy describes research approaches that address key research needs, including improved capabilities for cross-species extrapolation, prediction of population dynamics in spatially-explicit habitats, assessment of the relative risk of chemical and non-chemical stressors, and definition of appropriate spatial scales for wildlife risk assessments. This project is one of several that will be developed to evaluate the approaches and key hypotheses regarding risks to wildlife species that are described in the wildlife strategy. In addition to its consistency with these overall objectives, this specific project was identified because it involved minimal data collection activities and addressed a problem of immediate concern to the Agency.

The overall objective of this demonstration project is to develop the tools and approaches for assessing the risks of multiple stressors to populations of piscivorous wildlife, leading to the development of risk-based criteria. Three major research objectives include: 
- Develop approaches for predicting population-level responses to stressors, and identify the responses at the individual level that have the greatest influence on population-level responses (APG 3).

- Develop mechanistically-based approaches for extrapolating toxicological data across wildlife species, media, and individual-level response endpoints (APG 4).

- Develop approaches for evaluating the relative risks from chemical and non-chemical stressors on spatially structured wildlife populations across large areas or regions (APG 5).

The research described here attempts to make advances in each of these research areas through a single demonstration project designed to develop the tools and approaches necessary to conduct a multi-tiered assessment of the risks of PBTs, (e.g., mercury) to populations of piscivorous birds in New England and the upper Midwest. In the process of developing the approach and tools for conducting the risk assessment, we will also develop a framework for establishing wildlife criteria using piscivorous birds and $\mathrm{Hg}$ as the example. In conjunction with project $\mathrm{Bl}$, the methods and models developed in this demonstration project will be evaluated for their applicability to other PBTs and other wildlife species. This demonstration project focuses on issues starting with the exposure of birds to mercury in the fish (and other dietary components) they consume, rather than focusing on fate and bioaccumulation within the wholly aquatic portion of the food web. Many of the issues addressed in the development of population and spatial models in this project should contribute to the development of more generalized approaches for assessing risks to wildlife species.

It should also be noted that another component of this project involves the assessment of the interactive effects of landscape-level habitat alteration and mercury on loons. This project also is described in Section 4 (Habitat Alteration) because there are significant research issues regarding habitat alterations, including evaluating the spatial configuration of loon habitat and mercury impacts in the landscape mosaic and the issue of scaling up from local to regional impact assessments.

\section{Scientific Approach}

Mercury contamination remains a high priority issue for several EPA Program Offices and Regions because of widespread atmospheric deposition and concerns of accumulation through aquatic food webs. Although there is evidence of reduced productivity in some piscivorous birds and widespread reports of wildlife tissue mercury concentrations exceeding levels associated with adverse effects in controlled studies, it is unclear what impact this has on the viability of populations of piscivorous wildlife. Also, mercury contamination exists within a patchwork of other co-occurring stressors to wildlife populations, but the relative risks are poorly understood. Because mercury bioaccumulates in the aquatic food web, this demonstration project focuses on the risks of mercury to top level predators (piscivorous birds, in particular, common loons [Gavia immer]), associated with mercury exposure in the environment. Given the heterogeneous distribution of stressors (e.g., dietary methyl mercury, habitat degradation, acidification, human disturbance), the project will attempt to identify the spatial relationships among stressors (i.e., 
correlations in distributions), the potential interactions among stressor impacts, and the relative risks among potential stressors to populations of loons at various spatial scales. The research will secondarily characterize risks for the belted kingfisher (Ceryle alcyon), another piscivorous bird that is often the focus of ecological risk assessments because its small body size and high food ingestion rate lead to estimates of high potential risk.

To improve the process of developing risk-based criteria for mercury protective of loons and other piscivorous birds, advancements in model and method development and data acquisition are needed in five major areas. First, the landscape of interest needs to be characterized, including the spatial and temporal distribution of stressors and available habitat for species of interest. Second, stressor-response relationships are needed, especially for endpoints related to survival and fecundity rates. Relationships may be developed empirically from field data or generated in laboratory tests based on representative exposure scenarios. Third, methods for interspecies extrapolations of stressor-response relationships for mercury are needed. Fourth, age-class matrix population models incorporating stressor-response relationships are needed for loons and other piscivorous birds. Fifth, population dynamics need to be assessed across heterogeneous landscapes where variable stressor levels and habitat qualities influence the distribution of populations. Information from the five areas is connected through important feedback loops (e.g., knowledge of population dynamics captured in the matrix models also informs the selection of landscapes and endpoints for dose-response testing). Research on landscape characterization, population model development, and determining and extrapolating dose-response information will proceed in parallel. The level of refinement needed in the models and acquired data is a function of the degree of uncertainty acceptable for setting criteria, so the application of tools will explicitly consider the availability and quality of data for various tiers of risk assessment.

\section{Landscape Characterization.}

A demonstration project on risks to loons would focus on landscapes in the upper Midwest and Northeastern United States. Characterization of these landscapes would include:

Collection of mercury residue distribution in fish and water bodies across the landscape. This would be based primarily on a synthesis of existing monitoring data from Federal, State, academic, and non-profit organization sources.

- Characterization of habitat quality for species of interest across the landscape. For loons, key habitat characteristics would include presence of suitable nesting and brood rearing sites, measures of human disturbance, density or extent of human dwellings and other activities around lakes, turbidity, and the availability of suitable forage fish supplies. This information would be synthesized from available monitoring databases and/or aerial photographs.

- Collection of data on the abundance and distribution of loons and other piscivorous birds, and on juvenile production rates by location. This information would be based on longterm loon monitoring programs that exist in the upper Midwest and the Northeast. 


\section{Stressor-response Relationships.}

Although information currently exists on the toxicity of mercury to several bird species, none of the tests were conducted in such a way that dose-response relationships can be estimated and none were conducted with carnivorous species. In fact, testing of avian reproduction effects is rarely done with the intent of defining dose-response relationships for population-related endpoints. Development of dose-response relationships would include:

- A controlled dosing study to determine dose-response relationships for methyl mercury effects on survival and fecundity of American kestrels (Falco sparverius). Husbandry methods for breeding piscivorous birds in captivity generally have not been developed, but the kestrel has a long history of successful breeding under laboratory test conditions. This study is currently being conducted in cooperation with USGS Patuxent Wildlife Research Center and NCEA.

- Empirical development, from existing field monitoring data, of stressor-response relationships for measures of productivity for other types of stressors, including habitat impairment, human disturbance, and lake acidification. It will be more difficult to show a relationship of these stressors to adult survival.

\section{Interspecies Extrapolation.}

Extrapolation methods are needed for estimating toxicity in untested species from tested species, from laboratory tests to free-flying wildlife, and across media. Extrapolation of toxicity information includes:

- Development of PBTK/TD models for methyl mercury in kestrels for predicting effects in loons and other piscivorous birds. Mercury residue information from studies with kestrels will be used to develop residue-response relationships sensitive to the duration of exposure. The PBTK/TD model then will be used to predict the movement and effects of methyl $\mathrm{Hg}$ in other species. This model will be developed through a cooperative project with USGS (Patuxent) and NCEA.

- Empirical extrapolation methods based on a synthesis of existing toxicity databases. These methods estimate a distribution of sensitivity across tested species, but are poor predictors of where a specific species would fall in that distribution. This work would build on existing syntheses projects by including new data from the kestrel studies and other published data.

\section{Population Matrix Models.}

Age-class matrix models will be used to organize information on the population dynamics of loons and other piscivorous birds. Development of matrix models would include:

- Integration of life history information including adult and juvenile survival, fecundity, immigration and emigration rates, and density dependent factors into the model 
framework. This information largely will be synthesized from existing monitoring databases and literature. A data system for population modeling parameters will be evaluated with NCEA potentially as a component of the Wildlife Exposure Handbook and the NCEA-supported Wildlife Canada Exposure Model. Current monitoring efforts could also be focused to include measurement of this information.

- Development of approaches for integrating individual-level responses in order to extrapolate and predict population-level effects of anthropogenic stressors. This model development would be a primary objective of this demonstration project.

Identification of those responses at the individual-level that have the greatest influence on population-level responses (i.e., elasticity analysis). This analysis would be part of this demonstration project.

\section{Products}

FY03 PBTK/TD model for predicting individual effects of chronic mercury exposure to facilitate cross species extrapolation of toxicity responses.

APM 3A (GPRA \# 59) FY04 Population models that project the relative risks of multiple stressors (toxic chemicals, habitat alterations) to piscivorous birds (AED, MED).

APM 5B FY06 Approaches for addressing spatial scale issues in assessing risks of multiple stressors to wildlife populations in spatially-diverse landscapes (AED, MED).

Also see Section 4 Habitat Alteration, Project 4 for associated products.

\section{Benefits of Products}

This demonstration project will directly address APG 3 by providing methods for developing WQC based on characterization of population-level risks of toxic chemicals to aquatic-dependent wildlife.

Given the paucity of comparative toxicity data across taxonomic groups of wildlife, the development of a PBTK/TD model for mercury in birds will improve the capability for extrapolating chemical toxicity data across endpoints, life stages, and species of wildlife (APG 4).

The focus of this demonstration project, understanding stressor risks of individuals in the context of effects at the level of populations in spatially-diverse landscapes, will provide approaches for evaluating the relative and cumulative risks from toxic chemicals and non-chemical stressors on populations of aquatic-dependent wildlife (APG 5).

\section{Project Title B4. Risks to Fish Populations from PAHs in Natural Systems}

Project Coordination and Resources (4.0 FTEs: MED-4.0) 


\section{Objectives}

A major uncertainty in assessing the risks of PBTs to aquatic life is whether application of laboratory toxicological data adequately reflects complex exposure relationships and interactions important to responses in natural systems. Chemicals in one class of PBTs, PAHs, have been found in traditional laboratory tests to have relatively low toxicities, due both to a nonspecific mechanism of action and to reduced bioaccumulation in some organisms because of metabolic transformations of these chemicals. However, the toxicities of some PAHs to various aquatic organisms have been demonstrated to be greatly increased (by orders of magnitude) due to exposure to UV radiation (Bowling et al. 1983; Cody et al. 1984; Kagan et al. 1984, 1985; Oris and Giesy 1985, 1987; Newsted and Giesy 1987; Holst and Giesy 1989; Tilghman Hall and Oris 1991; Huang et al. 1993; Buckler et al. 1994; Ankley et al. 1994, 1995, 1997; Boese et al. 1997; Erickson et al. 1999). General principles of dosimetry for this enhanced toxicity, based on PAH accumulation and UV intensity, have been described (Newsted and Giesy 1987; Ankley et al. 1995, 1997; Erickson et al. 1999).

An analysis of fuel contamination of the clear waters of Lake Tahoe concluded that photoactivated toxicity posed a significant risk to zooplankton (Oris et al. 1998) and current data suggest that ELS fish in PAH-contaminated littoral zones of the Great Lakes are at risk (Mount et al. 2001). However, this risk is uncertain due to several factors, some specifically related to photo-activated toxicity and some of more concern to PBTs in general: 1) most research to date has used laboratory UV light sources with spectra different from natural sunlight; 2) both the intensity and spectra of UV light in natural systems vary spatially and temporally, resulting in receptor organisms receiving widely varying exposures depending on their life habits and the properties of the system; 3) PAH exposure can also vary widely within natural systems, especially between sediments and overlying waters, so that PAH accumulation can also depend on organism attributes and system properties; 4) the accumulation, and thus the effects, of PAHs can vary between laboratory and natural systems due to food chain influences and maternal transfer to young organisms; 5) the relative accumulation of and sensitivity to PAHs of different life stages are poorly known; and 6) research has usually used individual compounds or simple mixtures of commercially-obtained PAHs, in contrast to complex mixtures of PAHs occurring in contaminated natural systems. However, current knowledge of a) the general levels of PAH contamination and the magnitude of UV light in natural systems and b) the sensitivity of many organisms to photo-activated toxicity in the laboratory indicate a potential for major impacts due to these interacting factors.

Risks from PAHs will depend on a complex interaction among light, chemical, receptor organisms, and system characteristics. ELS fish are one group of organisms at potential risk. ELS fish potentially can have significant PAH accumulation due to maternal transfer to eggs, exposure of eggs to water and sediment, accumulation after hatching from food and water (especially when closely linked to sediments), and the absence of metabolic pathways which limit PAH accumulation in older fish. Provided that the fish behavior or the system attributes result in significant exposure to light, ELS fish might be particularly susceptible to UV-activated PAH toxicity because of their small size (i.e., large surface to volume ratios and short penetration distances) and lack of protective pigmentation and gill coverings. Past research has shown early life stage fish to be susceptible to photo-activated toxicity (Bowling et al. 1983; Oris and Giesy 
1985, 1987; Tilghman Hall and Oris 1991; Buckler et al. 1994), but use of this research to assess risk in natural systems is limited by the factors discussed above.

The overall objective of this research project is to develop more comprehensive and accurate assessments of the risks of PAHs to early-life-stages of fish that address the influence of UV radiation and exposure relationships in natural systems. To this end, PAH accumulation in ELS fish will be evaluated both in the laboratory and in natural systems; effects of accumulated PAH in ELS fish will be evaluated both under laboratory UV light and natural sunlight for both individual PAHs and PAH mixtures from contaminated systems; and likely risks based on these observed effects and on fish habits will be estimated for natural systems. This project will not address the incorporation of effects on ELS fish into fish population models, but will provide information important to population-level assessment methods such as those developed in projects B1 and B3 and also will examine the correlation of expected ELS effects with fish community health indices. Extensions of this work to general PBT assessments will be addressed in project $\mathrm{B} 1$.

\section{Scientific Approach}

Assessing the risks of PAHs to ELS fish requires consideration of several factors. First, environmental PAH concentrations must be characterized, including chemical partitioning information important to bioavailability. Second, UV radiation exposures must be evaluated relative to fish behavior and environmental conditions. Third, the accumulation of PAHs must be estimated as a function of fish age and environmental exposure concentrations, including consideration of maternal transfer, uptake by both egg and fry, multiple routes of exposure, and age-dependent metabolism. Fourth, good dosimetry relationships are needed which link mortality and growth to PAH accumulation in the fish, to the varying levels of UV radiation they receive, and to their age. Fifth, the combined effects of complex mixtures of PAH must be evaluated, including the effects of those PAHs which are not measured. This project will develop needed capabilities in these areas and will assess the likely risk of PAHs to ELS fish in selected natural systems.

\section{ELS Accumulation of PAHs.}

Meaningful assessment of the effects of PAHs (and other PBTs) on ELS fish requires that toxicity test results be applied with consideration of the importance of PAH accumulation to organism response and how accumulation might differ from that in natural systems. Such consideration should include not only accumulation after hatch from water and food, but also uptake from water during egg incubation and transfer from the matemal fish to the egg. The importance of these different routes of exposure depends on how rapidly PAHs accumulate during different life stages and at what life stages UV exposure is most important. Laboratory experiments will examine the accumulation of PAHs in ELS fish as a function of when exposure starts (parent fish, egg, newly hatched fry) to determine if PAHs originating from parents or taken up by eggs might significantly contribute to risks. Uptake relationships will be monitored as fish grow to determine at what age and to what extent metabolic transformation of PAHs becomes important for regulating accumulation. Accumulation also will be measured from ELS fish collected from and exposed in natural systems to determine its relationship to environmental 
PAH concentrations and to compare this with laboratory results. Results of these efforts will contribute to development of ELS fish bioaccumulation models for PBTs under project B2.

\section{Dosimetry Relationships for PAH Toxicity to ELS Fish.}

Effective assessment of the risk of PAHs to fish populations requires improved understanding of the relationship of PAH accumulation, UV intensity and spectrum, and fish age to various effects in ELS fish. Dosimetry relationships will be developed in the laboratory for selected individual PAHs. Experimental methods will be developed to allow continuous exposure of ELS fish to various levels of both PAHs and UV radiation. Tests will be conducted to address the effects of PAH levels, the duration/nature of prior exposure to PAHs, fish age, and UV intensity, duration, and variability.

A major impediment to PAH risk assessments is the complex mixtures that occur in most PAHcontaminated natural systems. Even if such mixtures could be completely characterized, the potencies of most constituents would be unknown and the combined toxicity could be significantly underestimated. The unaccounted-for toxicity could be addressed with an index which compares total measured photo-activated toxicity from a complex mixture to the expected toxicity based on measured accumulations of a subset of mixture constituents for which photoactivated potencies are known. Such an index could be based on the oligochaete Lumbriculus variegatus, for which phototoxicity bioassays are relatively simple and precise, and can involve either water or sediment exposures. The phototoxicity of complex PAH mixtures from selected sites and of reference PAHs to both $L$. variegatus and ELS fish will be tested to determine the utility of such an index.

\section{Assessment of PAH effects in Natural Systems and the Use of Photo-activated Potency as an Ecological Indicator.}

The effects of PAHs on ELS fish in selected natural systems will be evaluated using floating experimental platforms containing chambers in which fish can be exposed to site water and to various levels of UV radiation through selective wavelength screening. Such systems will provide a direct test of the legitimacy of concems about photo-activated toxicity for natural levels of PAHs and UV radiation, and provide data for testing the applicability of laboratory data and methods to the prediction of these effects.

MED scientists will also work cooperatively with researchers from the Great Lakes Ecological Indicators (GLEI) project to evaluate photo-activated PAH toxicity potency in sediments as an ecological indicator. GLEI staff will collect sediments samples from a stratified random set of coastal wetlands and tributaries to the Great Lakes. Samples will be shipped to MED and evaluated for photo-activated PAH toxicity potency using the oligochaete $L$. variegatus as described above. The measured potency of PAHs in these sediments will be compared to chemical characterization being conducted by the University of Minnesota cooperators, and indices of UV transmission in the water column, to estimate relative risk from this pathway at each site, using the photo-activated PAH toxicity models developed by MED in this and previous research. Additionally, estimated risk from photo-activated toxicants with be examined relative 
to measures of biological condition being collected for each site by GLEI staff to evaluate measured photo-activated $\mathrm{PAH}$ potency as an ecological indicator.

\section{Products}

FY03 Journal article on bioaccumulation of PAHs in ELS fish.

FY04 Journal article on dosimetry of photoactivated PAH toxicity to ELS fish.

FY05 Journal article on effects of complex PAH mixtures and ambient sunlight to ELS fish in natural systems.

APM 5A FY05 Report regarding assessment of risks to aquatic organisms from combined exposure to PAH mixtures and UV light in natural systems (MED).

\section{Benefits of Products}

Research to date has indicated that current PAH risk assessments do not adequately handle such issues as photo-activated toxicity, incompletely-characterized complex mixtures, and ELS exposure issues, so that risk might be greatly underestimated. However, there has been no direct evidence that risk is significant for the combinations of PAH contamination, UV light, and biological receptors in natural systems. This work will determine whether there should be concern regarding such toxicity for fish populations in PAH-contaminated areas. If this is the case, this would greatly impact the development of WQC and sediment guidelines for PAHs, as well as hazard assessments for other classes of PBTs which might require similar considerations. This work will also help improve general PBT exposure assessment methodologies, such as fish ELS accumulation models.

\section{Gap Analysis}

The overall goal of this research program is to develop procedures for risk-based criteria for toxic chemicals. The Critical Path subsection described the research needed to better describe the risks of toxic chemicals to aquatic life and aquatic-dependent wildlife populations and communities. The proposed research projects address these needs. Although the research program will expand and improve the approaches for developing criteria, this gap analysis reviews the needs (e.g., models, test methods, toxicity data, methods for assessing temporal and spatial distributions of exposure, and role of life history on species vulnerability) that will not be completely addressed by this program, but are required for development of a complete risk assessment capability for toxic chemicals.

Developing the scientific basis for risk-based criteria will require the overall conceptual framework and better modeling tools described in the research projects outlined above. While the focus of this research program is on the development of methods and models, there will be parameters required by these methods and models that can not be met adequately with existing data sources alone. New data will be generated for specific questions in a couple of our demonstration projects; however, a major gap for achieving our overall goal of developing risk- 
based criteria for chemicals will be the generation of new data for several steps on the critical path. For example, risk-based criteria will require data on dose-response relationships for various chemicals exposed to aquatic life and wildlife, but very few existing chronic exposure toxicity tests generate dose-response relationships, and we are not proposing new testing. Also, we are developing the basis for PBTK modeling that will be applied to a demonstration project for extrapolating toxicity estimates to other species, but more will be needed for generating physiological and metabolic information for broader applications of PBTK models. Finally, our demonstrations projects will use existing life history information, such as survival and fecundity rates, for setting parameters in population models, but scientifically-defensible population models for most aquatic and wildlife species will require new life history data that will not be the focus of this research program. These needs for new data for various models will be discussed further below.

Specific gaps are related to key components of the conceptual models for nonbioaccumulative and bioaccumulative toxicants (Figures 10 and 11). They are organized under the following headings: bioavailability, dosimetry and bioaccumulation, toxicity, and population models.

\section{Bioavailability}

One gap relates to the need to better understand exposure, which is outside of NHEERL's mission:

1. Exposure models are needed that can estimate physical transport and fate of chemicals. This includes persistence/degradation, partitioning, and especially chemical forms reaching aquatic organisms. Improved models will be needed for predicting chemical forms of metals and activities of organic chemicals in water, bulk sediments, and associated pore waters.

Two gaps relate to the needs for extending our modeling approaches to other chemicals and exposure scenarios:

2. Although this plan will, initially, develop models for ammonia and metals, gaps will remain for applying these models to other nonbioaccumulating chemicals. Organic chemicals with low bioaccumulation potential are an important class of chemicals which pose ecological risks through a variety of mechanisms of toxicity including disruption of endocrine functions. Present and future research in and outside of NHEERL on the effects of these chemicals requires models and data for exposure and bioavailability appropriate for linking the toxicology research results into criteria development and ecological risk assessment procedures.

3. Seasonal and spatial variability in bioavailabilities of chemicals, coupled with life stage changes, population movements, and mechanisms for avoidance of exposure, produce complications for determination of species vulnerabilities. This gap is presently being addressed only in the proposed research for loons (project B3). 


\section{Dosimetry and Bioaccumulation}

Two gaps relate to the development of PBTK models for improving understanding of doseresidue-response relationships and extrapolation among species or life stages:

1. Although the mercury-loon project (B3) will develop a PBTK/TD model in kestrels for use in estimating the toxicity of mercury to piscivorous birds, the toxicokinetics of mercury are not representative of other PBTs. This will limit the general applicability of these models to other chemicals.

2. Another gap for developing avian PBTK models is the paucity of information on avian physiology and metabolism for setting parameters in the models.

\section{Several gaps relate to improvements needed in bioaccumulation information:}

3. A method for determination of rates of metabolism for PBTs is needed in order to allow accurate predictions of bioaccumulation with aquatic food chain models. If the research proposed to demonstrate the feasibility of determining rates of metabolism from field data fills this important risk assessment need, additional studies will be required to provide the metabolism data for all PBTs of concern in diverse food webs.

4. Existing BAFs, BSAFs, and food chain models are based on whole adult organisms and thus may not be sufficient when dose to ELSs and/or specific tissues must be evaluated. ELS dosimetry-based BAFs and PB-TK models are needed to fill this gap. The metabolism rate gap extends to bioaccumulation of PBTs like the PAHs in embryo-larval stages of fish with potential vulnerability to photo-induced toxicity. Proposed photo-induced PAH toxicity research provides a beginning for filling this large gap. Additional research will be required to establish a general ELS toxicity risk assessment capability equal to that available for juvenile or adult organisms exposed to a wide variety of chemicals.

5. Very few bioaccumulation data sets are of sufficient quality to validate the uses of BAFs and BSAFs, especially when extrapolated across species and/or ecosystems. The intent of proposed NHEERL research is to maximize the capability for extrapolation of BAFs and BSAFs for PBTs. However, consistent data gathering efforts sponsored by Offices interested in the application of BAFs and BSAFs for criteria development and risk assessment are needed in order to provide measures of uncertainty involved in such extrapolations as well as bioaccumulation model predictions performed without calibration (site-specific measurement of BAFs and BSAFs).

6. Comprehensive and toxicity hazard assessment compatible BAFs, BSAFs, and food chain models are needed to meet the requirements of joint action toxicity models such as for TCDD toxicity equivalence or photo-induced PAH toxicity. 


\section{Toxicity}

Two gaps relate to the needs for toxicity data:

1. Critical to the idea of "risk-based" criteria is the need to understand the relationship between stressor intensity and responses affecting survival and reproduction (i.e., dose-response relationships). Although acute toxicity tests for aquatic life and wildlife usually produce doseresponse relationships, most chronic exposure test and reproduction tests are designed to estimate effects thresholds (e.g., no observed adverse effect levels [NOAELs]) rather than describe doseresponse relationships. Although some fish reproduction tests have been conducted with sufficient number and spacing of concentrations that dose-response relationships could be estimated, almost no avian reproduction testing has been done to quantify dose-response relationships. This is a large data gap, and OW presently may have no mechanism for generation of new toxicity data.

2. Because of their hydrophobicity, a majority of PBTs accumulate in the benthos of freshwater and marine systems. From benthic environments, PBTs transfer to higher tropic levels where adverse effects to wildlife may occur. Despite the acknowledged effects of PBTs at higher tropic levels, a gap exists in our knowledge of whether or not this class of chemicals also causes significantly adverse effects to benthic organisms, populations, and communities.

Bioaccumulation data for benthic organisms from contaminated sites around the country indicate exposure is occurring but we are not certain of the effects. To insure benthic ecosystems and resources are fully protected this gap should be addressed.

\section{Other gaps relate to the extrapolability of toxicity data among species and endpoints:}

3. Compared to aquatic organisms, the database of chronic exposure tests of effects on avian and mammalian survival and reproduction is much more limited, with much of the testing of nonpesticide chemicals done without standardized procedures. Consequently, the database for making interspecies extrapolations for wildlife is insufficient to significantly improve methods based on comparative toxicity relationships among species. This research program will be adding little new data for improving species sensitivity relationships for wildlife. Also, previous analyses of avian toxicity databases demonstrated no relationship between acute and chronic toxicity measurements for birds.

4. Virtually unexplored are the TKTD determinants for interspecies and inter-effect extrapolations of potency ratios required for $\mathrm{PBT}$ mixture toxicity risk assessment using a toxic units model approach, such as the additive TCDD toxicity equivalence model.

Several gaps relate to the need for improved toxicity models and databases:

5. Although models for predicting effects from fluctuating exposures models are proposed for development for metals and ammonia, a gap exists in this capability for organic chemicals.

6. Residue-based toxicity data bases need to be advanced and evaluated for applicability to aquatic ecological risk assessment requirements for PBTs. 
7. Complex, multi-stressor models, such as required for photo-induced PAH toxicity to fish during embryo-larval stage of development, need to be developed and applied to determine the magnitude of ecological risks which are presently highly uncertain.

\section{Other important gaps:}

8. In some cases, populations of chronically exposed aquatic organisms have demonstrated an evolved tolerance or genetic resistance to toxicity through chronic exposure. The potentially enormous and irreversible consequences of rapid evolutionary change suggest the importance of better understanding, predicting, and managing these anthropogenic impacts on aquatic and wildlife populations. In addition, technological advances now permit an identification of the genetic changes that may provide the key to understanding the mechanisms by which populations and species adapt or become extinct.

9. A gap exists in the development of biological indicators that can lead to diagnosis of developing toxicity problems in aquatic ecosystems before population impacts are observable. For example, commonly measured biochemical effects, such as P450 enzyme induction, are sometimes used as diagnostic indicators of exposure to specific categories of chemicals. However, these measurements are of limited use because their relationships to organismal, much less population-level, risks are not well understood.

10. NHEERL toxicology research plans organized outside of Goal 2 should consider criteria and aquatic ecological risk assessment needs in order to prevent gaps for the utilization of the research products to meet aquatic stressor data and methods requirements.

\section{Population Models}

Several gaps relate to the needs for information for developing population models:

1. The greatest limitation to the application of population matrix models is the paucity of high quality data on mortality and fecundity rates, and our limited understanding of density-dependent feedbacks and other ways populations compensate for losses due to stressors. Generalized population models are helpful for identifying information needs, but scenario-specific population models often will be limited by the lack of data about the populations of interest. Specific case studies have been chosen because of their relative wealth of population parameter information and the potential to identify the types and formats of data required for population models when applied to other species/region/stressor(s) combinations. The collection of basic life history information on fish and wildlife species is a gap not addressed by this effort outside of a few species covered under case studies.

2. Although life history information is being gathered by State and Federal resource agencies and others, it is not always in an adequate form for use in a population model. In addition to proposing methods for population modeling, we need to work with resource agencies to influence the format of life history information being gathered to improve its utility in risk assessment. 
3. Complex mixtures of PBTs are the norm, so interspecies differences in potency, as well as in bioaccumulation, for individual chemicals in the mixture must be factored into population level risk predictions.

4. Is absence of overt mortality, even for ELSs, an adequate effects end point for preventing population declines caused by PBTs or non-PBTs? If not, how do we determine what is adequate for aquatic invertebrates, fish, amphibians, or avian and mammalian wildlife? The presently proposed toxic chemicals research will fill this fundamental gap only to the extent that specific chemicals are intensively used as foci for development of models and risk assessment methods.

5. A national WQC methodology for different classes of PBTs needs definition, through use of a generic population model (or a suite of generic population models) of species characteristics, life stages, and toxicity effects that are most predictive of risks to populations, regardless of site conditions. This information will fill a gap which presently limits development of population level based, chemical-specific criteria, as well as determination of site-specific model and data requirements for application of the criteria.

Two gaps relate to the need for demonstrating and verifying the usefulness of population models:

6. Population models need to be developed and applied through case studies to explicitly demonstrate risk assessment requirements for prediction of adverse population impacts as a result of PBT toxicity-caused reductions in survival of aquatic organisms.

7. The proposed approaches in this research plan rely heavily on the accuracy of population models. The utility of these approaches must be evaluated through field verifications. More broadly, it must be better understood how different model types and levels of complexities are necessary to achieve the desired reduction in uncertainties for specific assessment needs. Only one project in this program addresses this need.

One gap relates to the importance of spatial scales for aquatic life assessments:

8. Spatially explicit population models are often required for assessment of risks to aquaticdependent wildlife populations that function in landscapes that integrate many lakes, wetlands, and streams. Because PBTs tend to distribute widely, if not uniformly, for long periods of time in aquatic habitats, uncertainty exists for when, and the extent to which, spatially explicit population models are requisite for assessment of risks to populations of aquatic organisms.

\section{References}

Aldenberg, T., Slob, W. 1993. Confidence limits for hazardous concentrations based on logistically distributed NOEC toxicity data. Ecotoxicol. Environ. Saf. 25:48-63.

Ankley, G.T., Collyard, S.A., Monson, P.D., Kosian, P.A. 1994. Influence of ultraviolet light on the toxicity of sediments contaminated with polycyclic aromatic hydrocarbons. Environ. Toxicol. Chem. 13:1791-1796. 
Ankley, G.T., Erickson, RJ., Phipps, G.L., Mattson, V.R., Kosian, P.A., Sheedy, B.R., Cox, J.S. 1995. Effects of light intensity on the phototoxicity of fluoranthene to a benthic macroinvertebrate. Environ. Sci. Technol. 29:2828-2833.

Ankley, G.T., Erickson, R.J., Sheedy, B.R., Kosian, P.A., Mattson, V.R., Cox, J.S. 1997. Evaluation of models for predicting the phototoxic potency of polycyclic aromatic hydrocarbons. Aquat. Toxicol. 37:37-50.

ASTM. 1988. Standard practice for conducting acute toxicity tests with fishes, macroinvertebrates, and amphibians. Designation: E 729-88. In 1988 Annual Book of ASTM Standards, Vol. 11.04. American Society for Testing and Materials, Philadelphia, PA, pp. 304322.

Baker, J.L., Barefoot, A.C., Beasley, L.E., Burns, L., Caulkins, P., Clark, J., Feulner, R.L., Giesy, J.P., Graney, R.L., Griggs, R., Jacoby, H., Laskowski, D., Maciorowski, A., Hihaich, E., Nelson, H., Parrish, R., Siefert, R.E., Solomon, K.R., van der Schalie, W. 1994. Aquatic Dialogue Group: Pesticide Risk Assessment and Mitigation. Society of Environmental Toxicology and Chemistry, Pensacola, FL.

Boese, B.L., Lamberson, J.O., Swartz, R.C., Ozretich, R.J. 1997. Photoinduced toxicity of fluoranthene to seven marine benthic crustaceans. Arch. Environ. Contam. Toxicol. 32:389-393.

Bonnet, C., Balbut, M., Ferard, J.-F., Martel, L., Garric, J. 2000. Assessing the potential toxicity of resuspended sediment. Environ. Toxicol. Chem. 19:1290-1296.

Bowling, J.W., Leversee, G.J., Landrum, P.F., Giesy, J.P. 1983. Acute mortality of anthracenecontaminated fish exposed to sunlight. Aquat. Toxicol. 3:79-90.

Breck, J.E. 1988. Relationships among models for acute toxicity effects: applications to fluctuating concentrations. Environ. Toxicol. Chem. 7:775-778.

Buckler, D.R., Kemble, N.E., Echols, K.R., Mount, D.R., Tillitt, D.E. 1994. Photoactivated toxicity of PAH to endangered fishes and standard laboratory test species. Abstracts, $15^{\text {th }}$ Annual Meeting, Society of Environmental Toxicology and Chemistry, Denver, CO, October 30November 3, 1994.

Burgess, R.M., Ryba, S.A., Cantwell, M.G. 2000. Importance of organic carbon quantity on the variation of $\mathrm{k}_{\mathrm{oc}}$ in marine sediments. Toxicol. Environ. Chem. 77:9-29.

Calvo, C., Donazzolo, R., Guidi, F., Orio, A.A. 1991. Heavy metal pollution studies by resuspension experiments in Venice Lagoon. Water Res. 25:1295-1302.

Cantwell, M.G., Burgess, R.M., Kester, D.R. 2002. Mobilization and phase partitioning of metals from anoxic estuarine sediments during periods of simulated resuspension. (In preparation.) 
Carey, J., Cook, P., Giesy, J., Hodson, P., Muir, D., Owens, W., Solomon, K., eds. 1998. Ecotoxicological Risk Assessment of Chlorinated Organic Chemicals. SETAC Press, Pensacola, FL. 375 pp.

Cody, T.E., Radike, M.J., Warshawsky, D. 1984. The phototoxicity of benzy[ $\alpha]$ pyrene in the green alga Selenastrum capricornutum. Environ. Res. 35:122-132.

Cook, P.M.., Carlson, A.R., Lee, H, II. 1992. Tissue residue approach. In Sediment Classification Methods Compendium, Chapter 7. EPA 823-R-92-006. EPA, Office of Water, Washington, DC.

Cook, P.M.., Zabel, E.W., Peterson, R.E. 1997. The TCDD toxicity equivalence approach for characterizing risks for early life stage mortality in trout. In Rolland, R., Gilbertson, M., Peterson, R., eds., Chemically-Induced Alterations in the Functional Development and Reproduction of Fishes. SETAC Press, Pensacola, FL, pp. 9-27.

Crane, M., Newman, M.C., Chapman, P.F., and Fenlon J. 2001. Risk Assessment with Time to Event Models. Lewis Publishers, Boca Raton, FL. 175 pp.

Di Toro, D.M., Hansen, D.J., McGrath, J.A., Berry, W.J. 2002. Predicting the toxicity of metals in sediments using organic carbon normalized SEM and AVS. (In preparation.)

Erickson, R., Kleiner, C., Fiandt, J., Highland, T. 1989. Feasibility of predicting the effects of fluctuating concentrations on aquatic organisms and possible application to water quality criteria. EPA-600/X-89-307. EPA, Duluth, MN.

Erickson, R.J., Ankley, G.T., DeFoe, D.L., Kosian, P.A., Makynen, E.A. 1999. Additive toxicity of binary mixtures of phototoxic polycyclic aromatic hydrocarbons to the oligochaete Lumbriculus variegatus. Toxicol. Appl. Pharmacol. 154:97-105.

EPA. 1973. Water quality criteria 1972. A report of the Committee on Water Quality Criteria, Environmental Studies Board, National Academy of Sciences, National Academy of Engineering. EPA-R3-73-033. Washington, DC.

EPA. 1980. Guidelines for deriving water quality criteria for the protection of aquatic life and its uses. Fed. Reg. 45:79341-79350.

EPA. 1991. Technical support document for water quality-based control. EPA/505/2-90-001. Office of Water, Washington, DC.

EPA. 1992. Framework for ecological risk assessment. EPA/630/R-92/001. Risk Assessment Forum, Washington, DC.

EPA. 1994. Interim guidance on determination and use of water-effect ratios for metals. EPA 823-B-94-001. Office of Water, Washington, DC.

EPA. 1995a. Final water quality guidance for the Great Lakes system, final rule. Fed. Reg. 60. 
EPA. 1995b. Great Lakes water quality initiative technical support document for the procedure to determine bioaccumulation factors. EPA-820-B-95-005. Office of Water. NTIS PB95187290.

EPA. 1997. Mercury study report to Congress-Volume VI: an ecological assessment for anthropogenic mercury emissions in the United States. EPA-452/R-97-008. Office of Air Quality Planning and Standards and Office of Research and Development, Washington, DC.

EPA. 1998. Guidelines for ecological risk assessment. EPA/630/R-95/002F. Risk Assessment Forum, Washington, DC.

EPA. 1999. 1999 update of ambient water quality criteria for ammonia. Office of Water, Washington, DC.

EPA. 2000a. Equilibrium partitioning sediment guidelines (ESGs) for the protection of benthic organisms: metal mixtures (cadmium, copper, lead, nickel, silver, and zinc). EPA-822-R-00-005. Office of Science and Technology and Office of Research and Development, Washington, DC.

EPA. 2000b. Technical basis for the derivation of equilibrium partitioning sediment guidelines (ESGs) for the protection of benthic organisms: nonionic organics. EPA-822-R-00-001. Office of Science and Technology and Office of Research and Development, Washington, DC.

EPA. 2000c. Methods for the derivation of site-specific equilibrium partitioning sediment guidelines (ESGs) for the protection of benthic organisms: nonionic organics.

EPA-822-R-00-002. Office of Science and Technology and Office of Research and Development, Washington, DC.

EPA. 2000d. Equilibrium partitioning sediment guidelines (ESGs) for the protection of benthic organisms: PAH mixtures. Draft report. Office of Science and Technology and Office of Research and Development, Washington, DC.

EPA. 2000e. Wildlife research strategy. NHEERL/ORD. September.

EPA. 2000f. Methodology for deriving ambient water quality criteria for the protection of human health. EPA-822-B-00-004. Office of Science and Technology, Washington, DC.

EPA. 2001. Workshop report on the application of 2,3,7,8-TCDD toxicity equivalence factors to fish and wildlife. Risk Assessment Forum, Washington, DC.

EPA. 2002. Framework for application of the toxicity equivalence methodology for polychlorinated dioxins, furans, and biphenyls in ecological risk assessments. Office of Research and Development, Washington, DC. (in prep.)

Farag, A.M., Boese, C.J., Woodward, D.F., Bergman, H.L. 1994. Physiological changes and tissue metal accumulation in rainbow trout exposed to foodborne and waterborne metals. Environ. Toxicol. Chem. 13:2021-2029. 
Farag, A.M., Woodward, D.F., Brumbaugh, W., Goldstein, J.N., MacConnell, E., Hogstrand, C. 1999. Dietary effects of metals-contaminated invertebrates from the Coeur d'Alene River, Idaho, on cutthroat trout. Trans. Amer. Fish. Soc. (in press).

Gobas, F.A.P.C. 1993. A model for predicting the bioaccumulation of hydrophobic organic chemicals in aquatic food-webs: application to Lake Ontario. Ecol. Model. 69:1-17.

Guiney, P.D., Cook, P.M., Casselman, J.M., Fitzsimons, J.D., Simonin, H.A., Zabel, E.W., Peterson, R.E. 1996. Assessment of 2,3,7,8-tetrachlorodibenzo-p-dioxin induced sac fry mortality in lake trout (Salvelimus namaycush) from different regions of the Great Lakes. Can. J. Fish. Aquat. Sci. 53:2080-2092.

Gustafsson, O., Gschwend, P.M. 1997. Soot as a strong partition medium for polycyclic aromatic hydrocarbons in aquatic systems. In Eganhouse, R.P., ed., Molecular Markers in Environmental Geochemistry. American Chemical Society, Orlando, FL, pp. 365-381.

Hall, L.W. Jr., Scott, M.C., Killen, W.D. 1998. Ecological risk assessment of copper and cadmium in surface waters of Chesapeake Bay watershed. Environ. Toxicol. Chem. 17:11721189.

Hickie, B.E., McCarty, L.S., Dixon, D.G. 1995. A residue-based toxicokinetic model for pulseexposure toxicity in aquatic systems. Environ. Toxicol. Chem. 14:2187-2197.

Holst, L.L., Giesey, J.P. 1989. Chronic effects of the photoenhanced toxicity of anthracene on Daphnia magna reproduction. Environ. Toxicol. Chem. 8:933-942.

Hook, S.E., Fisher, N.S. 2000. Sublethal toxicity of metals to marine copepods following dietary exposure: a consistent pattern emerges. Abstracts, 21 st Annual Meeting of Society of Environmental Toxicology and Chemistry.

Hook, S.E., Fisher, N.S. 2001. Sublethal effects of silver in zooplankton: importance of exposure pathways and implications for toxicity testing. Environ. Toxicol. Chem. 20:568-574.

Huang, X.D., Dixon, D.G., Greenberg, B.M. 1993. Impacts of UV radiation and photomodification on the toxicity of PAHs to the higher plant Lemna gibba (duckweed). Environ. Toxicol. Chem. 12:1067-1077.

Jones, J.R.E. 1964. Fish and River Pollution. Butterworths, London. 203 pp.

Kagan, J., Kagan, P.A., Buhse, H.E. Jr. 1984. Light-dependent toxicity of $\alpha$-terthienyl and anthracene toward late embryonic stages of Rana pipiens. J. Chem. Ecol. 10:1115-1122.

Kagan, J., Kagan, E.D., Kagan, I.A., Kagan, P.A., Quigley, S. 1985. The phototoxicity of noncarcinogenic polycyclic aromatic hydrocarbons in aquatic organisms. Chemosphere 14:18291834. 
Karickhoff, S.W., Morris, K.R.1985a. Sorption dynamics of hydrophobic pollutants in sediment suspensions. Environ. Toxicol. Chem. 4:469-479.

Karickhoff, S.W., Morris, K.R. 1985b. Impact of tubificid oligochaetes on pollutant transport in bottom sediments. Environ. Sci. Technol. 19:51-56.

Kim, S.D., Metzler, D.M., Cha, D.K., Allen, H.E. 2000. Is food-borne cadmium more bioavailable than sorbed/water-borne cadmium? Abstracts, 21 st Annual Meeting of Society of Environmental Toxicology and Chemistry.

Kooijman, S.A.L.M. 1987. A safety factor for LC50 values allowing for differences in sensitivity among species. Water Res. 21:269-276.

Latimer, J.S., Davis, W.R., Keith, D.J. 1999. Mobilization of PAHs and PCBs from in-place contaminated marine sediments during simulated resuspension events. Estuar. Coast. Shelf Sci. 49:577-595.

Lee, G., Ellersieck, M.R., Krause, G.F., Mayer, F.L. 1995. Predicting chronic toxicity of chemicals to fishes from acute toxicity test data: multifactor probit analysis. Environ. Toxicol. Chem. 14:345-349.

Leonard, E.N., Mattson, V.R., Benoit, D.A., Hoke, R., Ankley, G.T. 1993. Seasonal variation of acid volatile sulfide in sediment cores from three northeastem Minnesota lakes. Hydrobiologia 271:87-95.

Mancini, J.L. 1983. A method for calculating effects on aquatic organisms of time-varying concentrations. Water Res. 17:1355-1361.

Mayer, F.L. 1987. Acute toxicity handbook of chemicals to estuarine organisms. EPA/600/887/017. EPA, Gulf Breeze, FL. 274 pp.

Mayer, F.L., Ellersieck, M.R. 1986. Manual of acute toxicity: interpretation and data base for 410 chemicals and 66 species of freshwater animals. Resource Publ. 160. U.S. Fish and Wildlife Service, Washington, DC. 579 pp.

Mayer, F.L., Krause, G.F., Buckler, D.R., Ellersieck, M.R., Lee, G. 1994. Predicting chronic lethality of chemicals to fishes from acute toxicity test data: concept and linear regression. Environ. Toxicol. Chem. 13:671-678.

Meyer, J.S., Gulley, D.D., Goodrich, M.S., Szmania, D.C., Brooks, A.S. 1995. Modeling toxicity due to intermittent exposure of rainbow trout and common shiners to monochloramine. Environ. Toxicol. Chem. 14:165-175.

Mount, D.R., Barth, A.K., Garrison, T.D., Barten, K.A., Hockett, J.R. 1994. Dietary and waterborne exposure of rainbow trout (Oncorhynchus mykiss) to copper, cadmium, lead, and zinc using a live diet. Environ. Toxicol. Chem. 13:2031-2041. 
Mount, D.R., Diamond, S.A., Erickson, R.J., Simcik, M.F., Swackhamer, D.L. 2001. Linking exposure and dosimetry to risk from photo-activated toxicity of PAHs. Presentation, 22nd Annual Meeting of the Society of Environmental Toxicology and Chemistry, Baltimore, Maryland.

Neff, J.M. 1979. Polycyclic Aromatic Hydrocarbons in the Aquatic Environment: Sources, Fates, and Biological Effects. Applied Science Publishers, London.

Newman, M.C. 1995. Quantitative Methods in Aquatic Ecotoxicology. Lewis Publishers, Boca Raton.

Newman, M.C., Ownby, D.R., Laurent, C.A.M., Powell, D.C., Christensen, T.R.L., Lerberg, S.B., Anderson, B.-A. 2000. Applying species-sensitivity distributions in ecological risk assessment: assumptions of distribution type and sufficient numbers of species. Environ. Toxicol. Chem. 19:508-515.

Newsted, J.L., Giesy, J.P. 1987. Predictive models for photoinduced acute toxicity of polycyclic aromatic hydrocarbons to Daphnia magna, Strauss (cladocera, crustacea). Environ. Toxicol. Chem. 6:445-461.

Nichols, J.W., Jensen, K.M., Tietge, J.E., Johnson, R.D. 1997. A physiologically-based toxicokinetic model for maternal transfer of 2,3,7,8-tetrachlorodibenzo-p-dioxin in brook trout (Salvelimus fontinalis). Environ. Toxicol. Chem. 17:2422-2434.

Oris, J.T., Giesy, J.P. 1985. The photoenhanced toxicity of anthracene to juvenile sunfish (Lepomis spp.). Aquat. Toxicol. 6:133-146.

Oris, J.T., Giesy, J.P. 1987. The photo-induced toxicity of polycyclic aromatic hydrocarbons to larvae of the fathead minnow (Pimephales promelas). Chemosphere 16:1395-1404.

Oris, J.T., Hatch, A.C., Weinstein, J.E., Findlay, R.H., McGinn, P.J., Diamond, S.A., Garrett, R., Jackson, W., Burton, G.A., Allen, B. 1998. Toxicity of ambient levels of motorized watercraft emissions to fish and zooplankton in Lake Tahoe, California/Nevada, USA. Presentation, 8th Annual Meeting of the European Society of Environmental Toxicology and Chemistry, Bordeaux, France.

Simpson, S.L., Apte, S.C., Batley, G.E. 1998. Effect of short-term resuspension events on trace metal speciation in polluted anoxic sediments. Environ. Sci. Technol. 32:620-625.

Solomon, K.R., Baker, D.B., Richards, R.P., Dixon, K.R., Klaine, S.J., LaPoint, T.W., Kendall, R.J., Weiskopf, C.P., Giddings, J.M., Giesy, J.P., Hall, L.W. Jr., Williams, W.M. 1996. Ecological risk assessment of atrazine in North American surface waters. Environ. Toxicol. Chem. 15:31-76. 
Stephan, C.E., Mount, D.I., Hansen, D.J., Gentile, J.H., Chapman, G.A., Brungs, W.E. 1985. Guidelines for deriving numerical national water quality criteria for the protection of aquatic organisms and their uses. PB85-227049. NTIS, Springfield, VA.

Sun, K., Krause, G.F., Mayer, F.L., Ellersieck, M.R., Basu, A.P. 1995. Predicting chronic lethality of chemicals to fishes from acute toxicity data: theory of accelerated life testing. Environ. Toxicol. Chem. 14:1745-1752.

Thomann, R.V., Connolly, J.P., Parkerton, T.F. 1992. An equilibrium model of organic chemical accumulation in aquatic food webs with sediment interaction. Environ. Toxicol. Chem.17:615629.

Tilghman Hall, A., Oris, J.T. 1991. Anthracene reduces reproductive potential and is matemally transferred during long-term exposures to fathead minnow. Aquat. Toxicol. 19:249-264.

Wagner, C., Lokke, H. 1991. Estimation of ecotoxicological protection levels from NOEC toxicity data. Water Res. 25:1237-1242.

Weber, C.I. 1993. Methods for measuring the acute toxicity of effluents to freshwater and marine organisms. EPA/600/4-90/027F. EPA, Environmental Monitoring Systems Laboratory, Cincinnati, $\mathrm{OH}$.

Woodward, D.F., Brumbaugh, W.G., DeLonay, A.J., Little, E.E., Smith, C.E. 1994. Effects on rainbow trout fry of a metals-contaminated diet of benthic invertebrates from the Clark Fork River, Montana. Trans. Amer. Fish. Soc. 123:51-62.

Woodward, D.F., Farag, A.M., Bergman, H.L., DeLonay, A.J., Little, E.E., Smith, C.E., Barrows, F.T. 1995. Metals-contaminated benthic invertebrates in the Clark Fork River, Montana: effects on age-0 brown trout and rainbow trout. Can. J. Fish. Aquat. Sci. 52:1994-2004. 


\section{Section 8. \\ Implementation Plan for Diagnostics Research}

\section{Problem}

States list surface waters as impaired on 305(b) reports or 303(d) listings based on one or more of three types of criteria: biological criteria (narrative or numeric), chemical criteria, or physical attributes (e.g., habitat quality assessments). When impairment is determined based on biological criteria ( $26 \%$ of impairment decisions), States are faced with the problem of diagnosing the cause of impairment before plans can be made to reduce the loading of pollutants through the TMDL process (40 CFR Ch.1, Part 130; U.S. EPA 1991; http://www.epa.gov/owow/tmdl/). The nation-wide scope of this problem is enormous; approximately 21,000 water bodies have been designated as impaired; or $44 \%$ of stream or river miles, $49 \%$ of lakes, reservoirs, and ponds; $98 \%$ of Great Lakes shoreline waters; and $42 \%$ of estuaries (EPA 2000a).

To improve overall efficiency of the TMDL process and to coordinate remediation activities, diagnosis of the cause of impairment is needed not only at the scale of individual water bodies, but also at the watershed scale. Unified Watershed Assessments, as specified in the Clean Water Action Plan (EPA 1998a) are needed at the watershed scale to identify aquatic systems for restoration actions (EPA 1999, Federal Register 2000, http://www.epa.gov/owow/uwa).

\section{Overall vision}

This plan for diagnostics research provides a comprehensive and integrated approach for problem solving. It is primarily responsive to EPA's regulatory and management needs, in particular the need for research related to the TMDL program, but also supports needs defined under Superfund, National Pollution Discharge Elimination System (NPDES), site remediations, and other relevant activities (e.g., FWS Natural Resource Damage Assessments). It provides a conceptual framework to determine current and future research priorities coordinated across NHEERL, and also discusses implementation in the context of research and expertise provided by other ORD Laboratories and the broader scientific community. Outputs from diagnostics research will be incorporated into a series of decision-support systems or modules for use by clients (EPA Regions, States, Tribes, and Program Offices).

NHEERL's diagnostic research focuses on the need to diagnose causes of biological impairment within an integrated framework linking watersheds with receiving water bodies to support the TMDL process and other regulatory programs. All stressors (habitat alteration, nutrients, suspended and bedded sediments, and toxic chemicals) will be considered under diagnostics research; however, greater emphasis may be placed on an individual stressor, combinations of stressors, and/or modes of action according to the prevailing problems or issues of a habitat, water body, ecosystem, region, or the nation as a whole. The starting point for diagnostic research is the need to respond to reports of biological impairment, nonattainment of aquatic life use, and other indications of adverse effects (e.g., toxicity). Initial assessments also can record evidence of multiple potential causes of impairment and conflicting lines of evidence that might 
complicate a diagnosis. Thus, the endpoint for the diagnostic process includes both the definition of the primary causes of impairment as well as the allocation of observed effects among multiple potential stressors, and the assessment of potential interactive effects among stressors.

To narrow the number of realistic stressors of concem, an approach based on the Toxicity Identification Evaluation (TIE) procedures will be developed. In the TIE process, toxic chemicals are first considered in broad classes. As the evaluation proceeds, the focus moves towards specific chemicals. In this way, large numbers of insignificant chemicals are excluded from further evaluation. For example in a sediment TIE, sediment may be classified as toxic due to organic chemicals, then narrowed to pesticides, and finally to DDT. Analogously, in diagnosing causes of impairment, an approach will be developed which starts with broad stressor classes (i.e., habitat alteration, nutrients, suspended and bedded sediments and toxic chemicals), then unimportant stressors will be disregarded, and ultimately, a specific stressor(s) will be selected as the cause of impairment.

In developing this plan, we considered and evaluated the States' implementation stages from monitoring through diagnosis to restoration. Implementation stages were then linked to associated uncertainties, research needs, and desired research products. From these efforts, APGs, their accompanying APMs, and the critical path for diagnostic research were developed, and are presented in the next two subsections. The evolution of a combined TMDL/Restoration Path from the current parallel paths for State/Tribal assessments, TMDL, and watershed restoration processes is described below.

\section{Goals}

There are four primary goals for this diagnostics research:

- Provide a framework for interpreting cause-and-effect relationships, including:

- Conceptual ecosystem models based on appropriate mechanisms of action that can be used to improve the accuracy of impairment decisions;

- Conceptual models to define ecosystem and watershed natural conditions and driving factors to use as a basis to quantify degree of impairment and to set restoration goals; and

- Classification frameworks that explain variation in the response of individuals, populations, communities, and ecosystems at regional, watershed, water body, and habitat scales.

- Develop single-stressor diagnostic methods and models to determine the primary source of biological impairment of aquatic ecosystems.

- Develop methods and models to allocate causality among multiple stressors and/or to diagnose interactions among them. 
- Develop methods and models capable of forecasting causality to evaluate the ecological benefits of source reductions, to investigate stressor interactions, and to assess the gains and losses realized by various alternatives for restoration and remediation.

Ancillary goals are to improve the state-of-the-science of monitoring and assessment in support of diagnostic methods, and to provide clients with diagnostic tools in user-friendly interfaces. Tools with different levels of accuracy and sophistication are needed within the program depending on cost-benefit ratios of decision making. Accordingly, the tools currently presented in this research plan range from simple screening tools (watershed classification schemes) to those of intermediate complexity (e.g., development of diagnostic community-scale indicators) to those of even greater complexity (e.g., use of linked mass-balance and food web models for Lake Michigan regional case study). Decision-support systems will be developed to incorporate all of these features as a format for technical transfer to ORD's clients. Conceptual model development will provide a general framework for decision-support systems, which will then be regionalized based on classification systems developed to explain differences in system behavior (e.g., stressor-response relationships). Tools for diagnosing both single-stressor impacts and multiple stressor interactions will be piloted using regional case studies. These pilots will then be incorporated as example applications into decision-support systems. Ultimately, the decisionsupport systems will be linked to tools developed by NRMRL, forecasting not only future impacts based on no action, but also the results of alternative remediation scenarios.

Annual Performance Goals have been derived by defining five implementation stages that the States must go through between monitoring and diagnosis of the causes of impairment (Appendix 1). Within each implementation phase, tasks that the States need to perform are defined, along with their associated uncertainties. These defined tasks are then used to derive related NHEERL research needs. Finally, research and technical transfer products are linked with these tasks, uncertainties, and research areas, and research and technical transfer products are identified as APMs associated with each APG. The time line for implementation of APMs is shown below, with APMs grouped by APGs.

APG 1 FY03 (GPRA \# 16) Provide the scientific foundation and information management scheme for the 303(d) listing process including a classification framework for surface waters, watersheds, and regions to guide problem formulation.

APM 1 A FY02 Conceptual framework for both single and multiple stressors including a consideration of cross-scale issues (AED, MED).

APM 1B FY03 (GPRA \# 202) Classification frameworks for geographic regions and at the watershed, water body and habitat scale (MED, GED).

APG 2 FY05 Provide first generation diagnostic methods, including stressor identification (SI) methods, for causal linkage of observed major classes of single stressors and biological indicators to stressors in freshwater and marine systems; scale the methods to States and watershed organizations.

APM 2A FY03 Guidance on whole sediment TIE procedures (MED, AED). 
APM 2B FY05 Application of coastal watershed and estuarine/lacustuary classification schemes to predict probability of impairment based on Great Lakes and Gulf of Mexico regional case studies (GED, MED).

APM 2C FY05 Guidance on and user-friendly interfaces for derivation of diagnostic indicators for individual stressors (MED, AED).

APG 3 FY07 Provide diagnostic methods and technical support documents for determining the relative significance of multiple stressors in 303(d) listed waters.

APM 3A FY02 Case studies of multivariate approaches to community data analysis to apportion cause among stressors. (AED, MED).

APM 3B FY06 Simulation of key stressor interactions with generic ecosystem models using sensitivity analysis to define the range of stressors and stressor combinations under which nonadditive interactive effects will occur (MED, AED).

APM 3C FY07 Decision-support system(s), including forecasting of future cause-effect relationships (MED).

\section{Critical Path}

The relationship of the diagnostic APGs to each other and to the research of other ORD laboratories (NERL, NRMRL) is defined in the critical path diagram (Figure 12). The steps in the critical path are described as follows:

Step 1. Develop a conceptual framework (APG 1 FY03).

This APG includes the development of conceptual models illustrating stressor-response relationships for single and multiple stressors and development of appropriate classification frameworks at the habitat, water body, watershed, and regional scales. Development of hierarchical classification frameworks involves the determination of which types of habitats, water bodies, watersheds, and regions are expected to behave similarly in response to a given level of stressor or loading. Thus, classification helps establish regional, watershed, or habitatspecific criteria and the range across which model extrapolations (including empirical stressorresponse curves) are appropriate. At this stage, the nature of significant interactions among stressors also will be defined based on the expected modes of action.

Step 2. Development of single-stressor methods and models (APG 2 FY05).

Methods and models for diagnosis of the predominant source of impairment from single stressors are needed. Significant input is required at this stage from other research areas (Sections 4-7).

Step 3. Development of multiple-stressor methods and models (APG 3 FY07). 


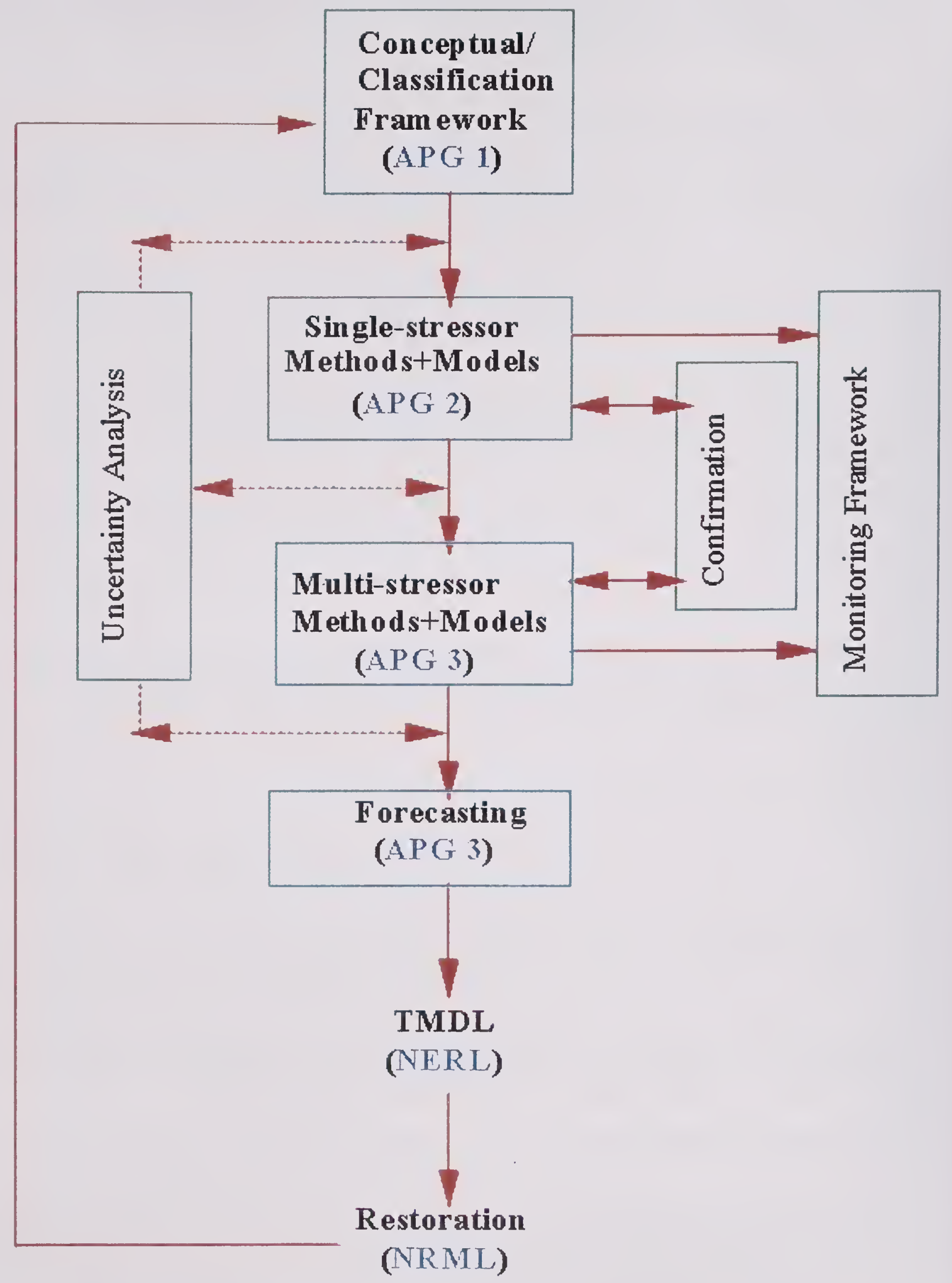

Figure 12. Critical path (flow of APGs) for diagnostics research. 
Methods and models for single stressors are combined and refined to diagnose multiple sources of impairment. The latter stage includes the development of tools both to allocate cause among multiple additive stressors and to diagnose significant interactive effects among stressors. The first stage in diagnosing significant stressor interactions will involve the use of generic ecosystem models to perform sensitivity analyses to determine the probability of observing significant interactions among stressor classes over realistic ranges of loadings or stressor levels (e.g., Bartell et al. 1984, Mitsch and Reeder 1991, Hanratty and Stay 1994, EPA 2000b). Ultimately these tools will be incorporated into a decision-support system.

\section{Step 4. Develop forecasting approaches.}

This step builds upon the development of multi-stressor methods and models to include forecasting techniques to project the response of aquatic ecosystems to load reductions and/or watershed restoration activities into the future. Forecasting methods will be particularly important in protecting large, complex, unique resources (e.g., Great Lakes, Gulf of Mexico, Chesapeake Bay) for which costs of restoration are large, interactions are involved, and lag times between an event and the eventual system response must be taken into consideration. Development of forecasting techniques will also allow NHEERL to be proactive in defining potential shifts in causes of impairment, and to anticipate future threats to the environment. Activities in this area will be coordinated with NRMRL.

Outputs from this research path will require collaborative efforts with NERL to develop improved loading models for TMDLs that include components predicting biological responses, and the development of appropriate exposure metrics to improve monitoring designs. In addition, classification frameworks and other tools developed here will be coordinated with research on prioritization of watershed restoration activities, prediction of recovery paths, and assessment of the success of remediation actions currently under way within NRMRL.

Methods and models developed under diagnostics research also will feed into the diagnostic logic flow sequence described in the EPA SI document for analysis of data for a weight-of-evidence approach (EPA 2000c). Potential points of influence on the SI overall process are presented in Figure 13.

In Figure 14, the research products (APMs) from the critical path are connected to the State/Tribal implementation stages for both the TMDL and watershed restoration processes for impaired surface waters, and then merged into an integrated process. The first APG, development of a conceptual framework, feeds directly into the problem formulation aspect of the diagnostic process and provides the basis for developing a decision-support system for the diagnostic process. The second APG connects directly to diagnosing the primary cause of impairment. The third APG provides research products which support three areas of the combined TMDL/Watershed Restoration path: Diagnostic and Condition-based Monitoring and Assessment, Allocation of Causes and Interactions among Multiple Stressors, and Confirmation of Diagnosis with Uncertainty Evaluation. The fourth goal supports diagnostic model development for forecasting and predictive approaches for the evaluation of remediation options. 


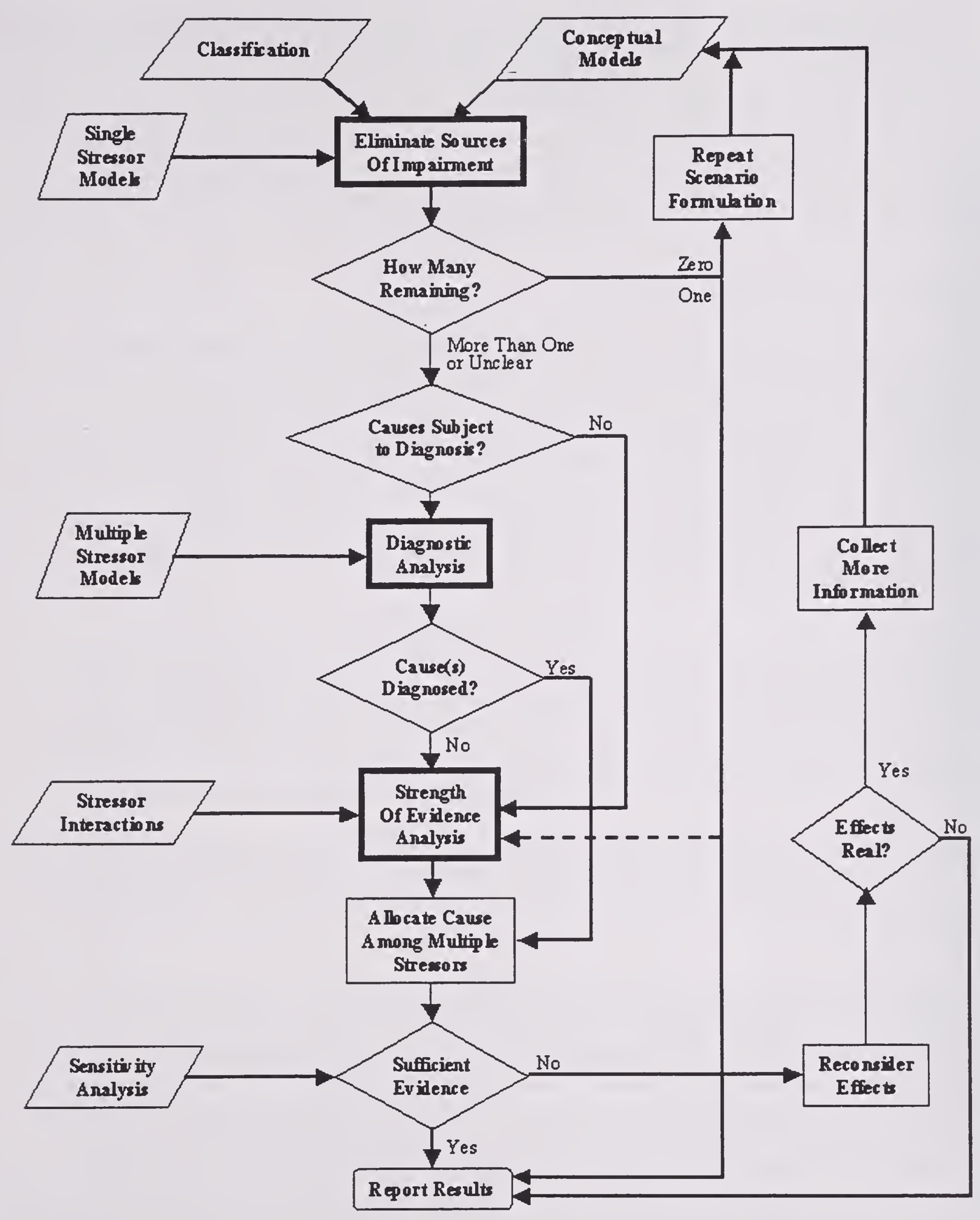

Figure 13. A logic for characterizing the causes of ecological injuries at specific sites. Modified from Figure 4-1 in SI document (EPA 2000c) to show potential inputs from aquatic stressors diagnostics research. 


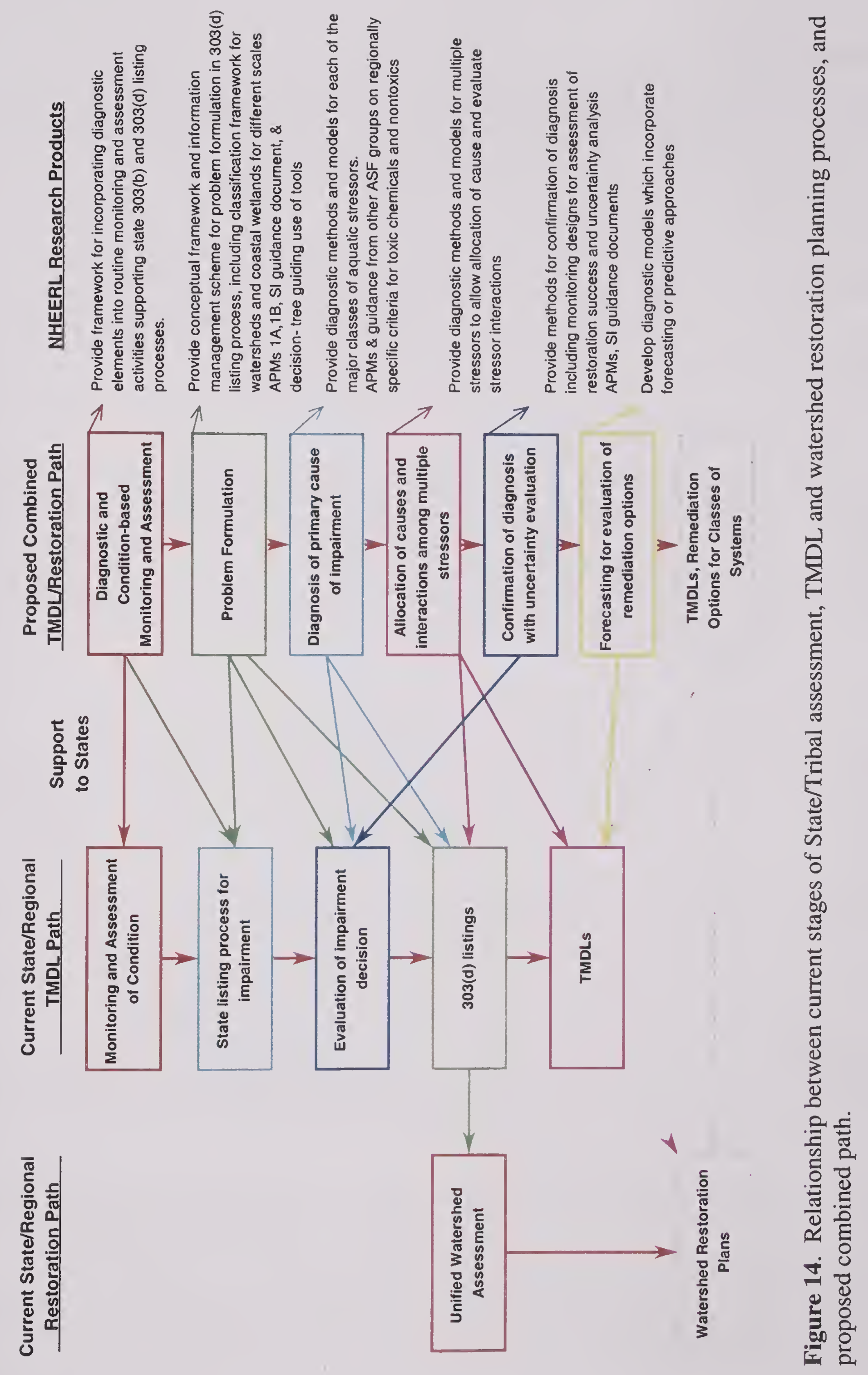




\section{Research Projects}

The research projects proposed here establish a conceptual framework to guide implementation of diagnostics, provide case studies to develop and test methods and models for both single-and multiple-stressor scenarios, assess the likelihood of multiple stressor interactions, and establish the structure for a decision-support system. Opportunities for interlaboratory collaboration on this research are shown in Appendix 2.

\section{Project Title 1. Conceptual Model Development and Information Management Framework}

Project Coordination and Resources (6.5 FTEs: FY02: AED, GED, MED [total $=6.0$ ]; FY03: MED-0.25, AED-0.25 [total $=0.5]$ )

\section{Objectives}

The goal of this project is to support the problem formulation stage in diagnostics (EPA 1996). The main objective is to develop conceptual models describing stressor-response relationships within ecosystems, including potential interactions among multiple stressors across all scales relevant to setting a protective TMDL (EPA 1996). These conceptual models will then provide the basis for creating a national database on nontoxic aquatic stressor-response relationships and for improving information management systems in support of 303(d) assessment activities.

\section{Scientific Approach}

Conceptual model development will focus on the effects of habitat alteration, nutrients, suspended and bedded sediments, and toxic chemicals on appropriate endpoints (individuals, populations, communities, ecosystems) across spatial scales (habitats, water body, watershed, region) relevant to setting a protective TMDL. This research will be coordinated across all of the Ecology Divisions and across all five research areas (Sections 4-7). Priorities for refining conceptual models for single and multiple stressors at the habitat scale will be established by examining the relative frequency of stressor $\mathrm{X}$ or stressor combination $\mathrm{X}_{1}, \mathrm{X}_{2} \ldots$ with habitat type Y combinations in the OW 303(d) listing database (EPA 2001, http://www.epa.gov/owow/tmdl/trcksys.html). A determination of impairment may be controlled by different factors as the scale of impact gets larger. Therefore, conceptual models will examine the cross-scale interactions (habitat $\Leftrightarrow$ water-body $\Leftrightarrow$ watershed $\Leftrightarrow=>$ region) that must be understood to determine the appropriate scale at which a protective TMDL must be established. In addition, the interactions among predominant stressors will be included as appropriate, based on expected mechanisms of action. Conceptual models will be developed through one or more cross-divisional workshops.

Two types of information management frameworks will be developed in support of the 303(d) listing process and diagnosis of the causes of impairments. First, a framework for supplying existing geospatial information for the problem formulation stage will be established. To identify potential causes of impairment, this framework will build upon database networks currently under development or refinement by $\mathrm{OW}$, including geospatial databases incorporated within the Better Assessment Science Interacting Point and Nonpoint Source (BASINS) 
modeling support system developed by EPA's OW/Office of Science and Technology (OST) (http://www.epa.gov/ost/basins/, EPA 1998b), STORAGE and RETRIEVAL database (STORET), the Water Quality Standards Database, the TMDL tracking database, and Watershed Assessment Tracking and Environmental Results Systems (WATERS). In addition, incorporation of toxicity data into EPA's STORET database will be coordinated with this effort.

In support of diagnostic efforts at the watershed scale, NHEERL will continue to collaborate with EPA's Office of Environmental Information (OED) and USGS Mapping Division (EROS Data Center) and Water Division in their work to produce a seamless nationwide geospatial database of watershed boundaries and associated hydrological derivatives [NED-H (now EDNA, Elevation Derivatives for Natural Applications), see http://edents 12.cr.usgs.gov/ned-h/index.html. Protocols for deriving watershed boundaries have been developed through an interagency task force coordinated by the Federal Geographic Data Committee (FGDC) and Advisory Committee on Water Information (ACWI), thus ensuring consistency across Federal agencies (see Federal Standards for Delineation of Hydrologic Unit Boundaries, 06/12/01 Draft; http://www.ftw.nrcs.usda.gov/huc data.html ). The USGS 8-digit hydrologic unit codes (HUCs) are being divided into finer units (10- and 12-digit HUCs) that are generally consistent with watershed boundaries for integrated drainages, and with boundaries for internal drainages to moderately-sized water bodies. The smallest of these units (12-digit HUCs) correspond to the scale of watersheds associated with wadeable streams. NHEERL is supporting development of GIS tools for automated watershed delineation using digital elevation models (DEMs), and hydrologic correction of existing DEMs to ensure consistency between synthetic streamlines and mapped hydrography. Thus, attributes coded using the National Hydrography Database for streams (the successor to EPAs Reach 3 stream files) will be consistent with the Nationwide Watershed Boundary Dataset under development. Regional case studies (project 3) will provide an opportunity to use the Nationwide Watershed Boundary Database under development to demonstrate its usefulness in watershed-scale monitoring designs, assessments, diagnosis, and management across an integrated series of watershed scales.

Second, a nonpoint-stressor analog to the Ecological Toxicity Database (ECOTOX) (http://www.epa.gov/ecotox/, Hunter et al. 1990) will be developed that will contain information on stressor-response relationships for nontoxics, stratified by an appropriate classification framework (project 2). ECOTOX is a source for locating single chemical toxicity data for aquatic life, terrestrial plants and wildlife. ECOTOX integrates three toxicology effects databases: AQUIRE, terrestrial plants (PHYTOTOX), and terrestrial wildlife (TERRETOX ). Toxicity test results and related testing information for any individual chemical from laboratory and field aquatic toxicity tests are extracted from the literature and recorded. Lethal, sublethal, and bioconcentration effects are recorded for freshwater and marine organisms, along with pertinent information on laboratory or field test conditions. The current database structure could be adapted readily to store information on stressor-response relationships for non-toxics. These data would ultimately support the development of regional and/or national criteria for nutrients and suspended and bedded sediments. 


\section{Products}

APM 1A FY02 Conceptual framework including consideration of both single and multiple stressors and cross-scale issues (AED, MED).

Database structure to support problem formulation in the diagnostic process (303(d) listings) and Nation-wide database for stressor-response relationships for non-point source stressors (all Ecology Divisions, FY03).

\section{Benefit of Products}

One of the difficulties in diagnosing the causes of impairment is the lack of an adequate information framework to support problem formulation. The APMs for this research area provide a conceptual framework for describing stressor-response relationships and an information framework for providing geospatial and toxicity data tailored to diagnostic applications (e.g., methods and models). Development of the geospatial database support system will be coordinated with the OW/OST because NHEERL will be adding to their BASINS modeling support system. These APMs will provide State, Regional, and Tribal authorities with critical and essential tools, which are currently unavailable, for starting the diagnosis process on an impairment problem. Ultimately, these information management tools can be incorporated into decision-support systems.

\section{Project Title 2. Classification Framework}

Project Coordination and Resources (10.6 FTEs: FY03: AED-0.4, GED-2.6, MED-5.0 [total = 8.0]; FY04: GED-2.6 [total $=2.6]$ )

\section{Objectives}

Integrated hierarchical classification schemes will be developed at the scale of habitats, water bodies, watersheds, and regions to identify systems that are expected to respond similarly to aquatic stressors (see Sections 4-7). For example, estuaries with longer retention times are more susceptible to the effects of nutrient loading (Palter and Dettman 1999). The relative impact of suspended and bedded sediments via sedimentation and physical habitat alteration versus turbidity also will depend on retention time. Even the effect of toxic chemicals can be expected to vary systematically depending on physico-chemical characteristics of water bodies and sediments such as organic carbon, acid-volatile sulfides, suspended solids, and hardness (Hamelink et al. 1994, Bergman and Dorward-King 1997).

\section{Scientific Approach}

The central question that must be answered to determine if a classification system will be useful for diagnosis is, "does grouping of systems by class simplify the problem of determining the cause of the observed ecological effects which are equated with an impaired condition of a water body?" We propose to answer this question by developing classification systems that are keyed to the different levels of a nested spatial hierarchy that proceeds as follows: habitat, water body, 
watershed, and region. Some classification schemes already exist for systems at each of the above levels of organization (Cowardin et al. 1979, Omernik 1987, McKee et al. 1992, Brinson 1993, Maxwell et al. 1995, Frissell et al. 1986, Rosgen 1996, Detenbeck et al. 2000). To be useful in diagnoses, classification systems must be based on differences in the spectrum of forcing functions that result in differences in the behavior of systems among classes, (e.g., fluvial versus lagoonal geomorphology of a water body). The key to the viability of a classification system at any of these hierarchical levels is that the classes identified behave differently under the influence of the stressor of concern. Once classes have been identified based on existing or new classification systems, an initial screening of the stressor-response data at all four levels of organization will determine if research should proceed further on a specific stressor/class combination.

Existing classification frameworks and necessary elements of an integrated classification strategy will be reviewed by a work group consisting of representatives from all Ecology Divisions, from each of the Aquatic Stressors research areas, and from experts on classification at each of the scales of interest. Representation will be requested from other ORD Laboratories and Centers, other Federal agencies, EPA Program Offices, and non-governmental organizations as appropriate. Logical collaborators on this task include the Landscape Sciences Branch at NERLLas Vegas, the Watershed Restoration planning group in NRMRL, OW [(OWOW), Office of Science and Technology (OST)], USGS (under NAWQA), FWS, NOAA, and the Nature Conservancy. Recent work on classification approaches within or outside of NHEERL is summarized in Table 4.

The classification workgroup will work towards the following goals:

- Identification of key factors (forcing functions) controlling sensitivity of response to different classes of toxic and nontoxic (non-point source) stressors.

- Identification of key factors determining sensitivity of response across multiple stressors to facilitate development of a comprehensive classification scheme rather than multiple schemes.

- Development of national and regional classification frameworks.

- Coordination of opportunities for testing classification strategies in a systematic fashion.

Efforts of this workgroup will be supplemented by the extramural grants STAR program. The STAR grants program has an existing request for proposals (RFP) on aquatic ecosystem classification, and might add an RFP on watershed classification strategies in the future.

Alternative strategies for classification will be tested through regional case studies (project 3). Regional case studies will be based on multiple-scale classification schemes, with coordination across Divisions to bring together appropriate areas of expertise. In particular, stressor-response relationships will be compared among regional/watershed/water-body classes. 


\begin{tabular}{|c|c|c|c|c|c|c|c|}
\hline & 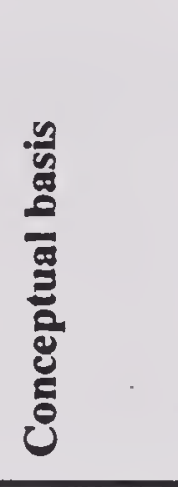 & 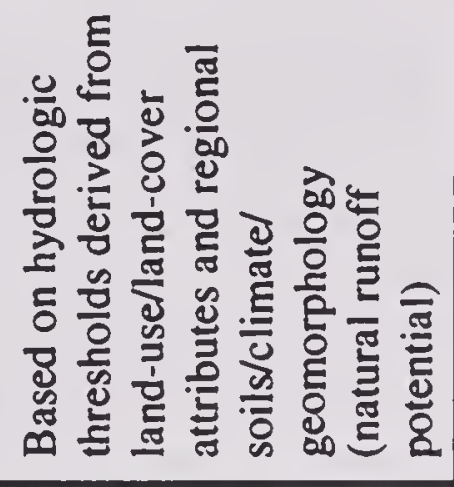 & 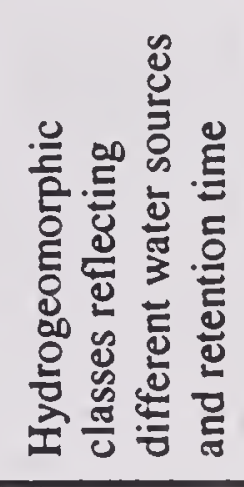 & 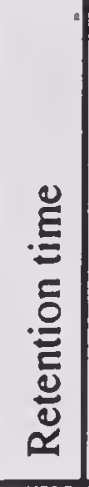 & 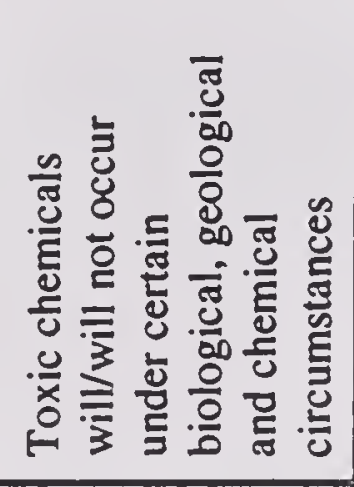 & 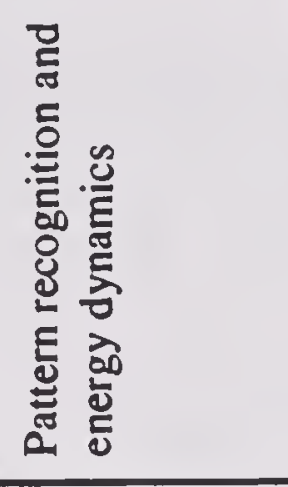 & 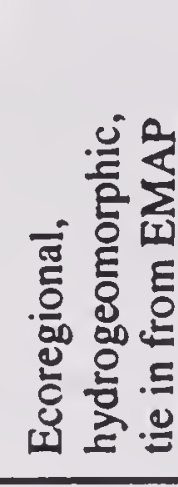 \\
\hline 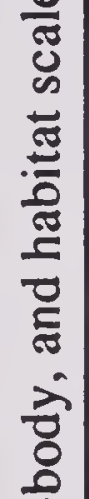 & 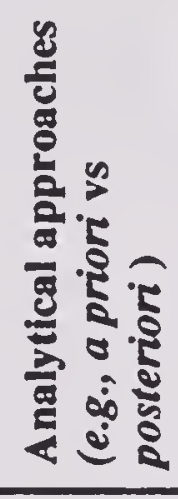 & 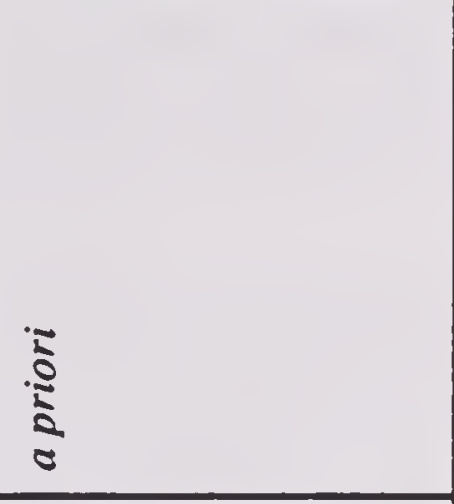 & 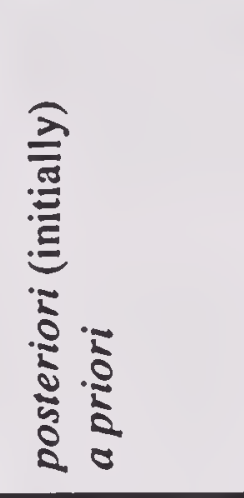 & 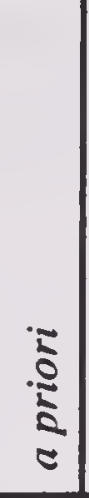 & 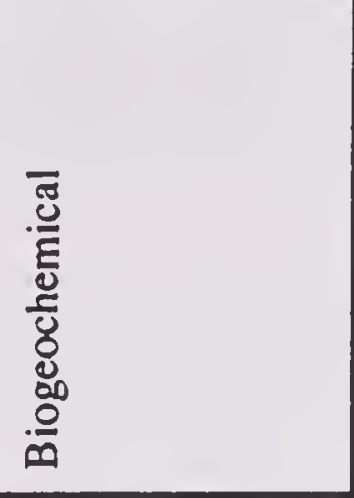 & 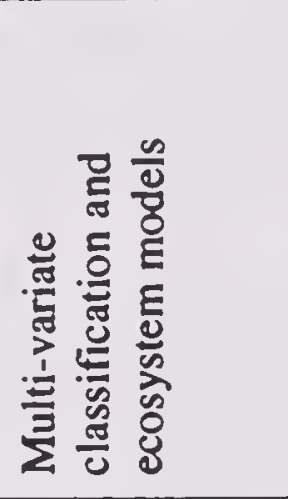 & $\begin{array}{l}\frac{\bar{d}}{x} \\
\frac{x}{\Sigma}\end{array}$ \\
\hline 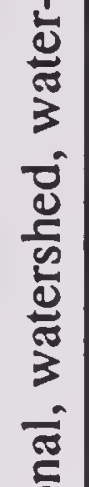 & 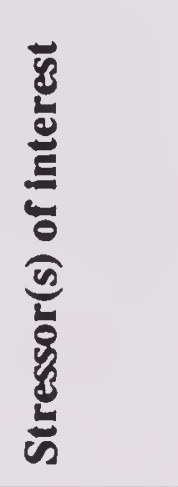 & 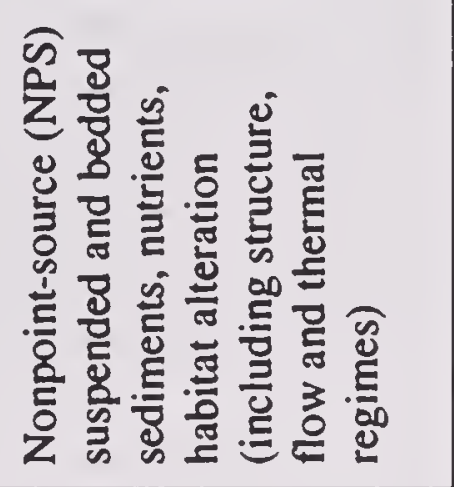 & 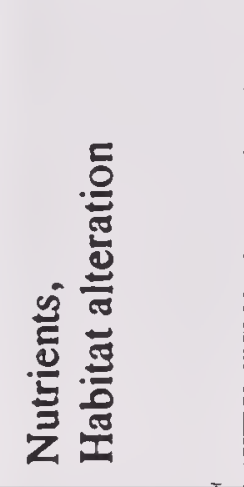 & 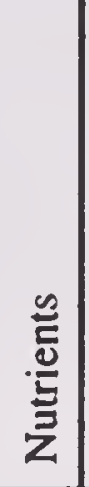 & 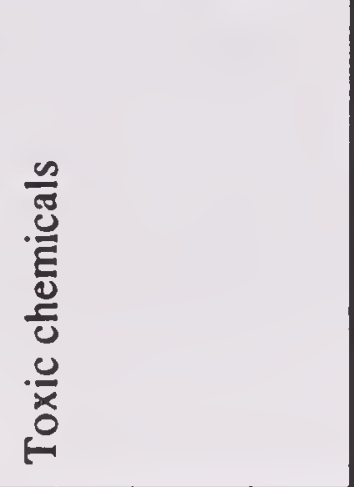 & 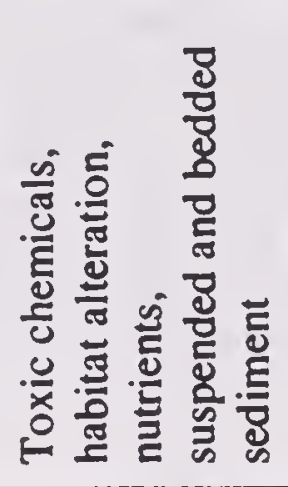 & 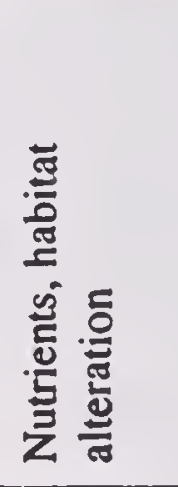 \\
\hline 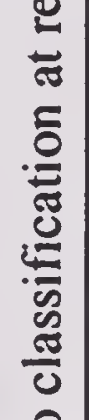 & 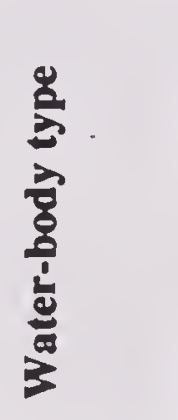 & 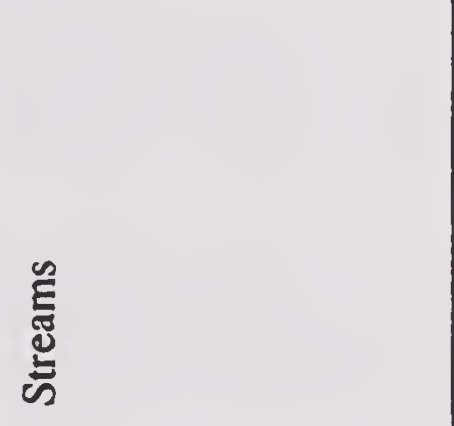 & 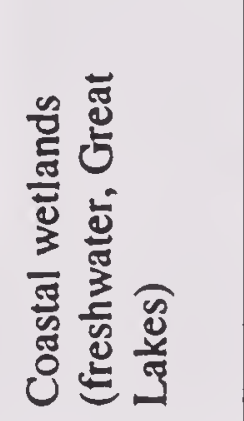 & 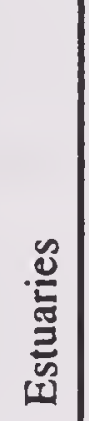 & 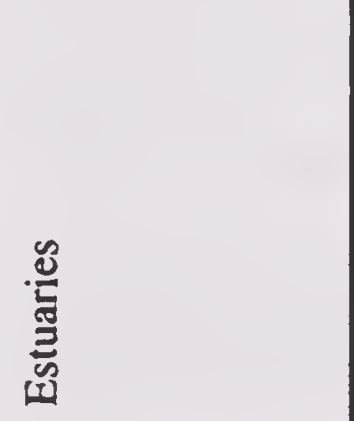 & 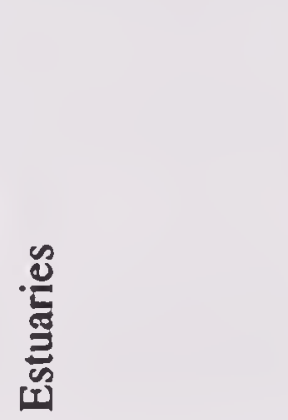 & 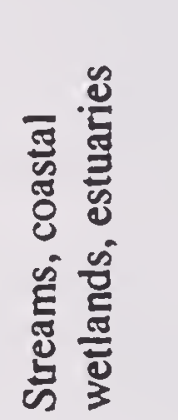 \\
\hline 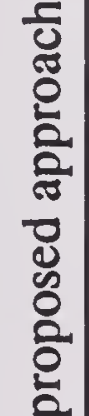 & 苋 & 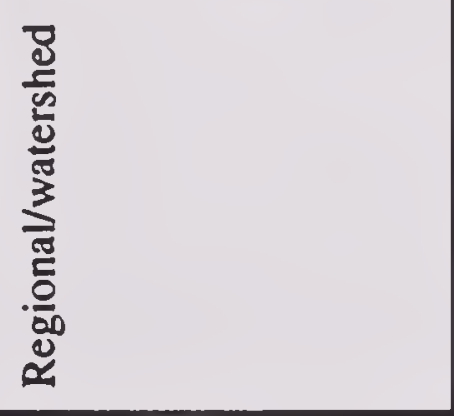 & 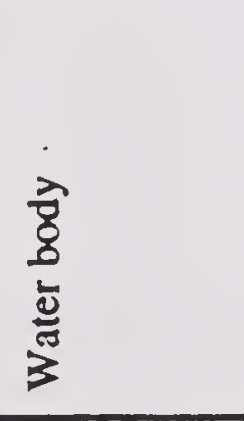 & $\begin{array}{l}\frac{2}{0} \\
\frac{8}{2} \\
\frac{\hat{d}}{5} \\
3\end{array}$ & 营 & 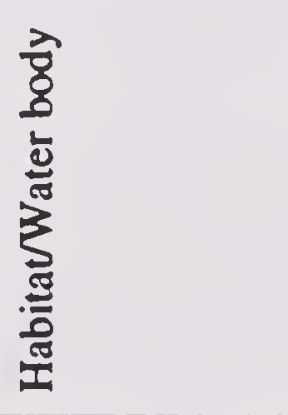 & 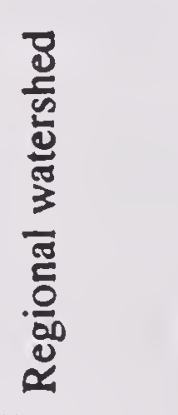 \\
\hline 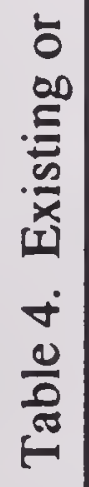 & 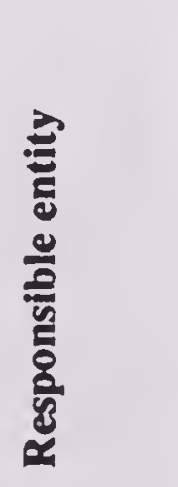 & 国 & 武 & 囯 & 爱 & 呂 & 焉 \\
\hline
\end{tabular}




\begin{tabular}{|c|c|c|c|c|c|}
\hline & 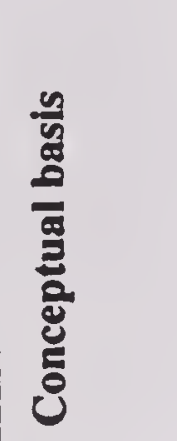 & 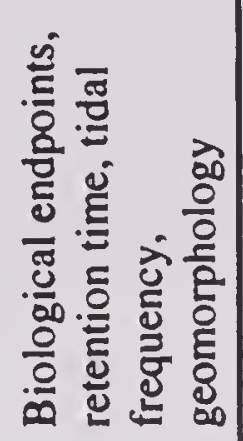 & 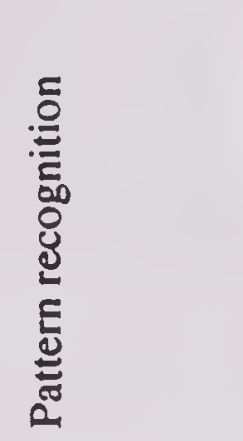 & 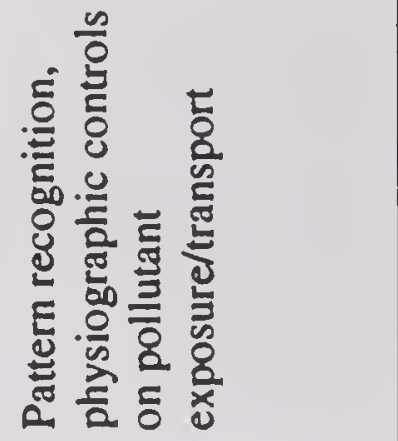 & 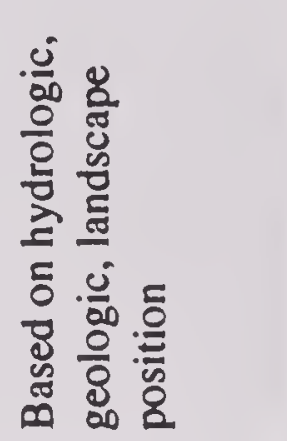 \\
\hline 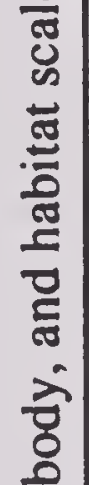 & 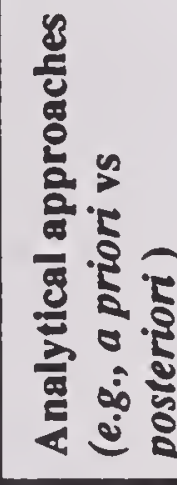 & 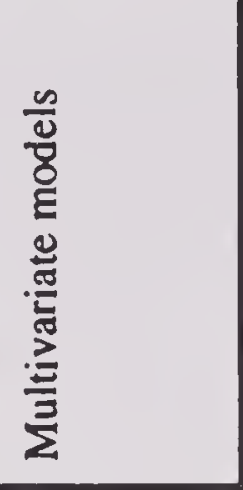 & 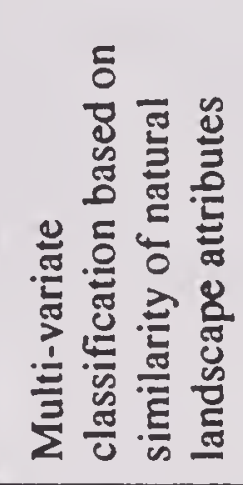 & 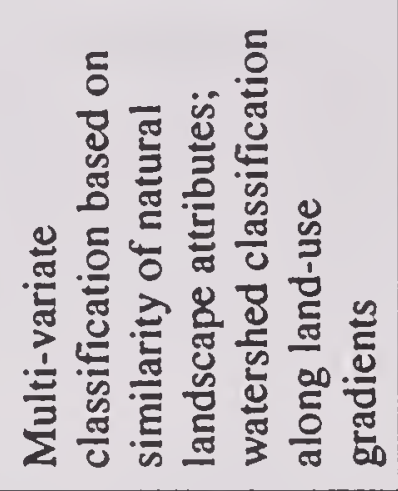 & $\frac{1}{0}$ \\
\hline 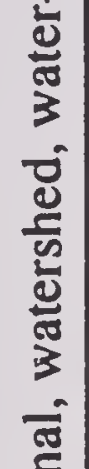 & 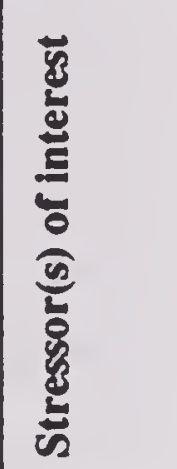 & 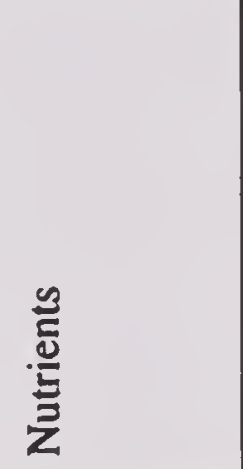 & & & $\overline{\bar{\varepsilon}}$ \\
\hline 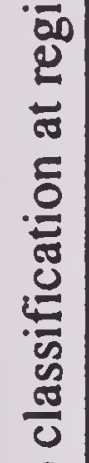 & 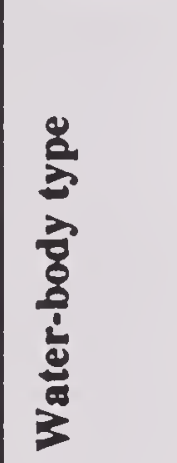 & 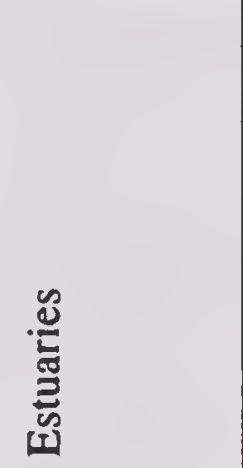 & $\bar{\varepsilon}$ & & 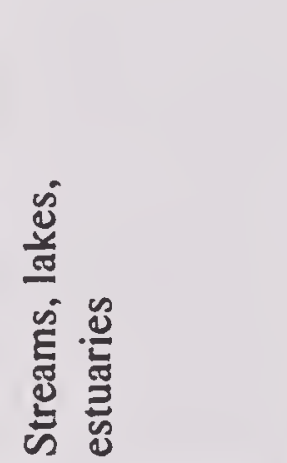 \\
\hline 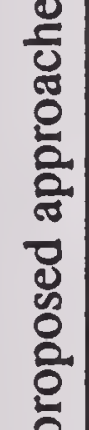 & हूँ & 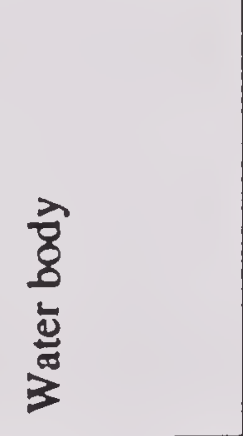 & 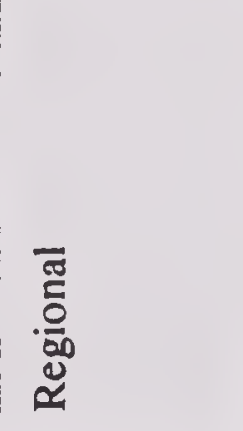 & 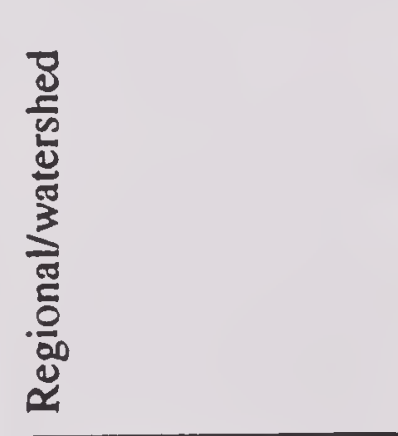 & 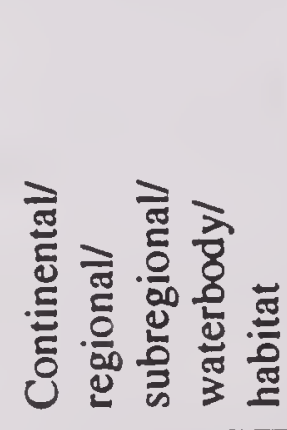 \\
\hline 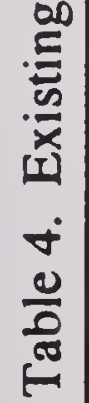 & 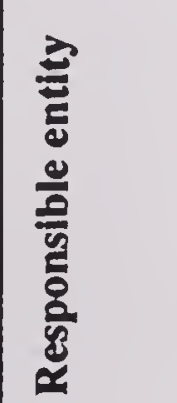 & 葪 & 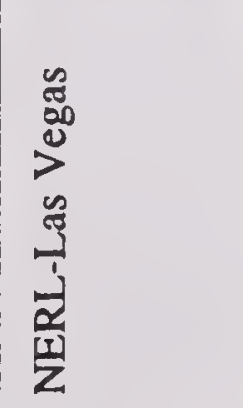 & $\begin{array}{l}\vdots \\
\vdots \\
\vdots \\
z \\
\dot{d} \\
0 \\
\vdots \\
\vdots\end{array}$ & 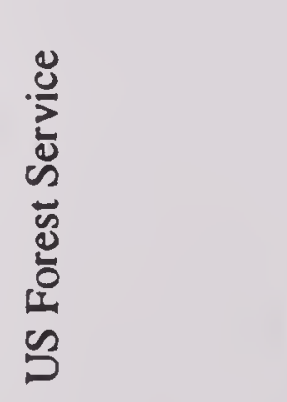 \\
\hline
\end{tabular}




\begin{tabular}{|c|c|c|c|}
\hline . & 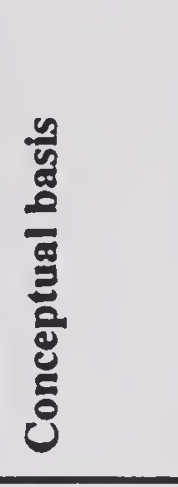 & 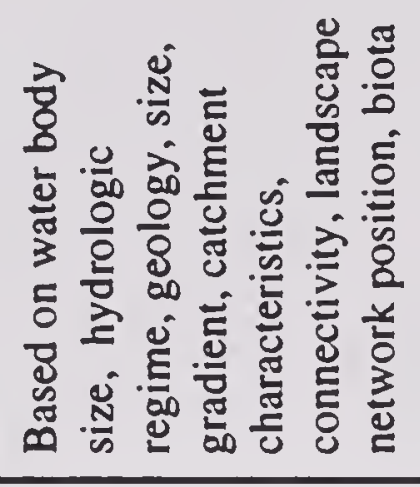 & 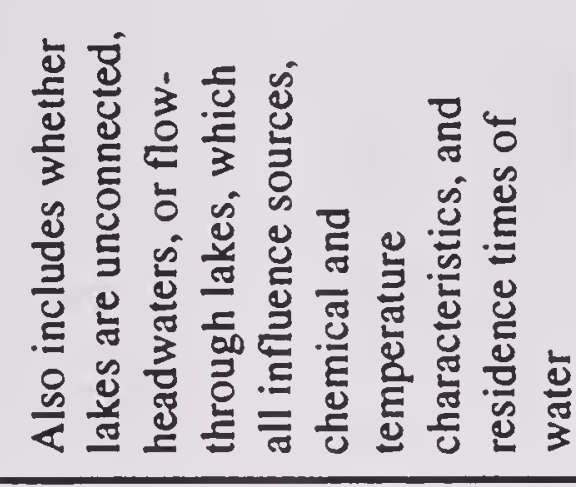 \\
\hline 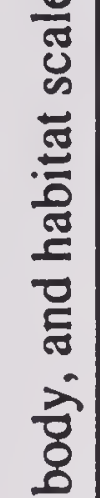 & 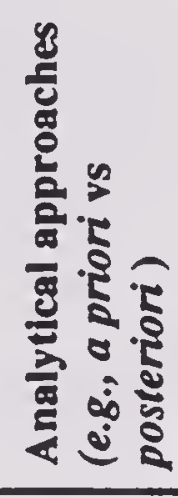 & 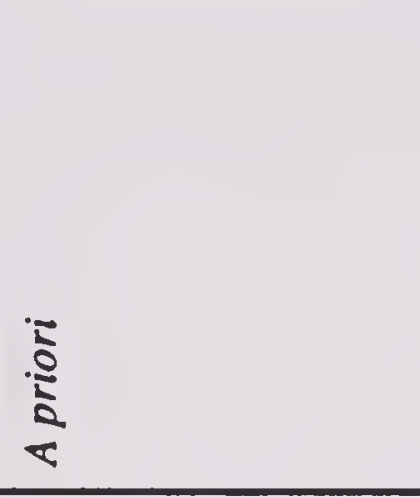 & \\
\hline 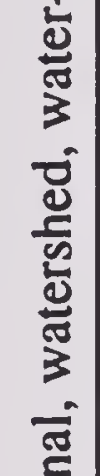 & 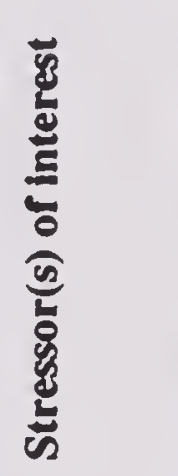 & $\overline{\bar{k}}$ & \\
\hline 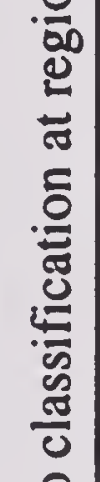 & 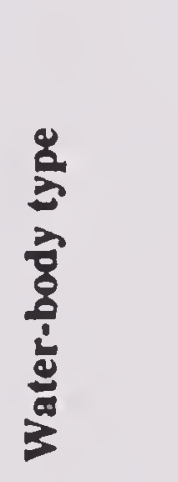 & 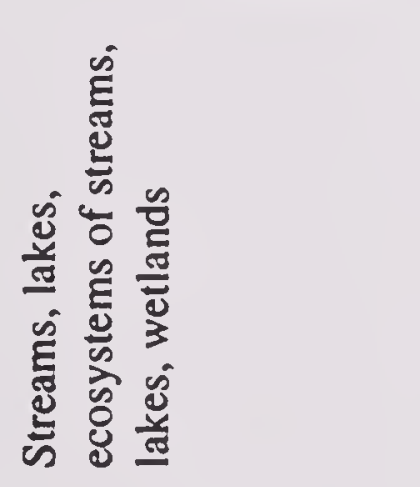 & \\
\hline 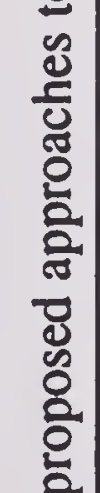 & 苋 & 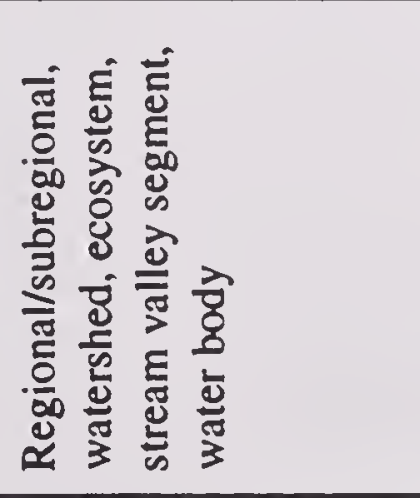 & \\
\hline 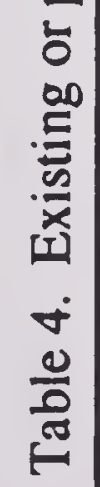 & 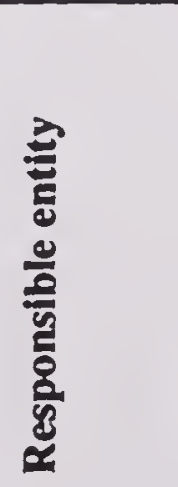 & 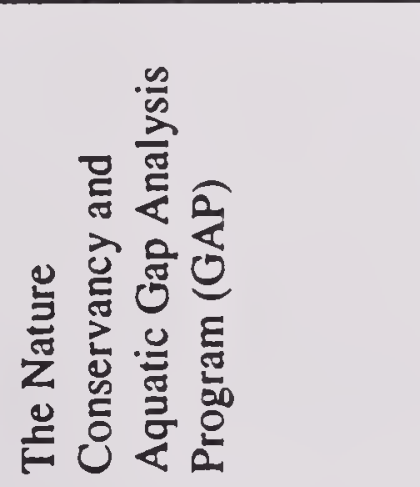 & \\
\hline
\end{tabular}


Products

APM 1B (GPRA \# 202) FY03 Classification frameworks for geographic regions, watersheds, water-body, and habitat scales (MED, GED).

Benefit of Products

A classification framework will provide regional, State, and Tribal regulatory authorities a tool to collapse the over 40,000 water bodies requiring TMDLs into a more manageable number of similar units or water body classes. With defined water body classes, a TMDL template for remediating the impairment could be created which could then be applied to all of the water bodies within the class with minor adjustments. This would eliminate the need for 40,000 unique TMDLs.

Classification frameworks will also help to regionalize criteria development or definition of thresholds for impairment. This would improve the applicability of criteria to specific sites or classes of sites and lower the error rate in identifying impaired or threatened aquatic ecosystems. In particular, a watershed classification scheme within a regional framework will help to integrate and coordinate the 303(d) listing process at the watershed scale.

\section{Project Title 3. Diagnostic Tool Development and Application through Regional Case Studies}

Project Coordination and Resources (36.55 FTEs: FY03: AED-3.25, GED-1.5, MED-8.4 [total = 13.15]; FY04: AED-7.8, GED-2.5, MED-13.1 [total = 23.4])

Objectives

- Develop diagnostic tools for single and multiple stressors;

- Develop forecasting models;

Illustrate the application of diagnostic methods, tools and models for single and multiple stressors, including forecasting models;

Provide input to regional decision-support systems;

Demonstrate how assessment results can be extrapolated across regions, watersheds, and water bodies, and biological levels of organization; and

Illustrate how stressor-response relationships vary among different classes of systems in a predictable fashion. 


\section{Scientific Approach}

Case studies are a useful vehicle for developing and testing conceptual models, classification systems, diagnostic tools and models, and stressor-response relationships. Furthermore, case studies focused on specific places or issues of interest to the Agency provide an excellent mechanism to address high priority environmental problems, including the development of TMDLs. Diagnostic case studies will provide a mechanism for developing, testing, and applying methods and models for distinguishing among single aquatic stressors and allocating cause among multiple stressors. Case studies will be performed to incorporate the habitat, ecosystem, watershed, and regional spatial scales as well as the organismal, population, community, and ecosystem levels of biological organization.

Case studies will be selected based on the following critical attributes:

- $\quad$ Sites will be selected from those already designated as impaired (or threatened) based on the 305(b) or 303(d) reporting process, representing a range of degrees of impairment, a range of stressor combinations, multiple stressors with interaction potential, and common stressor-resource class combinations.

- Sites will be selected to represent specific region-watershed-water body classes, such that results can be extrapolated using a regional or nationwide classification system.

- Coastal systems will be selected, to include both watershed(s) and receiving waters.

- Methods and information management will be coordinated across case studies.

Additional desired attributes of regional case studies include the following:

- Data have already been collected and/or analyzed in time series or at multiple time points.

- Studies will involve cross-Agency collaboration.

- Sites will have well-organized stakeholder groups [e.g., National Estuarine Reserve Program, National Estuary Program, Areas of Concern or Lakewide Management Plan (LaMP) committees for Great Lakes].

- Studies will not duplicate assessments of well-studied systems.

- Representative models exist.

- Research or monitoring at the sites is ongoing.

- Sites are in logistical proximity to an Ecology Division.

Each case study will include the following elements: 
- Study sites will be selected along stressor gradients within each class in the classification framework, to determine if stressor-response relationships vary among these classes.

Stressor gradients will be defined by land-cover/land-use attributes in order to provide the opportunity to develop simple diagnostic indicators of impairment at the watershed scale.

- Gradients representing multiple stressors will be used to test multivariate methods in order to allocate variation in biological community composition to different environmental gradients or stressors.

Model development will incorporate both single stressor-response relationships and multiple stressor interactions to enhance forecasting of potential future impacts or recovery based on future scenarios.

\section{Great Lakes Coastal Watersheds/Wetlands/Nearshore Zones.}

Magnitude of watershed loadings and the relative sensitivities of instream and coastal ecosystems will be predicted and assessed through the application of watershed and coastal wetland classification schemes in the Lake Michigan basin. A watershed classification scheme based on hydrologic thresholds of response to forest fragmentation and watershed storage already has been tested for small coastal watersheds surrounding the western arm of Lake Superior across two distinct hydrogeomorphic regions (Detenbeck et al. 2000). This classification scheme is being extended to other regions with different single land-use gradients, and to watersheds with mixed land-use gradients (Simon 1999, Cincotta 2000). Through collaboration on a West Virginia REMAP project, watershed classification schemes are being developed for a region with mountainous terrain, and consider land-use gradients related to agriculture, urban and residential development, and mining. Through collaboration on a Great Lakes coastal wetlands REMAP project, watershed classification strategies are being developed for watersheds spanning a range of sizes ( 1 to $450 \mathrm{ha}$ ) and a mixture of land-uses. In addition, MED scientists have assessed differences in nutrient dynamics among hydrogeomorphic types of coastal wetlands, based on expected differences in retention time and relative influence of riverine versus lacustrine inputs. This approach will be extended to evaluate impacts from suspended and bedded sediment loading. For toxic chemicals, methodologies will be developed for predicting the parameters and variables which affect the bioavailability of the chemicals for the different levels of the classification schemes.

MED will continue to develop a series of empirical stressor-response relationships in the Great Lakes basin for stressors known to constrain community composition for specific combinations of taxa and aquatic resource classes: a) temperature, flow, and clean sediments for instream fish communities; b) suspended and bedded sediments and flow for macroinvertebrate communities; c) flow, suspended and bedded sediments and nutrients for periphyton communities; d) nutrients and suspended and bedded sediments for coastal wetland vegetation; and e) habitat alteration and food-web structure for coastal fish populations and communities (Detenbeck et al. 2000).

Current protocols for development of indices of biotic integrity (IBIs) yield indicators of general condition of biological communities for State $305 \mathrm{~b}$ assessments, but do not yet provide 
information on causes of biological impairment for the State $303 \mathrm{~d}$ listing process. Analysis of existing State, REMAP, and EMAP monitoring databases (www.epa.gov/emap/) and aquatic toxicity databases (AQUIRE, PHYTOTOX; www epa.gov/ecotox/) with associated exposure data will be coordinated across Divisions to derive diagnostic indicators to predict cause of impairment based on aquatic community composition. Examples of multivariate tools that can be applied to suggest causal hypotheses include nonmetric dimensional scaling (NMDS) ordinations to identify environmental gradients associated with gradients in community composition (Beals 1984), indicator analysis (Dufrene and Legendre 1997), discriminant function analysis relating environmental factors with species presence/absence (Scheller et al. 1998), and redundancy analysis to partition variance among multiple potential causal factors (Richards et al. 1993).

To address water column toxicity, EPA has developed TIE methods (Mount and AndersonCarnahan 1988, 1989; Burkhard and Ankley 1989; Mount 1989; Ankley et al. 1991; NorbergKing et al. 1991,1992; Durhan et al. 1993; Mount and Norberg-King 1993; Burgess et al. 1996; Ho et al. 2002), which are a battery of physical/chemical manipulations coupled with toxicity tests. By determining which physical/chemical manipulation affect toxicity of the samples, the general characteristics of the causative chemical(s) can be determined. With this knowledge, appropriate analysis techniques and in some cases, in combination with additional sample fractionation techniques, are used to obtain a list of the tentative chemical(s) in the sample. With this information, toxicity tests using the suspected chemical(s) would be performed to establish the effect level for these chemicals in the water samples of interest and in reference waters using the TIE organisms. Successful TIEs occur when the concentrations of the suspected chemicals at the affect endpoint agree among the water samples and reference waters.

For toxicity in sediments, substantial progress has been made to date for a number chemical classes and manipulations for whole sediments and sediment pore waters (Ankley and Schubauer-Berigan 1995, Besser et al. 1998, Ho et al. 1999, Leonard et al. 1999, Burgess et al. 2000). With the successful development of solid-phase sediment TIE methods, field validation of interstitial water and whole sediment TIE methods is needed. After development of the whole sediment and interstitial waters TIE methods, field validation of the methodologies are required to determine if the causes of toxicity identified by TIE represent the source of toxicity at the field site. Field validation will involve the TIE analysis of sediments with impaired benthic communities from both fresh and marine sites, and ideally, the causes of impairment for these sediments would not be some other stressor (e.g., suspended and bedded sediment or degraded habitat). Once a suspected toxicant is identified, field sediments and organisms would be analyzed. The final step in the validation process would be to reproduce the same community signature observed in the field, within laboratory-controlled situations by introducing the suspected toxicant into clean sediments in a mesocosm. The field validation effort will also allow the evaluation of benthic community signatures and toxicant relationships. If useful relationships can be developed, a library of chemical stressor-benthic community responses would be developed to complement relationships derived from toxicity databases above, and this library would be developed on a water body class scale. Field validation will also permit the evaluation of toxicant/stressor and biological indices relationships for benthic communities. Specifically, a collaborative effort between MED and AED will seek to link cause and effect relationships observed in the laboratory to field effects using micro/mesocosm simulations. 
A suite of ecosystem response models is being developed for Lake Michigan that link inputs from tributaries to their associated large receiving water bodies and ecological responses. The construct is best described as mechanistic, mass balance models, and the primary suite of coupled and linked models being applied include: atmospheric, meteorological, hydrodynamic, sediment transport, eutrophication, sorbent dynamics, water quality transport and fate, and food chain bioaccumulation. The modeling focuses on establishing relationships of contaminant and nutrient loadings and ambient concentrations with chlorophyll, DO, N/P ratios, phytoplankton species composition, lower food chain productivity, water column transparency, habitat, fish consumption advisories, and lake trout egg hatchability. These models improve the predictive ability for forecasting environmental benefits of specific load reduction scenarios of nutrients and contaminants, as well as the time to realize those benefits.

\section{Shallow Estuarine Systems in the Northeast Atlantic.}

A case study is proposed by AED to quantify the endpoint parameters being proposed in the Habitat Alteration, Nutrients, and Toxic Chemicals implementation plans (see Sections 4, 5, and 7 , respectively), integrate the results within the conceptual framework proposed in this Section, and use this information to test the utility of stressor-response relationships and diagnostic methods and models under development. The initial research studies will be carried out within the coastal ecosystems of the Northeastern U.S., particularly the Narragansett Bay and neighboring coastal systems in Regions 1 and 2 at sites listed for TMDL development.

Two stressors will be emphasized initially: nutrients and toxic chemicals. Several related projects will examine the effects of a range of nutrient loadings on several different coastal ecosystems, (e.g., marshes, shallow coves, and small estuaries) through field studies and model development. Concurrently, another project will study the effects of several classes of toxic chemicals on organisms, populations, and communities that dwell in critical habitats along a salinity gradient from fresh to salt water. Each investigation will synthesize data in a manner that allows us to characterize the contribution of each stressor to adverse ecological effects. For example, a collaborative effort between MED and AED will seek to link cause and effect relationships observed in laboratory to field effects using micro/mesocosm simulations. These studies will be integrated through an ecological model that examines the individual and interactive effects of nutrients and specific toxic chemicals on important habitats. This model will be validated by laboratory and field studies of systems where both nutrients and toxic chemicals are thought to be responsible for observed conditions.

\section{Shallow Estuarine Systems in the Gulf of Mexico.}

A case study is proposed by GED to quantify the endpoint parameters being proposed in Sections 4,5 , and 7 , respectively, integrate the results within the conceptual framework proposed in this Section, and use this information to test the utility of stressor-response relationships and diagnostic methods and models under development. The initial research studies will be carried out within the coastal ecosystems of the Gulf of Mexico, particularly the Pensacola Bay and neighboring coastal systems in Regions 4 and 6. 
Again two stressors will be emphasized initially: nutrients and toxic chemicals. The first step in the approach will be to examine existing 303(d) impairment lists, databases on nutrients and toxic chemicals, and land use/land cover characterištics for Gulf of Mexico estuaries to delineate four classes of sites based on observed effects or criteria. The four classes include sites affected by nutrients only, toxic chemicals only, both nutrients and toxic chemicals, and neither nutrients nor toxic chemicals. A candidate suite of biological indicators would then be developed that demonstrates differential sensitivity to either stressors. This would require examination of historical effects databases and population or community response data as well as receiving input on single-stressor response models for nutrients and toxic chemical efforts (see Sections 5 and 7). In collaboration with AED, lab or field tests will be used to validate the sensitivity of these indicators in each of the four classes of sites. If historical data exists for indicators in the study areas, tests will confirm the sensitivity of indicators to these two stressors. Multivariate analysis methods will be applied to allocate variation in the response indicators to differentiate between nutrient and toxic effects. Modeling approaches will then be used to integrate individual and interactive effects of nutrients and toxic chemicals on biological indicators. Models would account for population and community levels of response across the four classes of sites and along stressor gradients. GED and AED will coordinate the development of models within the context of the classification framework and diagnostics.

\section{Coordination with other Goal 2 Research (WED).}

The freshwater habitat alteration group at WED is developing a project to examine the influence of human activities on native fish habitat at reach, watershed, and landscape scales. This group, led by Jim Wigington, is developing salmon and native fish assemblage modeling approaches while concurrently evaluating the interactive influences of flow, temperature, physical habitat, and nutrients on salmon and native fish. This project is focused on coastal drainages of Oregon where there is a great opportunity to contribute to the restoration of salmon populations through cooperative research efforts with State (Oregon Department of Fish and Wildlife, Department of Environmental Quality) and other Federal agencies (NMFS, U.S. Forest Service).

\section{Coordination with GPRA Goal 8 (AED, GED, MED, WED).}

Goal 2 activities under Diagnostics will be coordinated with Goal 8 activities in monitoring and assessment through the EMAP program. There are currently monitoring initiatives underway through: 1) the Coastal Initiative, examining the condition of marine estuaries; 2) the STAR grants program to develop indicators for coastal freshwater and marine systems, (including the GLEI cooperative agreement for indicator development on coastal Great Lakes systems); 3) Western EMAP (including coastal watersheds in the states of Washington, Oregon, and California as intensive monitoring sites); and 4) a variety of Regional EMAP projects. The latter program currently emphasizes watershed-scale approaches to monitoring and assessment. For example, a recently initiated REMAP project with the state of West Virginia will demonstrate both the development of a watershed classification system and test thresholds of land-use/landcover along gradients of disturbance (related to forestry, agricultural, development, and mining activity), while at the same time developing fish indices of biotic integrity. 
Development of regional case studies will take advantage of ongoing monitoring and assessment activities by State, regional, and Federal agencies. The USGS NAWQA program is examining a nationwide approach to regionalization of watersheds, based on common vulnerabilities to nonpoint stressors (McMahon and Cuffney 2000 and Carolyn Couch, personal communication).

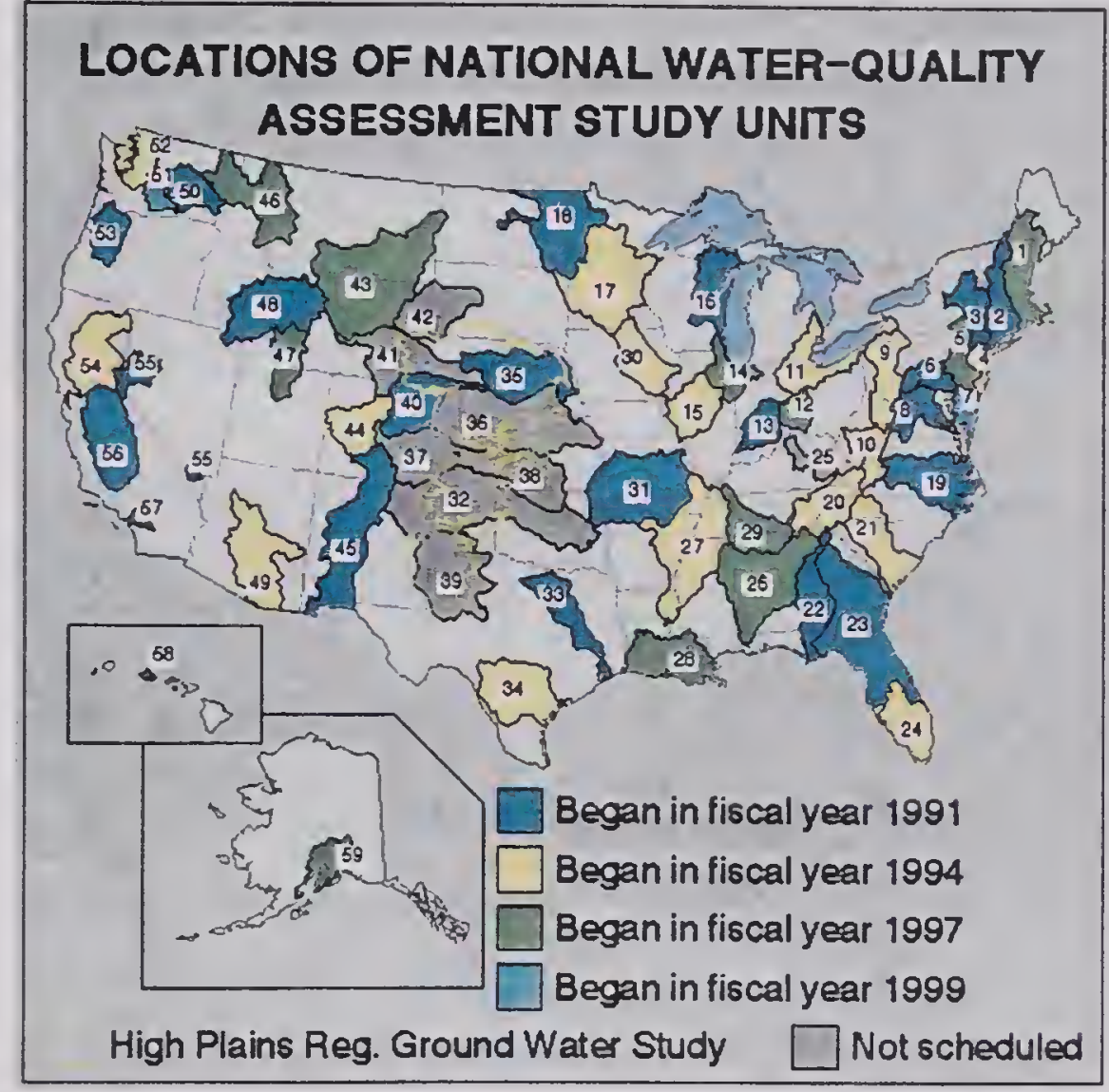

Figure 15. Locations of national water-quality assessment study units.
Within this regional classification framework, watersheds in NAWQA study units are being selected along gradients of urbanization to examine response of stream ecosystems to development pressures. Each of the NHEERL divisions is located in proximity to NAWQA study units that are scheduled to adopt this approach during the near future, with the start of the second 10 -year phase of monitoring (units in dark blue on Figure 15).

In addition, opportunities exist to coordinate studies with the National Estuarine Program (NEP), Great Lakes Areas of Concern, and Great Lakes LaMPs.

\section{Products}

1. Single stressor-methods and models.

APM 2A FY03 Guidance document on whole sediment TIEs ( MED, AED).

APM 2C FY05 Guidance on and user-friendly interface for derivation of diagnostic indicators for individual stressors (MED, AED).

2. Multiple stressor-methods and models.

APM 3A FY02 Case studies of multivariate approaches to community data analysis to apportion cause among stressors (AED, MED).

APM 3B FY06 Methods and models for multiple stressors with case studies (MED, AED). 


\section{Forecasting Approaches}

FY07 Methods and models to support alternative remediation schemes to achieve specific management goals (MED).

\section{Case Studies.}

APM 2B FY05 Application of coastal watershed and estuarine/lacustuary classification schemes to predict probability of impairment based on Great Lakes and Gulf of Mexico regional case studies (GED, MED).

\section{Benefit of Products}

Diagnostic tool development will produce the single stressor, multiple stressor, and forecasting methods and models necessary to determine the causes of adverse effects on intact water bodies. Regional case studies will provide the basis for verifying the efficacy of these diagnostic tools. Further, regional case studies will provide the basis for development of the guidance listed above, and allow diagnostic tools to be demonstrated to stakeholders in sites where TMDLs need to be developed. These studies will enable OW to understand how multiple stressors, such as nutrients and toxic chemical loadings, affect important habitats separately and in combination for several types of coastal ecosystems across the U.S. We expect the methods and models developed here to be generic for specific stressor-ecosystem combinations. Therefore, we predict that they can be applied in other regions that contain similar stressor-ecosystem combinations.

Classification schemes will allow us to regionalize results and recommendations for TMDLs and watershed restoration activities. The scientific approach used here is also generic and it could be applied to develop similar relationships for the ecosystems and stressors that predominate in any region.

\section{Project Title 4. Generic Models for the Evaluation of Multiple Stressor Interactions}

Project Coordination and Resources (1.5-8.0 FTEs: AED, GED, MED, starting in FY04/05, increase over time)

\section{Objectives}

The objective of this research area is to assess the likelihood that synergistic and/or antagonistic ecological effects will occur from the interactions of multiple stressors. To set priorities for the development of TMDLs and the restoration of impaired water bodies, it is necessary to understand how the potential interactions among stressors will affect system recovery once one of the stressors is reduced. For example, in a turbid coastal wetland, a reduction in suspended solids loading without an accompanying reduction in $\mathrm{P}$ loading from upstream animal feed lots could unmask a eutrophication problem that was previously not evident due to light limitations on primary production. 
As a first step, key combinations of stressors for which interactions are expected to occur will be identified based on mechanisms of action outlined in conceptual models and review of 303(d) listings for common combinations of stressors. Individual stressor dose-response relationships and models developed under project 3 will provide a starting point for examining the interactions of multiple stressors in freshwater and marine ecosystems. The importance of interactive effects will be evaluated by including the documented pathways of stressor action and interaction in deterministic dynamic models calibrated with field studies and/or historic data, and then simulated over many runs to discover the sensitivity of measurement endpoints to changes in one or more of the stressors (e.g., Bartell et al. 1984, Mitsch and Reeder 1991, Hanratty and Stay 1994, EPA 2000c). A generic model including the impact and interaction paths for the dominant stressors of interest will be applied for each of three resource classes: streams, lakes and reservoirs, and estuaries. These generic model frameworks will be developed as a joint product among the four Ecology Divisions. Sensitivity analysis of these models will serve as a first order estimator for allocating observed ecological effects among two or more interacting stressors, as well as a means for evaluating the relative importance of indirect and interactive effects. This approach is independent of scale requiring only that the stressor- response relationships and interaction pathways be documented on the scale of interest. Once expected interactive effects and ranges of interactions are identified, the results of existing case studies and ongoing regional case studies will be reviewed for evidence of interaction effects. Pending outcomes of simulation exercises, additional field studies will be performed, combined with carefully crafted laboratory experiments and physical models calibrated to match loadings and functional properties observed in the field system.

\section{Products}

FY03 Identification of key combinations of stressors expected to interact within conceptual model (all Ecology Divisions).

APM 3B FY06 Simulation of key stressor interactions with generic ecosystem models using sensitivity analysis to define the range of stressors and stressor combinations under which nonadditive interactive effects will occur (MED, AED).

\section{Benefit of Products}

Part of the TMDL process involves allocation of the cause of impairment among multiple stressors. The simplest case possible involves additive effects, which can be predicted from single stressor models. If effects are synergistic or antagonistic, then the results of reduced loadings will be more difficult to predict. The proposed products would identify the extent to which stressor interactions are expected to occur in natural ecosystems and those combinations of factors which favor their occurrence. This knowledge is critical to allow the States and Tribes to develop viable restoration and remediation plans for water bodies and watersheds affected by multiple stressors. 


\section{Project Title 5. Decision-Support System}

Project Coordination and Resources (3.0-6.0 FTEs: AED, GED, MED, starting in FY05/06, plus programming support)

\section{Objectives}

The objective of this research is to develop a decision-support system for diagnosing the causes of biological impairment at multiple scales. The decision-support system will be based on conceptual models outlining expected cause-effect relationships involving single and multiple stressors (project 1). At the most basic level, this interface will consist of a guide to the use of existing EPA databases, methods, and models. As tools are developed for diagnosis of single or multiple stressors, these will be incorporated into an expert-system framework. Simple empirical relationships between exposure and response indicators will be incorporated, as well as more detailed mechanistically-based models.

\section{Scientific Approach}

Phase 1. Identify existing tools, methods, and models available to support establishment of cause-effect relationships

A conceptual model is proposed to provide a framework for documentation of existing tools to support diagnosis (Figure 16). Within this conceptual framework, it is possible to develop methods and models that bypass many of the linkages, for example, relating alterations in landuse/land-cover within an existing watershed class to projected effects on fish community integrity. Examples of existing methods and models available to establish or confirm the causeeffect linkages in Figure 16 are listed in Table 5.

\section{Phase 2. Produce a decision support system design}

Existing decision support systems will be investigated to choose an appropriate approach. Based on the approach chosen, a system framework will be developed and a document produced to instruct collaborators on the intent and use of the decision-support system and to build management support for this system through practical demonstrations of its utility.

The technology now exists to produce a computerized, web-based decision support system. The BASINS system supported by OW consolidates a geospatial framework to support a comprehensive diagnostic decision-support system. At present, it is a collection of models and databases organized around a GIS-based computer program. This system will be expanded to include the information and tools produced under this Aquatic Stressors research effort. "Expert system" modules will be added that would lead persons in the Program Offices and State agencies through a guided, rule-based scenario that leads to a diagnosis of the causes of 

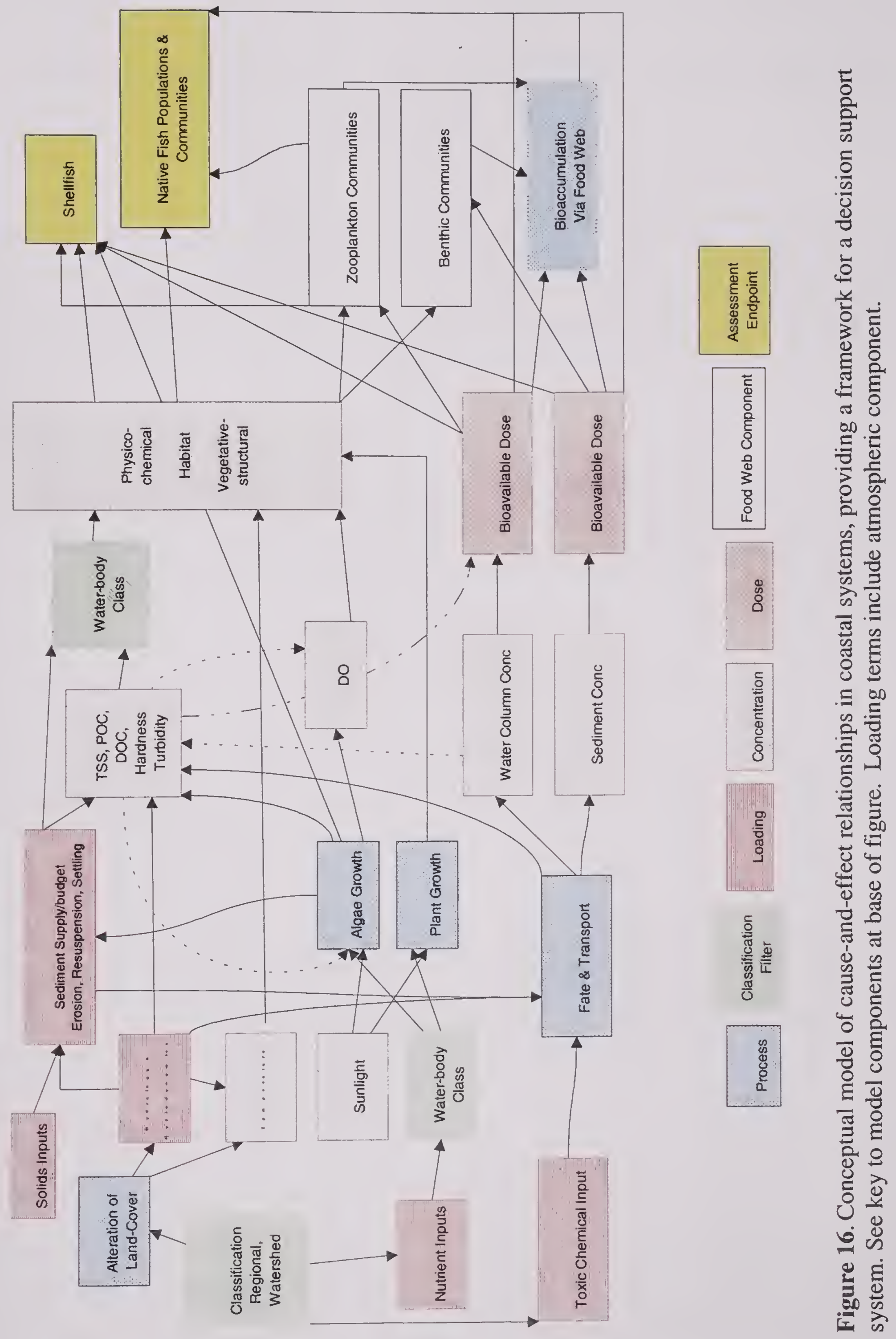


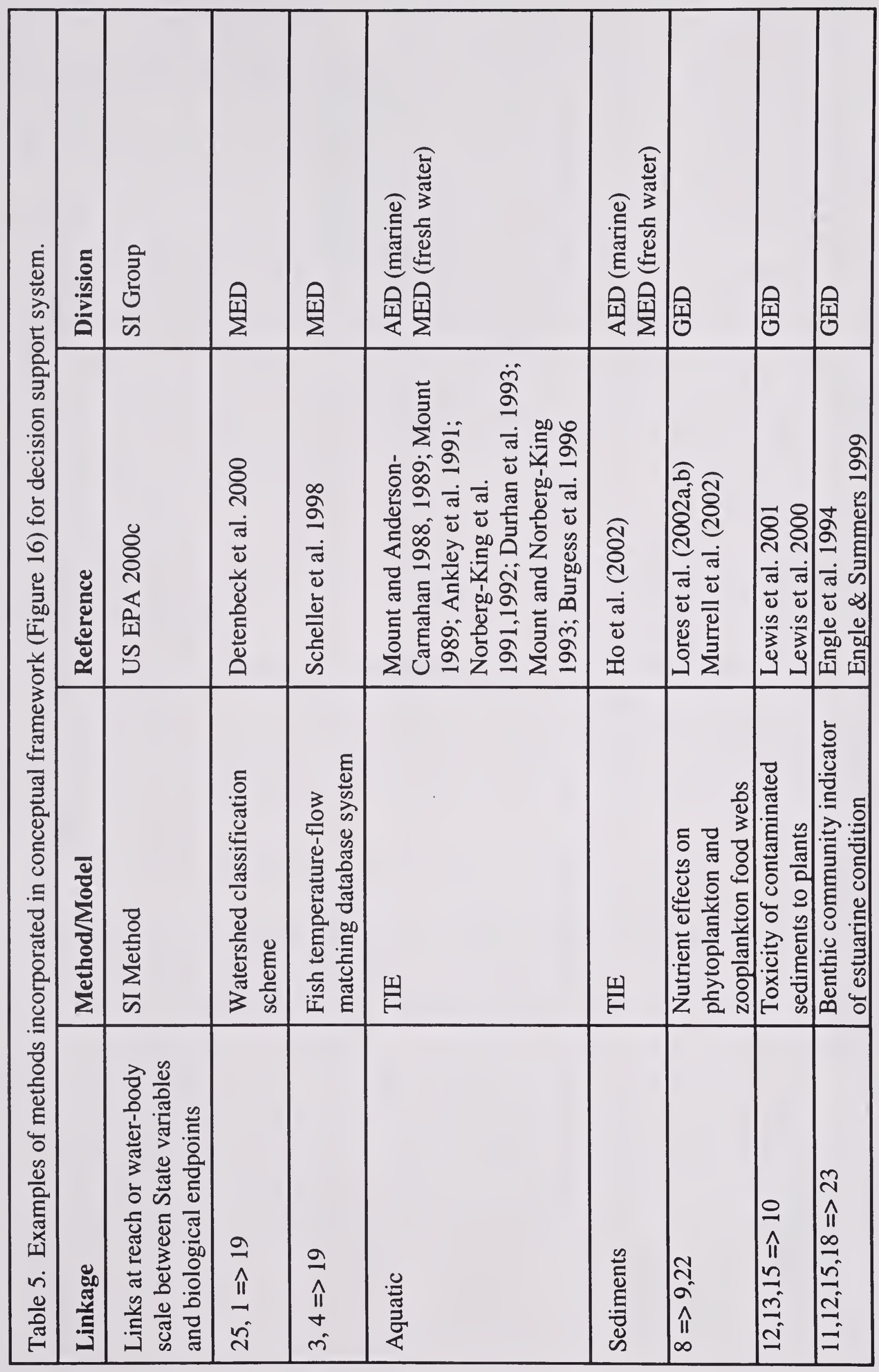


impairment, the development of a TMDL, and recommendations for restoration of remediation (e.g., see Reynolds 1999a,b; http://www.fsl.orst.edu/emds/ ).

\section{Phase 3. Development and implementation}

A team will be formed consisting of research scientists, modelers, computer systems analysts, and WEB page designers to develop and implement the system. Contact persons from each of the research teams working in the Aquatic Stressors research program will be assigned to provide liaison with the decision support team. If appropriate, other team members and contacts would be provided from other EPA Laboratories, Program Offices, and State agencies. This development effort would produce the decision support system and a guidance document on its application.

\section{Phase 4. Application}

During the final stages of development, data, models, and information from selected case studies will be incorporated into the expert system. This would be done in cooperation with the decision personnel associated with the studies and training would be provided along with a guidance document and system documentation.

\section{Products}

FY04 Framework(s) for decision-support system (all Ecology Divisions).

FY06 Decision-tree guiding application of approaches with case studies (all Ecology Divisions).

APM 3C FY07 Decision-support system(s), including forecasting of future cause-effect relationships (MED).

Benefit of Products

A series of decision-support systems will provide States and Regions with a common set of tools for approaching TMDL development and assessing alternative options for watershed restoration. Existing tools and databases will be made readily available, and gaps in knowledge bases will be more readily identified. Decision-support systems will also facilitate an integrated approach to assessment and diagnosis at the regional scale, thus improving the efficiency of the TMDL process.

\section{Gap Analysis}

Gaps by geographic region, biological scale, resource class, and stressor type

The research tasks outlined above will be applied within coastal watersheds bordering on both freshwater and saltwater receiving water bodies. Regional case studies will be developed within each of three areas, the Great Lakes, the Atlantic coast, and the Gulf coast. This research area will depend heavily upon each of the other research areas of this document (Sections 4-7) for 
development of stressor-response relationships for individual stressors and will coordinate with these respective research groups in the development of diagnostic methods and models for individual stressors. The focus of each stressor-specific research area is outlined below in Table 6 , with the biological endpoints and spatial scale of investigation noted. Gaps have been identified relating to the investigation of nutrient effects in freshwater streams and rivers, and the investigation of clean sediment effects on coastal wetlands and estuaries. Because these are significant stressors in the EPA Regions, biological scales and resource types of interest, the diagnostics work will have to be supplemented by work in other research areas or rely on

Table 6. Single aquatic stressors method development covered by other research areas within the Aquatic Stressors Framework [in italics = endpoints: biological scale (organism, population, community, ecosystem); spatial scale (habitat, water body, watershed, region)]

\begin{tabular}{|l|l|l|l|}
\hline \multicolumn{1}{|c|}{ Stressor } & \multicolumn{1}{|c|}{$\begin{array}{c}\text { Fresh Water } \\
\text { Coastal \& Lakes }\end{array}$} & \multicolumn{1}{|c|}{$\begin{array}{c}\text { Fresh Water } \\
\text { Watershed }\end{array}$} & \multicolumn{1}{|c|}{ Marine Coastal } \\
\hline Nutrients & $\begin{array}{l}\text { Community, } \\
\text { Ecosystem } \\
\text { Nutrient Group }\end{array}$ & & $\begin{array}{l}\text { Organismal (SAV) } \\
\text { Population (SAV) } \\
\text { Community, } \\
\text { Ecosystem, } \\
\text { Watershed } \\
\text { Nutrient Group }\end{array}$ \\
\hline $\begin{array}{l}\text { Suspended and } \\
\text { Bedded Sediments }\end{array}$ & & Habitat, community & $\begin{array}{l}\text { Organismal (SAV) } \\
\text { Population (SAV) }\end{array}$ \\
\hline Habitat Alteration & $\begin{array}{l}\text { Population scale, } \\
\text { Habitat Alteration } \\
\text { Group }\end{array}$ & $\begin{array}{l}\text { Salmon populations, } \\
\text { Habitat Alteration } \\
\text { Group }\end{array}$ & $\begin{array}{l}\text { Shrimp populations, } \\
\text { Habitat Alteration } \\
\text { Group }\end{array}$ \\
\hline Toxic Chemicals & $\begin{array}{l}\text { Population level, } \\
\text { Toxic Chemicals } \\
\text { Group }\end{array}$ & $\begin{array}{l}\text { Population level, } \\
\text { Toxic Chemicals } \\
\text { Group }\end{array}$ & $\begin{array}{l}\text { Organismal, } \\
\text { population, } \\
\text { community, } \\
\text { Toxic Chemicals } \\
\text { Group }\end{array}$ \\
\hline
\end{tabular}

existing literature to fill these gaps. In addition, the lack of effects work at the community level for many resource class/stressor combinations will need to be addressed, as this is the biological scale at which the States are assessing biological impairment in current monitoring programs.

Other gaps have been identified by geographic region. Expertise available at AED and GED will be supplemented with expertise in watershed classification and assessment through collaboration with other research groups (e.g., MED or WED, USGS NAWQA program). Development of regional case studies or decision-support systems for the Pacific Northwest will require close 
collaboration with Goal 8 research efforts, and/or other research areas under the Aquatic Stressor research effort.

\section{Gaps by skill area and level of effort}

The level of effort and required areas of expertise for each of the different research tasks discussed in this document are summarized in Table 7. Overall, the total number of FTEs estimated for implementation of the Diagnostics plan is consistent with the total number of FTEs allocated to Diagnostics across all Ecology Divisions. This conclusion is based on two assumptions:

1. There will be close coordination with other Aquatic Stressors research areas (Sections 4-7) in the development of conceptual models, classification frameworks, implementation of regional case studies, and development of decision support systems.

2. The requisite expertise available within the Ecology Divisions will be made available for diagnostics research by management at the respective Divisions.

Some gaps do exist in the types of expertise available relative to resource needs. Additional expertise and/or support will be needed for statistics (design issues), futures analysis (socioeconomics, ecological economics), near coastal modeling for marine systems, ecosystem simulation modeling, and programming support for decision-support system design and development. Some of these needs could be met through additional infrastructure support for existing contracts (statistical support available through AED, ADP support contracts at all Divisions), while other needs must be factored into long-term hiring plans (ecological economics, socioeconomics) or development of extramural grants. Some modeling support needs could be met through coordination with NERL Divisions, Regions, or Program Offices, but additional support will be needed to develop food web components of models. 
Detenbeck, N.E., Batterman, S.L., Brady, V.J., Brazner, J.C., Snarski, V.M., Taylor, D.M., Thompson, J.A., Arthur, J.W. 2000. A test of watershed classification systems for ecological risk assessment. Environ. Toxicol. Chem. 19:1174-81.

Dufrene, M., Legendre, P. 1997. Species assemblages and indicator species: the need for a flexible asymmetrical approach. Ecol. Monogr. 67:345-366.

Durhan, E.J., Norberg-King, T., Burkhard, L.P. 1993. Methods for aquatic toxicity identification evaluations: phase II toxicity identification procedures for samples exhibiting acute and chronic toxicity. EPA/600/R-92/080. Environmental Research Laboratory, Duluth, MN.

Engle, V.D., Summers, J.K. 1999. Refinement, validation, and application of a benthic condition index for Gulf of Mexico estuaries. Estuaries 22:624-635.

Engle, V.D., Summers, J.K., Gaston, G.R. 1994. A benthic index of environmental condition of Gulf of Mexico estuaries. Estuaries 17:372-384.

EPA. 1991. Guidance for water-quality-based decisions: the TMDL process. EPA 440-4-91-001. Office of Water, Washington, DC.

EPA. 1996. Proposed guidelines for ecological risk assessment. EPA-630/R-95-002B. Washington, DC.

EPA. 1998a. Clean Water Action Plan. EPA 840-R-98-001.

EPA. 1998b. Better assessment science integrating point and nonpoint sources: BASINS version 2.0. EPA-823-B-98-006. Office of Water, Washington, DC.

EPA. 1999. Clean water action plan: restoring and protecting America's waters. EPA-840-R-98001. Washington, DC.

EPA. 2000a. National water quality inventory: 1998 report to Congress. EPA-841-F-00-006. Office of Water, Washington, DC.

EPA. 2000b. Aquatox release 1: a simulation model for aquatic ecosystems. EPA-823-F-00-015. Office of Water, Washington, DC.

EPA. 2000c. Stressor identification guidance document. EPA-822-B-00-025. Office of Water and Office of Research and Development, Washington, DC.

EPA. 2001. 1998 TMDL tracking system (version April 2, 2001).

Federal Register. 2000. Unified federal policy for a watershed approach to federal land and resource management. 62566 Federal Register, Vol. 65, No. 202, Wednesday, October 18, 2000. 
Frissell, C.A., Liss, W.J., Warren, C.E., Hurley, M.D. 1986. A hierarchical framework for stream habitat classification: viewing streams in a watershed context. Environ. Manag. 10:199-214.

Hamelink, J.L., Landrum, P.F., Bergman., H.L., Benson, W.H., eds. 1994. Bioavialability: Physical, Chemical and Biological Interactions. Lewis Publishers, Ann Arbor, MI.

Hanratty, M.P., Stay, F.S. 1994. Field evaluation of the littoral ecosystem risk assessment model's prediction of the effects of chlorpyrifos. J. Appl. Ecol. 31:439-53.

Ho, K.T., Kuhn, A., Pelletier, M.C., Burgess, R.M., Helmstetter, A. 1999. Use of Ulva lactuca to distinguish $\mathrm{pH}$ dependent toxicants in marine waters and sediments. Environ. Toxicol. Chem. 18:207-212.

Ho, K.T. et al. 2002. Methods for aquatic toxicity identification evaluations of freshwater and marine sediments. EPA, Office of Research and Development, Atlantic Ecology Division/MidContinent Ecology Division, Narragansett, RI/Duluth, MN. (in prep.)

Hunter, R.S., Niemi, G.J., Pilli, A., Veith, G.D. 1990. Aquatic information and rEtrieval (AQUIRE) database system. In Pillman, W., ed., Envirotech Vienna 1990: Computer Applications for Environmental Impact Analysis. International Society for Environmental Protection, Vienna, Austria. pp. 42-48.

Leonard, E.N., Mount, D.R., Ankley, G.T. 1999. Modification of metal partitioning by addition of synthetic AVS to freshwater sediments. Environ. Toxicol. Chem. 18:858-864.

Lewis, M.A., Weber, D.E., Stanley, R.S. 2000. Wetland plant seedlings as indicators of nearcoastal sediment quality: interspecific variation. Mar. Environ. Res. 50:535-540.

Lewis, M.A., Weber, D.E., Stanley, R.S., Moore, J.C. 2001. Relevance of rooted vascular plants as indicators of estuarine sediment quality. Arch. Environ. Contam. Toxicol. 40:25-34.

Lores, E.M., Murrell, M.C., DiDonato, G.T., Stanley, R.S., Snyder, R.A., Sipura, J., Flemer, D.A. 2002a. Effects of zooplankton grazing on phytoplankton communities in Escambia Bay, FL. Mar. Ecol. Prog. Ser. 39 pp. (submitted.)

Lores, E.M., Lewis, M.A., Malaeb, Z.A. 2002b. Spatial and temporal variability in zooplankton community dynamics in three urbanized bayous of the Pensacola Bay system, Florida, USA. Gulf Mex. Sci. 21 pp. (submitted.)

Maxwell, J.R., Edwards, C.J., Jensen, M.E., Paustian, S.J., Parott, H., Hill, D.M. 1995. A hierarchical framework of aquatic ecological units in North America (Nearctic Zone). Technical report, USDA, Forest Service, NC.

McKee, P.M., Batterson, T.R., Dahl, T.E, Glooschenko, V., Jaworski, V., Pearce, J.B., Raphael, C.N., Whillans, T.H., LaRoe, E.T. 1992. Great Lakes aquatic habitat classification based on 
wetland classification systems, Chapter 4. In Dieter, W. Busch, N., Sly, P.G., eds., The Development of an Aquatic Habitat Classification System for Lakes. CRC Press, Ann Arbor, MI.

McMahon, G., Cuffney, T.F. 2000. Quantifying urban intensity in drainage basins for assessing stream ecological conditions. J. Am. Water Resourc. Assoc. (in press).

Mitsch, W.J., Reeder, B.C. 1991. Modeling nutrient retention of a freshwater coastal wetland: estimating the roles of primary productivity, sedimentation, resuspension and hydrology. Ecol. Model. 54:151-187.

Mount, D.I. 1989. Methods for aquatic toxicity identification evaluations: phase III toxicity confirmation procedures. EPA/600/3-88/036. EPA, Office of Research and Development, Environmental Research Laboratory, Duluth, MN.

Mount, D.I., Anderson-Carnahan, L. 1988. Methods for aquatic toxicity identification evaluations: phase I toxicity characterization procedures. EPA/600/3-88/034. EPA, Office of Research and Development, Environmental Research Laboratory, Duluth, MN.

Mount, D.I., Anderson-Carnahan, L. 1989. Methods for aquatic toxicity identification evaluations: phase II toxicity identification procedures. EPA/600/3-88/035. EPA, Office of Research and Development, Environmental Research Laboratory, Duluth, MN.

Mount, D.I., Norberg-King, T. 1993. Methods for aquatic toxicity identification evaluations: phase III toxicity confirmation procedures for samples exhibiting acute and chronic toxicity. EPA/600/R-92/081. Environmental Research Laboratory, Duluth, MN.

Murrell, M.C., Stanley, R.S., Lores, E.M., DiDonato, G.T., Smith, L.M., Flemer, D.A. 2002. Evidence that phosphorus limits phytoplankton growth in a Gulf of Mexico estuary: Pensacola Bay, FL, USA. Mar. Ecol. Prog. Ser. (submitted).

Norberg-King, T., Mount, D., Durhan, E., Ankley, G., Burkhard, L., Amato, J., Lukasewycz, M. Schubauer-Berigan, M.R., Anderson-Carnahan, L. 1991. Methods for aquatic toxicity identification evaluations: phase I toxicity characterization procedures, $2^{\text {nd }}$ ed. EPA/600/691/003. Environmental Research Laboratory, Duluth, MN.

Norberg-King, T.J., Mount, D.I., Amato, J.R., Jensen, D.A., Thompson, J.A. 1992. Toxicity identification evaluation: characterization of chronically toxic effluents, phase I. EPA/600/691/005F. Environmental Research Laboratory, Duluth, MN.

Omernik, J.M. 1987. Ecoregions of the conterminous United States. Ann. Assoc. Am. Geogr. 77:118-125.

Palter, J.B., Dettmann, E.H. 1999. The effects of nitrogen loading and freshwater residence time on the estuarine ecosystem. $15^{\text {th }}$ Biennial International Conference of the Estuarine Research Federation, September 25-30, 1999, New Orleans. 
Reynolds, K.M. 1999a. EMDS users guide (version 2.0): knowledge-based decision support for ecological assessment. Gen. Tech. Rep. PNW-GTR-470. U.S. Department of Agriculture, Forest Service, Pacific Northwest Research Station, Portland, OR. 63 pp.

Reynolds, K.M. 1999b. NetWeaver for EMDS version 1.0 user guide: a knowledge base development system. Gen. Tech. Rep. PNW-GTR-471. U.S. Department of Agriculture, Forest Service, Pacific Northwest Research Station, Portland, OR. 75 pp.

Richards, C., Host, G.E., Arthur, J.W. 1993. Identification of predominant environmental factors structuring stream macro invertebrate communities within a large agricultural catchment. Freshw. Biol. 29:285-294.

Rosgen, D.L. 1996. Applied river morphology. Wildland Hydrology, Pargosa Springs, CO.

Scheller, R.M., Snarski, V.M., Eaton, J.G., Oehlert, G. 1998. An analysis of the influence of annual thermal variables on the occurrence of warm water fishes. Trans. Am. Fish. Soc. 128:257264.

Simon, T.F. 1999. Regional environmental monitoring and assessment (REMAP): evaluation of the Great Lakes nearshore coastal wetlands: with emphasis on development of watershed environmental indicators and status. R-EMAP proposal submitted to EPA, Mid-Continent Ecology Division, Duluth, MN. 


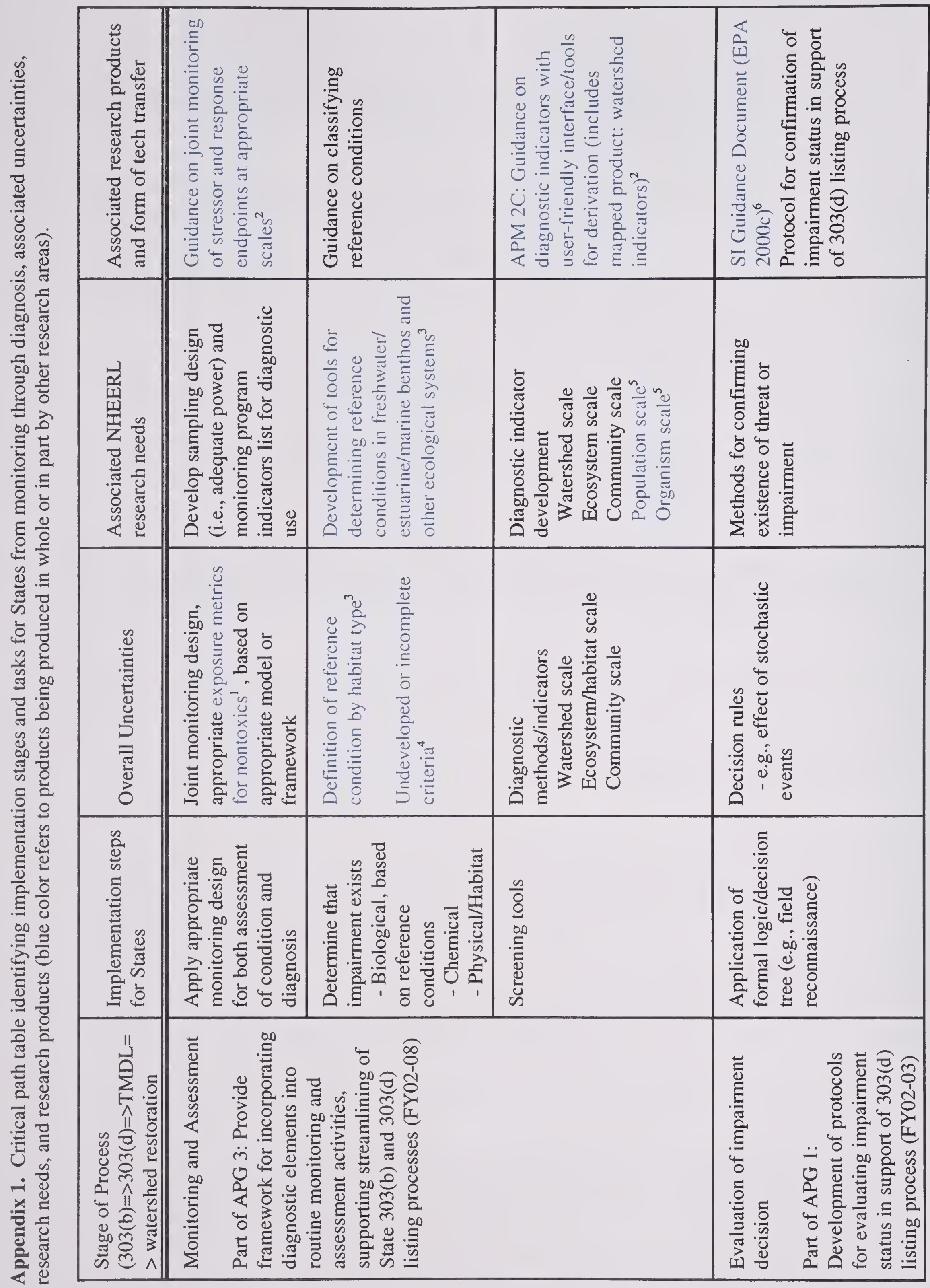




\begin{tabular}{|c|c|c|c|}
\hline 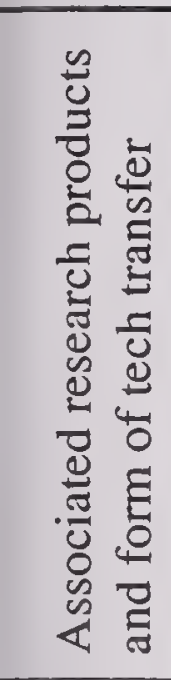 & 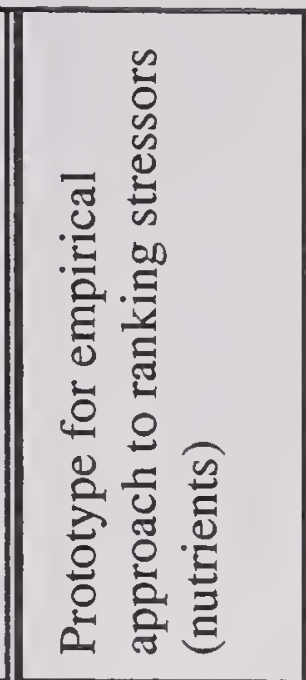 & 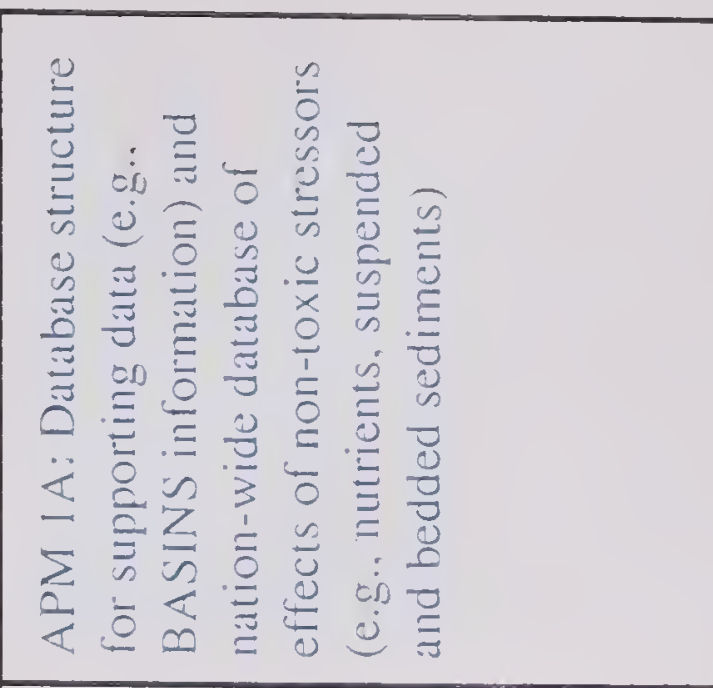 & 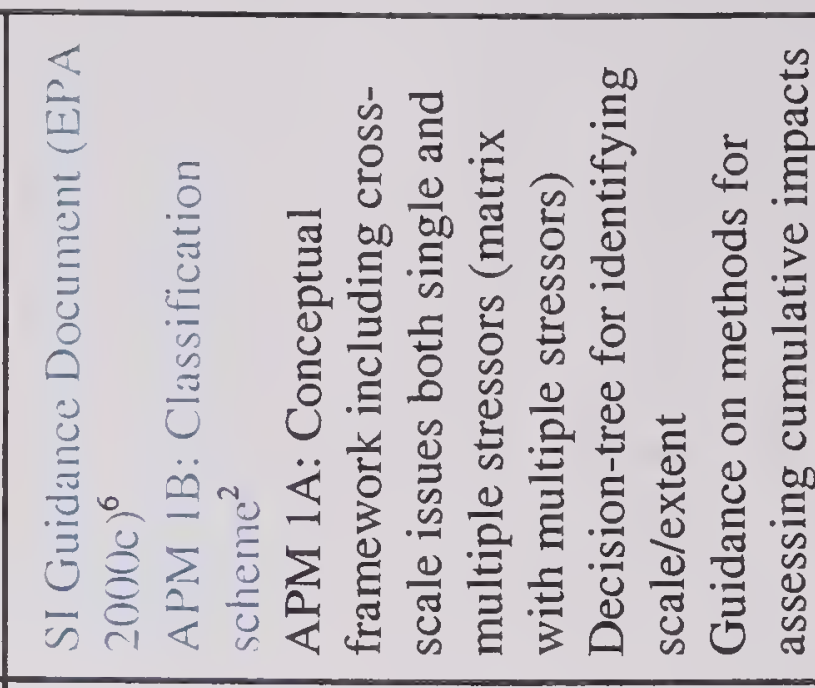 \\
\hline 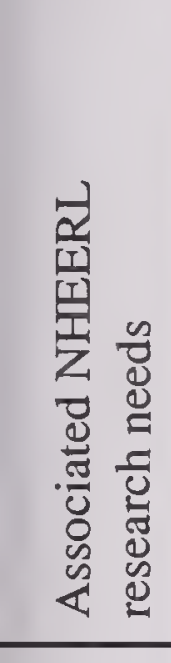 & 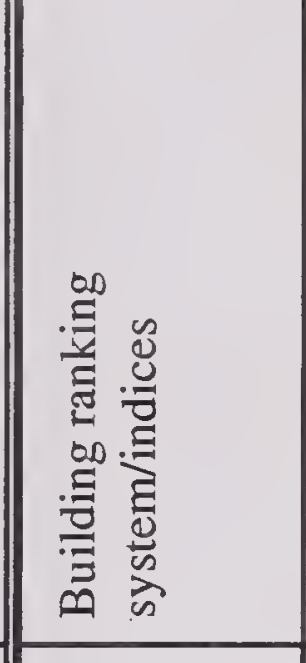 & 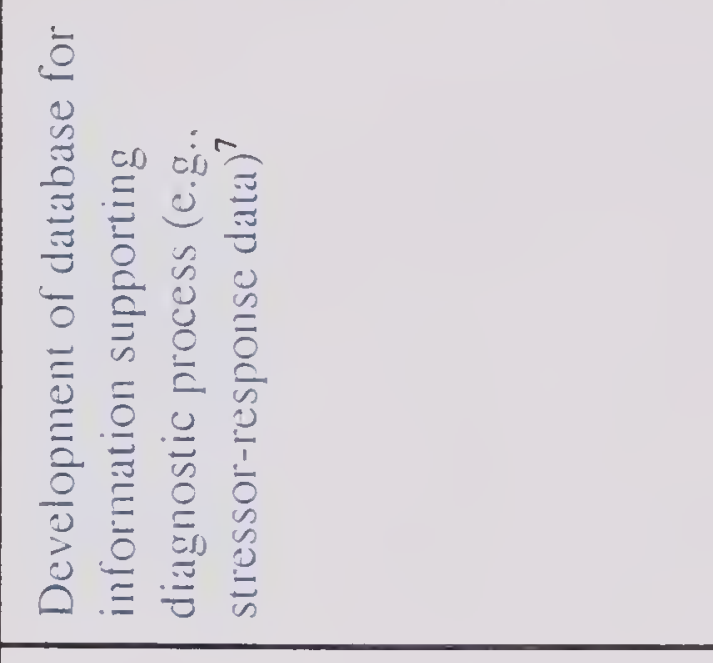 & 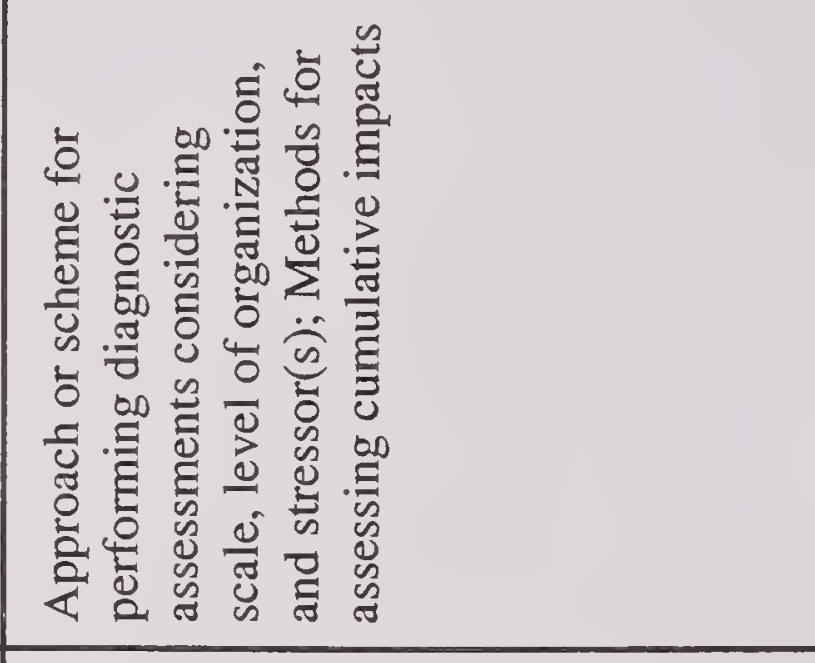 \\
\hline 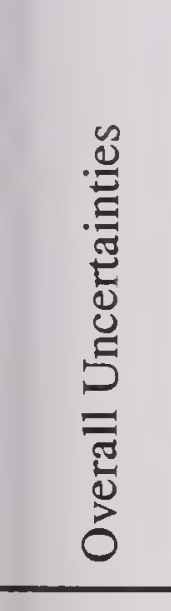 & 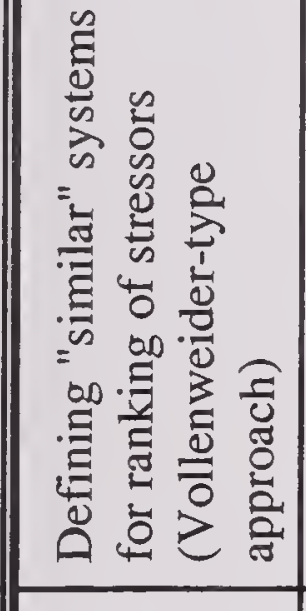 & 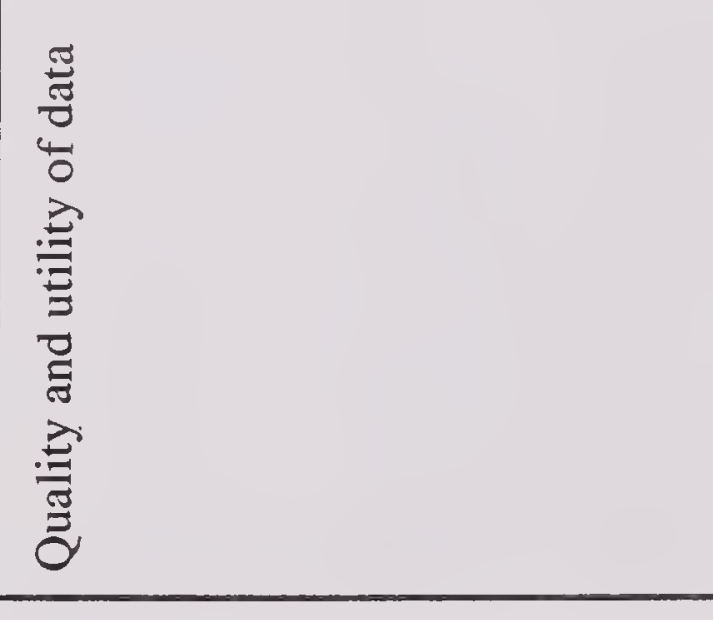 & 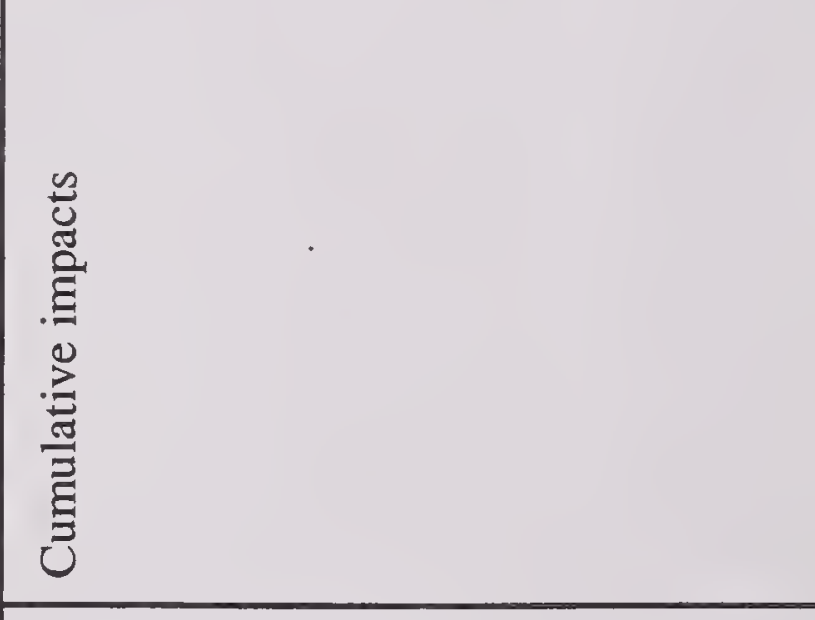 \\
\hline 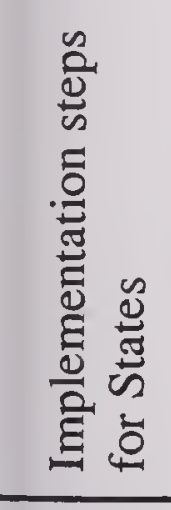 & 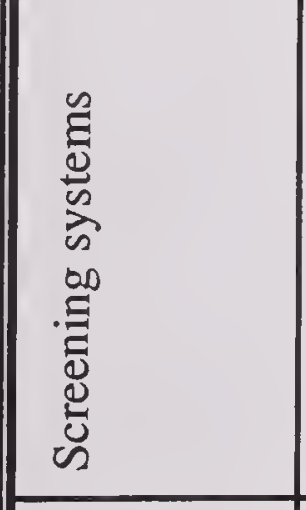 & 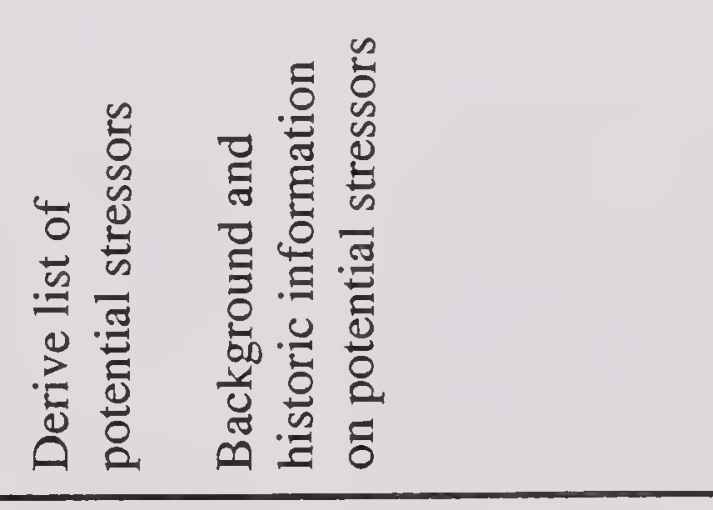 & 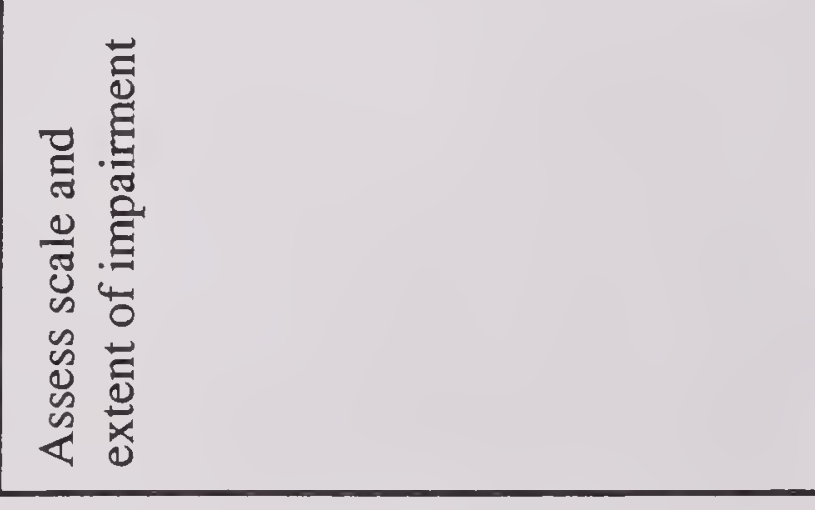 \\
\hline 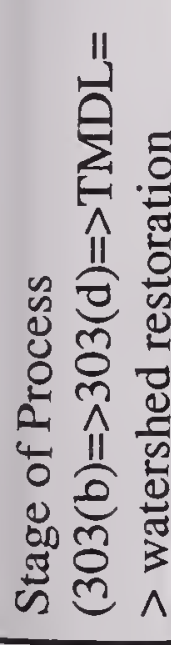 & & 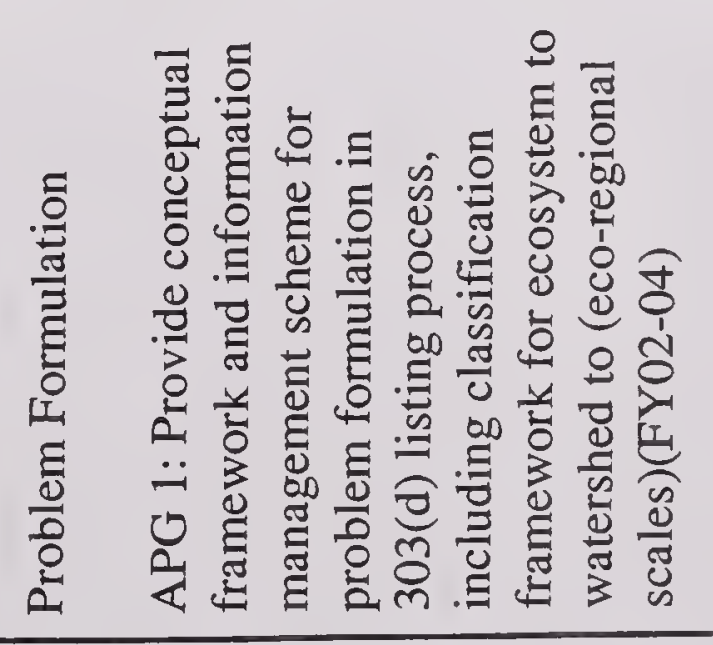 & \\
\hline
\end{tabular}




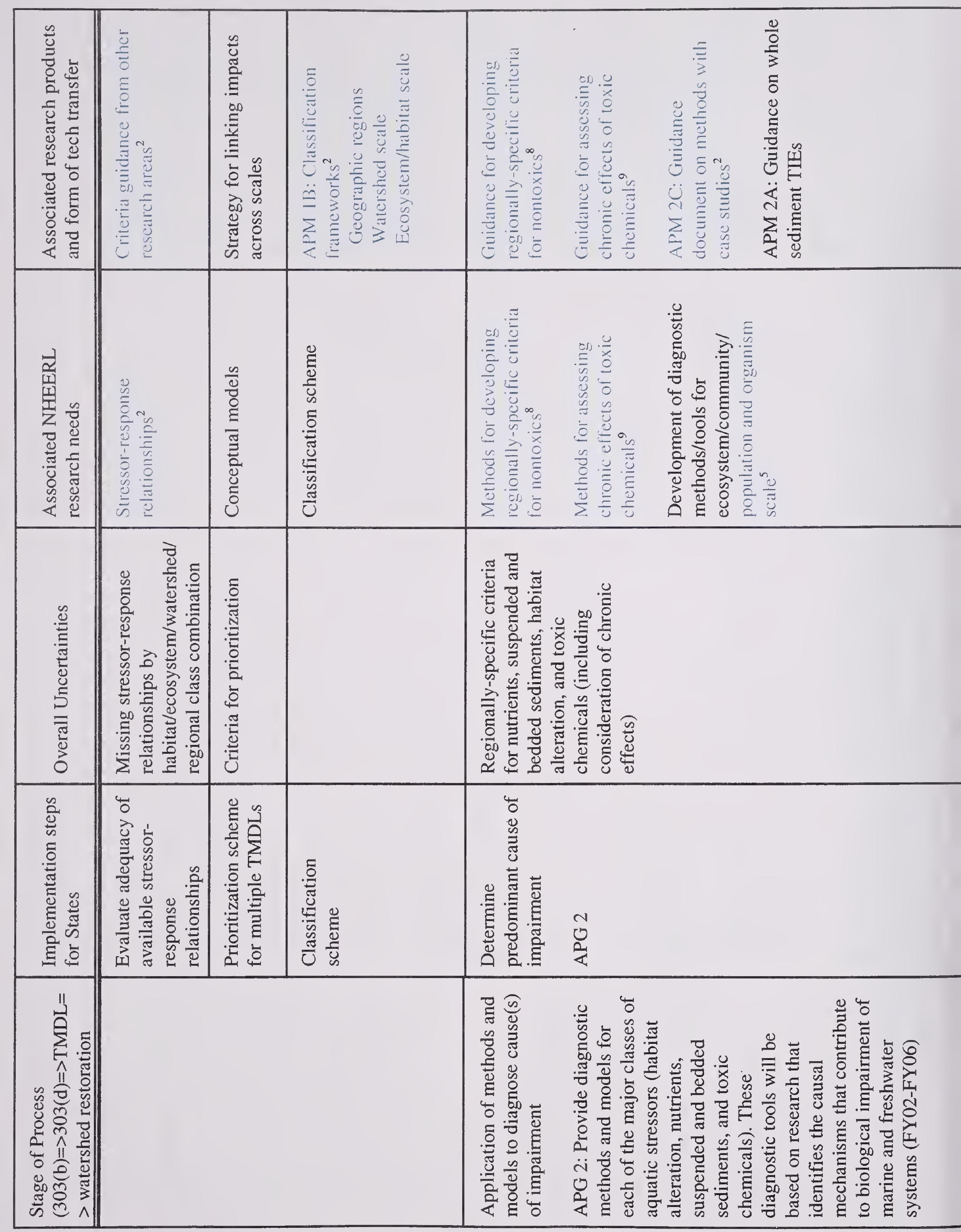




\begin{tabular}{|c|c|c|c|c|}
\hline 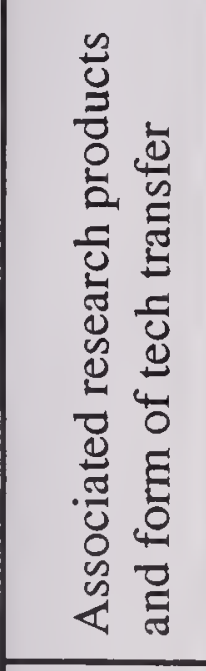 & \multicolumn{2}{|c|}{ 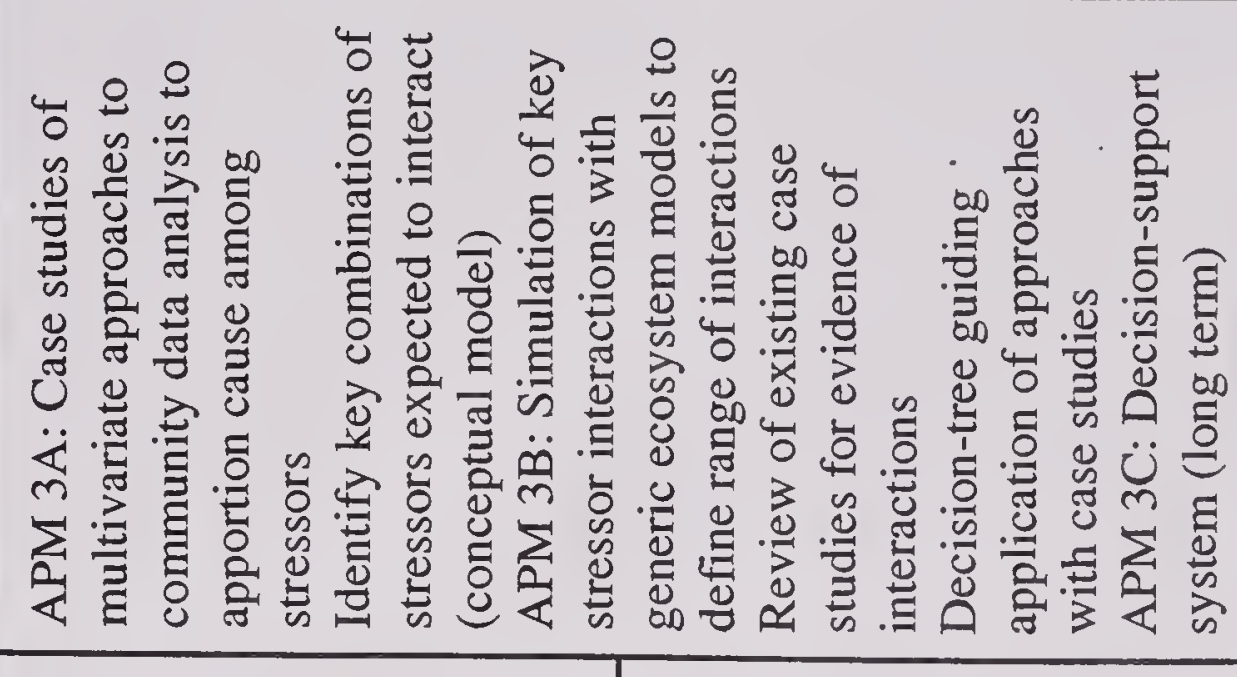 } & 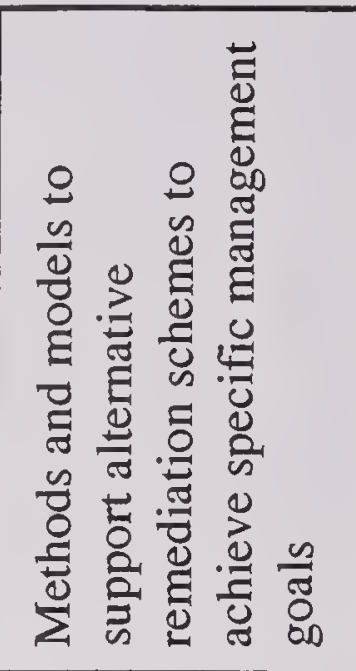 & 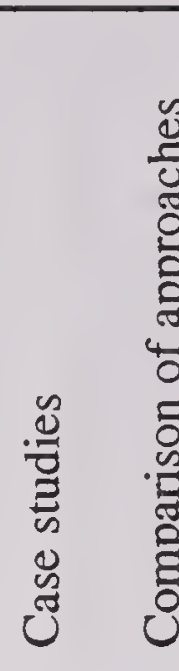 \\
\hline 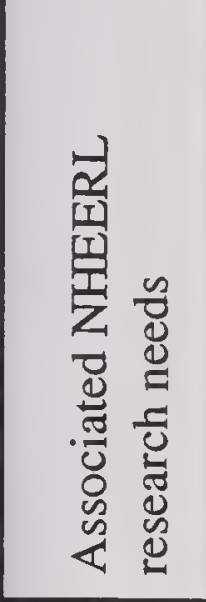 & 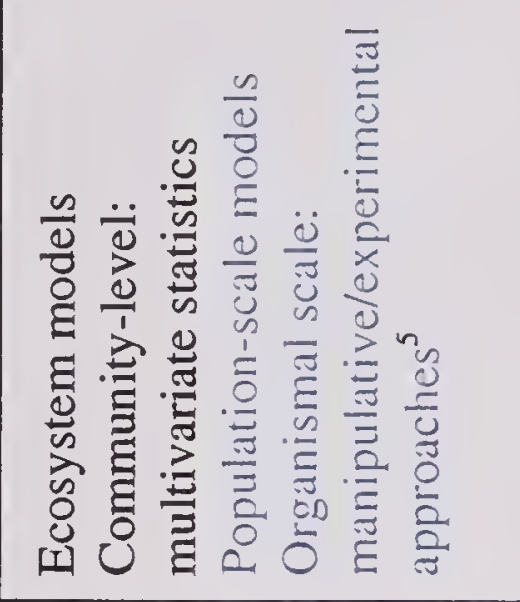 & 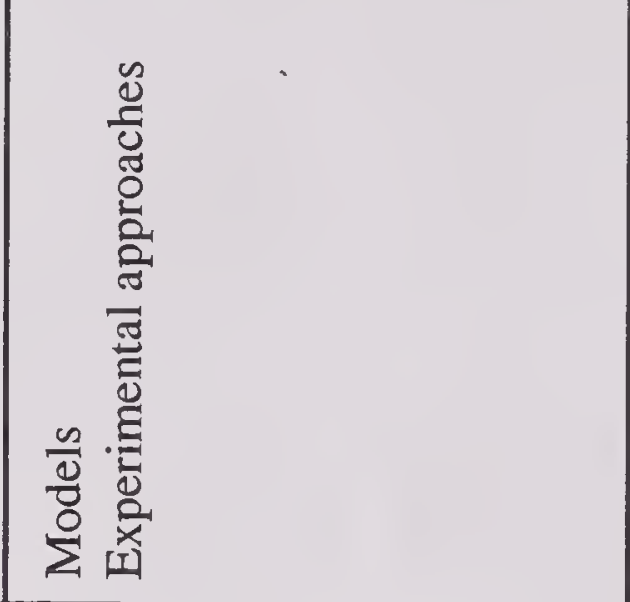 & 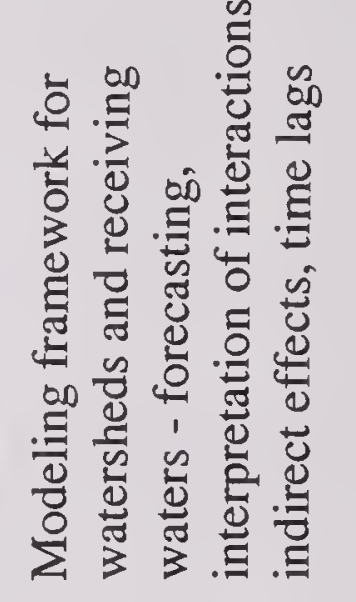 & \\
\hline 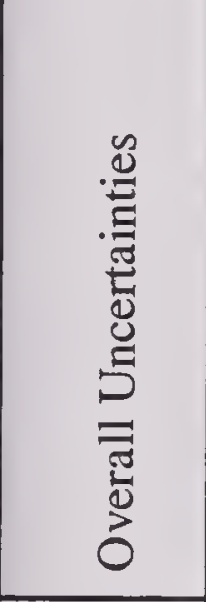 & 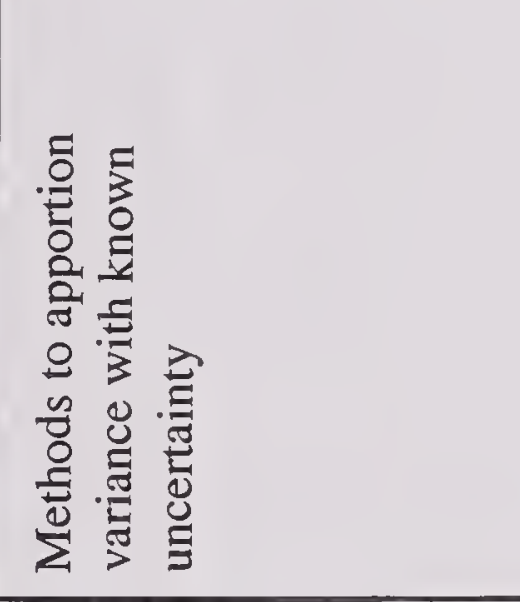 & 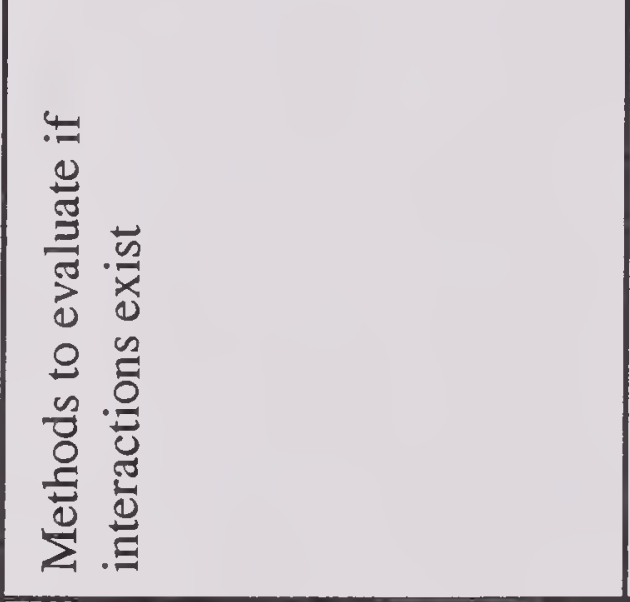 & 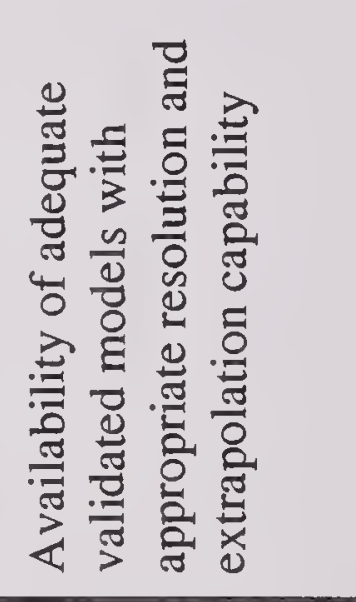 & \\
\hline 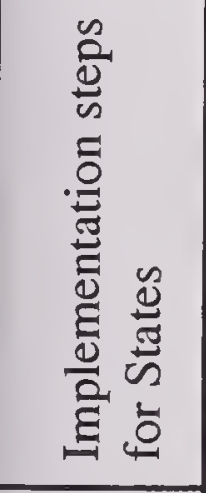 & 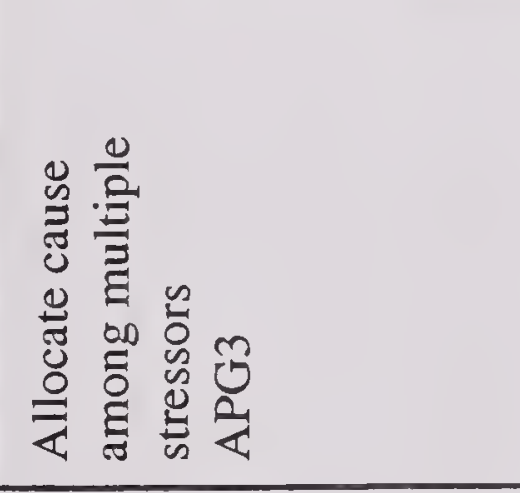 & 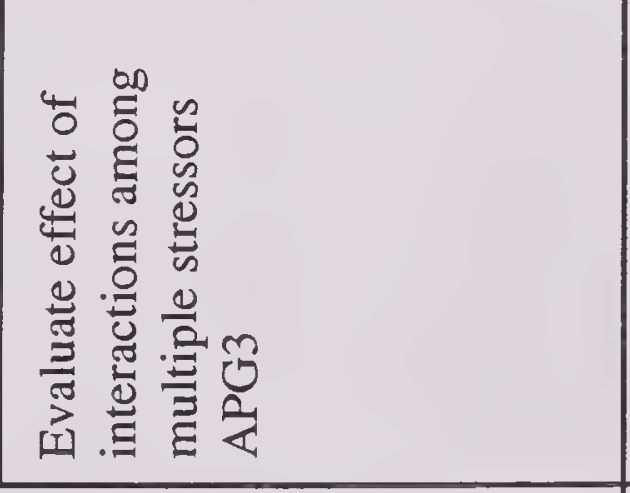 & 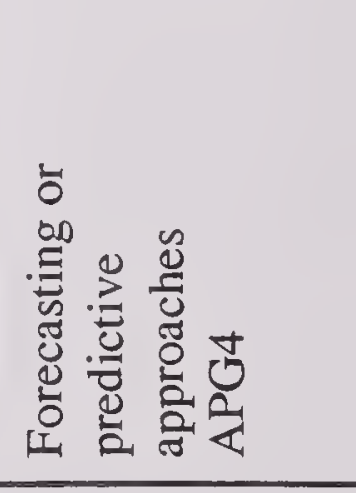 & \\
\hline 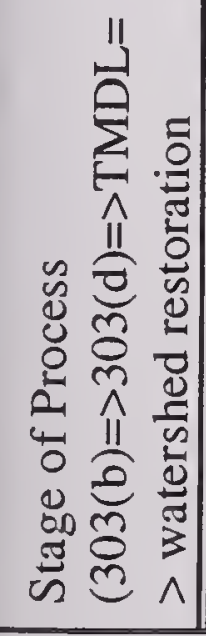 & 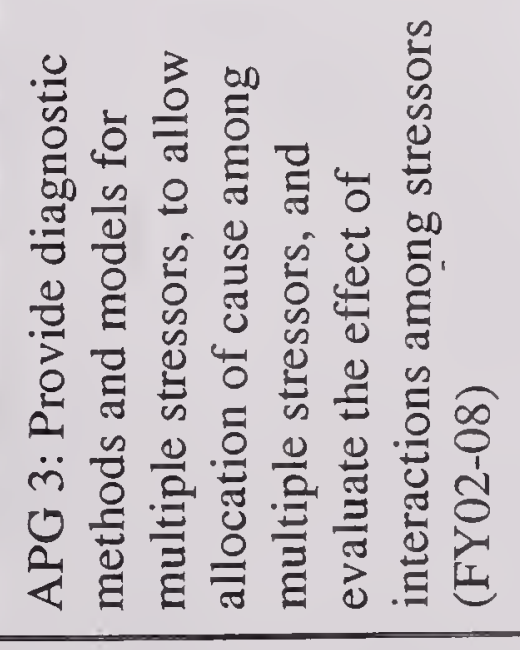 & & 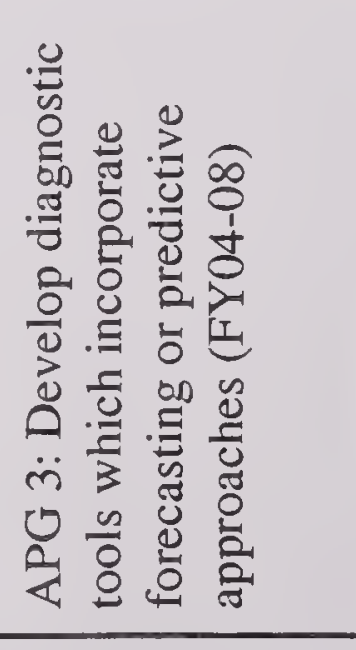 & \\
\hline
\end{tabular}




\begin{tabular}{|c|c|c|c|c|}
\hline 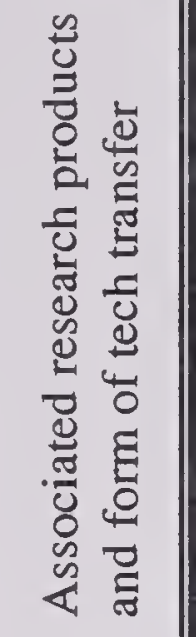 & 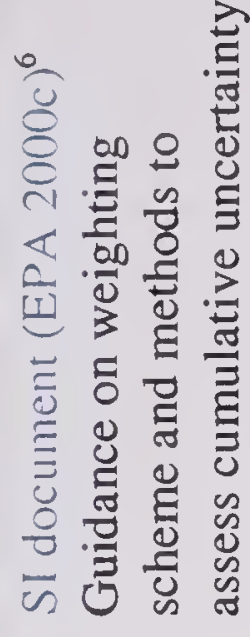 & 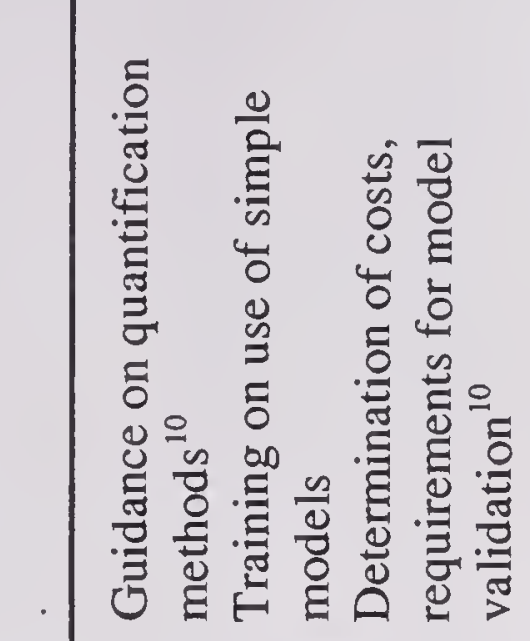 & 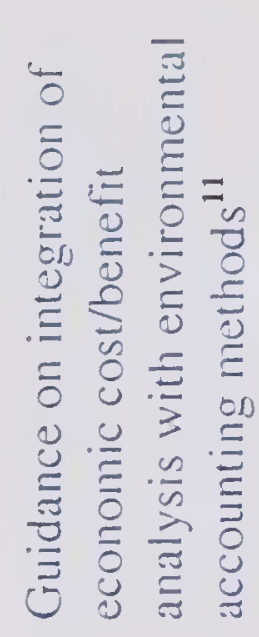 & 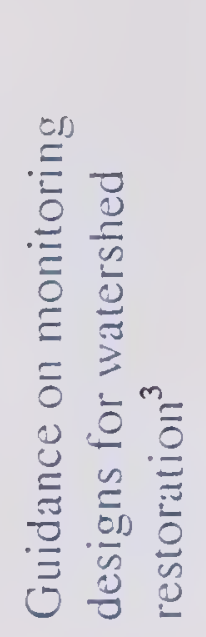 \\
\hline 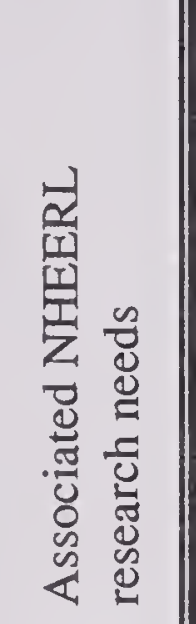 & 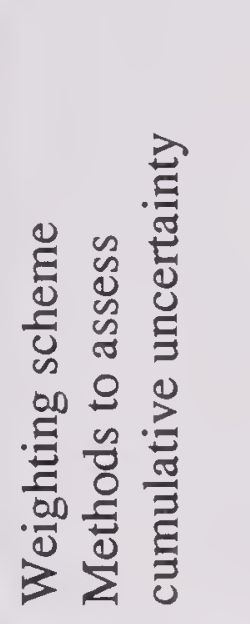 & 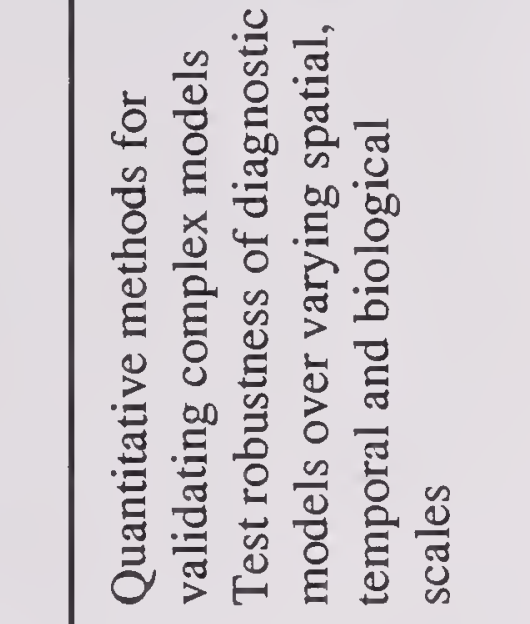 & 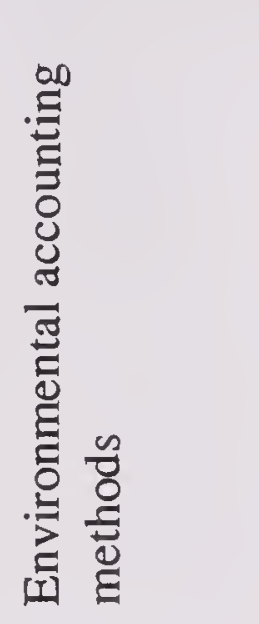 & 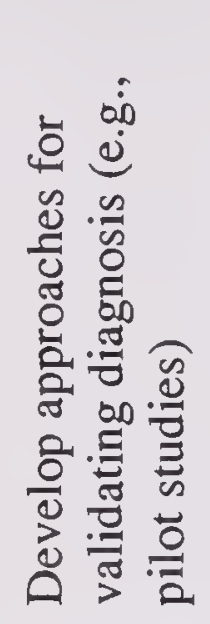 \\
\hline 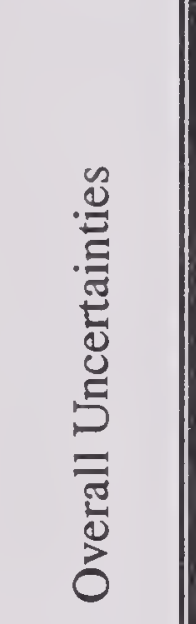 & 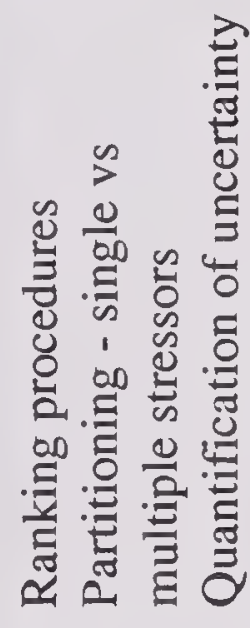 & 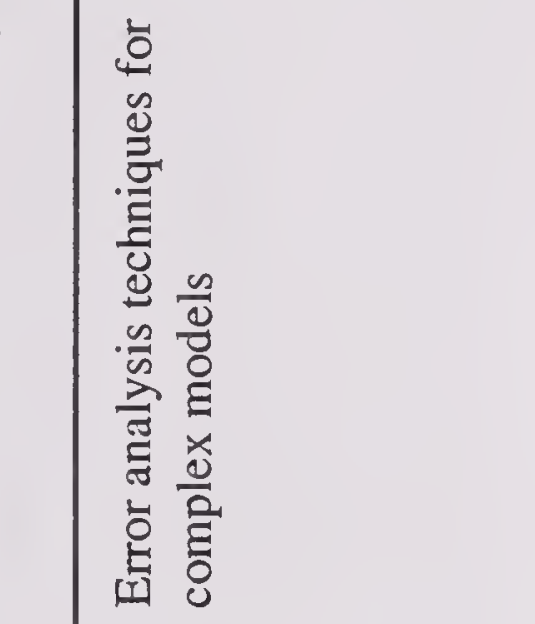 & 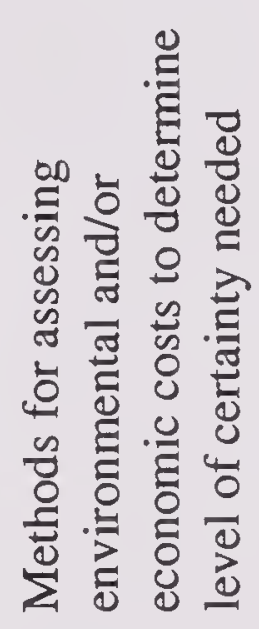 & 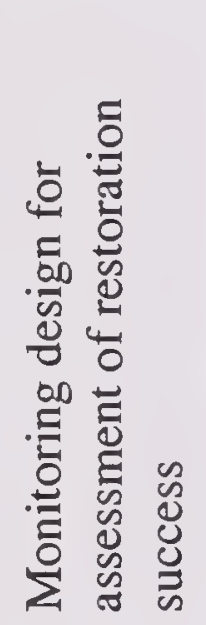 \\
\hline 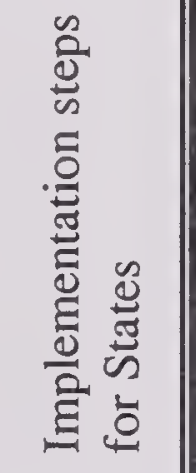 & 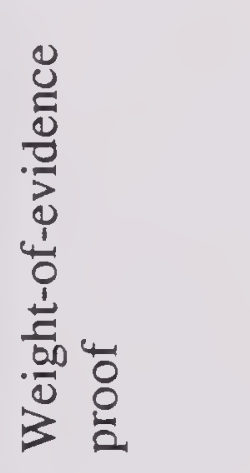 & 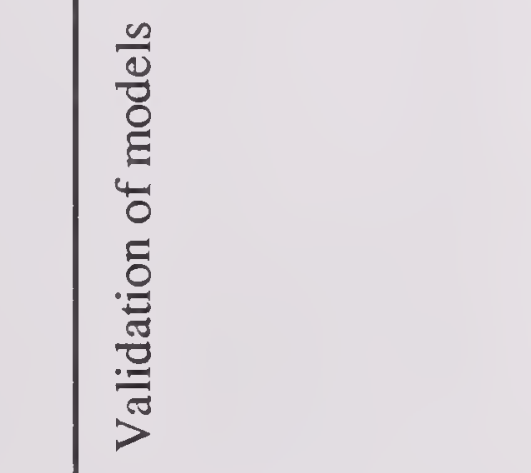 & 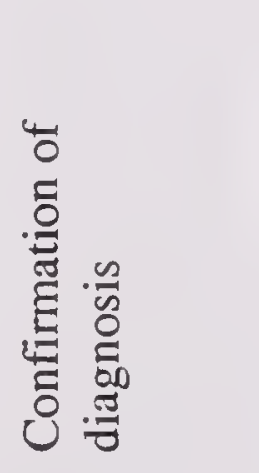 & 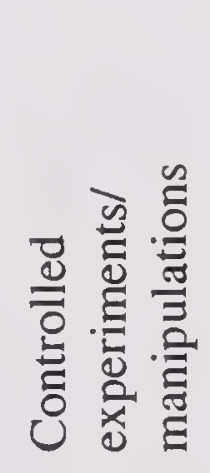 \\
\hline 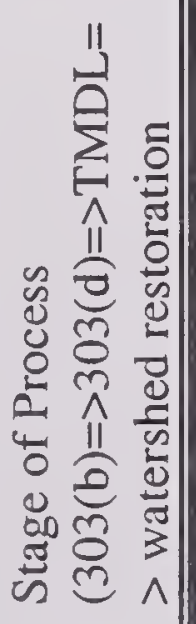 & 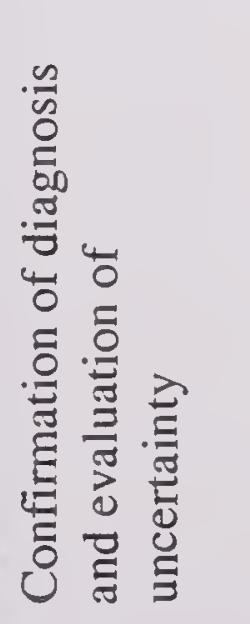 & 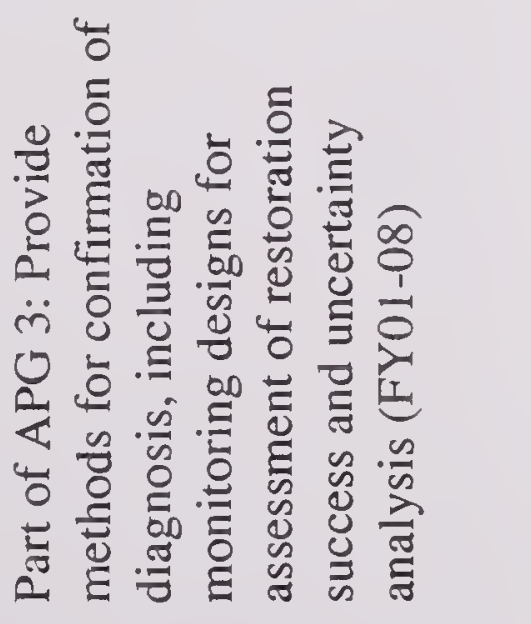 & & \\
\hline
\end{tabular}

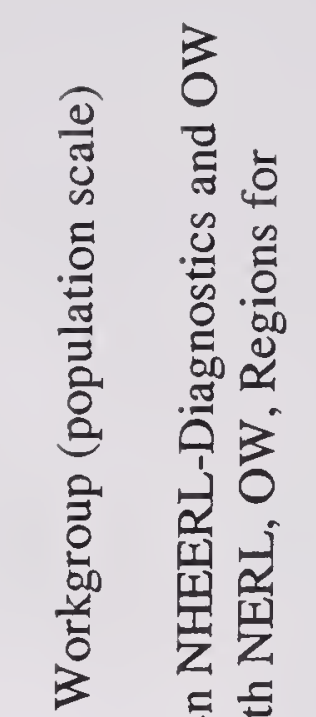

ลิ

嵒焉

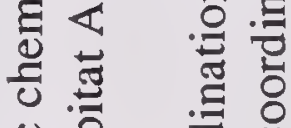

.

苛

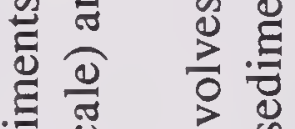

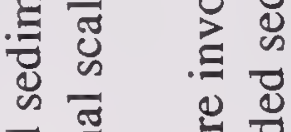

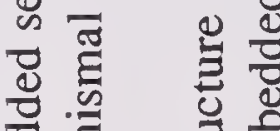

ป

ర 0 \%

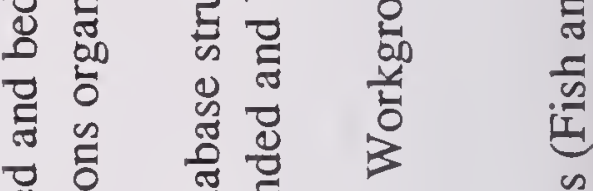

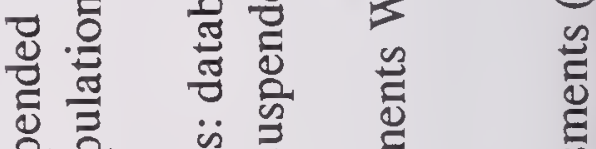

क言 总家

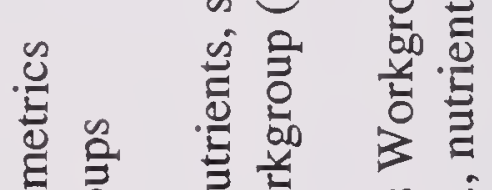

ซ

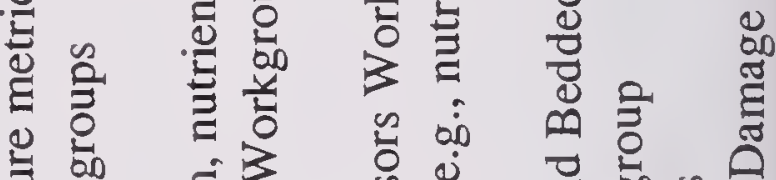

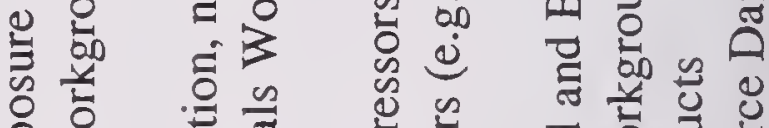

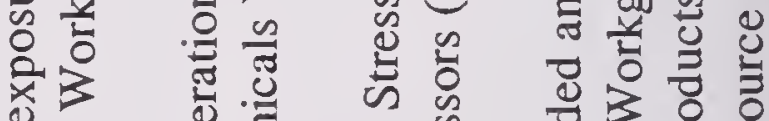

क एँ

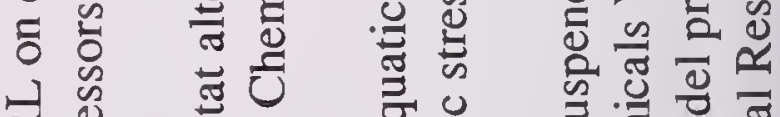

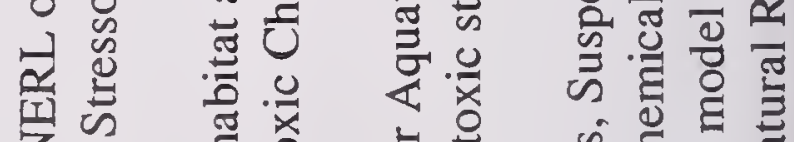

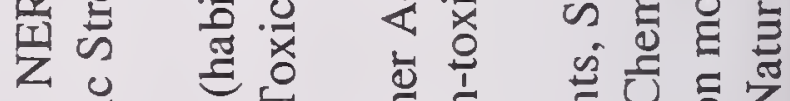

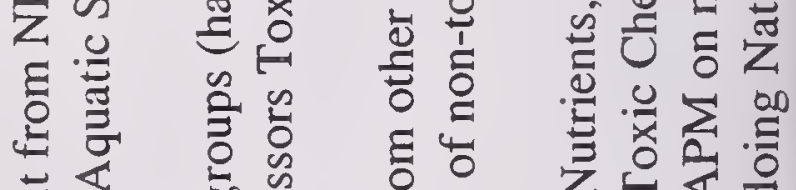
三 क्ष

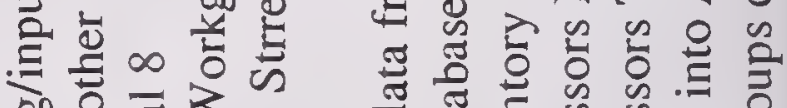
क人

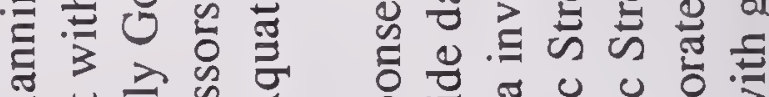

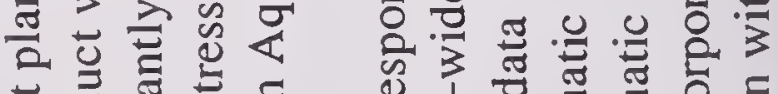

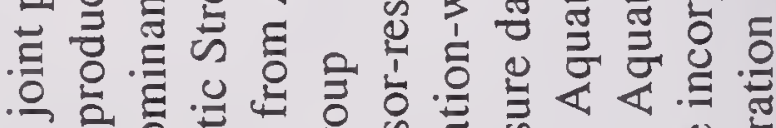

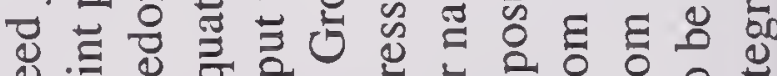

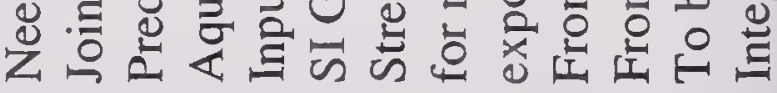




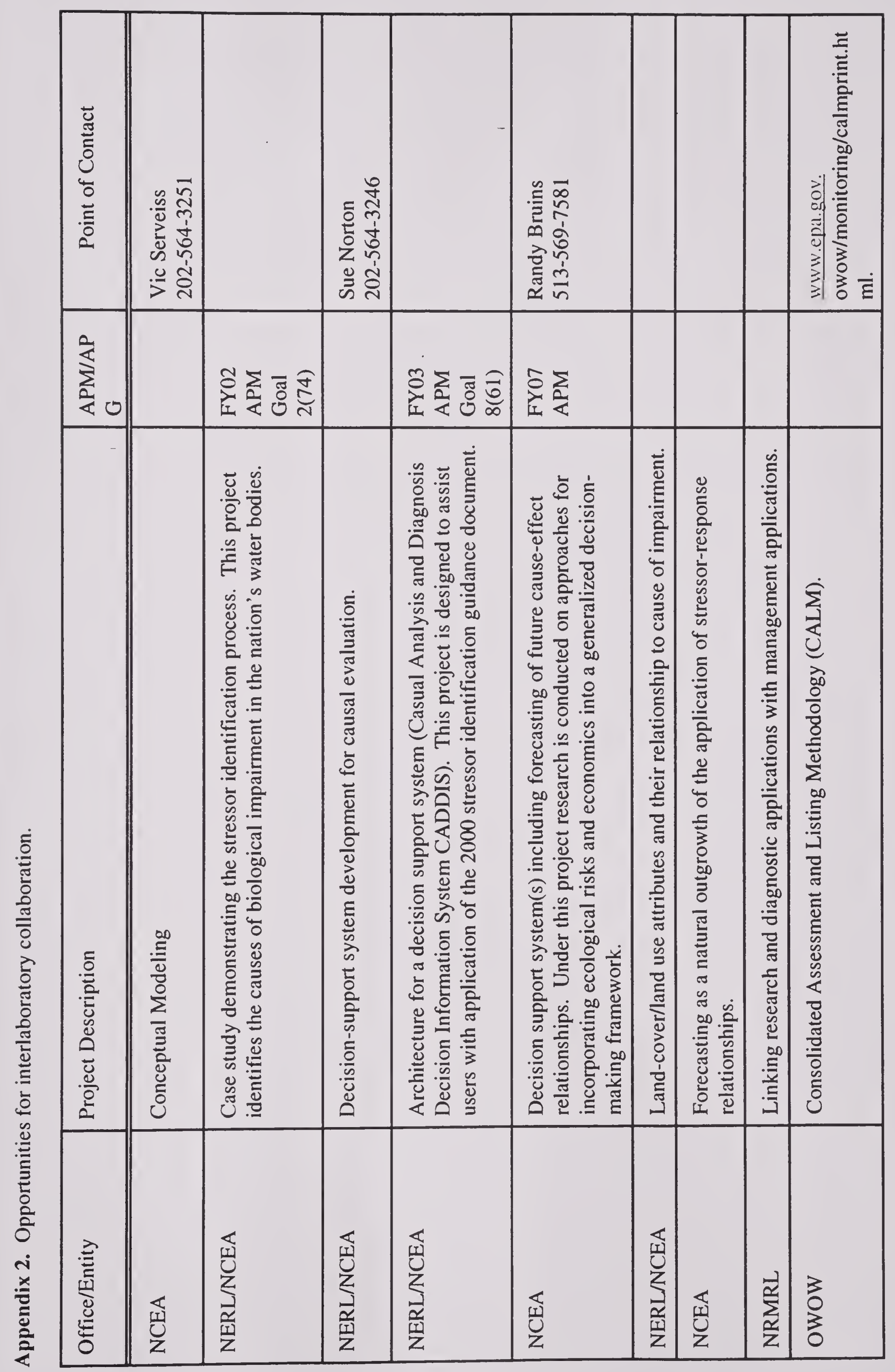




United States

Environmental Protection

Agency
If you do not wish to rec detach, or copy this cov upper left-hand corner.
PRESORTED STANDARL

POSTAGE \& FEES PAID

EPA

PERMIT No. G-35

National Health and Environmental

Effects Research Laboratory

Research Triangle Park, NC 27711

Official Business

Penalty for Private Use

$\$ 300$

EPA 600/R-02/074

September 2002 


LIBRARY OF CONGRESS

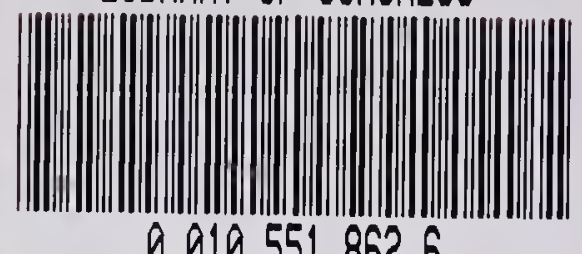

00105518626

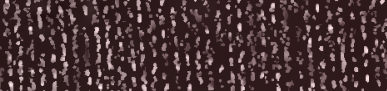

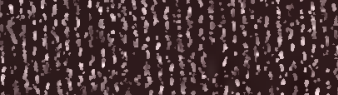

